\title{
Desenvolvimento de um Modelador para Superfícies Implícitas em $\mathrm{R}^{3}$
}

\author{
José Geraldo Veloso Moreira
}

Orientador: Prof. Dr. Antonio Castelo Filho

Dissertação apresentada ao Instituto de Ciências Matemáticas e de Computação - ICMC-USP, como parte dos requisitos para obtenção do título de Mestre em Ciências - Área: Ciências de Computação e Matemática Computacional.

USP - São Carlos

Junho de 2000 
Aos meus pais:

Geraldo de Araújo Moreira e Maria Raimunda Veloso Moreira 


\section{Agradecimentos}

Ao Prof. Castelo, pela orientação, ensinamentos, apoio e amizade no transcorrer deste trabalho.

Aos meus pais, Geraldo e Maria, pelo apoio e carinho presentc $\mathrm{cm}$ todos os momentos por mim vividos. Pelo carinho dos meus irmãos Luiz Carlos, Maria do Carmo e Rafael.

Aos professores do gxupo de Computação Gráfica Rosane, Cristina e Gustavo, pela amizade e apoio.

Aos amigos Igor, Vangrei e Denilson, companheiros de república, pelo respeito e amizade.

Aos amigos Fábio Hernandes, Carlos Eduardo, Edmilson, Mauro, Alexandre, especialmente pela acolhida em São Carlos, Cláudio, Enzo, Willian, Walter, Claudia, Gedson e Daniela, pela amizade e momentos de descontração.

Aos funcionários do ICMC em especial à Adriana, Beth, Laura e Marília pela atenção dedicada.

À Deus pela vida, pelo consolo nos momentos difíceis, pela esperança.

À Fapesp pelo apoio financeiro. 


\section{Sumário}

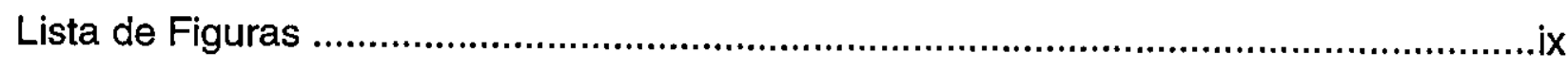

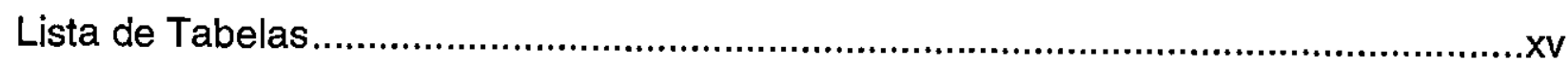

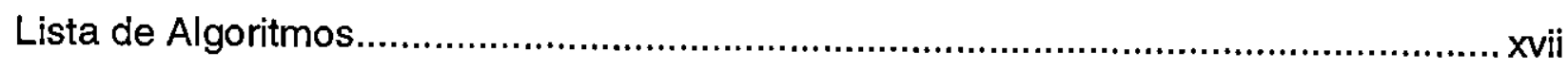

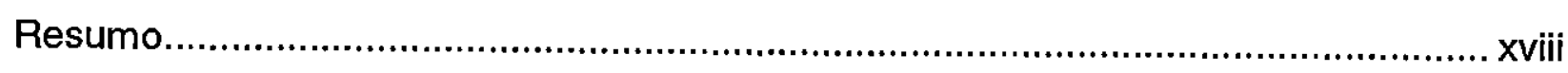

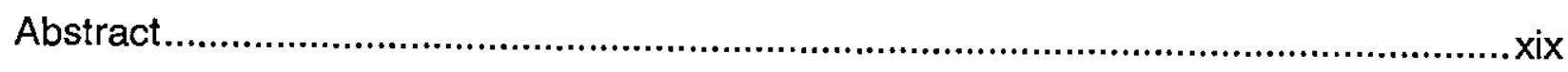

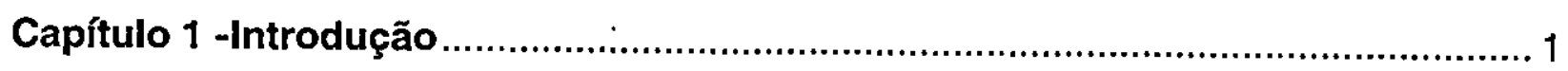

Capítulo 2 -Modelagem de Superfícies …............................................................ 5

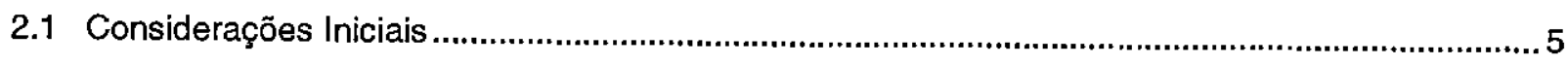

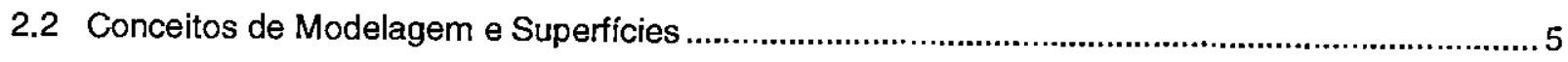

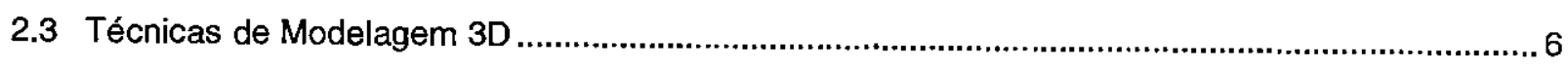

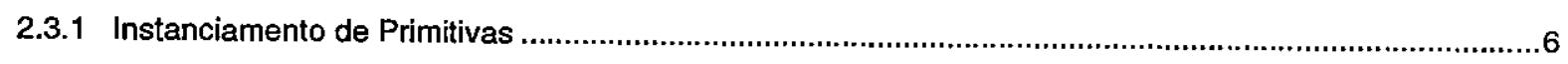

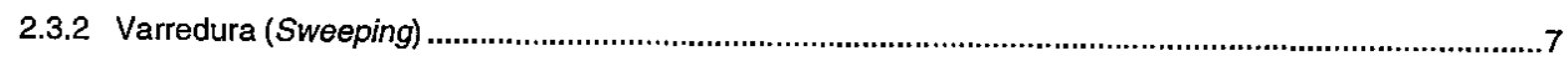

2.3.3 Geometria Sólida Construtiva (Constructive Solid Geometry - CSG)...................................................7

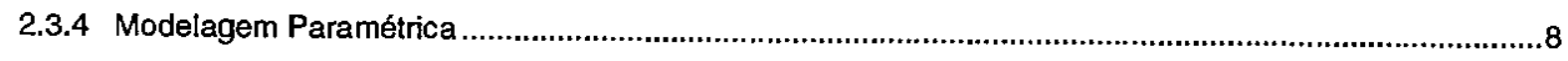

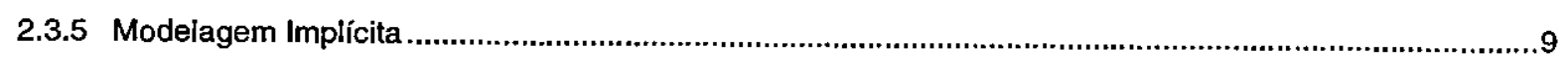

2.3.6 Modelagem baseada em Geometria Fractal ..................................................................................

2.4 Variedades Diferenciáveis e Lineares por Partes.................................................................. 10 
2.4.1 Variedades.

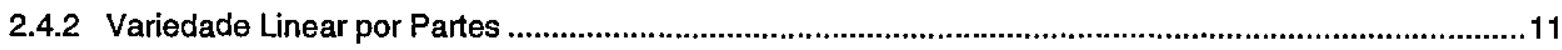

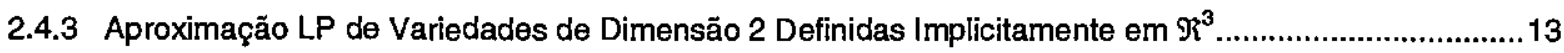

2.5 Representação de Superfícies .................................................................................. 15

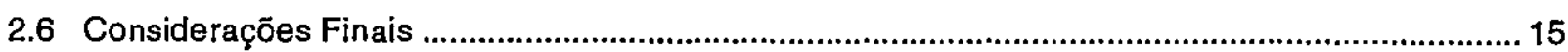

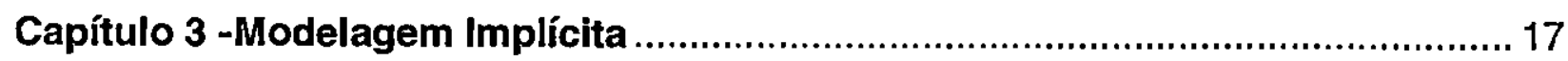

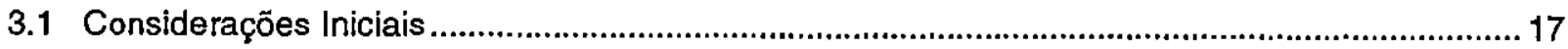

3.2 Modelagem Implícita de Superfícies e de Sólidos................................................................. 18

3.2.1 Tipos de Superfícies Implícitas e Definiçăo de Sólido..................................................................18

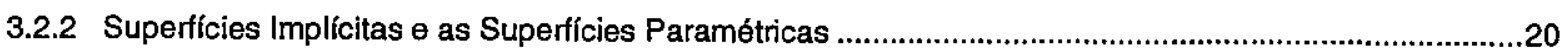

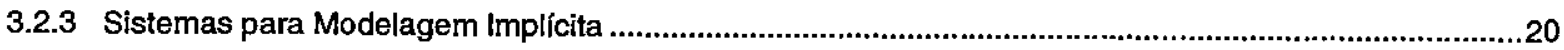

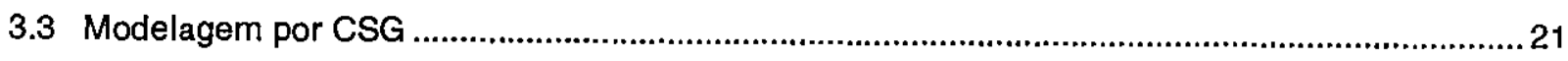

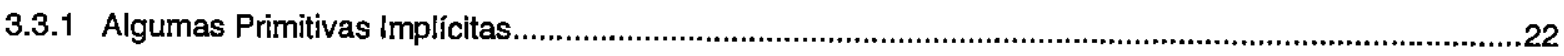

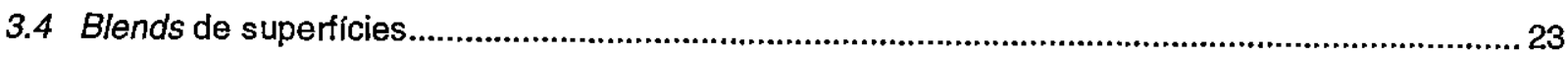

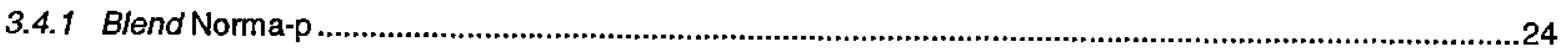

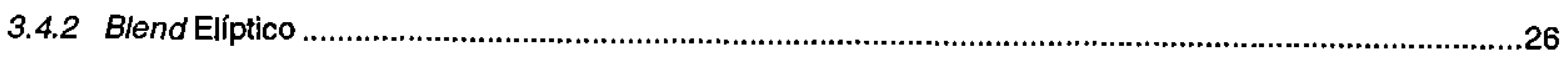

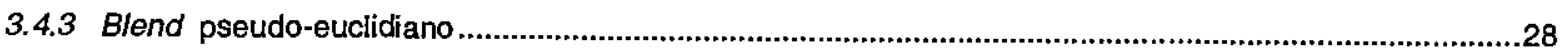

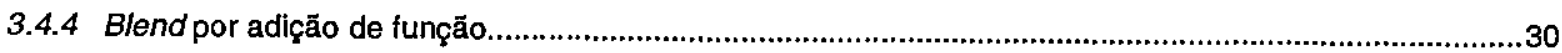

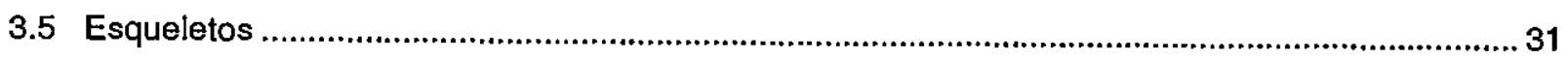

3.5.1 Superfícies Implicitamente definidas a partir de Distância de Esqueleto .............................................32

3.5.2 Superfícies Implicitamente Definidas a partir de Campos Eqüipotenciais...........................................33

3.5.3 Superfícies Implicitamente Definidas a partir de Convolução de Esqueletos..........................................34

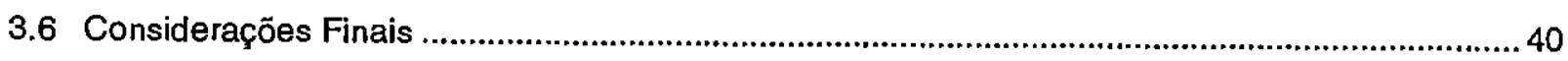

Capítulo 4 -Poligonalização de Superfícies Implícitas em $\mathfrak{R}^{3}$........................... 43

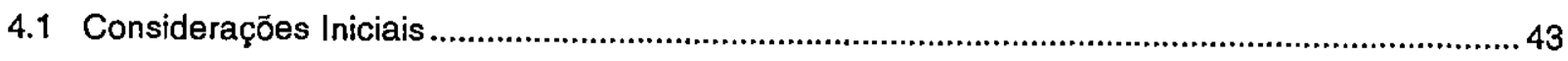

4.2 Visão Geral da Poligonalização de Superfícies Implícitas ........................................................... 43

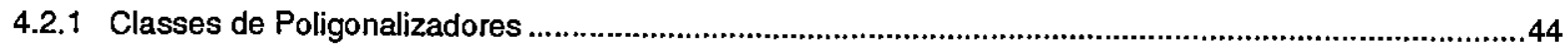

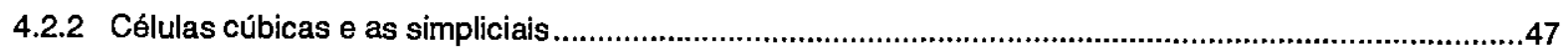


4.2.4 Poligonalização Variedades não Diferenciáveis..............................................................................49

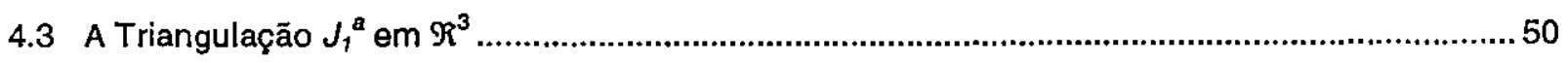

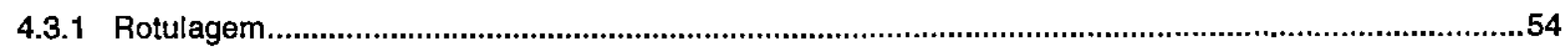

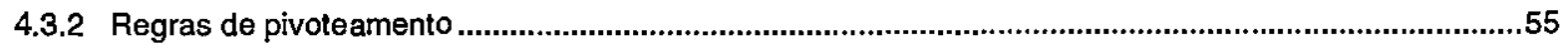

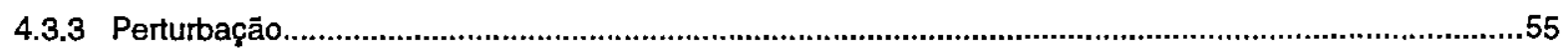

4.4 A Poligonalização de Superfícies Implícitas através da Triangulação $\mathcal{J}_{1}^{a} \ldots . . . . . . . . . . . . . . . . . . . . . . . . . . . .566$

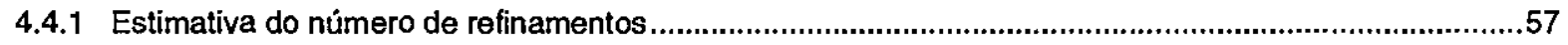

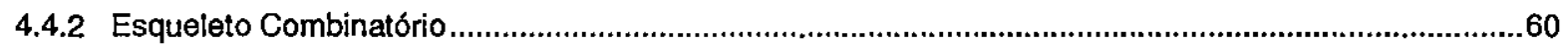

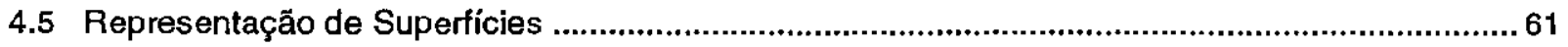

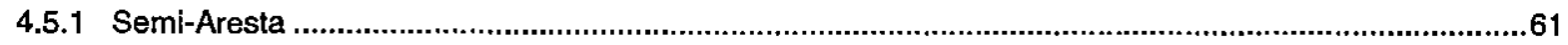

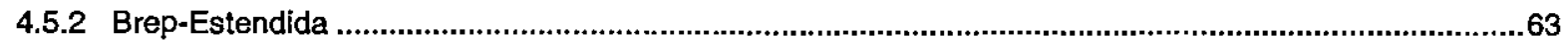

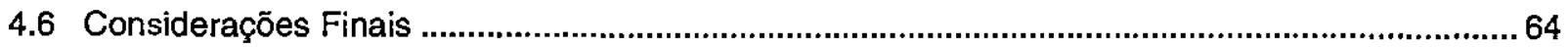

Capítulo 5 -Arquitetura e Ambiente de Desenvolvimento do Modelador...............65

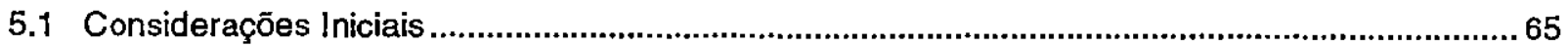

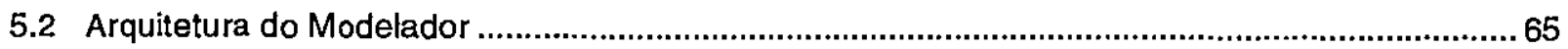

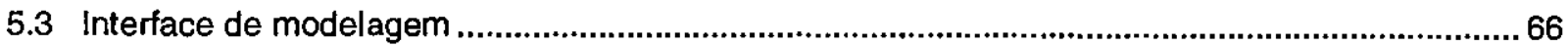

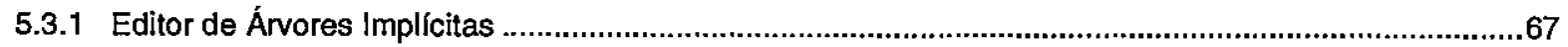

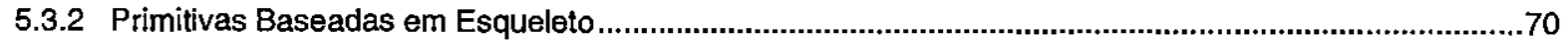

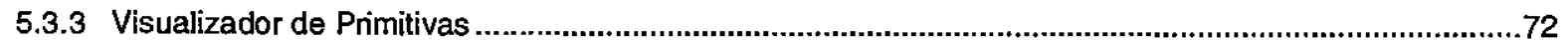

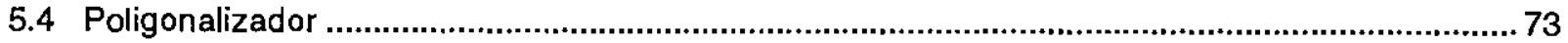

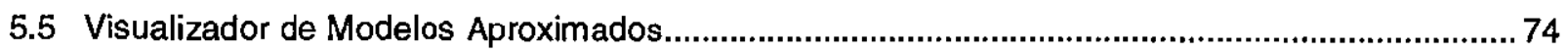

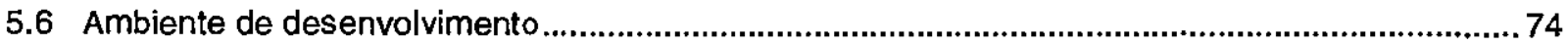

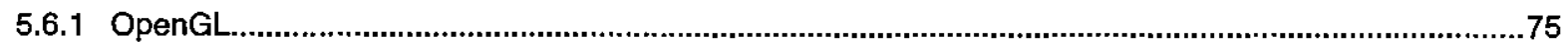

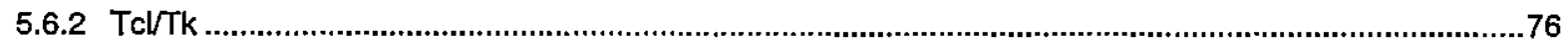

5.6.3 Algumas considerações sobre o ambiente de desenvolvimento........................................................81

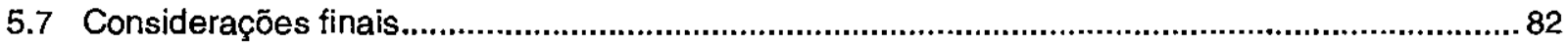

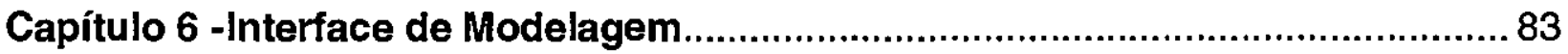




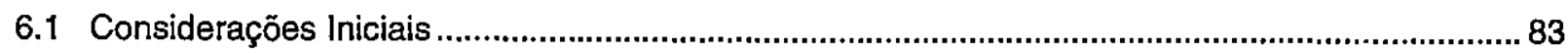

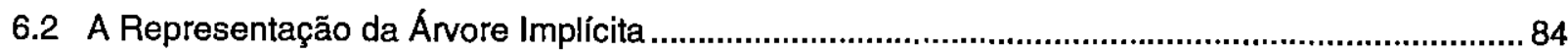

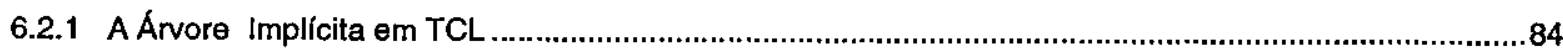

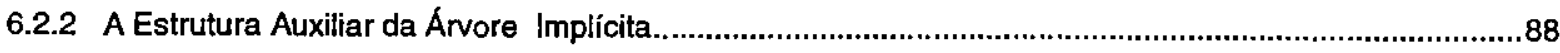

6.2.3 Representação das Primitivas Esqueletais .................................................................................92

6.2.4 Primitivas Ativas e Primitivas Selecionadas .................................................................................93

6.2.5 Transformaçōes Geométricas sobre as Primitivas.......................................................................94

6.2.6 Registro $\theta$ Recuperação da Árvore Implícita em Disco ................................................................95

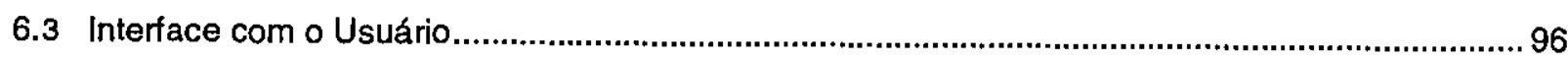

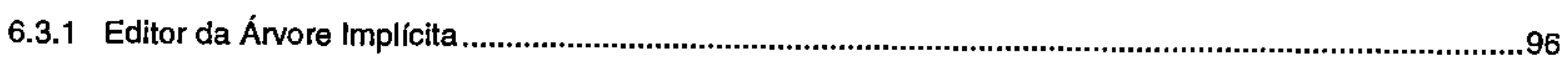

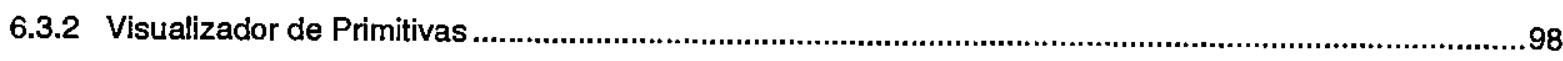

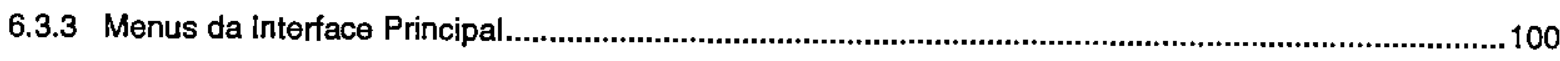

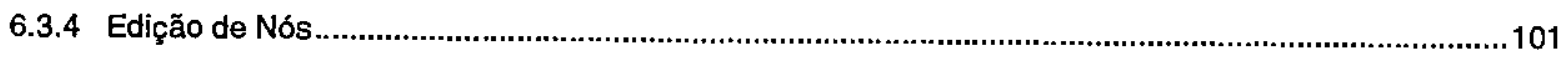

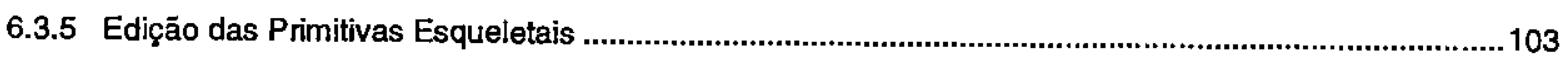

6.3.6 Definição do modelo principal e de modelos temporários .................................................................104

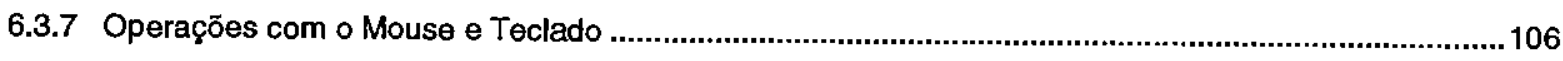

6.4 Poligonalização e Visualização do Modelo Implícito ............................................................... 107

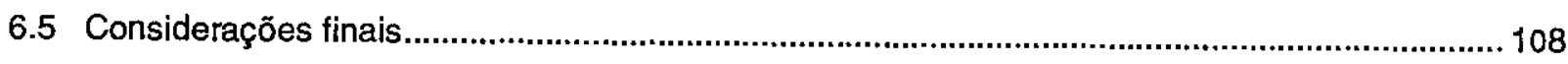

Capítulo 7 - Poligonalização e Apresentação dos Modelos Implícitos ........................ 109

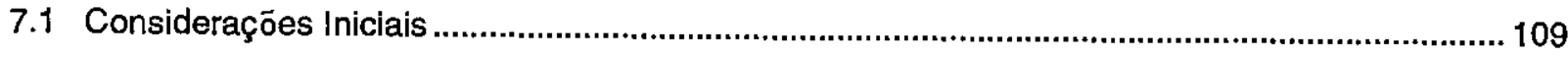

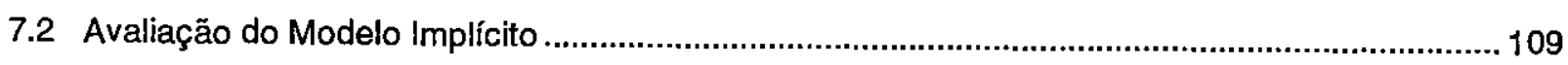

7.2.1 Arquivo de Definiçåo do Modelo Implícito ..................................................................................110

7.2.2 Estrutura de Avaliaçāo do Modelo Implícito .............................................................................112

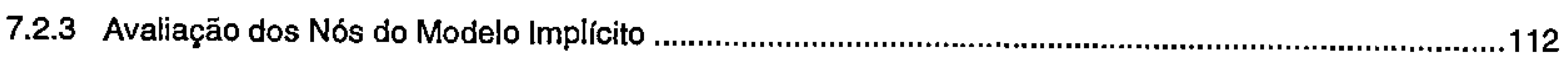

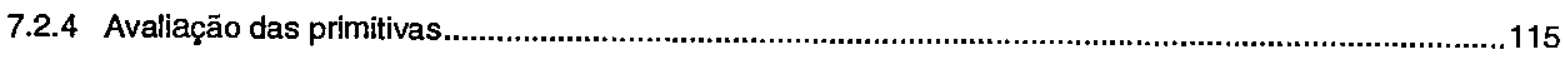

7.2.5 Avaliação das operações de composição ..................................................................................125

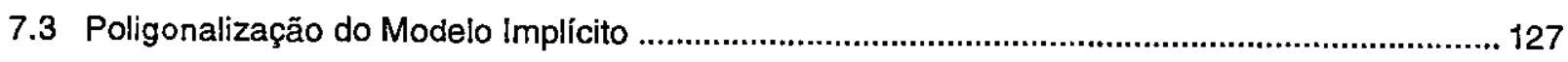

7.4 Conversão do Esqueleto Combinatório para B-Rep Estendida ............................................. 131 
7.4.1 Extração das Cascas .131

7.4.2 Classificą̧ão das Cascas em Pseudo-Sólidos. .......................................................................134

7.5 Visualização de Modelos Aproximados ...................................................................... 135

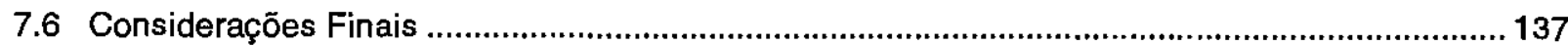

Capítulo 8 -Resultados e Conclusões ............................................................... 139

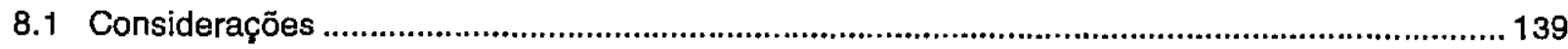

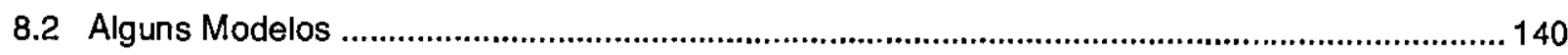

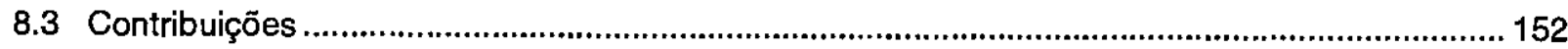

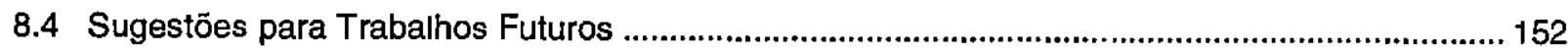

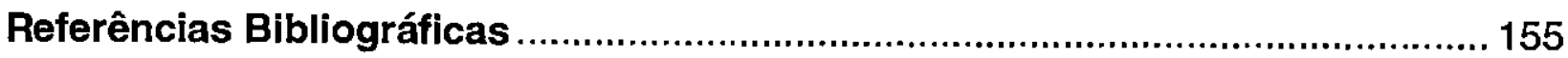




\section{Lista de Figuras}

\section{Capítulo 2}

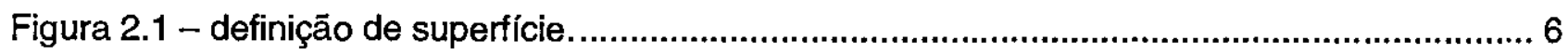

Figura 2.2 - taxonomia de modelagem de sólidos e superfícies................................................ 6

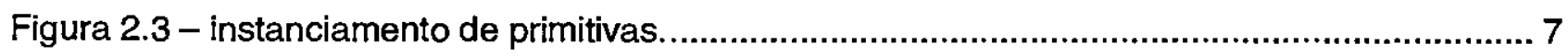

Figura 2.4 - modelagem de superfície e de sólido por varredura . .............................................. 7

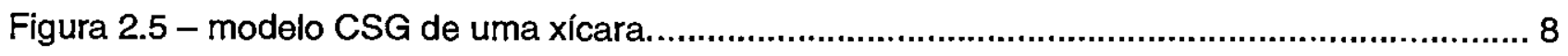

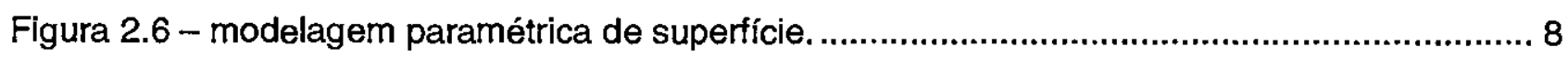

Figura 2.7 - cena montada com um modelo fractal. .............................................................. 10

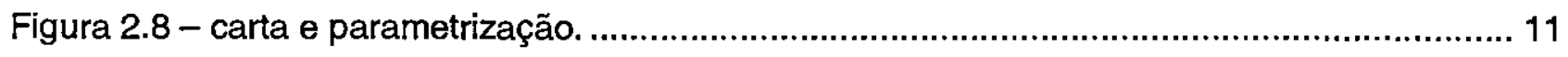

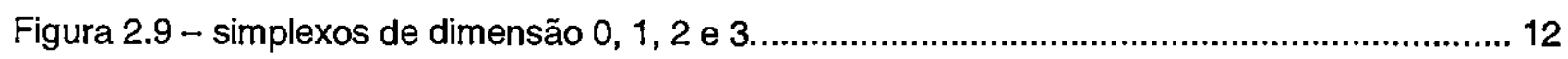

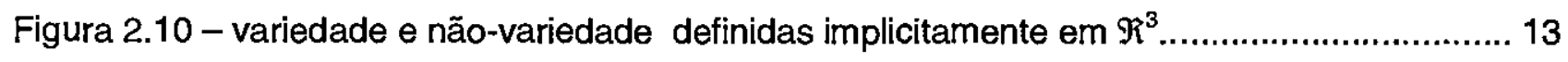

\section{Capítulo 3}

Figura 3.1 - superfície com bordo.

Figura 3.2 - exemplo de CSG: (a) sólido; (b) árvore de avaliação............................................. 22

Figura 3.3 - superelipsóides............................................................................................ 24 
Figura 3.4 - blend com norma-p.

Figura 3.5 - blend elíptico: entre duas retas e entre primitivas

Figura 3.6 - saliência devido ao blend elíptico.

Figura 3.7 - deslocamento provocado pelo blend elíptico composto.

27

Figura 3.8 - divisão do espaço conforme a relação entre as primitivas e seus raios de blend...... 28

Figura 3.9 - blend por adição de função. 31

Figura 3.10 - exemplo de objeto definido implicitamente por um esqueleto. 32

Figura 3.11 - superfície de distância de um esqueleto formado por segmentos de reta. 33

Figura 3.12 - função de campo $g_{E}(r)$ 34

Figura 3.13 - saliências e redução das saliências. 34

Figura 3.14 - avião simplificado gerado por esqueleto utilizando superfície eqüipotencial. 34

Figura 3.15 - superposição da convolução de esqueletos. 35

Figura 3.16 - convolução de um segmento de reta qualquer. 38

Figura 3.17 - convolução de um polígono. 38

Figura 3.18 - esqueleto definido por segmentos com saliência e redução da saliência. 40

Figura 3.19 - estudo das saliências em esqueletos definidos por segmentos. 40

\section{Capítulo 4}

Figura 4.1 - processo de poligonalização 44

Figura 4.2 - erro no teste de transversalidade. 45

Figura 4.3 - poligonalização de toro com Octree. 45

Figura 4.4 - métod(b)o de Previsão e Correção. 46

Figura 4.5 - aproximação linear por partes de uma curva. 47 
Figura 4.6 - ambigüidade na decomposição em cubos.

Figura 4.7 - perda de detalhes e número excessivo de células na decomposição uniforme. 48

Figura 4.8 - aproximação Linear por partes de variedades não diferenciáveis. 49

Figura 4.9 - uma possível aproximação linear por partes de uma não variedade. 49

Figura 4.10 - passos da triangulação $J_{1}^{a} \mathrm{em} \Re^{2}$ 50

Figura 4.11 - exemplos das faces. 51

Figura 4.12 - triangulação em um bloco básico 52

Figura 4.13 - triangulação em bloco de transição. 53

Figura 4.14 - exemplo da identificação de blocos por vetor de inteiros. 53

Figura 4.15 - perturbação de uma triangulação em $R^{2}$. 55

Figura 4.16 - aproximação da superfície implícita para estimativa do refinamento. 58

Figura 4.17 - exemplo de esqueleto combinatório 60

Figura 4.18 - representação semi-aresta. 62

Figura 4.19 - superfície com bordo devido ao domínio da poligonalização. 63

Figura 4.20 - estrutura brep-estendida. 63

\section{Capítulo 5}

Figura 5.1 - componentes do Modelador e comunicação entre eles. 66

Figura 5.2 - módulos da interface de Modelagem. 67

Figura 5.3 - exemplo de uma coleção de árvores implícitas manipuladas no editor. 69

Figura 5.4 - forma definida por uma linha. 71

Figura 5.5 - forma definida por um polígono. 72

Figura 5.6 - módulo do Poligonalizador. 73 
Figura 5.7 - Visualizador de Modelos Aproximados.

Figura 5.8 - arquitetura de uma aplicação escrita em C e Tcl. 77

Figura 5.9 - exemplo da widget canvas do TK. 79

Figura 5.10 - loop de eventos do Tk. 80

\section{Capítulo 6}

Figura 6.1 - interface com o usuário do componente Interface de Modelagem. 83

Figura 6.2 - exemplo de coleção de árvores implícitas. 87

Figura 6.3 - estrutura da iTreeC 89

Figura 6.4 - manutenção dos dados que representam a árvore implícita. 91

Figura 6.5 - sintaxe do arquivo que uma árvore implícita. 95

Figura 6.6 - editor de Árvores Implícitas 97

Figura 6.7 - apresentação das primitivas com OpenGL. 99

Figura 6.8 - diálogos para a configuração das primitivas pré-definidas. .102

Figura 6.9 - diálogos para os nós que representam operações. .103

Figura 6.10 - diálogo para configuração de uma primitiva baseada em um ponto. .104

Figura 6.11 - configuração de uma primitiva baseada em uma linha. .105

Figura 6.12 - configuração de uma primitiva baseada em um polígono. 105

Figura 6.13 - exemplo de movimentação de nós no editor com o mouse. 106

Figura 6.14 - diálogo para configuração da poligonalização. 107

\section{Capítulo 7}

Figura 7.1 - sintaxe do arquivo de definição do modelo implícito. .110 
Figura 7.2 - exemplo da estrutura de avaliação.

Figura 7.3 - configuração de um cilindro implícito.

Figura 7.4 - configuração de um cone implícito 120

Figura 7.5 - projeção de um ponto em uma reta.

Figura 7.6 - projeção de um ponto no plano que contém o polígono.

Figura 7.7 - teste de ponto polígono.

Figura 7.8 - estrutura do esqueleto combinatório.

Figura 7.9 - criaçāo das semi-arestas e arestas em uma face da brep. 133

Figura 7.10 - faces completas e incompletas na extração de uma casca.. 133

Figura 7.11 - classificação das cascas em positivas e negativas.

Figura 7.12 - visualização da brep-estendida que representa a caneca implícita 135

Figura 7.13 - configuração de um pseudo-sólido. 137

\section{Capítulo 8}

Figura 8.1 - definição do modelo cano/caixa.

Figura 8.2 - modelo cano/caixa sem blend.

Figura 8.3 - modelo cano/caixa com blend norma p: exemplo 1

Figura 8.4 - modelo cano/caixa com blend norma p: exemplo 2

Figura 8.5 - modelo cano/caixa com blend norma p: exemplo 3

Figura 8.6 - modelo cano/caixa com blend pseudo-euclidiano: exemplo 1

Figura 8.7 - modelo cano/caixa com blend pseudo-euclidiano: exemplo 2

Figura 8.8 - modelo exemplo com múltiplas cascas: definição.

Figura 8.9 - modelo exemplo com múltiplas cascas: resultado. 
Figura 8.10 - definição do T.

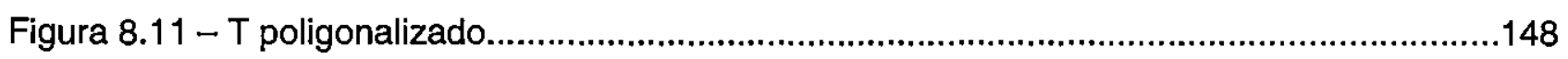

Figura 8.12 - definição da peça com superelipsóides. ..........................................................149

Figura 8.13 - peça com superelipsóides: wireframe e tonalização gouraud. .............................149

Figura 8.14 - definição do avião simplificado. .................................................................150

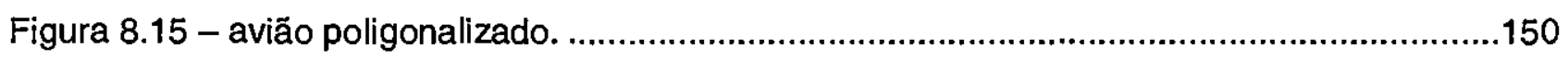

Figura 8.16 - definição do símbolo do ICMC ......................................................................151

Figura 8.17 - símbolo do ICMC poligonalizado ...........................................................151 


\section{Lista de Tabelas}

\section{Capítulo 4}

Tabela 4.1 - possiveis índices dos blocos conforme o refinamento. 53

\section{Capítulo 6}

Tabela 6.1 - informaçōes de configuração da coleção de árvores implícitas. 84

Tabela 6.2 - parâmetros dos nós de uma árvore implícita. 85

Tabela 6.3 - identificadores dos tipos dos nós da árvore implícita e suas listas de parâmetros. .. 86

Tabela 6.4 - informações de configuração de uma árvore implícita exemplificada. 87

Tabela 6.5 - representação da uma árvore implícita exemplificada em um array do Tcl. 87

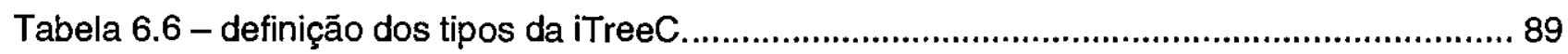

Tabela 6.7 - definição dos tipos das primitivas pré-definidas na iTreeC................................ 90

Tabela 6.8 - opções do menu principal ....................................................................100

Tabela 6.9 - opções dos menus pop-ups. ...............................................................101

\section{Capítulo 7}

Tabela 7.1 - identificadores para os tipos das primitvas. . .112 
Tabela 7.2 - identificadores para os tipos das operações

Tabela 7.3 - identificadores para os tipos de blend...........................................................112

Tabela 7.4 - estruturas que implementam a árvore implícita. .............................................113

Tabela 7.5 - etapa de pré-processamento (construção da malha) do método de malha .............124

Tabela 7.6 - teste de crossing em uma célula intermediária. ...............................................125

Tabela 7.7 - funções disponíveis da interface do Visualizador...........................................136 


\section{Lista de Algoritmos}

Algoritmo 6.1 - translação das primitivas selecionadas.................................................. 94

Algoritmo 6.2 - rotação e escalonamento das primitivas selecionadas...................................95

Algoritmo 7.1 - avaliação da função implícita definida pela união com blend pseudo-euclidiano.126

Algoritmo 7.2 - extração de cascas do esqueleto combinatório...........................................133

Algoritmo 7.3 - classificação das cascas em pseudo-sólidos .................................................134 


\section{Resumo}

Este trabalho envolve estudos na área de Modelagem Geométrica, e descreve a implementação de um Modelador de Superficies Implícitas em $\mathfrak{R}^{3}$. Esse modelador tem objetivo de auxiliar o grupo de Mecânica de Fluidos Computacional do ICMC na definição de domínios complexos para realização de simulações de escoamentos de fluidos.

O Modelador utiliza a técnica de Modelagem Implícita. Um modelo é definido por uma árvore CSG (Constructive Solid Geometry). As primitivas que podem constituir essa árvote são: primitivas pré-definidas como esfera, cilindros, etc. , e primitivas baseadas em esqueletos definidos por pontos, segmentos de teta ou polígonos planares. O Modelador é constituído por três componentes: a Interface de Modelagem, responsável pela definição da árvore CSG que representa o modelo implícito; o Poligonalizador, que transforma o modelo implícito em uma malha de polígonos; e o Visualizador que apresenta essa malha de polígonos. 


\section{Abstract}

This work involves studies in the topics of Geometric Modeling, and it describes the development of an Implicit Surface Modeler. The Modeler has the objective of aiding the ICMC group of Computational Fluid Mechanics in the definition of complex domains for numerical simulations of fluid flows.

The Modeler system uses implicit Modeling technique. A model is defined by a constructive solid geometry tree (CSG). Two types of primitives can be used to build the tree: pre-defined primitives, the sphere, cylinder, etc., and primitives defined by skeletons, either points, line segments, or planar polygons. The Modeler is constituted by three components: the Modeling Interface for definition of CSG tree that represents implicit model; Poligonizer for transformation of the implicit model in a mesh of polygons; and Visualizator, form the presentation the polygonal mesh resulting of poligonization. 


\section{Capítulo 1 - Introdução}

Ao longo da última década a Computação Gráfica tem-se expandido de forma a tornar uma poderosa ferramenta utilizada para a visualização e apoio à solução de inúmeros problemas relacionados aos mais diversos fenômenos. Muitos desses problemas são resolvidos através de modelos geométricos. Nesse contexto o computador funciona como uma ferramenta, que provê técnicas para criação de modelos e para a observação de seu comportamento. A Modelagem Geométrica é a área da Computação Gráfica que cuida da criação desses modelos e consiste numa coleção de métodos usados para descrever a forma e outras características de um objeto.

Além da Computação Gráfica, outra área que tem progredido muito é a área de interface homem/computador. No inicio da computação eletrônica, quando o computador era usado por grupos restritos de pessoas, na execução de tarefas especializadas, não era estranho que requisitasse grande experiência do usuário. Também naquela época, devido ao computador ser tão caro, os usuários poderiam "sofrer" um pouco em favor da eficiência computacional. Nos dias atuais, uma grande parte dos recursos computacionais é dedicada exclusivamente a tornar mais fácil a interação homem/computador (Silva, 1996). A preocupação com esta interação é cada vez maior na Ciência da Computação e dos esforços dos cientistas de computação têm surgido novos dispositivos e técnicas para projetos e implementações de interfaces. Em alguns casos, como os softwares comerciais, a interface é ao menos tão importante quanto à funcionalidade do software em si.

A Modelagem Geométrica, como todas as áreas da Ciência da Computação, é beneficiada pelo avanço da área de interface homem/computador permitindo a construção de sistemas de modelagem geométrica mais amigáveis. Nesses sistemas é dado ao usuário um ferramental que lhe permite construir e alterar os modelos de modo mais eficiente.

Voltando à Computação Gráfica, outra área que têm evoluído muito nos últimos anos é a Visualização Computacional. A Visualização Computacional procuta traduzir dados de mediçōes de fenômenos reais ou de simulações para um formato gráfico. Muitos fenôtmenos e simulações geram dados complexos e/ou em enorme quantidade. A tradução para um formato gráfico possibilita uma 
compreensão mais efetiva desses dados e com isto um aumento de produtividade (Minghim \& Oliveira, 1997).

Os avanços da Modelagem Geométrica e da Visualização Computacional têm favorecido os estudos em Mecânica de Fluídos. Entre os ptoblemas da Mecânica de Fluídos, existem três classes especiais: a de escoamento com superficies livtes, a de escoamentos internos e a de escoamentos extemos. No escoamento em superfícies livres, o fluido escoa sem estar necessariamente submetido a uma fronteira rígida. Esse tipo de escoamento pode ser observado no dia-a-dia: no escoamento das ondas do mar, na água a fluir na torneira; e também em muitas aplicaçōes industriais como enchimento de moldes e escoamento de metais líquidos. Nos escoamentos internos, o fluido está submetido a uma fronteira rígida. Escoamentos desse tipo podem ser observados nas tubulações. Nos escoamentos externos, o fluido escoa ao redor de uma fronteira rígida. Esse tipo de escoamento é observado ao redor de um automóvel ou de um avião em movimento.

No ICMC-USP existe um projeto em desenvolvimento denominado SNENS: Solução Numérica das Equações de Navier-Stokes. O objetivo desse projeto é a simulação de escoamento de fluídos, e em particular escoamento de fluídos com superficies livres. O projeto SNENS II, financiado pela FAPESP (processo $n^{\circ} .1998 / 4346-7$ ), está em desenvolvimento e tem como principais objetivos:

- a extensão dos ambientes de simulação para que possam tratar igualmente escoamento de fluídos com superficies livres e escoamentos intemos em domínios complexos;

- o uso técnicas de computação paralela para a redução do tempo de computação, que atualmente está na ordem de alguns dias.

Os escoamentos internos, externos e de superficies livres são encontrados em modelos envolvendo entrada e saída de fluidos em um recipiente. A geometria desses recipientes é importante para a distribuição de fluidos viscosos. Há a necessidade de descrever domínio (região de entrada ou saída) onde é realizada a simulação. Atualmente, a descrição da geometria dos recipientes e dos fluidos é feita através da introdução das coordenadas dos pontos de bordo em uma malha estruturada. Essa estratégia é pouco intuitiva, propensa a erros e aumenta o custo computacional das simulações, pois passa a ser necessário verificar a presença de bordo em cada célula da malha. Além disto, quando a geometria do domínio é complexa, essa abotdagem apresenta-se inviável. Uma possível solução é o uso de uma malha não estruturada para descrever o domínio físico submetido à simulação. A construção dessa malha é dividida em dois passos: (1) a especificação da fronteira do domínio e (2) a geração da malha conforme a fronteira. 
O objetivo deste projeto de mestrado foi a construção de um sistema computacional para a especificação da fronteira dos domínios em que serão realizadas simulações. Como saída esse sistema fornece uma aproximação linear por partes da fronteira. A partir dessa aproximação, posteriormente, será gerada uma malha não estruturada que representará do domínio.

Para modelagem da fronteira podem ser utilizadas várias técnicas de modelagem de superfícies. A técnica que se apresenta como a mais completa para construção de modelos complexos e que tem evoluído bastante nos últimos anos é de modelagem implícita. A modelagem implícita é mais adequada para responder se um objeto está no interiot, exterior ou sobre a fronteira do domínio e permite a construção de formas complexas a partir de objetos mais simples utilizando operações booleanas, de blend e de esqueletos.

Infelizmente, a modelagem implícita, como o próprio nome indica, não fornece uma representação explícita da superfície que é importante para a geração de malhas. Uma forma de obter uma representação explícita é utilizar uma aproximação linear por partes da superfície. O processo de cálculo de uma aproximação linear por partes é denominado poligonalização.

Esta dissertação apresenta o desenvolvimento de um modelador de superfícies implícitas em $\mathfrak{R}^{3}$, e está organizada em oito capítulos. Os três capítulos seguintes a esta introdução abordam pontos teóricos de modelagem implícita e da poligonalização de superficies, em seguida, três capítulos descrevem o desenvolvimento do Modelador e por último um capítulo de conclusão. O conteúdo de todos esses capítulos é brevemente descrito a seguir:

- O capítulo 2 apresenta uma visão geral da modelagem de superficies, apresentando alguns conceitos relacionados, técnicas de modelagem, e os conceitos de vatiedades e variedades lineares por partes.

- O capítulo 3 descreve a técnica de modelagem implícita de formas. É apresenta a construção de modelos implícitos complexos por CSG, o uso de técnicas de blends e a construção de modelos implícitos complexos a partir de esqueletos.

- O capítulo 4 apresenta uma visão geral dos métodos de poligonalização, o método de poligonalização utilizado no Modelador e estruturas de dados para a representação de superficies.

- O capítulo 5 apresenta a arquitetura do Modelador, o princípio de funcionamento e descreve seus componentes. Também é apresentado o ambiente de desenvolvimento do Modelador. 
- O capítulo 6 apresenta a Interface de Modelagem, principal componente do Modelador e tesponsável pela definição do modelo implícito. São descritas as estruturas de dados para representar o modelo implícito.

- O capítulo 7 apresenta o desenvolvimento de dois componentes do Modelador: o Poligonalizador e o Visualizador de Modelos Aproximados.

- O capítulo 8 conclui a dissertação apresentando as conclusões do trabalho realizado, alguns modelos construídos com o Modelador e sugestões para trabalhos futuros. 


\section{Capítulo 2 - Modelagem de Superfícies}

\subsection{Considerações Iniciais}

Muitas vezes, a construção de modelos de objetos ou de processos é não apenas conveniente, mas também necessária para manipular e a analisar processos ou objetos reais. Construir um modelo de um objeto significa substitui-lo por uma representação que possa ser analisada de maneira mais fácil e barata (Mäntyla, 1988).

Este capítulo apresenta uma visão getal da modelagem de superficies e sua organização é a seguinte: a próxima apresenta conceitos de modelagem e de superficies; a seção 2.3 apresenta algumas técnicas de modelagem; a seção 2.4 apresenta os conceitos de variedades e variedades lineares por partes o que permite caracterizar os modelos implícitos de interesse deste trabalho; a seção 2.5 relaciona a representação concreta de superficies com modelos planares; e a seção 2.6 apresenta as considerações finais deste capítulo.

\subsection{Conceitos de Modelagem e Superfícies}

Segundo (Persiano, 1996), quando se modela algo que ainda não existe, está sendo criado algo à semelhança do que se farão reproduções. O modelo é algo abstrato que materializa a concepção de algo passível de ser concretamente realizável ou não. Assim, modelar é construir uma representação de uma idéia. Quando algo que já existe é modelado o sentido de modelar é o de capturar sua natureza de modo a torná-la compreensível ao intelecto humano. O significado genérico de modelo torna-se o de um objeto feito à semelhança de outro, guardando suas propriedades e os comportamentos relevantes ao estudo de interesse. 
Uma superfície em $\mathfrak{R}^{3}$ é um conjunto de pontos onde a vizinhança, dentro desse conjunto, de qualquer um de seus pontos, é equivalente topologicamente a um disco ou semidisco em $\mathfrak{R}^{2}$ (Gomes \& Velho, 1998). A figura 2.1 ilustra esse conceito.

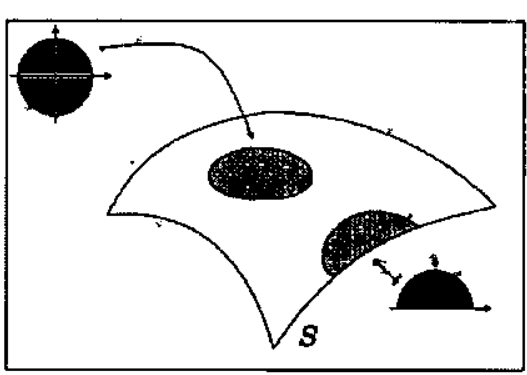

Figura 2.1 - definição de superfície.

A próxima seção apresenta algumas técnicas de modelagem de superfícies. Algumas dessas técnicas são de modelagem de sólidos, sendo que a superfície é definida pelo bordo de sólido.

\subsection{Técnicas de Modelagem 3D}

Técnicas de modelagem são meios para construir modelos. Não se pretende apresentar todas as técnicas de modelagem, e sim as mais comuns nos pacotes de modelagem e na literatura. Uma taxonomia para a modelagem de formas é apresentada em (Wyvill, 2000). A figura 2.2 apresenta uma simplificação dessa taxonomia para sólidos e superfícies.

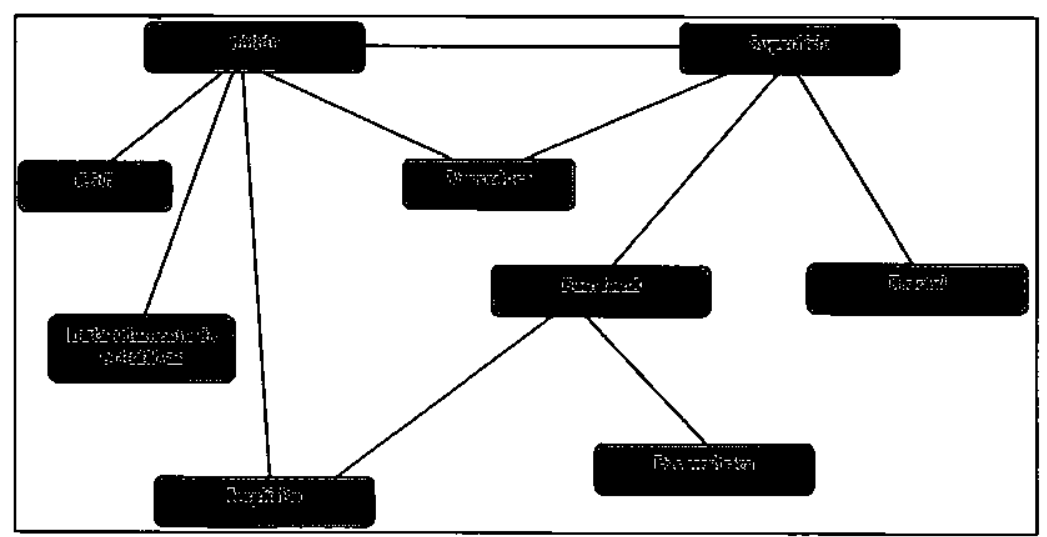

Figura 2.2 - taxonomia de modelagem de sólidos e superfícies.

\subsubsection{Instanciamento de Primitivas}

$O$ instanciamento de primitivas consiste em, a partir de formas primitivas, gerar uma familia de novas formas que variam em relação a alguns parâmetros. A figura 2.3 ilustra essa técnica criando cilindros 
com a variação do eixo e do raio da base. O instanciamento de primitiva está presente em quase todos os modeladores. Os modelos definidos são limitados pelo número de primitivas que o modelador possui.

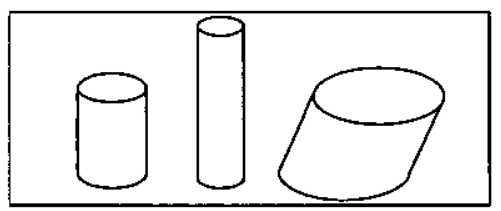

Figura 2.3 - instanciamento de primitivas.

\subsubsection{Varredura (Sweeping)}

A técnica de varredura pode ser utilizada para modelar sólidos ou superficies. A modelagem consiste na definição de uma região e de um caminho diretor. O modelo é gerado pela varredura dessa região no caminho diretor (Foley et al., 1990). Quando se modela superfície a região definida é uma curva, e quando se modela sólidos a região é uma superfície (figura 2.4a). Os tipos de varredura mais comuns são a rotacional (figura 2.4a e 2.4b) e a translacional (figura 2.4c). A técnica de varredura é utilizada para gerar modelos que apresentam algum grau de simetria.

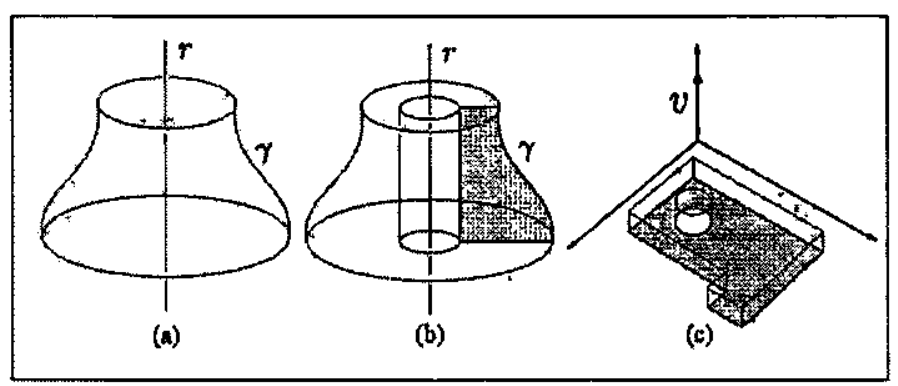

Figura 2.4 - modelagem de superficie (a) e de sólido (b) com varredura rotacional e varredura transacional (c).

\subsubsection{Geometria Sólida Construtiva (Constructive Solid Geometry - CSG)}

O técnico CSG modela sólido a partir da composição booleana de instancias de sólidos primitivos. Em CSG um sólido é descrito por uma árvore: os nós folhas são primitivas de sólidos dimensionadas e regularizadas no espaço; e os nós internos são operadores booleanos (união, interseção e diferença) que atuam sobre as primitivas (Castelo, 1998). A figura 2.5 ilustra a construção de uma xícara por CSG. A CSG é muito poderosa para descrever modelos complexos. Sua limitação está no número de primitivas que os modeladores implementam. 


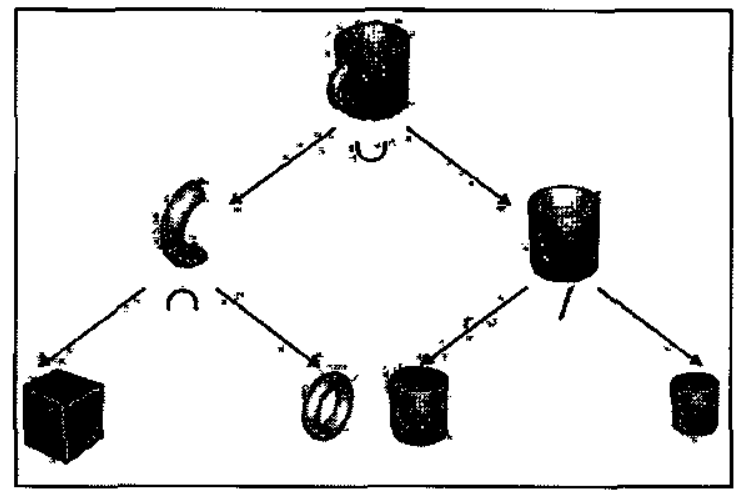

Figura 2.5 - modelo CSG de uma xícara.

\subsubsection{Modelagem Paramétrica}

Formalmente, a forma paramétrica é caracterizada por uma função $F: P \rightarrow F$ do espaço de parâmetros $P$ no espaço de pontos $F$ onde se encontra a forma a modelar. A função $F$ é denominada parametrização da forma. Em modelagem de supetfícies o espaço $F$ é, usualmente, $\mathfrak{R}^{3}$ e o espaço de parâmetros $P$ é um subconjunto de $\Re^{2}$. Cada valor do parâmetro da forma, $\mathbf{p} \in P$ é associado a um ponto $\mathrm{F}(\mathrm{p}) \in F$ da forma geométrica (Petsiano, 1996). A modelagem paramétrica associa a uma forma geométrica uma fórmula que permite calcular as coordenadas de cada um de seus pontos, fornecendo uma representação analítica da forma. A figura 2.6 ilustra a modelagem paramétrica de uma superficie.

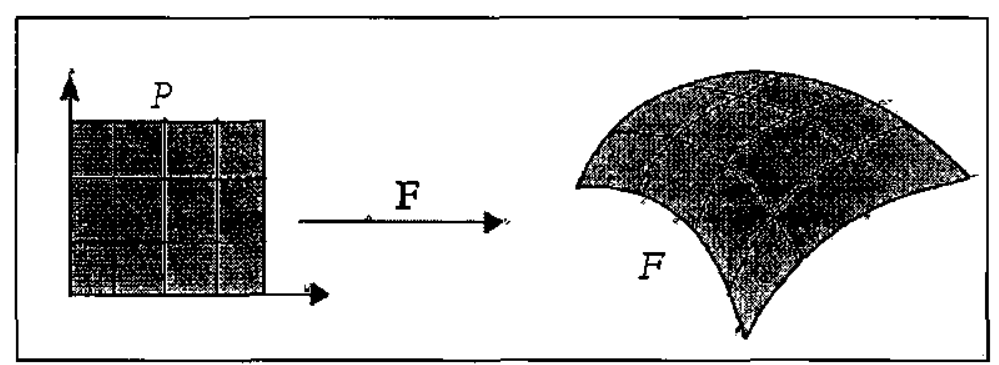

Figura 2.6 - modelagem paramétrica de superfície.

As superficies paramétricas mais comuns na literatura são as superficies de Beziet e as B-Splines. Essas superfícies são obtidas por aproximação polinomial de um conjunto de pontos de controle. Uma introdução sobre os métodos de interpolação utilizados em modelagem paramétrica é apresentada em (Hearn \& Baker, 1997).

A modelagem paramétrica pode set utilizada para modelar supetficies complexas, mas não é uma tarefa simples definir uma única parametrização para superfícies complexas. Uma alternativa utilizada é a modelagem de pedaços da supetfície. 


\subsubsection{Modelagem Implícita}

A modelagem implícita, como o próprio nome indica, não fornece explicitamente expressões para o cálculo de pontos da forma a ser modelada. Os pontos da forma geométrica são caracterizados por uma propriedade comum, tipicamente uma equação. Uma superfície implícita em $\mathfrak{R}^{3}$ é determinada por uma função $f$ definida em $\mathfrak{R}^{3}$ com valores reais (Persiano, 1996).

Os pontos da forma são implicitamente todos aqueles que satisfazem a equação: $f(p)=0$, ou seja, são as raízes de $f$. Para determinar essas raízes são utilizados métodos analíticos em casos simples, como quádricas, mas nos casos gerais são necessátias técnicas de pesquisa numérica (Badler \& Glassner, 1998a). Nos últimos anos pesquisadores têm se dedicado ao estudo de técnicas interativas para a definição de modelos implícitos complexos (Bloomenthal \& Wyvill, 1989) (Bloomenthal, 1995) (Wyvill et al., 1998). O capítulo 3 é dedicado a essa técnica de modelagem.

\subsubsection{Modelagem baseada em Geometria Fractal}

As técnicas apresentadas nas seçōes anteriores usam a geometria euclidiana, por isso são adequados para descrever modelos artificiais com formas regulares. Para as formas naturais como montanhas e nuvens, que apresentam formas irregulares e fragmentadas, os métodos baseados na geometria euclidiana não podem produzir modelos realísticos. Nesse caso, o realismo pode ser obtido por métodos baseados em geometria fractal (Hearn \& Baker, 1997).

Os modelos fractais possuem duas características básicas: detalhes infinitos em todo o modelo e similaridade entre as características das partes e as características globais do modelo (Hearn \& Baket, 1997). Modelo fractal é descrito por um procedimento que, recursivamente, insere detalhes. Teoricamente, a execução de desse procedimento nunca termina (Bloomenthal, 1997a). Os modelos fractais podem gerar um conjunto de pontos, ou uma malha poligonal que representa o modelo com nivel de detalhe tão bom quanto se queira.

(Badler \& Glassner, 1998a) dividem os modelos baseados em geometria fractal em duas classes: os fractais que utilizam processos randômicos para obter a irregularidade presente em pedtas, montanhas e nuvens; e os graftais que utilizam processos determinísticos que representam melhor a repetição de parâmetros como a apresentada em árvores, folhas e flocos neve. A figura 2.7 apresenta uma cena construída com uma montanha definida por um fractal. 


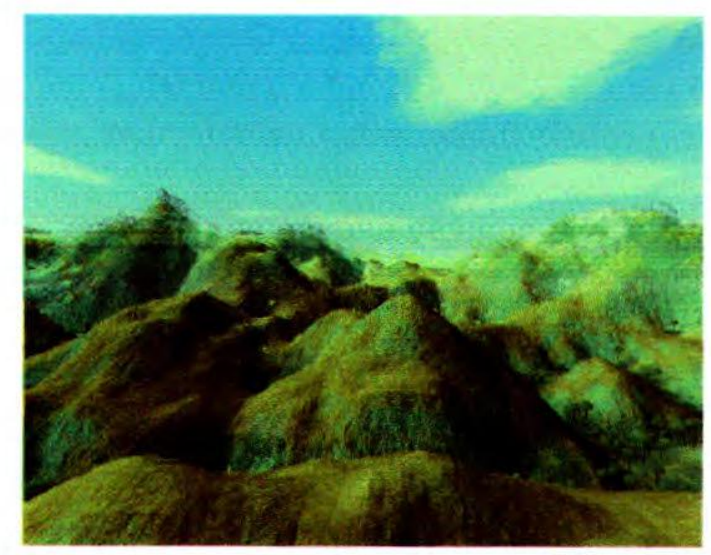

Figura 2.7 - cena montada com um modelo fractal.

\subsection{Variedades Diferenciáveis e Lineares por Partes}

Esta seção apresenta alguns conceitos que permitem caracterizar as superfícies implícitas matematicamente: variedades e variedades lineares por partes. Nesse texto, a expressão "linear por partes" é abreviada por LP. As definições e conceitos apresentados foram extraídos de (Castelo, 1992), a menos quando indicado por outras referências.

\subsubsection{Variedades}

Antes de definir variedades é necessário conceituar homeomorfismo e difeomorfismo. Sejam dois conjuntos abertos $U$ e $V$ e uma aplicação, $f: U \rightarrow V$, inversível. $f$ é chamada de homeomorfismo se $f$ e $f^{-1}$ são contínuas. Se $f$ é um homeomorfismo, é dito que o conjunto $U$ é homeomorfo ao conjunto V.

Seja $f: U \subset \mathfrak{R}^{\mathrm{p}} \rightarrow V \subset \mathfrak{R}^{\mathrm{q}}$ uma função bijetora. $f$ é chamada de difeomorfismo de classe $C^{\mathrm{k}}$ se $f$ e $f^{-1}$ são de classe $C^{k}, \mathrm{k} \geq 1$.

Uma variedade de dimensão $\mathrm{n}$ é um conjunto $V \subset \mathfrak{R}^{\mathrm{m}}$ em que a interseção entre esse conjunto e a vizinhança de qualquer ponto de $V, U \subset \mathfrak{R}^{\mathrm{m}}$ ( $U$ é a vizinhança do ponto), é sempre homeomorfa a uma região aberta $W \subset \mathfrak{R}^{\mathrm{n}-1} \times \mathfrak{R}^{+}$.

Se, ao invés de um homeomorfismo, for apresentado um difeomorfismo entre $U \cap V$ e $W$, a variedade é chamada de variedade diferenciável. Um difeomorfismo $\varphi: W \rightarrow U \cap V$ é chamado de parametrização da região $V \cap U$ e sua inversa, $\varphi^{-1}: U \cap V \rightarrow W$ é chamada carta. 
Os pontos de $V$, que na patametrização, correspondem aos pontos do eixo $\mathfrak{R}^{\mathrm{n}-1} \times\{0\}$, são os pontos que pertencem ao bordo da variedade, denotado por $\partial V$. Caso o conjunto $\partial V$ seja nāo vazio, $V$ é chamado variedade com bordo (Tavates et al., 1992). A figura 2.8 apresenta uma variedade de dimensão 1.

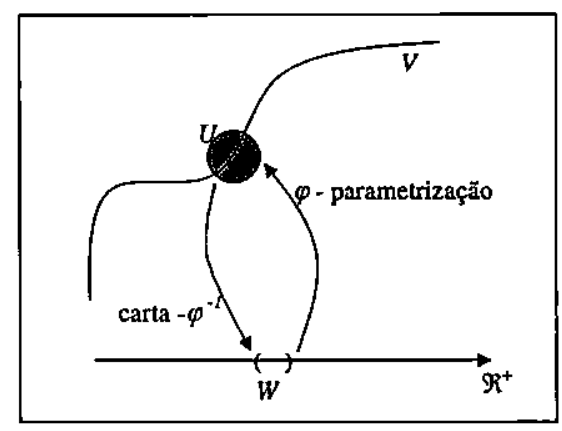

Figura 2.8 - carta e parametrizaçăo.

A imagem inversa de algumas funções do tipo $f: U \subset \Re^{m} \rightarrow \Re^{n}$ definem vatiedades. Para caracterizat essas funções é necessário definir ponto regular e valor regular.

Seja uma aplicação $f: U \rightarrow \Re^{\mathrm{n}}$ de classe $C^{k}$ no aberto $U \subset \mathfrak{R}^{\mathrm{m}}$ com $k \geq 1$ e $m \geq n$. Um ponto $x \in U$ é um ponto regular de $f$ se a derivada de $f$ em $x, D f: \Re^{\mathrm{m}} \rightarrow \Re^{\mathrm{n}}$ é sobrejetora, caso contrário $x$ é chamado de ponto crítico. Pata funções do tipo $f: U \subset \mathfrak{R}^{3} \rightarrow \mathfrak{R}$, a derivada ser sobrejetora significa que o gradiente não é nulo.

Seja $c \in \Re^{\mathrm{n}}$, se o conjunto $f^{-1}(c)=\{x \in U ; f(x)=c\}$ é formado apenas por pontos regulares de $f$, então $c$ é um valor regular de $f$, caso contrário $c$ é um valor crítico de $f$ (Castelo, 1992).

Se $c$ é um valor regulat de $f: U \rightarrow \Re^{\mathrm{n}}$ de classe $C^{k}$ no aberto $U \subset \Re^{\mathrm{m}}$ com $k \geq 1$ e $m \geq n$, então $S=f^{-1}(c)$ é uma vatiedade diferenciável de dimensão $m-n$.

\subsubsection{Variedade Linear por Partes}

Para conceituat vatiedades lineares por partes são necessárias algumas definições.

Uma célula afim, $\sigma$, em $\Re^{\mathrm{m}}$ é o fecho convexo de um conjunto finito de pontos $\left\{v_{0}, v_{1}, \ldots, v_{\mathrm{p}}\right\}$, ou seja, $\sigma=\left[\nu_{0}, v_{1}, \ldots, \nu_{\mathrm{p}}\right]=\left\{\mathrm{v} \in \mathfrak{R}^{\mathrm{m}} \mid \Sigma_{\mathrm{i}} \lambda_{\mathrm{i}} \nu_{\mathrm{i}}=\nu, \Sigma_{\mathrm{i}} \lambda_{\mathrm{i}}=1 \mathrm{e} \lambda_{\mathrm{i}} \geq 0 ; \mathrm{i}=0 . \mathrm{p}\right\}$. A dimensão de $\sigma, \operatorname{dim}(\sigma)$, é igual ao número máximo de vetores linearmente independentes em $\left\{v_{1}-v_{0}, v_{2}-v_{0}, \ldots, v_{\mathrm{p}^{-}} v_{0}\right\}$. Quando $\operatorname{dim}(\sigma)=p, \sigma$ é chamado simplexo, dessa forma um ponto é um simplexo de dimensão 0 ; um segmento 
é um simplexo de dimensão 1; um triângulo é um simplexo de dimensão 2 e um tetraedro é um simplexo de dimensão 3 (figura 2.9).

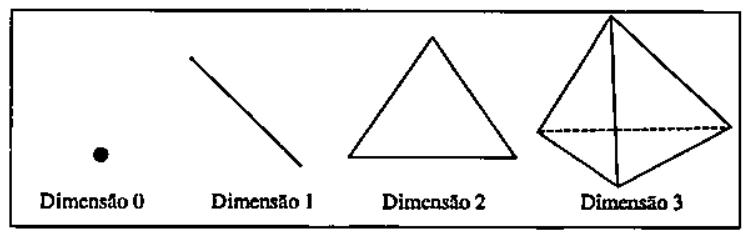

Figura 2.9 - simplexos de dimensão $0,1,2$ e 3.

Seja o simplexo $\sigma=\left[\nu_{0}, \ldots, \nu_{\mathrm{m}}\right]$ de $\Re^{\mathrm{m}}$ e o conjunto $\left\{\nu_{0}, \ldots, \nu_{\mathrm{k}}\right\} \subset\left\{\nu_{0}, \ldots, \nu_{\mathrm{m}}\right\}$, a célula convexa afim definida por $\tau=\left[w_{0}, \ldots, w_{k}\right]$ é chamada de face de dimensão $k$ de $\sigma$. As faces geradas por um único ponto são denominadas vértices de $\sigma$; por dois pontos, arestas de $\sigma$; e por três pontos, faces de $\sigma$.

Dado um simplexo $\sigma=\left[v_{0}, v_{1}, \ldots, v_{\mathrm{m}}\right] \Re^{\mathrm{m}}$, define-se:

- o baricentro de $\sigma, b(\sigma)$, como $b(\sigma)=\frac{1}{m+1} \sum_{i=0}^{m} v_{i}$

- o diâmetro de $\sigma, \rho(\sigma)$, como sendo o maior comprimento das arestas de $\sigma$, ou seja, $\max \left\{|| v_{\mathrm{i}}-v_{\mathrm{j}}|| ; \mathrm{i}, \mathrm{j}=0, \ldots, \mathrm{m}\right\}$;

- o raio de $\sigma, r(\sigma)$, como o raio da bola inscrita em $\sigma: r(\sigma)=\min \{|| v-b(\sigma)||, \nu \in \partial(\sigma)\}$;

- a robustez de $\sigma, \theta(\sigma)$, como $\theta(\sigma)=r(\sigma) / \rho(\sigma)$.

Uma coleção de células afins, $C$, é chamada de decomposição celular de uma região $D \subset \Re^{\mathrm{m}}$ se:

- $D=\cup\{\sigma \in C\}$;

- caso $\sigma$ e $\tau \in C$ então $(\sigma \cap \tau) \in C$ e essa interseção é vazia ou é uma face comum a $\sigma$ e $\tau$;

- qualquer região compacta de $D$ intercepta apenas um número finito de células em $C$.

Caso as células convexas de $C$ sejam todas simplexos então essa decomposição celular é chamada de triangulação. Para uma triangulação $T$ de uma região $U \subset \Re^{m}$ define-se o diâmetro de $T, \rho(T)$, como o máximo dentre os diâmetros dos simplexo de $\mathrm{T}$ e a robustez de $\mathrm{T}, \theta(\mathrm{T})$, como a menor robustez dentre os simplexos de $\mathrm{T}$.

Seja $C$ uma decomposição celular de $D \subset \mathfrak{R}^{\mathrm{m}}$, o par $(D, C)$ é uma variedade linear por partes de dimensão $n$ se:

- todas as suas células possuem, no máximo, dimensão $n$;

- existe, pelo menos uma célula de $C$ com dimensão $n$;

- cada célula de dimensão n-1 de $C$ está contida em uma ou duas células de dimensão n de $C$; 
- toda célula de dimensão menor que $n$ está contida em uma célula de dimensão $n$.

O bordo de $(D, C)$ é definido como o conjunto de todas as células de dimensão $n$-1 de $C$ que estão contidas em apenas uma célula de dimensão $n$ de $C$.

\subsubsection{Aproximação LP de Variedades de Dimensão 2 Definidas Implicitamente em $\Re^{3}$}

Uma superfície implícita em $\Re^{3}$ é definida como o conjunto-zero de uma função $f: \Re^{3} \rightarrow \mathfrak{R}$, ou seja, $\{\mathbf{p}$ $\left.\in \mathfrak{R}^{3} ; f(\mathbf{p})=0\right\}$. As superficies implícitas podem ser variedades ou não. Como exemplo de variedade, seja uma esfera de raio $r$ definida implicitamente por $f(\mathbf{p})=\mathbf{p}_{\mathrm{x}}{ }^{2}+\mathbf{p}_{\mathrm{y}}{ }^{2}+\mathbf{p}_{z}{ }^{2}-r^{2}=0$. A vizinhança em qualquer ponto nessa esfera é homeomorfa a uma região aberta de $\mathfrak{R}^{2}$ (figura $2.10(\mathrm{a})$ ) e qualquer ponto contido na esfera é um ponto regular. Como um exemplo de não-variedade seja o cone $g(\mathbf{p})=\mathbf{p}_{\mathbf{x}}{ }^{2}+\mathbf{p}_{y}{ }^{2}$ - $\mathbf{p}_{z}{ }^{2}=0$, a vizinhança da origem $(\mathbf{p}=(0,0,0))$ não é homeomorfa a uma região aberta de $\mathfrak{R}^{2}$ e a origem não é um ponto regular (figura 2.10(b)).

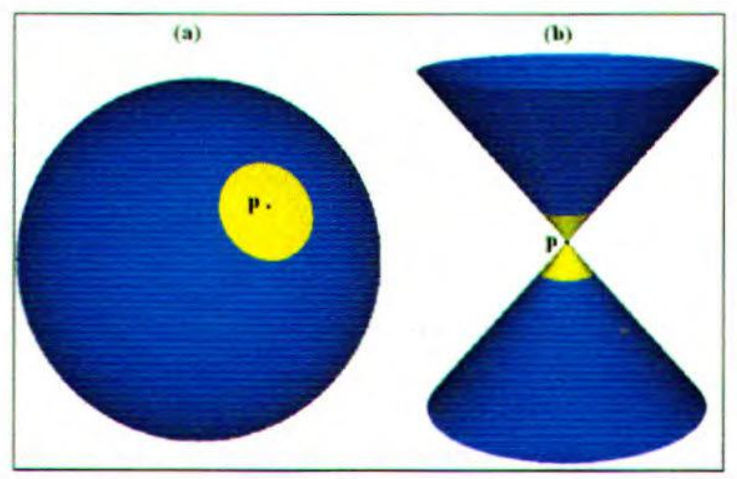

Figura 2.10 - variedade (a) e não-variedade (b) definidas implicitamente em $\Re^{3}$. A região em amarelo indica a vizinhança do ponto $\mathbf{p}$ que pertence a superficie.

Os resultados desta seção são utilizados no capítulo 4 na descrição do processo que calcula uma aproximação LP de uma superfície a partir de uma superfície definida implicitamente, processo conhecido como poligonalização.

A seguir são apresentados pontos importantes para o processo de poligonalização de superfícies implícitas. Os resultados apresentados foram restritos a $\mathfrak{R}^{3}$ por questão de simplicidade e porque esse é o espaço de interesse do trabalho. 


\section{Função Afim Associada}

Seja $f: \mathfrak{R}^{3} \rightarrow \mathfrak{R}$, uma função contínua e $\sigma=\left[v_{0}, \ldots, \nu_{3}\right] \subset \mathfrak{R}^{3}$ um simplexo. Se $\nu \in \sigma$, então $\nu$ pode ser escrito como:

$$
\begin{aligned}
& v=\sum_{i=0}^{3} \lambda_{i} v_{i}, \text { onde } \sum_{i=0}^{3} \lambda_{i}=1 \text { e } \lambda_{l} \geq 0 \text { para } i=0,1,2,3 . \text { Define-se, a função } f_{\sigma}: \sigma \subset \mathfrak{R}^{3} \rightarrow \mathfrak{K} \text { por: } \\
& f_{\sigma}(v)=\sum_{i=0}^{3} \lambda_{i} f_{\sigma}\left(v_{i}\right)=\sum_{i=0}^{3} \lambda_{i} f\left(v_{i}\right) .
\end{aligned}
$$

$f_{\sigma}$ é denominada função afim associada a $f . f_{\sigma}(v)$ é uma função afim que interpola $f$ nos pontos $u_{i}$, i $=0, \ldots, 3$, ou seja, $f_{\sigma}(v)$ é uma interpolação linear para $f$ nos vértices de $\sigma$.

\section{Aproximação LP de uma Superfície}

Esta seção apresenta duas proposições que mostram como encontrar uma aproximação LP de uma superficie definida implicitamente e como se caracteriza uma boa aproximação LP para a superficie. Antes é necessário definir o que é um de simplexo transversal.

Os simplexos presentes em uma triangulação de uma região de $\mathfrak{R}^{3}$ são vértices, arestas, triângulos e tetraedros, assim:

- um vértice $\left[\nu_{0}\right]$ é dito transversal a $S$ se, e somente se, não estiver sobre $S$;

- uma aresta $\left[v_{0}, \nu_{1}\right]$ é dita transversal a $S$ se, e somente se, a interseção $\left(\left[v_{0}, v_{1}\right] \cap S\right)$ é ou vazia ou um ponto no interior de $\left[v_{0}, \nu_{1}\right]$;

- um triângulo $\left[v_{0}, v_{1}, v_{2}\right]$ é dito transversal a $S$ se, e somente se, cada uma de suas arestas for transversal a $S$ e $\left(\left[v_{0}, v_{1}, v_{2}\right] \cap S\right)$ é vazia ou homeomorfa a um intervalo de $\mathfrak{K}^{+}$.

- um tetraedto $\left[v_{0}, v_{1}, v_{2}, v_{3}\right]$ é dito transversal a $S$ se, e somente se, cada uma de suas faces, for transversal a $S$.

Proposição 2.1 - Se $U$ é uma região compacta de $\mathfrak{R}^{3} ; f: U \rightarrow \Re$ é uma função contínua sendo 0 (zero) um valor regular; T uma triangulação de $U$ e $f_{\mathrm{T}}$ a aproximação de $f$ conforme $\mathrm{T}$. Então $S_{\mathrm{T}}=\{u \in U$; $\left.f_{\mathrm{T}}(u)=0\right\}$ é uma aproximação linear por partes de $S$.

Essa proposição não assegura que todos os simplexos sejam transversais a $S$ e a $S_{\mathrm{T}}$, mas simplesmente que a partir de uma superficie implícita e uma triangulação é possível definit uma aproximação linear por partes da superfície. Uma boa aproximação LP de uma superficie é aquela em que todo simplexo de 
$\mathrm{T}$ (triangulação) é transversal a $S$ (superficie) e a $S_{\mathrm{T}}$ (aproximação da superfície); e se um simplexo de T intercepta $S$ também interceptará $S_{1}$.

Proposição 2.2 - Para quase todas triangulações robustas $\mathrm{T}$ de $U$ com diâmetro suficientemente pequeno, tem-se que todo simplexo de T é transversal a $S$ e a $S_{\mathrm{T}}$; e se intercepta $S$ também intercepta $S_{\mathrm{T}}$.

Essa proposição tem como conseqüência importantes propriedades: para quase toda a triangulação $T$ de $U$ com diâmetro suficientemente pequeno, tem-se que:

- se $\sigma$ é uma aresta de T e $u \in(\sigma \cap S)$ então existe $\nu \in\left(\sigma \cap S_{\mathrm{T}}\right)$ tal que $\|u-v\| \leq \rho(\sigma) \leq$ $\rho(\mathrm{T})$

- se $\sigma$ é um simplexo de dimensão $\mathrm{k}+1(0 \leq \mathrm{k} \leq 2)$ de $\mathrm{T}$ e se $\left(\sigma \cap S_{\mathrm{T}}\right) \neq \varnothing$, então $\left(\sigma \cap S_{\mathrm{T}}\right)$ é uma célula convexa afim de dimensão $\mathrm{k}$.

\subsection{Representação de Superfícies}

As técnicas modelagem definem modelos abstratos. Algumas operações podem ser adaptadas aos modelos abstratos. Já outras operações, como as de simulação, necessitam de uma representação concreta. Então, a partir de um modelo abstrato deve-se obter descrições simbólicas e frnitas que posteriormente serão implementadas em uma estrutura de dados em um sistema computacional (Gomes \& Velho, 1998).

Os modelos mais utilizados, para representar concretamente uma superfície, são os modelos planares. Segundo (Mäntyla, 1988) um modelo planar é uma grafo planar dirigido definido pelo conjunto $\{N$, $\mathbf{A}, \mathbf{R}\}$ com um número finito de vértices $\mathbf{N}=\left\{\mathbf{n}_{1}, \mathbf{n}_{2}, \mathbf{n}_{3}, \ldots\right\}$, de arestas $\mathbf{A}=\left\{\mathbf{a}_{1}, \mathbf{a}_{2}, \mathbf{a}_{3}, \ldots\right\}$, e de polígonos $\mathbf{R}=\left\{\mathbf{t}_{1}, \mathbf{t}_{2}, \mathbf{t}_{3}, \ldots\right\}$. Esse grafo dirigido representa uma aproximação linear por parte $\mathrm{da}$ superfície e descreve explicitamente a topologia dessa (Siqueita, 1994). Desse modo a aproximação LP de uma superfície é utilizada para representar concretamente uma superfície implicitamente definida.

\subsection{Considerações Finais}

Neste capítulo foram apresentados conceitos relacionados à modelagem de superfícies e técnicas para modelagem. A técnica de modelagem, a ser utilizada neste trabalho, é a modelagem implícita apresentada no capítulo 3. Foram apresentados, também, os conceitos de variedade, de variedades LP e 
a base matemática para se calcular uma variedade LP de dimensão $2 \mathrm{em} \mathfrak{R}^{3}$ a partir de uma variedade definida implicitamente.

No próximo capítulo são apresentados tópicos de modelagem implícita em Computação Gráfica. O cálculo de uma variedade LP a partir de uma variedade implícita é abordado no capítulo 4. 


\section{Capítulo 3 - Modelagem Implícita}

\subsection{Considerações Iniciais}

A Computação Gráfica sempre privilegiou o uso de modelos paramétricos na construção de superfícies especialmente pela facilidade de renderizá- $\operatorname{los}^{1}$ (Bloomenthal, 1997a). Entretanto, nos últimos anos foram realizados vários de trabalhos e eventos dedicados à modelagem implícita. Os principais eventos relacionados com esse tipo de modelagem são:

- Workshop on Implicit Surfaces - esse workshop tem sido realizado desde 1995 a cada ano e meio e conta com o apoio da ACM SIGGRAPH ${ }^{2}$ e Eurographics ${ }^{3}$.

- Shape Modeling International - esse encontro é organizado pela Universidade de Aizu, Japão, em cooperação com ACM SIGGRAPH e Eurographics. O primeito foi realizado em 97 e o segundo foi em 1999.

- Cursos do SIGGRAPH - nos últimos quatro anos $(96,97,98$ e 99) foram apresentados cursos sobre superficies implícitas nas conferências anuais do SIGGRAPH.

Este capítulo apresenta uma visão geral da modelagem implícita de formas (superfícies e sólidos) no espaço tridimensional destacando a definição objetos complexos. A seção 3.2 trata da formulação implícita de sólidos e superfícies, apresentando uma comparação entre as formulações implícitas e paramétricas e considerações sobre os sistemas de modelagem implícita. A seção 3.3 apresenta a construção de modelos implícitos complexos por CSG e a seção 3.4 apresenta técnicas de blends para composição de superfícies implícitas suaves. A seção 3.5 apresenta a construção de modelos implícitos complexos a partir de esqueletos. Por fim, a seção 3.6 apresenta as considerações finais deste capítulo.

\footnotetext{
${ }^{1} \mathrm{O}$ verbo renderizar indica o processo rendering, ou seja, a partir de um modelo geométrico, de um modelo de huz de uma câmera e outros parâmetros computar uma imagem.

2 ACM SIGGRAPH - Special Interest Group on Graphics of the Association for Computing Machinery - Grupo de Computação Gráfica da ACM.

${ }^{3}$ Eurographics - Associação européia de pesquisadores em Computação Gráfica.
} 


\subsection{Modelagem Implícita de Superfícies e de Sólidos}

O uso de funções de várias variáveis reais na definição de objetos geométricos é comum em Matemática e em Computação Gráfica. Equações do tipo $f\left(x_{1}, x_{2}, \ldots, x_{n}\right)=0$ definem funções implícitas de $n-1$ variáveis que podem descrever uma forma de dimensão $n-1$, e as inequações $f\left(x_{1}, x_{2}, \ldots, x_{n}\right) \leq 0$ ou $f\left(x_{1}, x_{2}, \ldots, x_{n}\right) \geq 0$ podem descrever semi-espaços em um espaço euclidiano de dimensão $n$. As superfícies definidas implicitamente em $\mathfrak{R}^{3}$ são formas geométricas, chamadas de superfícies implícitas, e consistem um conjunto de pontos no espaço que satisfazem uma equação definida a partir da função de superfície implícita (Pasko et al., 1995).

Como o próprio nome indica essa função não descreve explicitamente seus pontos, apenas indica se um ponto pertence ou não à mesma. Assim, seja $f: \mathbf{D} \subset \Re^{3} \rightarrow \Re$ uma função, e $c$ um valor regular de $f$. A equação $f(\mathbf{p})=c$, define um conjunto de pontos de $\mathfrak{R}^{3},\{\mathbf{p} \in \mathbf{D} \mid f(\mathbf{p})=c\}$, que pertencem a uma superfície. Usualmente toma-se $c=0$ e a superfície implícita é também chamada de conjunto zero com a notação $f^{-1}(0)$ ou $Z(\not)$. Exemplos comuns de superficies implícitas são esferas $\left(f(\mathbf{p})=\mathbf{p}_{\mathbf{x}}{ }^{2}+\mathbf{p}_{\mathbf{y}}{ }^{2}+\mathbf{p}_{z}{ }^{2}-\right.$ $\left.r^{2}=0\right)$ e planos $\left(g(\mathbf{p})=a \mathbf{p}_{\mathbf{x}}+b \mathbf{p}_{\mathbf{y}}+c \mathbf{p}_{\mathbf{z}}+d=0\right)$.

\subsubsection{Tipos de Superfícies Implícitas e Definição de Sólido}

Neste trabalho o interesse é por formulações implícitas que definam variedades de dimensão 2. As superficies implícitas podem ser de vários tipos: superficies com uma ou mais componentes conexas; superficies limitadas ou ilimitadas e superficies com ou sem bordo.

Uma componente conexa $C$ de uma superfície $S$ é uma porção de $S$, em que a partir de um ponto qualquer é possível atingir outro ponto qualquer "caminhando sobre" essa porção. A esfera é uma superfície com apenas uma componente conexa enquanto uma hiperbolóide de duas folhas possui duas componentes. Algumas superficies definidas por funções transcendentais podem possuir infinitas componentes.

Superficies implícitas podem ser limitadas, ou seja, é possível definir uma região compacta de $\mathfrak{R}^{3}$ que contenha toda a superfície, como as esferas, ou ilimitadas como planos e cilindros.

As superfícies implícitas podem possuir ou não bordo. Em uma superfície o bordo define uma curva. As superfícies fechadas como esferas e elipsóides não possuem bordo. O bordo pode ser inserido em uma superfície implícita restringindo o espaço de sua definição, por exemplo, a formulação: 


$$
f(\mathbf{p})=\left\{\begin{array}{l}
\mathbf{p}_{x}^{2}+\mathbf{p}_{y}^{2}+\mathbf{p}_{z}^{2}-25, \text { para }-3 \leq \mathbf{p}_{z} \cdot \leq+3 \\
1, \text { para }-3 \mathbf{p}_{z} \text { ou } \mathbf{p}_{z} \geq+3
\end{array}\right.
$$

define a superfície com duas curvas de bordo apresentada na figura 3.1 .

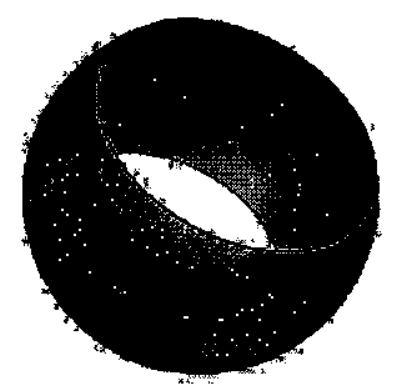

Figura 3.1 - superfície com bordo.

As superfícies que definem um número finito de componentes conexas, sem bordo e limitadas, podem ser vistas como bordos de sólidos e utilizadas para definir sólidos: como as desigualdades $f(\mathrm{p}) \leq 0$ e $f(\mathrm{p}) \geq 0$ definem semi-espaços para superfícies sem bordo, os semi-espaços podem ser interpretados como duas regiões, uma região interior à superfície e outra região exterior à superfície. $O$ sólido é definido pela superficie mais seu interior. Conforme a interpretação do valor de $f(p)$ a caracterização do interior do sólido é diferente:

O valor de $f(\mathrm{p})$ pode referir à proximidade do ponto $\mathrm{p}$ em relação à superfície. Esse valor não indica obrigatoriamente a distância euclidiana, mas pode ser entendido como uma medida de distância. Para superfícies implícitas definidas por expressões algébricas, o valor de $f(\mathrm{p})$ é chamado de distância algébrica. Desse modo os pontos onde $f(p)$ é definida são classificados como:

- pontos interiores à superfície (pertencentes ao sólido): $f(\mathrm{p})<0$;

- pontos exteriores à superfície (não pertencentes ao sólido): $f(\mathrm{p})>0 \mathrm{e}$

- pontos da superfície (pertencentes ao sólido): $f(\mathrm{p})=0$.

O valor de $f(\mathrm{p})$ pode ser interpretado como o potencial no ponto $\mathrm{p}$ em relação a uma fonte, geralmente um esqueleto. O potencial em $\mathbf{p}$ diminui conforme aumenta a distância da fonte, assim a caracterização do interior da superfície ocorre de modo inverso:

- pontos interiores à superfície (pertencentes ao sólido): $f(\mathrm{p})>0$;

- pontos exteriores à superfície (não pertencentes ao sólido): $f(\mathrm{p})<0 \mathrm{e}$

- pontos da superfície (pertencentes ao sólido): $f(\mathrm{p})=0$. 


\subsubsection{Superfícies Implícitas e as Superfícies Paramétricas}

As técnicas paramétricas nas quais cada coordenada é representada por uma função polinomial de duas variáveis são muito utilizadas na Computação Gráfica, principalmente pela facilidade de renderizá-las, o que permite um projeto interativo dessas superficie. Além disso, as superficies paramétricas são mais convenientes para certas operações como: cálculo de curvatura, controle de posição e de tangência (Bloomenthal, 1997a). Em geral as operações que necessitam conhecer a posição na superfície são facilitadas pela modelagem paramétrica.

A formulação implícita tetrata a relação do modelo com o espaço onde está imetso e define uma familia de modelos (Persiano, 1996). Ao definir uma forma geométrica pela equação $f(\mathbf{p})=0$, está-se definindo outros modelos expressos por $f(\mathrm{p})=c$, onde $c$ é um valor regular de $f$. Logo, ao contrário da modelagem patamétrica, a modelagem implícita descreve um volume e não somente a superfície. Segundo (Bloomenthal, 1997a), as superficies implícitas apresentam algumas vantagens se comparadas com as superficies paramétricas:

- A união ou interseção suave entre superfícies implícitas são definidas de modo mais fácil que as superfícies paramétricas;

- a noção de volume na modelagem implícita facilita a detecção de colisão e assim a construção de objetos complexos;

- as superfícies implícitas são fechadas sobre as operações de composição;

- as superfícies paramétricas geralmente são variedades com bordo e dificultam a definição de pontos internos e externos.

A construção de superfícies complexas na modelagem implícita pode ser vista como a definição de uma função implícita mais complexa, enquanto que na modelagem patamétrica são definidos pedaços paramétricos da superfície e a união desses pedaços é uma tarefa difícil e geralmente apresenta problemas de continuidade numérica (Bloomenthal, 1997a).

\subsubsection{Sistemas para Modelagem Implícita}

A construção de um sistema computacional que permita a modelagem interativa de qualquer tipo de função $f: \mathbf{D} \subset \mathfrak{R}^{3} \rightarrow \mathfrak{R}$ é inviável devido à complexidade das funções que se pode obter. Alguns trabalhos como (Siquiera, 1994) (Pasko et al., 1995)implementam interpretadores em que o usuário especifica uma função implícita através de uma linguagem; e o modelador gera uma representação poligonal da superfície. Nessa abordagem um maior número de superfícies pode ser getado conforme $o$ 
poder da linguagem utilizada, mas a interatividade é quase inexistente, pois é difícil o usuário prever a forma através da função que ele descreve.

Para a modelagem interativa de superficies implícitas existem duas abordagens na literatura. A primeira é a definição de superfícies implícitas complexas utilizando operadores de CSG e funções implícitas simples como quádricas, superquádricas e planos. A segunda abordagem é a utilização de elementos simples, chamados esqueletos, que controlam a forma da superfície. A próxima seção apresenta a definição de modelos implícitos por CSG.

\subsection{Modelagem por CSG}

$\mathrm{Na}$ construção de superfícies implícitas complexas é muito utilizado o princípio da Geometria Sólida Construtiva (CSG): é possível modelar sólidos complexos, a partir de sólidos simples. Na CSG, formas simples são combinadas através de operações de união, de interseção e de diferença. Na modelagem implícita essas operações de composição podem ser implementadas com operadores min e max e atuam sobre formulações implícitas mais simples chamadas de primitivas implícitas.

Conforme a desigualdade $\left(\leq\right.$ ou $\geq$ ) que define os sólidos a definição dos operadores é diferente. Se $f_{1}$ e $f_{2}$ são funções implícitas que definem dois sólidos $\left(f_{1}(\mathrm{p}) \leq 0\right.$ e $\left.f_{2}(\mathrm{p}) \leq 0\right)$, então as operações de composição são definidas como (Ricci, 1973):

$$
\begin{array}{ll}
\text { União: } & f=f_{1} \cup f_{2}=\min \left(f_{1}, f_{2}\right) ; \\
\text { Interseção: } & f=f_{1} \cap f_{2}=\max \left(f_{1}, f_{2}\right) \mathrm{e} \\
\text { Diferença: } & f=f_{1} \backslash f_{2}=f_{1} \cap C\left(f_{2}\right)=\max \left(f_{1},-f_{2}\right) \text {, }
\end{array}
$$

$C\left(f_{2}\right)$ denota o complemento de $f_{2}$, como a fronteita do sólido é definida por $f_{2}(\mathbf{p})=0$ e o interior do sólido por $f_{2}(\mathbf{p})<0$, então seu complemento é definido por $C\left(f_{2}\right) \equiv-f_{2}$. Como exemplo de modelagem através de CSG a figura 3.2(a) apresenta uma superficie definida por:

$$
f(p)=\max \left(\min \left(\min \left(\operatorname{esf}_{1}(p), \operatorname{esf}_{2}(p)\right), \operatorname{esf}_{3}(p)\right), \operatorname{esf}_{4}(p)\right)=0
$$

onde esf $f_{i}(p)$ representa o valor da função implícita que define a esfera $i$ no ponto p. O sólido é definido por $f(\mathrm{p}) \leq 0$. A figura 3.2(b) apresenta a árvore CSG da definição desta superfície.

Para os sólidos definidos por $f(p) \geq 0$, as operações são definidas trocando o operador min por max e vice-versa. Os operadores min e max são semi-analíticos, assim não é possível definir o gradiente em 
todos os pontos da fronteira do sólido complexo, ou seja, a superfície composta apresentará quinas e/ou picos. Na seção 3.4 são apresentadas as técnicas que permitem obter sólidos compostos com superfícies suáveis. O conjunto de formas a serem modeladas por modelagem implícita através de CSG depende das primitivas utilizadas na composição, algumas primitivas implícitas são apresentas a seguir.

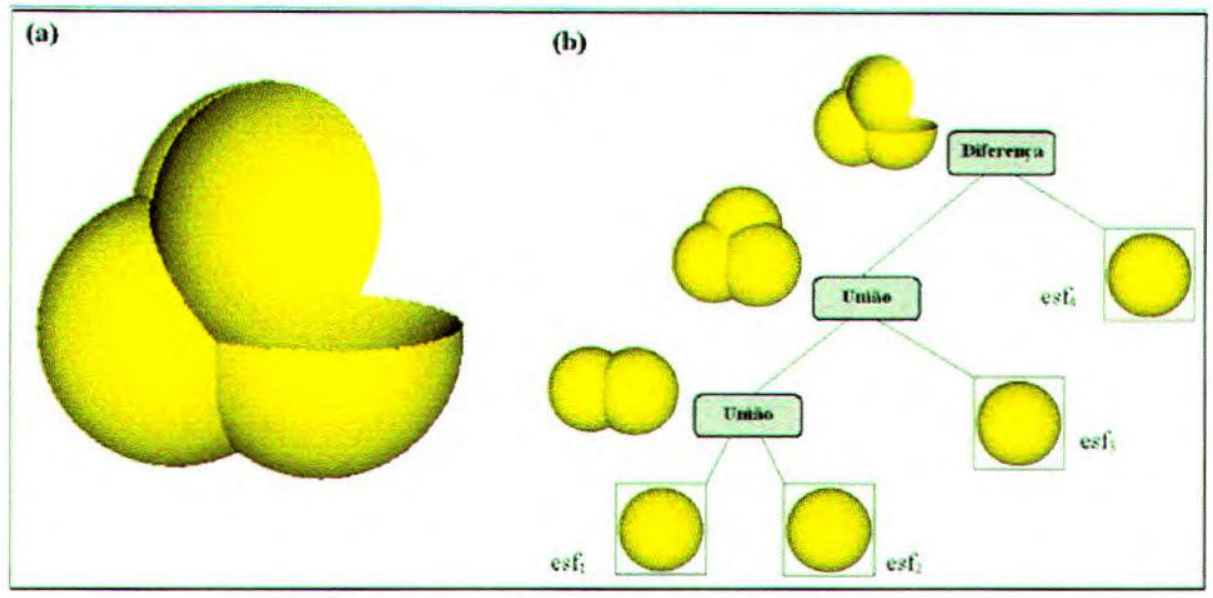

Figura 3.2 - exemplo de CSG: (a) sólido; (b) árvore de avaliação.

\subsubsection{Algumas Primitivas Implícitas}

As quádricas, superfícies definidas por expressões algébricas de grau 2, são superfícies comuns em modelagem implícita. Essas superfícies são fáceis de renderizar e é possível a partir da formulação implícita obter a formulação paramétrica. (Blinn, 1997) discute as propriedades das superfícies definidas por quádricas. Dentre as quádricas estão esferas, elipsóides, toros ${ }^{4}$, parabolóides e hiperbolóides. Particularmente esferas, elipsóides e toros são comuns em pacotes gráficos e podem ser utilizados na construção de objetos complexos (Hearn \& Baker, 1997).

Uma esfera com raio R centrada na origem é definida pelos pontos que satisfazem a equação:

$$
\begin{aligned}
& f(\mathbf{p})=\mathbf{p}_{x}^{2}+\mathbf{p}_{y}^{2}+\mathbf{p}_{z}^{2}-R^{2}=0, \text { a representação paramétrica dessa esfera é: } \\
& \mathbf{p}_{x}=R \cdot \operatorname{sen} \varphi \cdot \cos \theta \\
& \mathbf{p}_{y}=R \cdot \cos \varphi \quad-\pi / 2 \leq \varphi \leq \pi / 2 \\
& \mathbf{p}_{z}=R \cdot \operatorname{sen} \varphi \cdot \operatorname{sen} \theta
\end{aligned}
$$

Um elipsóide é uma extensão das superfícies esféricas onde um raio diferente pode ser associado a cada eixo:

\footnotetext{
${ }^{4}$ Embora a equação de um toro seja de grau 4 é comum classificá-lo como uma quádrica.
} 


$$
\begin{aligned}
& f(\mathbf{p})=\left(\frac{\mathbf{p}_{x}}{R_{x}}\right)^{2}+\left(\frac{\mathbf{p}_{y}}{R_{y}}\right)^{2}+\left(\frac{\mathbf{p}_{z}}{R_{z}}\right)^{2}-1=0 \text { e a representação paramétrica é dada por: } \\
& \mathbf{p}_{x}=R_{x} \cdot \operatorname{sen} \varphi \cdot \cos \theta \quad-\pi / 2 \leq \varphi \leq \pi / 2 \\
& \mathbf{p}_{y}=R_{y} \cdot \cos \varphi \quad-\pi \leq \theta \leq \pi \\
& \left.\mathbf{p}_{z}=R_{z} \cdot \operatorname{sen} \varphi \cdot \operatorname{sen} \theta \quad-\pi\right)
\end{aligned}
$$

Um toro é definido pela varredura de um esfera sobre um segundo círculo. Um toro definido pela varredura da esfera $\mathbf{p}_{x}^{2}+\mathbf{p}_{y}^{2}+\mathbf{p}_{z}^{2}-R_{\text {menor }}^{2}=0$ sobre o círculo, $\mathbf{p}_{z}^{2}+\mathbf{p}_{x}^{2}-R_{\text {mator }}^{2}=0$ com $\mathbf{p}_{y}=0$, é definido por:

$$
f(\mathbf{p})=\left[\frac{R_{\text {mator }}}{R_{\text {menor }}}-\sqrt{\left(\frac{\mathbf{p}_{x}}{R_{\text {menor }}}\right)^{2}+\left(\frac{\mathbf{p}_{z}}{R_{\text {menar }}}\right)^{2}}\right]^{2}+\left(\frac{\mathbf{p}_{y}}{R_{\text {menor }}}\right)^{2}-1=0,
$$

e a representação paramétrica:

$$
\begin{array}{ll}
\mathbf{p}_{x}=R_{\text {maior }}+R_{\text {menor }} \cdot \operatorname{sen} \varphi \cdot \cos \theta & -\pi \leq \varphi \leq \pi \\
\mathbf{p}_{y}=R_{\text {menor }} \cdot \cos \phi & -\pi \leq \theta \leq \pi \\
\mathbf{p}_{z}=R_{\text {maior }}+R_{\text {menor }} \cdot \operatorname{sen} \varphi \cdot \operatorname{sen} \theta &
\end{array}
$$

Outras formas interessantes para a modelagem são as superelipsóides. Superelipsóides são superficies definidas a partir de elipsóides adicionando dois parâmetros, $s_{\mathbf{x z}}$ e $s_{y}$, como mostra a equação (3.4). Esses parâmetros são números positivos, sendo que $s_{x z}$ controla a forma ao longo dos eixos $\mathrm{X}$ e $\mathrm{Z}$ e $s_{\mathrm{y}}$ controla a forma ao longo do eixo Y. A figura 3.3(a) ilustra a forma definida ao longo de um eixo conforme a variação de $s\left(s_{x z}\right.$ ou $\left.s_{y}\right)$. A formulação implícita e a paramétrica das superelipsóides são apresentadas a seguir:

$$
\begin{aligned}
& f(\mathbf{p})=\left[\left(\frac{\mathbf{p}_{x}}{R_{z}}\right)^{2 / s_{x z}}+\left(\frac{\mathbf{p}_{z}}{R_{z}}\right)^{2 / s_{s x}}\right]^{s_{z} / s_{y}}+\left(\frac{\mathbf{p}_{y}}{R_{y}}\right)^{2 / s_{y}}-1=0, \\
& \begin{array}{ll}
\mathbf{p}_{x}=R_{x} \cdot \operatorname{sen}^{s y} \varphi \cdot \cos ^{s_{x}} \theta & -\pi / 2 \leq \varphi \leq \pi / 2 \\
\mathbf{p}_{y}=R_{y} \cdot \cos ^{s_{y}} \phi &
\end{array} \\
& \begin{array}{l}
\mathbf{p}_{y}=R_{y} \cdot \cos ^{s_{y}} \varphi \\
\mathbf{p}_{z}=R_{z} \cdot \operatorname{sen}^{s_{y}} \varphi \cdot \operatorname{sen}^{s_{z}} \theta
\end{array} \quad-\pi \leq \theta \leq \pi
\end{aligned}
$$

A figura 3.3(b) ilustra algumas formas definidas por elipsóides variando os parâmetros $s_{x z}$ e $s_{y}$ entre 0.5 e $2.5, \operatorname{com} R_{x}=R_{y}=R_{z}=1$.

\subsection{Blends de superfícies}

As funções implícitas definidas pelas operações de CSG através das funções min e max são fáceis de serem calculadas, mas apresentam descontinuidade na primeira derivada. Assim, essa função implícita não é de classe $C^{1}$ e a forma que ela descreve pode possuir quinas e/ou picos. A presença desses 
artefatos na superfície dificulta o calculo de sua aproximação linear por partes. Para evitar a presença de quinas em superfícies implícitas compostas sào utilizadas técnicas de blend que redefinem as operações de composição garantindo que a superfície gerada seja suave.

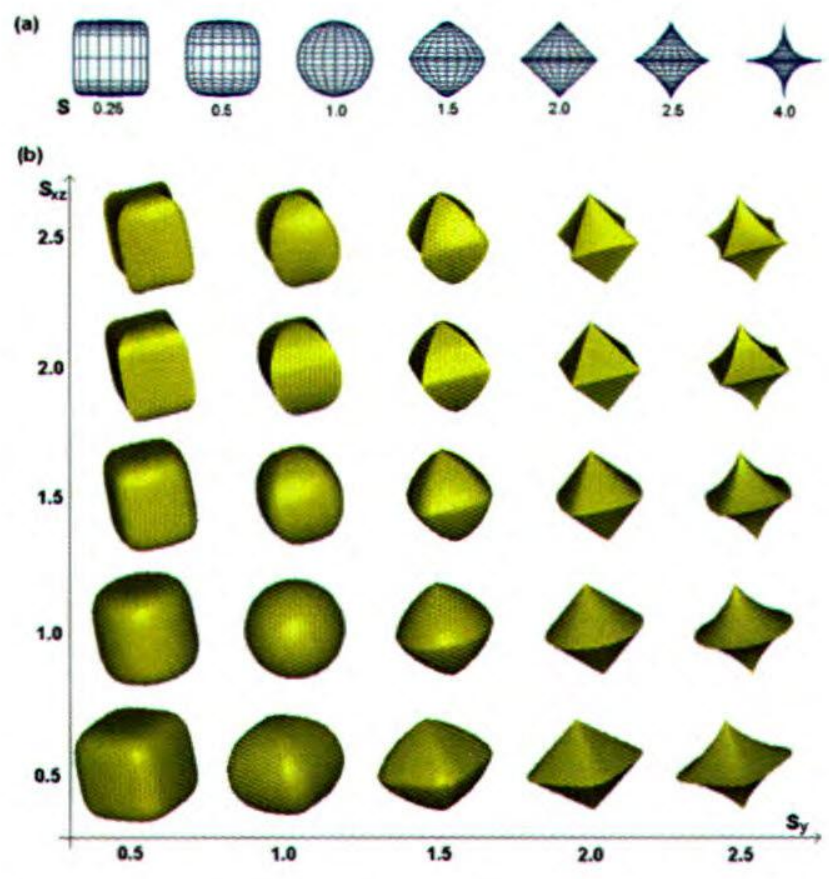

Figura 3.3 - superelipsóides

Um exemplo do poder de superfícies definidas implicitamente através de operações de blend é o projeto de uma máquina copiadora por Rossignac, de cujas 100 peças somente uma não pode ser definida por blend de quádricas e toros (Rockwood, 1989). Esta seção apresenta quatro técnicas blend e analisa as vantagens e desvantagens de cada uma. A primeira pode ser classificada como uma técnica global, pois atuam em todos os pontos da superfície mesmo naqueles distantes da região de descontinuidade e as demais técnicas restringem a região de ação.

\subsubsection{Blend Norma-p}

A base desta técnica é o fato do operador max ser definido como norma infinita (Bloomenthal, 1997a), ou seja:

$$
\max (a, b)=\lim _{p \rightarrow \infty}\left(a^{p}+b^{p}\right)^{1 / p}, \operatorname{com} a, b>0
$$

${ }^{5}$ A tradução literal de blend é mistura. As técnicas de blend determinam uma superfície implícita suave a partir da "mistura" de duas ou mais superfície. 
do mesmo modo, min é definido como:

$$
\min (a, b)=\lim _{p \rightarrow \infty}\left(a^{-p}+b^{-p}\right)^{-1 / p}, \operatorname{com} a, b>0 .
$$

A partir dessa observação os operadores de composição são redefinidos não mais utilizando a norma infinita, mas a norma-p. Então, o operador $\max (a, b)$ é substituído por $\left(d^{b}+b^{b}\right)^{1 / p}$ e $\min (a, b)$ é substituído por $\left(a^{\not p}+b^{\not p}\right)^{-1 / p} \operatorname{com} p>1$.

A aplicação do blend por norma-p necessita que a função de superfície implícita seja redefinida, pois se for utilizado $f(\mathbf{p})=0$ o cálculo de $(f(\mathbf{p}))^{-p}$ pode provocar erro. A função $f: \Re^{3} \rightarrow \Re$ deve ser substituída por uma função $g: \mathfrak{R}^{3} \rightarrow \mathfrak{R}^{+}$tal que para $\mathbf{p} \in \mathfrak{R}^{3}$ têm-se que:

$$
\begin{aligned}
& \text { se } f(\mathbf{p})=0 \text { então } g(\mathbf{p})=1 \\
& \text { se } f(\mathbf{p})<0 \text { então } g(\mathbf{p})<1 \\
& \text { se } f(\mathbf{p})>0 \text { então } g(\mathbf{p})>1
\end{aligned}
$$

O complemento de um sólido definido por $g(\mathbf{p}) \leq 1$ é calculado por $\mathbf{C}(g(\mathbf{p}))=(g(\mathbf{p}))^{-1}$. Para dois sólidos definidos por $g_{1}(\mathbf{p}) \geq 1$ e $g_{2}(\mathbf{p}) \geq 1$ as operações de composição definidas por blend norma-p são (Ricci, 1973) :

$$
\begin{array}{ll}
\text { interseção: } & g=g_{1} \cap g_{2}=\left(g_{1}^{-p}+g_{2}^{-p-p}\right)^{-1 / p}, \\
\text { união: } & g=g_{1} \cup g_{2}=\left(g_{1}^{\mathrm{p}}+g_{2}^{\mathrm{P}}\right)^{1 / p}, \\
\text { diferença: } & g=g_{1} \backslash g_{2}=g_{1} \cap C\left(g_{2}\right)=\left(g_{1}^{-p}+g_{2}^{p}\right)^{-1 / p} \operatorname{com} p>1 .
\end{array}
$$

Segundo (Wyvill et al. 1998) essa técnica é associativa o que permite a extensão das operações acima para mais de duas superfícies. Outra característica é o fato da função composta possuir continuidade $\mathrm{C}^{\mathrm{n}}$, desde que $g_{1}(\mathbf{p})$ e $g_{2}(\mathbf{p})$ apresentem continuidade $\mathrm{C}^{\mathrm{n}}$ e suas imagens estejam em $\mathfrak{R}^{+}$. O blend por norma-p suaviza toda superfície composta, mesmo as regiões afastadas da interseção de dois objetos implícitos são afetadas. Isso pode suavizar a superfície em excesso caso o valor de $p$ seja pequeno ou o blend seja realizado várias vezes. Como exemplo, a figura 3.4 apresenta o mesmo objeto da figura 3.2, sendo que os operadores min e max foram substituídos pela norma-p $\operatorname{com} p=2,4$ e 8 .

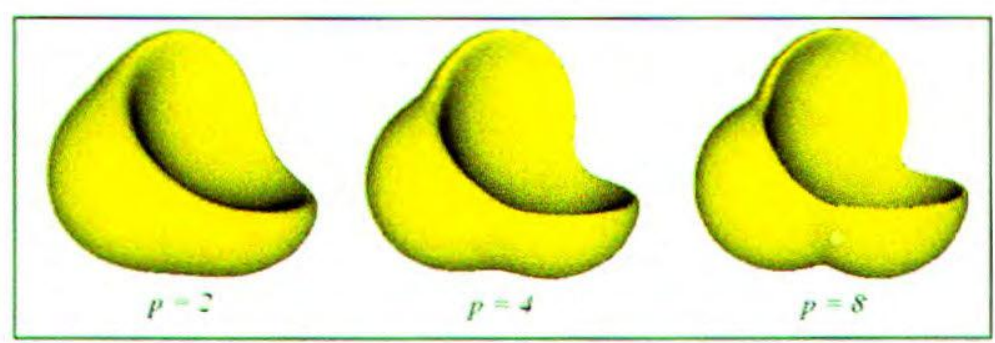

Figura 3.4 - blend com norma-p. 


\subsubsection{Blend Elíptico}

O blend elíptico é definido a partir de uma função $B: \mathfrak{R}^{2} \rightarrow \mathfrak{R}$, que cria uma transição suave entre duas retas perpendiculares em $\Re^{2}$. Essa função é definida por (Rockwood, 1989):

(3.5) $B(x, y)=1-\left[1-\frac{x}{r_{1}}\right]_{+}^{t}-\left[1-\frac{y}{r_{2}}\right]_{+}^{t}, \operatorname{com} t>1$.

A notação $[A]_{+}$equivale a $\max (0, A)$. Conforme o valor de $t$ a transição varia entre uma transição suave e uma mais abrupta e os valores de $r_{1}$ e $r_{2}$ indicam a partir de quando a transição entre as retas é iniciada (figura 3.5(a)).

A função (3.5) pode ser utilizada para unir de modo suave duas superfícies implícitas. Se $f_{1}(\mathbf{p}) \leq 0$ e $f_{2}(\mathbf{p}) \leq 0$ definem dois sólidos, então a união suave entre eles, pode ser definida por:

$$
\text { (3.6) } \bar{B}(\mathbf{p})=B\left(f_{1}(\mathbf{p}), f_{2}(\mathbf{p})\right)=1-\left[1-\frac{f_{1}(\mathbf{p})}{r_{1}}\right]_{+}^{t}+\left[1-\frac{f_{2}(\mathbf{p})}{r_{2}}\right]_{+}^{t} \text {. }
$$

A figura 3.5(b), mostra o blend entre duas primitivas (esferas) e a "adição de material" para suavizar a união entre as duas primitivas.

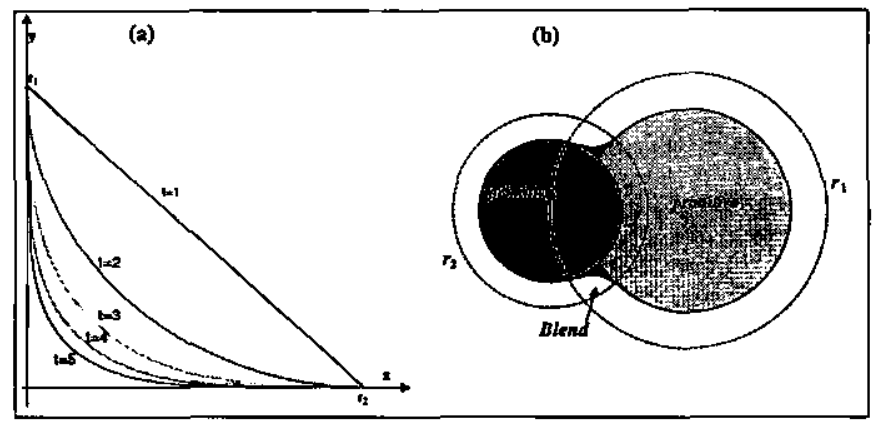

Figura 3.5 - blend elíptico: (a) entre duas retas; (b) entre primitivas ilustrando a adição de material.

A equação definida em (3.6) implementa a união de superfícies, a interseção é definida como (Rockwood, 1989):

$$
\text { (3.7) } \bar{B}(\mathbf{p})=-B\left(-f_{1}(\mathbf{p}),-f_{2}(\mathbf{p})\right)=\left[1+\frac{f_{1}(\mathbf{p})}{r_{1}}\right]_{+}^{t}+\left[1+\frac{f_{2}(\mathbf{p})}{r_{2}}\right]_{+}^{t}-1 \text {. }
$$

Como no blend norma-p o blend elíptico pode ser estendido para mais de duas primitivas, definindo:

$$
B(\mathbf{p})=B\left(f_{1}(\mathbf{p}), f_{2}(\mathbf{p}), \ldots, f_{n}(\mathbf{p})\right)=1-\left[1-\frac{f_{1}(\mathbf{p})}{r_{1}}\right]_{+}^{t}-\left[1-\frac{f_{2}(\mathbf{p})}{r_{2}}\right]_{+}^{t}-\ldots-\left[1-\frac{f_{n}(\mathbf{p})}{r_{n}}\right]_{+}^{t}
$$




$$
\text { (3.9) } \bar{B}(\mathbf{p})=B\left(-f_{1}(\mathbf{p}),-f_{2}(\mathbf{p}), \ldots,-f_{n}(\mathbf{p})\right)=\left[1+\frac{f_{1}(\mathbf{p})}{r_{1}}\right]_{+}^{t}+\left[1+\frac{f_{2}(\mathbf{p})}{r_{2}}\right]_{+}^{t}+\ldots+\left[1+\frac{f_{n}(\mathbf{p})}{r_{n}}\right]_{+}^{t}-1
$$

O blend elíptico apresenta dois problemas: a presença de saliências em regiões tangentes e o deslocamento constante na realização de blend compostos. A figura 3.6 ilustra o primeiro problema: o blend define a união de dois cilindros a superfície é corretamente suavizada no plano yz (figura 3.6(a)), mas ocorre uma saliência ao longo do eixo $\mathbf{x}$ (figura 3.6(b)). A solução para esse problema é verificar as regiões onde as superfícies são tangentes e reduzir o raio de influência do blend nessas regiões.

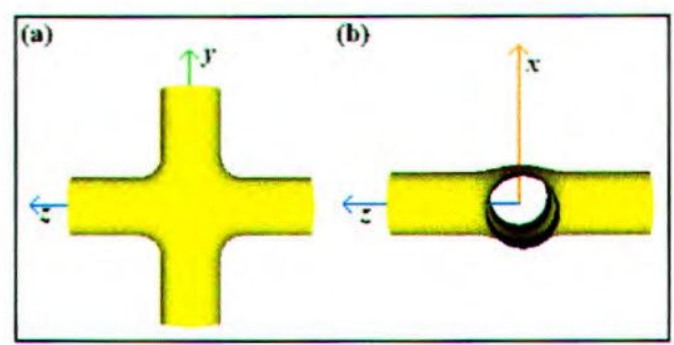

Figura 3.6 - saliência devido ao blend elíptico.

O segundo problema é observado já na equação (3.6) e na figura 3.5: a região além de $r_{1}$ e $r_{2}$ define $B(\mathbf{p})$ $=1$, para qualquer ponto $\mathbf{p}$, logo nessa região $\nabla B(\mathbf{p})=0$ e $B(\mathbf{p})$ não é de classe $C^{1}$. Isso impede a realização correta de blend compostos. Por exemplo, seja uma superfície, $\mathrm{S}_{1}$, for composta por blend elíptico e uma segunda superfície, $S_{2}$. Ao unir $S_{1}$ e $S_{2}$, a parte de $S_{2}$ localizada na região onde a função implícita de $\mathrm{S}_{1}$ é 1 sofrerá um deslocamento constante. Esse problema é ilustrado na figura 3.7.

- A figura 3.7(a) apresenta a união de duas esferas.

- A figura 3.7(b) apresenta a união de 4 esferas, utilizando a equação (3.8) para 4 esferas;

- A figura 3.7(c) apresenta união de 4 esferas, mas utilizando a união de duas superfícies por vez, aplicando três vezes a equação (3.6). Nesse caso a superfície resultante se afasta das primitivas que a compõem.

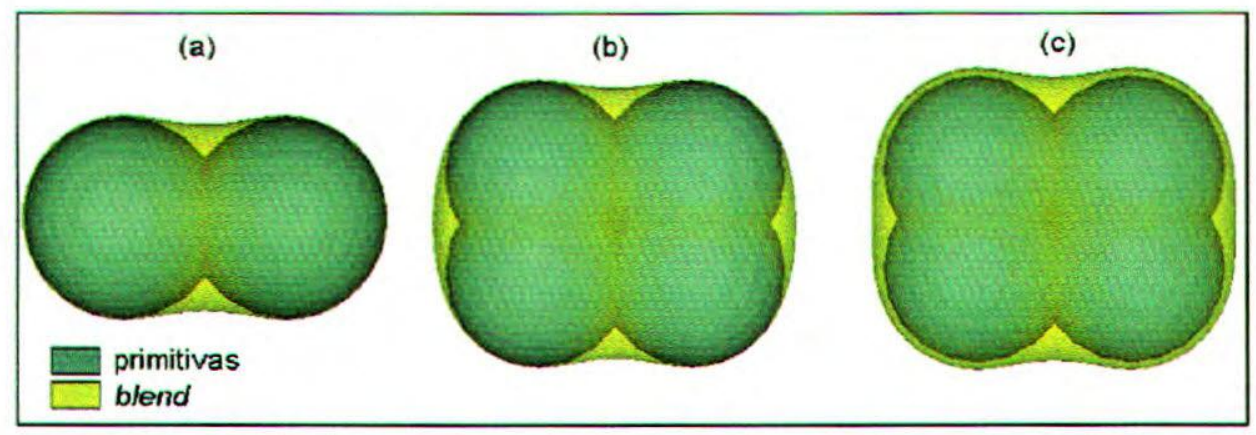

Figura 3.7 - deslocamento provocado pelo blend eliptico composto. 
(Rockwood, 1989) propõe outras formas de blend a partir da evolução do blend elíptico, que fornecem melhores soluções para a composição de superficies implícitas. A próxima seção apresenta uma dessas formas de blend.

\subsubsection{Blend pseudo-euclidiano}

O problema da definição de blend composto a partir de blend elíptico é o fato dessa formulação não fornecer valores que representem, de modo consistente, a distância entre um ponto do espaço e a superficie implícita. Para ilustrar esse fato, a figura 3.8 apresenta as primitivas $P_{1}$ e $P_{2}$ e seus respectivos raios de blend $R_{1}$ e $R_{2}$ e a superficie definida pelo blend de $P_{1}$ e $P_{2}, B_{12}$. A relação entre as primitivas, $P_{1}$ e $\mathrm{P}_{2}$, e seus taios de blend dividem o espaço em quatro regiões:

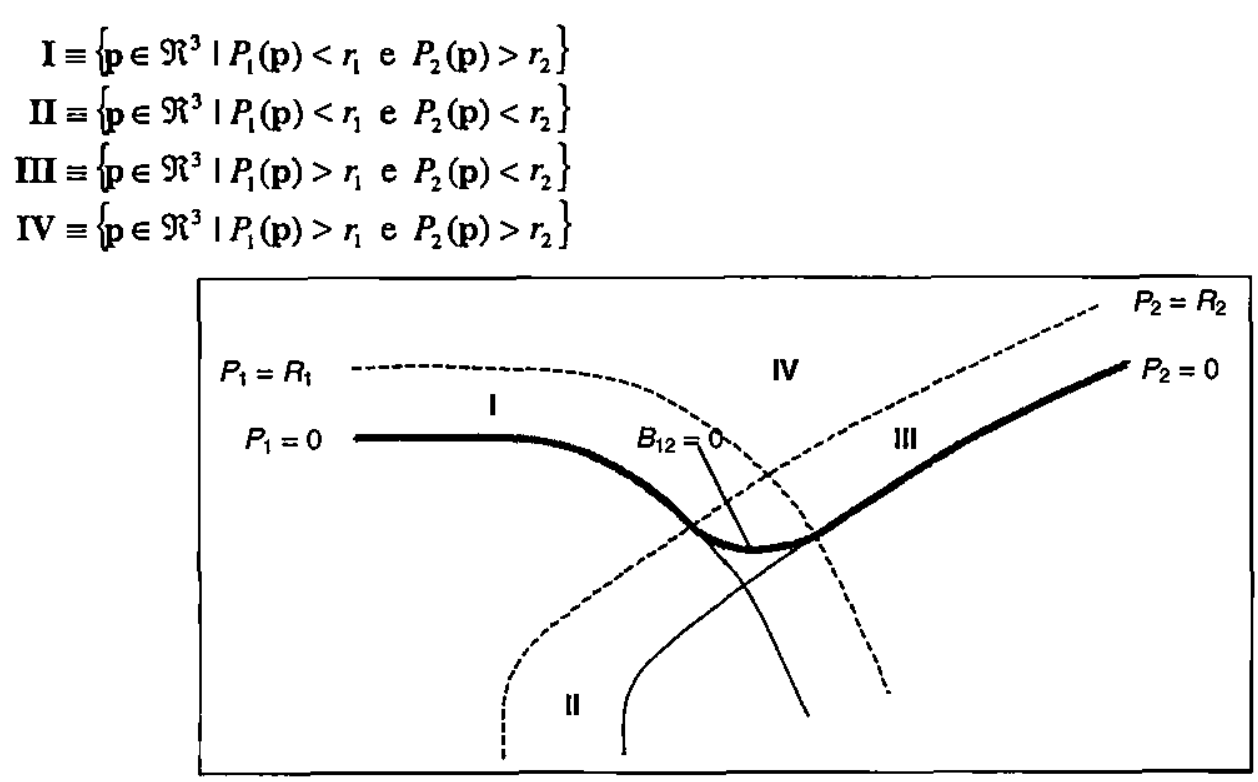

Figura 3.8 - divisão do espaço conforme a relação entre as primitivas e seus raios de blend.

$\mathrm{Na}$ região IV, $B_{12}$ é igual a $1 \mathrm{em}$ qualquer ponto, então nessa região $\nabla B_{12}=0$. Isso provoca erro na composição da superfície $B_{12}$ com outra primitiva e o valor de $B_{12}$ não pode ser utilizado para indicar uma medida qualquer de distância entre um ponto e a superfície $B_{12}=0$. Além disso, na tegião $I$, onde $B_{12}{ }^{-1}(0)=P_{1}^{-1}(0)$, (ou na região III, onde $\left.B_{12}{ }^{-1}(0)=P_{2}^{-1}(0)\right)$ se o valor de $P_{1}\left(P_{2}\right)$ indica uma medida de distância é desejável que $B_{12}$ fornecesse o mesmo valor para todos os pontos de I (III), o que não acontece.

Uma forma de resolver esses problemas é vincular a superficie definida implicitamente pelo blend com uma formulação que caracterize melhor uma medida de distância. Considerando a superfície $B_{12}{ }^{-1}(0)$ definida pela equação (3.6) esse mesmo conjunto pode ser vinculado a uma nova função $N_{12}$, definida nas regiões I e III por: 
(3.10) $\left[1-\frac{N_{12}(\mathbf{p})}{R(\mathbf{p})}\right]^{t}=1-\left[1-\frac{P_{1}(\mathbf{p})}{r_{1}}\right]^{t}+\left[1-\frac{P_{2}(\mathbf{p})}{r_{2}}\right]^{t}$

onde $R(\mathbf{p})=r_{1}$ para $\mathbf{p} \in$ I e $R(\mathbf{p})=r_{2}$ para $\mathbf{p} \in$ III. Para definir $N_{12}$ na região II toma-se $R$ como a combinação convexa de $r_{1}$ e $r_{2}$ :

$$
\begin{aligned}
& R(\mathbf{p})=\frac{Q_{1}(\mathbf{p}) r_{1}+Q_{2}(\mathbf{p}) r_{2}}{Q_{1}(\mathbf{p})+Q_{1}(\mathbf{p})}, \text { onde } \\
& \text { (3.11) } Q_{i}(\mathbf{p})=\left[1-\frac{P_{i}(\mathbf{p})}{r_{i}}\right]_{+}^{t}
\end{aligned}
$$

Para os pontos da região IV $N_{12}$ é definido como na região I para os pontos de IV mais "próximos" de I e como na região III para os pontos de IV mais "próximos" de III. Assim a região IV é dividida em duas regiões, IVA e IVB:

$$
\begin{aligned}
& \mathbf{I V A} \equiv \operatorname{IV} \cap\left\{\mathbf{p} \in \mathfrak{R}^{3} \mid P_{1}(\mathbf{p})-r_{1}<P_{2}(\mathbf{p})-r_{2}\right\} \\
& \mathbf{I V B} \equiv \mathbf{I V} \cap\left\{\mathbf{p} \in \Re^{3} \mid P_{2}(\mathbf{p})-r_{2} \leq P_{1}(\mathbf{p})-r_{1}\right\}
\end{aligned}
$$

e $N_{12}$ pode ser definido como:

$$
\text { (3.12) } N_{12}(\mathbf{p})= \begin{cases}R(\mathbf{p})\left[1-\left(Q_{1}(\mathbf{p})+Q_{2}(\mathbf{p})\right)^{1 / t}\right] & \text { se } \mathbf{p} \in \mathbf{I I} \\ P_{1}(\mathbf{p}) & \text { se } \mathbf{p} \in \mathbf{I} \cup \mathrm{IVA} \\ P_{2}(\mathbf{p}) & \text { se } \mathbf{p} \in \text { III } \cup \mathrm{IVB}\end{cases}
$$

É importante destacar que a definição de $R(\mathbf{p})$ na região II assegura a continuidade $C^{1}$ de $N_{12}$ na região I $\cup$ II $\cup$ III. Mas a divisão da região IV torna a função $\mathbf{N}_{12}$ descontínua na primeira derivada nessa região. Entretanto como a superfície $N_{12}(\mathbf{p})=0$ está apenas na região I $\cup$ II $\cup$ III ela descreverá sempre uma forma suave desde que $P_{1}$ e $P_{2}$ descrevam formas suaves. Como o valor de $N_{12}(\mathrm{p})$ indica um medida de distância de p em relação a superficie $N_{12}{ }^{-1}(0)$ o blend definido pela $N_{12}$ é chamado blend pseudo-euclidiano.

A formulação apresentada nessa seção apresenta a união entre duas primitivas. Para a interseção de duas primitivas $P_{1}$ e $P_{2}$ é utilizada a formulação apresentada a seguir:

$$
\bar{N}_{12}(\mathbf{p})= \begin{cases}\left.\bar{R}(\mathbf{p}) \mid\left(\bar{Q}_{1}(\mathbf{p})+\bar{Q}_{2}(\mathbf{p})\right)^{1 / t}-1\right] & \text { se } \mathbf{p} \in \mathbf{I V} \\ P_{1}(\mathbf{p}) & \text { se } \mathbf{p} \in \text { III } \cup \text { IIA } \\ P_{2}(\mathbf{p}) & \text { se } \mathbf{p} \in \text { I } \cup \text { IIB }\end{cases}
$$

sendo: 


$$
\begin{aligned}
& \mathbf{I} \equiv\left\{\mathbf{p} \in \Re^{3} \mid P_{1}(\mathbf{p})<-r_{1} \text { e } P_{2}(\mathbf{p})>-r_{2}\right\} \\
& \mathbf{I} \equiv\left\{\mathbf{p} \in \Re^{3} \mid P_{1}(\mathbf{p})<-r_{1} \text { e } P_{2}(\mathbf{p})<-r_{2}\right\} \text {, } \\
& \text { III } \equiv\left\{\mathbf{p} \in \Re^{3} \mid P_{1}(\mathbf{p})>-r_{1} \text { e } P_{2}(\mathbf{p})<-r_{2}\right\}, \\
& \mathrm{IV} \equiv\left\{\mathbf{p} \in \mathfrak{R}^{3} \mid P_{1}(\mathbf{p})>-r_{1} \text { e } P_{2}(\mathbf{p})>-r_{2}\right\} \\
& \text { IIA } \equiv I I \cap\left\{\mathbf{p} \in \Re^{3} \mid P_{1}(\mathbf{p})-r_{1}>P_{2}(\mathbf{p})-r_{2}\right\}, \\
& \mathbf{I I B} \equiv \mathrm{II} \cap\left\{\mathbf{p} \in \Re^{3} \mid P_{2}(\mathbf{p})-r_{2} \geq P_{1}(\mathbf{p})-r_{1}\right\}, \\
& \text { (3.14) } \bar{R}(\mathbf{p})=\frac{\bar{Q}_{1}(\mathbf{p}) r_{1}+\bar{Q}_{2}(\mathbf{p}) r_{2}}{\bar{Q}_{1}(\mathbf{p})+\bar{Q}_{1}(\mathbf{p})} \mathrm{e} \\
& \bar{Q}_{i}(\mathbf{p})=\left[1+\frac{P_{i}(\mathbf{p})}{r_{i}}\right]_{+}^{t}
\end{aligned}
$$

Para o calculo da diferença com blend pseudo-euclidiano entre duas primitivas, $P_{1}$ e $P_{2}$ é definido o complemento da segunda primitiva, $P_{2}^{\prime}=-P_{2}$, e calculada a interseção entre a primeira , $P_{1}$, e esse complemento $P_{2}^{\prime}$. As equações (3.12) e (3.14) podem ser estendidas para a união ou interseção de mais de duas primitivas.

\subsubsection{Blend por adição de função}

Um outro método de blend que interfere apenas nas regiões próximas às interseções de primitivas é o proposto em (Dekkers et al., 1996). Esse método consiste em adicionar uma função, $f_{b}$ às expressões dos operadores min e max a fim de "adicionar material" na união e "retirar" na interseção suavizando a forma definida. $f_{b}$ tem como argumento o módulo da diferença entre as primitiva e um valor real maior que zero que controla a região afetada pelo blend. Para que essa função adicione e retire material, seu gráfico deve ser semelhante ao apresentado na figura 3.9(a).

Para dois sólidos definidos por $f_{1}(\mathbf{p}) \leq 0, f_{2}(\mathbf{p}) \leq 0$ as expressões de composição com blend por adição de funç̧ão são definidas como:

$$
\begin{array}{ll}
\text { União: } & f=\min \left(f_{1}, f_{2}\right)-f_{b}\left(\left|f_{1}-f_{2}\right|, n\right) ; \\
\text { Interseção: } & f=\max \left(f_{1}, f_{2}\right)+f_{b}\left(\left|f_{1}-f_{2}\right|, n\right) ; \\
\text { Diferença: } & f=\max \left(f_{1},-f_{2}\right)+f_{b}\left(\left|-f_{1}-f_{2}\right|, n\right) .
\end{array}
$$

(Dekkers et al., 1996) apresentam várias instâncias e teste de $f_{b}(x, n)$, a que apresentou melhor resultado foi:

$$
f_{b}(x, n)= \begin{cases}n\left(\frac{x}{n}-\frac{1}{4}\right)^{2} & \text { para } x<\frac{n}{4} \\ 0 & \text { para } x \geq \frac{n}{4}\end{cases}
$$


A figura 3.9(b) apresenta o mesmo objeto da figura 3.2 definido por blend por adição de função utilizando a função acima com $n=2$. Conforme a função, $f_{\mathrm{b}}(x, \mathrm{n})$, escolhida é possível realizar blend compostos. O blend por adição de função só é aplicável em funções de lipschitz, ou seja, em funções onde a taxa de crescimento é limitada.

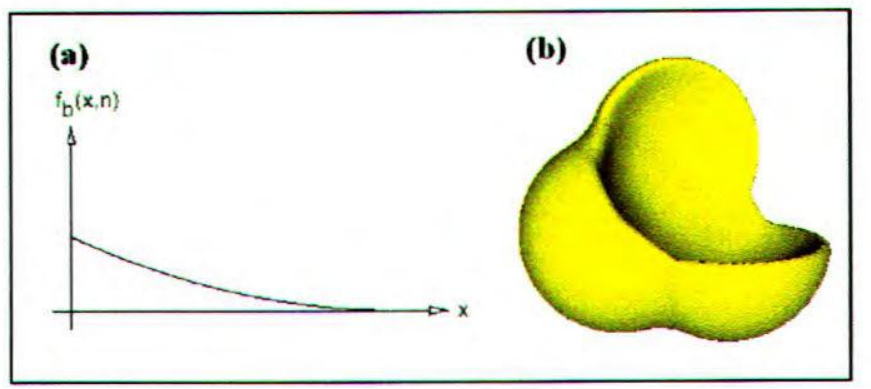

Figura 3.9 - blend por adição de função: (a) gráfico de $f_{\mathrm{b}}(x, \mathrm{n}) \times x$; (b) objeto composto.

O uso de técnicas de blend com CSG permite a construção de superfícies implícitas complexas suaves. A próxima seção apresenta a utilização de esqueletos como uma outra abordagem para construção de modelos implícitos complexos.

\subsection{Esqueletos}

Esqueleto é um padrão de representação em $\mathrm{CAD}^{6}$ que vem se popularizando na construção de superfícies implícitas. Esse padrão representa a estrutura interna de um objeto (Bloomenthal, 1997a) de forma que a partir de um esqueleto tem-se a forma mínima, ou essencial, do objeto. Um esqueleto consiste de um número arbitrário de elementos cada qual gerando uma primitiva implícita (Bloomenthal, 1997a).

(Bloomenthal \& Wyvill, 1989) definem os elementos dos esqueletos como sendo: pontos - elementos que servem como centros de quádricas; splines - definem o eixo central dos cilindros generalizados; polígonos - podem ser utilizados para se obter uma superfície por deslocamento (offset surface). A figura 3.10 ilustra o uso desses três elementos na definição de um esqueleto e na construção de um objeto implicitamente. $\mathrm{O}$ uso de esqueletos possibilita um meio interativo de projetar superfícies implícitas, pois a simplicidade dos elementos do esqueleto permite uma manipulação simples.

${ }^{6} \mathrm{CAD}$ - Computer-Aided Design - projeto de modelos geométricos assistido por Computador. 


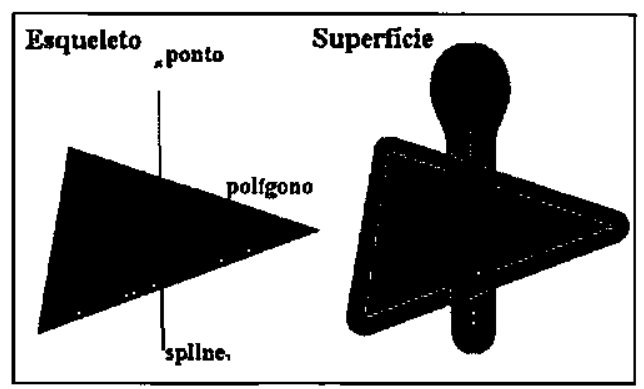

Figura 3.10 - exemplo de objeto definido implicltamente por um esqueleto.

$\mathrm{Na}$ literatura são encontradas três formas de getar superfícies implícitas a partir de esqueletos: superfícies por distância, superfícies eqüipotenciais e superfícies por convolução. Nas três abordagens cada elemento do esqueleto gera uma primitiva implícita e a superfície é gerada pela união dessas primitivas. O modo de realizar essa união é particular a cada abordagem.

$\mathrm{Na}$ exposição das três abordagens é adotada a seguinte notação:

$E$ - indica um esqueleto;

$E_{\mathrm{i}}$ - indica um elemento (ponto, spline ou polígono) do esqueleto $\mathrm{E}$; e

$R_{\mathrm{Ei}}$ - indica o raio de ação do elemento $E_{\mathrm{i}}$, ou seja, a que distância do elemento $E_{\mathrm{i}}$ está a superfície implícita.

\subsubsection{Superfícies Implicitamente definidas a partir de Distância de Esqueleto}

Nas superfícies implícitas definidas por distância cada elemento, $E_{\mathrm{i}}$, do esqueleto, $E$, gera uma primitiva definida pelos pontos que estão no limite do seu raio de ação, $R_{\mathrm{Ei}}$. Cada elemento do esqueleto gera uma superfície implícita cuja função associada é dada por (Bloomenthal, 1995b):

(3.14) $f_{E i}(\mathbf{p})=d\left(\mathbf{p}, E_{i}\right) / R_{E i}-1=0$.

O cálculo de $d\left(\mathbf{p}, E_{\mathrm{i}}\right)$ é realizado determinando o ponto $\mathbf{q}$ que pertença a $E_{\mathrm{i}}$ mais próximo de $\mathbf{p}$, de modo que, $d\left(\mathbf{p}, E_{i}\right)=|| \mathbf{p}-\mathbf{q}||$. A complexidade da função implícita associada a $E_{\mathrm{i}}$ está relacionada com a complexidade do cálculo do ponto q. Para elementos simples como pontos e segmentos de reta o cálculo de $d\left(\mathbf{p}, E_{i}\right)$ é trivial, mas se torna muito complexos para elementos definidos por splines e polígonos.

A união entre as primitivas geradas pelos elementos do esqueleto é realizada da mesma forma que a união por CSG, e dessa forma a função implícita definida pelo esqueleto $E$ é dada por:

$$
\text { (3.15) } f_{E}(\mathbf{p})=\min _{i}\left(f_{E}(\mathbf{p})\right)
$$


A união das primitivas getadas por distância torna a superficie implícita suave nas regiões convexas, mas nas regiōes côncavas a superfície apresenta quinas, como mostra a figura 3.11. As outras abordagens, apresentadas a seguir geram superficies implícitas suaves diretamente do esqueleto.

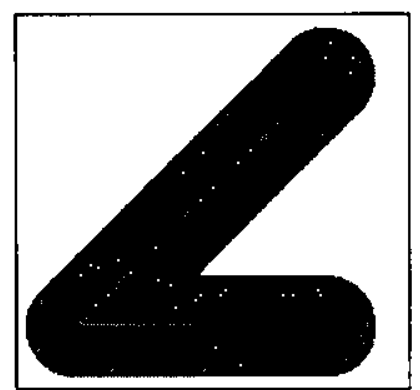

Figura 3.11 - superfície de distância de um esqueleto formado por segmentos de reta.

\subsubsection{Superfícies Implicitamente Definidas a partir de Campos Eqüipotenciais}

(Blinn, 1982) introduziu a idéia de modelagem com campos eqüipotenciais a partir de esqueletos pontuais. Cada ponto do esqueleto é definido como uma fonte de energia, e o potencial devido a esta fonte diminui conforme aumenta a distância. O potencial em um ponto qualquer do espaço é dado pela soma dos potenciais devido a todas as fontes e a superficie implícita é definida por uma superfície eqüipotencial.

As superficies eqüipotenciais são uma extensão das superficies por distância: em um esqueleto $E$ cada elemento $E_{\mathrm{i}}$ define um campo potencial, $h_{E v}$ que diminui conforme a distância e a partir de uma certa distância (raio de ação) o campo potencial torna-se nulo (Wyvill et al., 1998). Para um esqueleto $E$ definido por $n$ elementos o potencial em um ponto $\mathbf{p}$ do espaço é dado por:

(3.16) $f_{E}(\mathbf{p})=\sum_{i=1}^{n} h_{E_{i}}(\mathbf{p})$

A superfície é implicitamente definida por $f_{\mathrm{E}}(X)-c=0$, onde $c$ é uma constante associada a uma superfície eqüipotencial. Cada função $b_{E i}$ pode ser decomposta em duas funções: uma de distância $d_{\mathrm{Ei}}(\mathbf{p}): \mathfrak{N}^{3} \rightarrow \mathfrak{N}$ e outra de campo $g_{\mathrm{Ei}}(r): \mathfrak{R} \rightarrow \mathfrak{N}$ que decai com o aumento de $r$ (figura 3.12 ) de modo que: $b_{E \mathrm{i}}(\mathbf{p})=g_{E \mathrm{i}} \mathrm{O} d_{E \mathrm{i}}(\mathbf{p})$.

(Bloomenthal, 1997a) exemplifica uma implementação desse método com c = 1/2 e a função de campo dada pela sigmóide :

$$
\text { (3.17) } g_{E_{i}}(r)= \begin{cases}1-\frac{4}{9} \cdot \frac{r^{6}}{R_{E i}^{6}}+\frac{17}{9} \cdot \frac{r^{4}}{R_{E t}^{4}}-\frac{22}{9} \cdot \frac{r^{2}}{R_{E i}^{2}} & \text { para } r<R_{E i} \\ 0 & \text { para } r \geq R_{E i}\end{cases}
$$




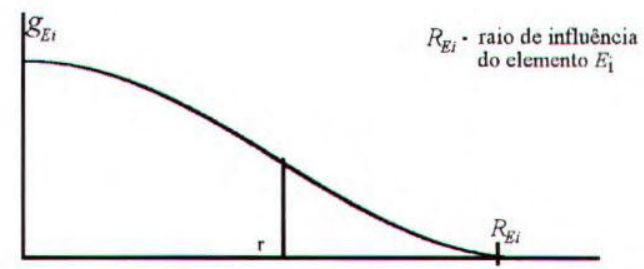

Figura 3.12 - função de campo $g_{E i}(r)$.

A composição das superfícies eqüipotenciais é realizada simplesmente pela soma das primitivas e possui a vantagem de gerar superfícies suaves. A desvantagem dessa composição é a presença de saliências como ilustra a figura 3.13(a). Uma alternativa para evitar essas saliências, é o novo posicionamento e redimensionamento dos elementos do esqueleto (figura 3.13(b)).

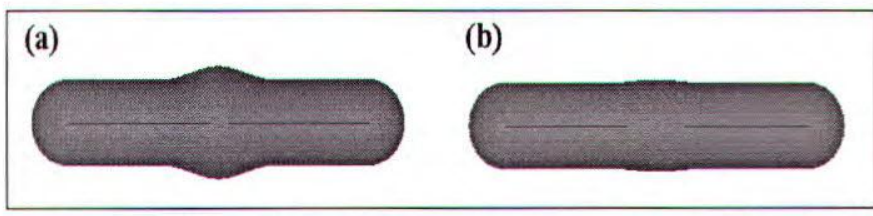

Figura 3.13 - (a) saliências; (b) redução das saliências.

Para ilustrar o uso de esqueleto na construção de superfícies implícitas juntamente com superfície eqüipotenciais a figura 3.14 a apresenta um avião simplificado obtido por essa abordagem. A próxima seção apresenta as superfícies por convolução uma técnica mais complexa para gerar superfícies implícitas.

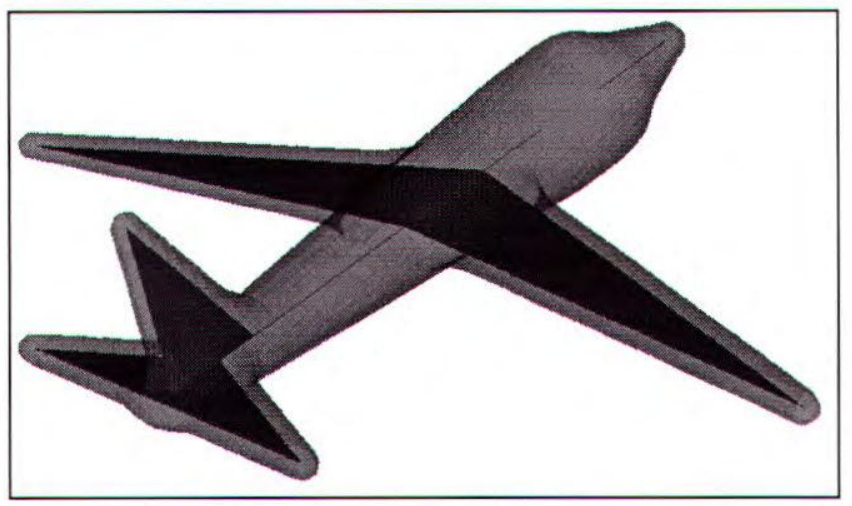

Figura 3.14 - avião simplificado gerado por esqueleto utilizando superfície eqüipotencial.

\subsubsection{Superfícies Implicitamente Definidas a partir de Convolução de Esqueletos}

Segundo (Bloomenthal \& Shoemake, 1991) as superfícies por convolução são uma re-interpretação e generalização das superfícies eqüipotenciais. Nas superfícies eqüipotenciais, o cálculo da função de superfície implícita devido a um elemento de esqueleto $E_{\mathrm{i}}$ em um ponto $\mathbf{p}, f_{E i}(\mathbf{p})$, considera apenas o 
ponto de $E_{\mathrm{i}}$ mais próximo de $\mathbf{p}$. Nas superfícies por convolução são considerados todos os pontos do elemento $E_{\mathrm{i}}$. As superfícies por convolução incorporam o blend por soma e só apresentam saliências em alguns casos.

(McCormark \& Sherstyuk, 1998) apresenta a seguinte definição de superfície por convolução: Um elemento do esqueleto $E_{\mathrm{i}}$ define uma função $g: \mathfrak{R}^{3} \rightarrow \Re$, representando a geometria desse elemento:

$$
g(\mathbf{p})=\left\{\begin{array}{ll}
1 & \mathbf{p} \in E_{i} \\
0 & \mathbf{p} \notin E_{i}
\end{array} .\right.
$$

Seja $h$ a função que descreve o campo potencial gerado pela primitiva $E_{i}: h: \Re^{3} \rightarrow \Re$. O potencial total em um ponto $\mathbf{p}$ gerado pelo elemento $E_{\mathrm{i}}$ é dado por:

$$
\text { (3.18) } f(\mathbf{p})=\int_{R^{3}} g(\mathbf{x}) h(\mathbf{p}-\mathbf{x}) \cdot d \mathbf{x},
$$

que é a convolução de duas funções $g$ e $h$. Embora a convolução seja comutativa, as funções $g$ e $h$ são caracterizadas de modo diferente. A função de potencial, $f$, é obtida aplicando o núcleo de convolução, $h$, na função de geometria de $E_{\mathrm{i}}, g$. A equação (3.18) pode ser reescrita como uma integração do núcleo de convolução sobre $E_{i}$.

(3.19) $f(\mathbf{p})=\int_{E_{i}} h(\mathbf{p}-\mathbf{x}) \cdot d E_{i}$.

Como mostra (Bloomenthal, 1995) a propriedade que favorece o uso de convolução na construção de superfícies implícitas em relação as superfície eqüipotenciais é a superposição. Como a convolução é um operador linear, a convolução de um esqueleto pode ser definida como a soma das convoluções de cada um dos seus elementos. Assim, se $\otimes$ é o operador de convolução, $h$ o filtro de convolução e $E$, e $E_{2}$ dois elementos de um esqueleto. A convolução através do filtro $h$, dada por $h \otimes\left(E_{1}+E_{2}\right)$ pode ser escrita como $h \otimes E_{1}+b \otimes E_{2}$. A superposição garante que dois segmentos produzem por convolução a mesma superfície definida pela união de ambos (figura 3.15).

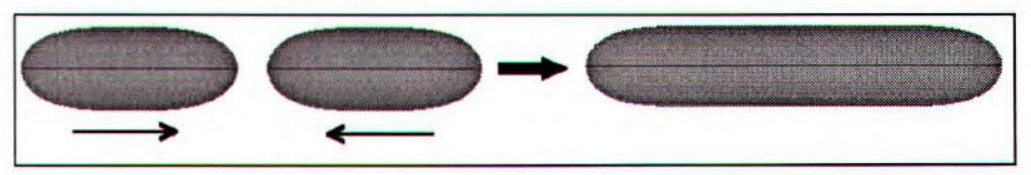

Figura 3.15 - superposição da convolução de esqueletos.

O nível de facilidade da resolução da integral da equação (3.19) depende da complexidade do elemento submetido à convolução e do núcleo. Em (Bloomenthal, 1995) são analisados três núcleos de convolução: 
núcleo B-spline:

$$
h_{\text {BSpline }}(x)= \begin{cases}(x+2)^{3} / 6 & x \in(-2,-1) \\ \left(-3 x^{3}-6 x^{2}+4\right) / 6 & x \in(-1,0) \\ \left(3 x^{3}-+x^{2}-4\right) / 6 & x \in(0,1) \\ (2-x)^{3} / 6 & x \in(1,2) \\ 0 & x<-2 \text { ou } x>2\end{cases}
$$

núcleo Wyvill:

$$
h_{\text {Wyvill }}(x)= \begin{cases}1-\frac{4}{9} \cdot x^{6}+\frac{17}{9} \cdot x^{4}-\frac{22}{9} \cdot x^{2} & |x|<1 \\ 0 & |x| \geq 1\end{cases}
$$

núcleo Gaussiano:

$$
h_{\text {Gouss }}(x)=e^{x^{2} / 2}
$$

Os núcleos B-spline e Wyvill permitem solução analítica. Segundo (McCormark \& Sherstyuk, 1998) esta vantagem muitas vezes inviabiliza a implementação, pois para alguns elementos de esqueletos mais complexos como polígonos, a solução analítica é de complexidade muito alta. Logo é recomendado o uso do núcleo gaussiano. Nesse caso a integral de (3.19) deve ser resolvida numericamente aproveitando a propriedade de simetria e a possibilidade de decompor a aplicação do núcleo gaussiano.

O suporte dos núcleos é outro fator que os diferenciam. O suporte de um núcleo é definido como a distância entre o seu centro e um ponto a partit de que a convolução é nula. Os núcleos B-spline e de Wyvill possuem suporte 2 e 1 respectivamente. Já o núcleo gaussiano possui um suporte infinito, mas como a convolução com esse núcleo é resolvida numericamente, é definido um valor a partir do qual a convolução é desprezível.

O núcleo gaussiano é simétrico, ou seja, $h(x)=b(-x)$, e em $\mathfrak{R}^{3}$ apresenta simetria esférica. Além disto, se a função de geometria puder ser fatorada, a aplicação do núcleo gaussiano pode ser decomposta. Por exemplo, se a função de geometria de um elemento do esqueleto, $g(\mathbf{p})$, permitir a fatoração $g(\mathbf{p})=g_{x}\left(\mathbf{p}_{x}\right)$ $g_{y}\left(\mathbf{p}_{y}\right) g_{z}\left(\mathbf{p}_{z}\right)$ então a convolução com o núcleo gaussiano torna-se:

$$
f(\mathbf{p})=\int_{R} g_{x}(x) e^{\left|x-p_{x}\right|^{2} / 2} \cdot \int_{R} g_{y}(y) e^{\left|y-p_{y}\right|^{2} / 2} \cdot \int_{R} g_{z}(z) e^{\left|z-p_{z}\right|^{2} / 2} \cdot d z d y d x .
$$

A seguir é apresentado como é calculado a convolução para pontos, segmentos de retas e polígonos planares.

\section{Convolução de Elementos Pontuais}

Para um elemento pontual, definido no ponto $\mathbf{q}$, a sua função de geometria é dada por: 


$$
g(\mathbf{p})= \begin{cases}1 & \mathbf{p}=\mathbf{q} \\ 0 & \mathbf{p} \neq \mathbf{q}\end{cases}
$$

desse modo:

$$
\begin{aligned}
& f(\mathbf{p})=\int_{R^{3}} g(\mathbf{x}) h(\|\mathbf{p}-\mathbf{x}\|) \cdot d \mathbf{x}=h(\|\mathbf{p}-\mathbf{q}\|), \\
& \text { (3.21) } f(\mathbf{p})=e^{|\mathbf{p}-\mathbf{q}|^{2} / 2} .
\end{aligned}
$$

A superfície obtida pela convolução de um conjunto de pontos é definida como a soma da convolução dos pontos. Para esqueletos formados apenas por pontos, não há diferenças entre as superfícies definidas por convolução e as definidas por campo eqüipotencial.

\section{Convolução de Elementos Unidimensionais - Segmentos de Reta}

Seja um segmento de reta sobre o eixo x cujos extremos são $(0,0,0)$ e $(a, 0,0)$, sua função de geometria' $g$ pode ser fatorada como:

$$
g_{x}\left(\mathbf{p}_{x}\right)=\left\{\begin{array}{ll}
1 & 0 \leq \mathbf{p}_{x} \leq a \\
0 & \text { caso contrário }
\end{array}, g_{y}\left(\mathbf{p}_{y}\right)=\left\{\begin{array}{ll}
1 & \mathbf{p}_{y}=0 \\
0 & \text { caso contrário }
\end{array} \text { e } g_{z}\left(\mathbf{p}_{z}\right)=\left\{\begin{array}{ll}
1 & \mathbf{p}_{z}=0 \\
0 & \text { caso contrário }
\end{array}\right. \text {. }\right.\right.
$$

aplicando a equação (3.20) é obtido:

$$
\text { (3.22) } f(\mathbf{p})=\left(\int_{0}^{a} e^{\left|x-\mathbf{p}_{x}\right|^{2} / 2} \cdot d x\right) e^{-\left(\mathbf{p}_{y}^{2}+\mathbf{p}_{2}^{2}\right) / 2}-c \text {. }
$$

A equação (3.22) apresenta a convolução do segmento de reta definido pelos pontos $(0,0,0)$ e $(a, 0,0)$. Essa convolução pode ser apresentada como a aplicação de dois filtros: o filtro de integração, definido pela integxal, e o filtro de distância, pela exponencial. A resolução do filtro de integtação é realizada numericamente através de uma tabela pré-computada.

(Bloomenthal, 1995) generaliza a convolução para um segmento de reta qualquer aplicando o seguinte procedimento:

1. o ponto $\mathbf{p}$ em que é aplicado a convolução é projetado na reta que contém o segmento, dando origem à projeção $\mathrm{p}^{\prime}$;

2. as distâncias entre $\mathbf{p}^{\prime}$ e os extremos do segmento são utilizadas na resolução do filtro de integtação (área $A_{d s}$ na figura 3.16); a distância entre p e p' é utilizada no filtro de distância.

A figura 3.16 ilustra esse procedimento em (a) da esquerda para direita têm-se o filtro de integração, o filtro de distância, e a convolução resultante do produto dos dois filtros; em (b) têm-se a geometria do 
segmento e de p, o filtro de integração ao longo do segmento e o filtro de distância no plano ortogonal ao segmento.

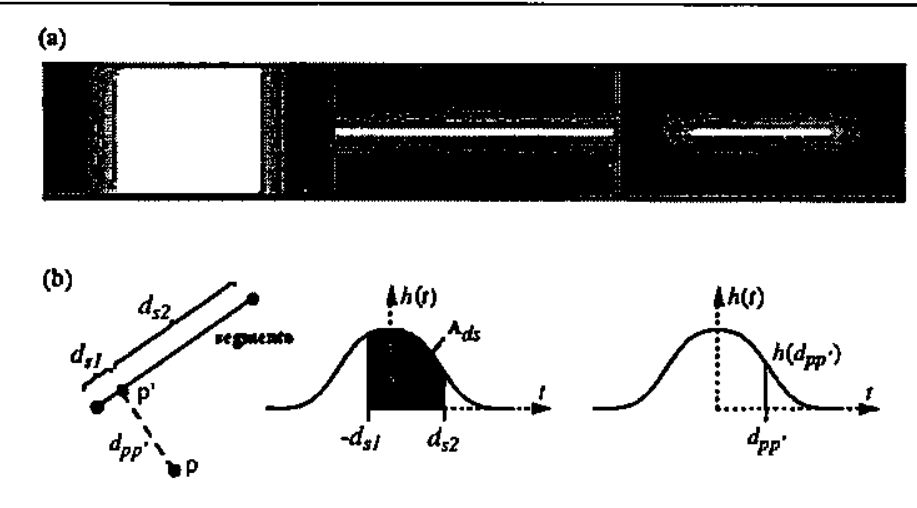

Figura 3.16 - convolução de um segmento de reta qualquer.

\section{Convolução de Elementos Bidimensionais - Polígonos}

$\mathrm{Na}$ convolução de polígonos também é utilizada a decomposição da convolução. O filtro de distância é calculado pela distância entre o ponto onde se aplica a convolução e o plano que contém o polígono. $O$ filtro de integração é novamente resolvido numericamente, mas agora é necessário resolver uma integral sobre $\mathfrak{R}^{2}$. (Bloomenthal \& Shoemake, 1991) define o procedimento para resolver essa convolução:

1. inicialmente, o polígono é convertido na sua imagem matricial no plano que o contém;

2. essa imagem, é filtrada em duas dimensões através do gaussiano, como realizado em processamento de imagens, obtendo a convolução do polígono em seu plano;

3. a convolução em $\mathfrak{R}^{3}$ é obtida multiplicando o filtro de distância e a convolução no plano (figura 3.17).

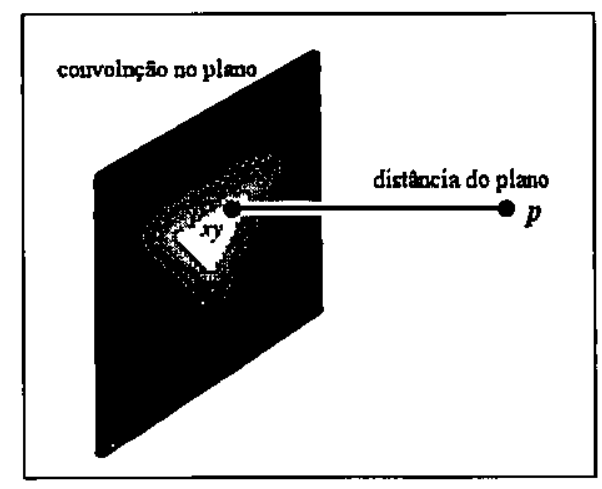

Figura 3.17 - convolução de um poligono.

O maior problema desse procedimento é a conversão do polígono para a imagem matricial. Caso a resolução da matriz seja pequena a convolução apresentará distorções. Para um melhor controle da forma obtida pela convolução de polígonos (Bloomenthal \& Ferguson, 1997) sugere que os polígonos 
adjacentes devam estar sempre grudados e a largura no polígono ser sempre maior ou igual ao suporte do núcleo de convolução.

As conclusões de (Bloomenthal \& Shoemake, 1991) sobre a convolução com núcleo gaussiano revelam que a convolução superficies podem ser computadas mais eficientemente que as superficies por distância ou superficies eqüipotenciais. Aparentemente esta é uma conclusão estranha, devido a complexidade da convolução, mas é explicada pelos métodos numéticos utilizados. (McCormark \& Sherstyuk, 1998) utiliza um núcleo que permite resoluções analíticas na convolução de esqueletos definidos por: pontos, segmentos de retas, arco de circunferência, triângulos e planos e a comparação dos seus resultados com o núcleo gaussiano revelou-se até seis vezes menos eficiente.

\section{Saliências em Superfícies por Convolução}

A convolução em um ponto do espaço é a soma do potencial devido a todos os pontos de um esqueleto. Como a concentração de pontos no esqueleto não é uniforme podem aparecer saliências nas superfícies.

Caso o esqueleto seja definido por um conjunto de segmentos as saliências ocorrem nas ramificações, como mostra a figura 3.18(a). A figura 3.19(a) apresenta o comportamento da função implícita $f(\mathrm{p})$, que define a superficie apresentada na figura 3.18(a), nos pontos $\mathbf{p}=\left(\mathbf{p}_{x>}, 0, r\right)$. Com $\mathbf{p}_{x}$ crescendo, $\mathbf{p}$ move-se ao longo da linha $\mathbf{z}=r$, a convolução em $\mathbf{p}$ é alterada conforme o gráfico a direita. A redução da saliência pode ser feita afastando os elementos do esqueleto (figura 3.18(b) e 3.19(b)) como nas superficies geradas por campos eqüipotenciais.

Para os esqueletos definidos por polígonos, além das ramificações, as saliências podem ser geradas em outros dois casos (Bloomenthal \& Ferguson, 1997). O primeiro são os polígonos com largura variável e menor que o suporte do núcleo de convolução. Nesse caso onde a largura do polígono for maior, a convolução aptesentará saliências. Logo é necessário manter a largura do polígono sempre maior ou igual ao suporte do núcleo. O segundo caso ocorre quando o ângulo entre đois elementos provocar uma maior concentração de pontos em uma região do esqueleto o que pode set evitado definindo esqueletos mais suaves.

As superficies definidas por esqueletos são mais indicadas para modelagem de formas orgânicas (Bloomenthal, 1995), especialmente as definidas por convolução, ou campos potenciais. Isso porque, nessas superficies, é difícil manter um controle fino sobre a suavidade das superficies, necessário às 
formas manufaturadas. Assim, no uso de esqueletos para formas manufaturadas é aconselhável o uso de superfícies baseadas em distância.

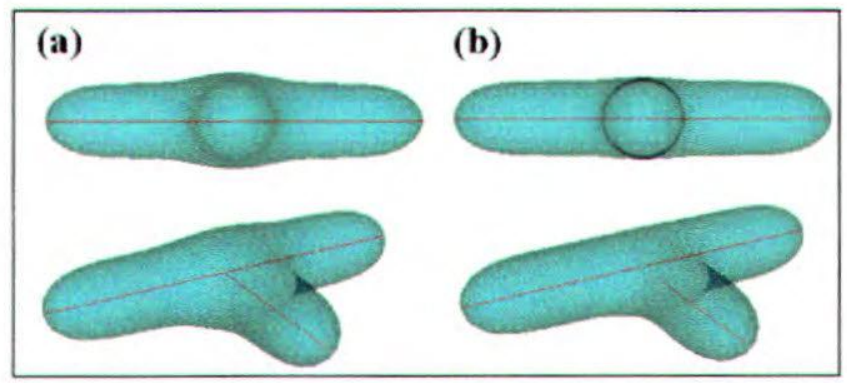

Figura 3.18 - esqueleto definido por segmentos com ramificação e sua superficie: (a) com saliência; (b) redefinido o esqueleto para redução da saliência.

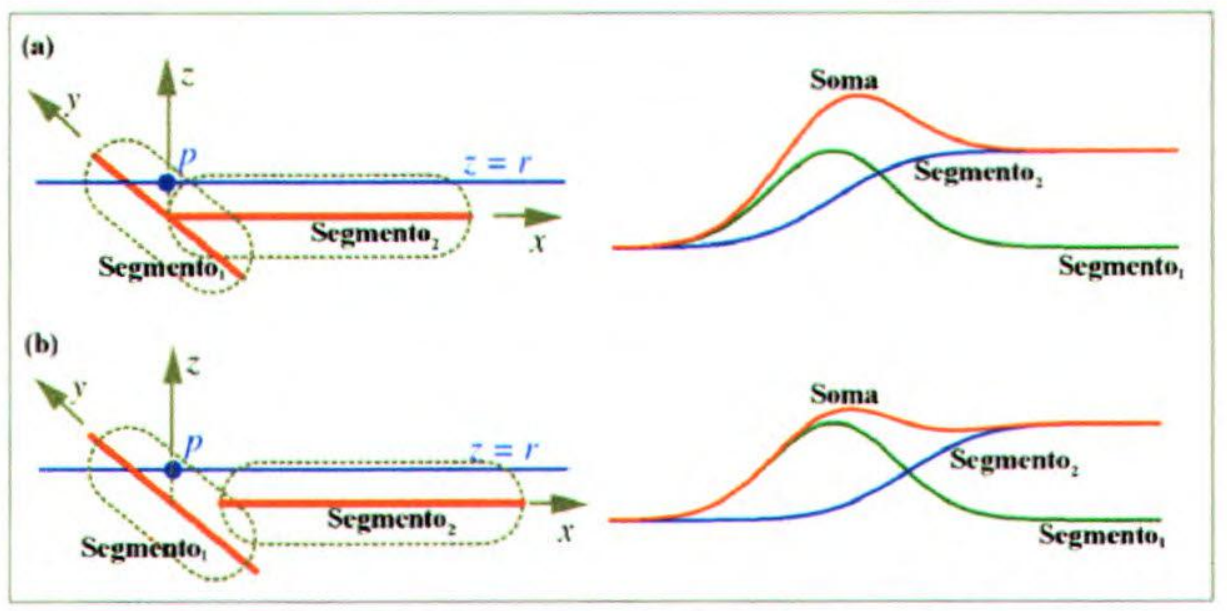

Figura 3.19 - estudo das saliências em esqueletos definidos por segmentos.

\subsection{Considerações Finais}

Neste capítulo foi apresentada uma visão geral da modelagem implícita. O principal deste capítulo objetivo é a apresentação do uso de CSG e de esqueletos para definir modelos implícitos complexos. As técnicas de CSG podem ser combinadas com técnicas de blends para compor superfícies suaves. Essa abordagem permite o controle da suavidade das interseções entre objetos e é mais indicada para construção de objetos manufaturados. Em um modelador que utiliza essa abordagem a variedade de formas possíveis de modelar depende do conjunto de primitivas implícitas oferecidas.

O uso de esqueletos em modelagem implícita possui como principal vantagem a facilidade de construir modeladores interativos. Os elementos que definem um esqueleto podem ser definidos interativamente com certa facilidade. A geração de superfícies implícitas por esqueletos através de campos 
eqü̈potenciais e de convolução definem superficies suaves diretamente, mas é difícil o controle de suavidade da forma definida. Superfícies implícitas definidas por esqueletos são mais indicadas para formas orgânicas (Bloomenthal, 1995). (Wyvill et al., 1998) mescla o uso de CSG e de esqueletos para a definição de superfícies implícitas.

O próximo capítulo apresenta uma visão geral dos métodos de poligonalização e o método de poligonalização que é utilizado neste trabalho. Os métodos de poligonalização permitem a computação de uma representação explícita a partir de um modelo implícito 


\section{.}




\section{Capítulo 4 - Poligonalização de Superfícies Implícitas em $\mathfrak{R}^{3}$}

\subsection{Considerações Iniciais}

A representação explicita mais utilizada para superfícies implícitas são os modelos planares. Um modelo planar representa uma malha poligonal que aproxima a superficie. O processo de cálculo de uma malha poligonal a partir de um modelo implícito é conhecido como poligonalização.

Este capitulo apresenta uma visão geral dos métodos de poligonalização conforme o (Bloomenthal, 1997b). Em seguida, duas seção são dedicadas a apresentação do método de poligonalização utilizado no Modelador, uma descreve a triangulação. $J_{1}^{0}$, e a outra, o método em si. A quinta seção deste capítulo apresenta algumas estruturas de dados para a representação da malha de polígonos, e em seguida são feitas as considerações finais deste capítulo.

\subsection{Visão Geral da Poligonalização de Superfícies Implícitas}

A poligonalização consiste em a partir de uma decomposição celular de uma região de $\mathfrak{R}^{3}$ e uma superficie definida implicitamente obter uma superficie linear por partes que aproxima essa superficie. Os processos de poligonalização iniciam com uma decomposição celular de uma região compacta $D \subset \Re^{3}$, que pertence ao domínio da função implícita $f$. A cada intercessão de uma célula dessa decomposição com a superficie, são obtidos os pontos dessa intercessão e ligando esses pontos são produzidos os polígonos que aproximam a superficie. O conjunto de todos os polígonos gera uma representação poligonal que aproxima a superficie implicita A figura 4.1 ilustra o processo de poligonalização. 


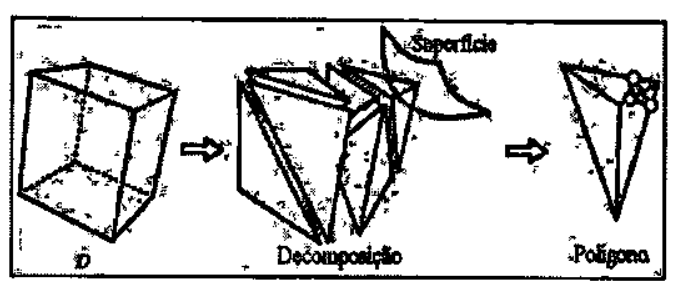

Figura 4.1 - processo de poligonalização.

\subsubsection{Classes de Poligonalizadores}

(Bloomenthal, 1997b) divide os poligonalizadores em duas classes os que trabalham sobre dados discretos e os que trabalham sobre dados contínuos. Para a primeira classe os valores estão disponíveis apenas em certas posições do espaço, enquanto que para a segunda uma função contínua é capaz de fornecer um valor em qualquer ponto do espaço de interesse. A segunda classe favorece a poligonalização de superfícies implícitas. Os poligonalizadores de dados discretos trabalham com o método de enumeração exaustiva, enquanto que os de dados contínuos trabalham por subdivisão ou por continuação numérica.

Uma operação comum a todos os métodos de poligonalização é o teste de transversalidade de células. $O$ teste consiste em determinar se a célula possui uma interseção não vazia com a superfície, classificando os vértices das células em internos e externos à superficie. $E$ definindo as células transiversais, ou seja, as células que possuem vértices internos e externos à superficie.

Aṣ seções a seguir mostram a base de funcionamento e as diferenças entre os métodos de enumeração exaustiva, subdivisão e continuação numérica.

\section{Enumeração Exaustiva}

$\mathrm{Na}$ enumeração exaustiva os valores de estudo estão disponíveis nos vértices de uma malha tridimensional (decomposição celular de uma região de $\mathfrak{R}^{3}$ ). Geralmente, as malhas utilizadạs são regulares, ou seja, todos os pontos, exceto os do bordo, possuem o mesmo número de pontos adjacentes e esses estão regularmente espaçados. Os métodos de enumeração exaustiva aplicam o teste de transversalidade em todas as células $d_{a}$ malha. Isso não torna o processo proibitivo para dados discretos, uma vez que os valores de estudo estão disponíveis diretamente nos vértices não necessitando de nenhum cálculo para obtê-los.

Para superficies implícitas a enumeração exaustiva pode ser aplicada em alguns casos, mas a complexidade da função implícita pode levar esse processo a um custo proibitivo. A técnica de 
enumeração exaustiva mais conhecida é o Marching Cubes. A descrição dessa técnica assim como uma visão geral da organização de dados discretos é apresentada em (Schroeder et al., 1998).

\section{Subdivisão}

A subdivisão consiste na divisão tecursiva e limitada de uma tegião compacta que contenha a superfície. Um volume (célula), inicial é dividido recursivamente em subvolumes. Durante as divisões, a transversalidade das células é verificada, e somente as células transversais são subdivididas. O processo tecursivo implica em uma organização hierátquica das células como uma átvore. Os nós folhas dessa árvore, que representam células transversais, produzem polígonos e a união de todos os polígonos forma a aproximação da superfície.

As divisões recursivas são limitadas pelo nível máximo de refinamento que indica a altura da árvore de subvolumes e quão boa deve ser a poligonalização. Esse valor é limitado pela capacidade de memória, pois um valor alto implica na produção de muitos subvolumes e grande quantidade de memória para armazená-los. Como a cada divisão recursiva apenas as células transversais são divididas, o número de subvolumes produzidos é reduzido. Nos algoritmos de subdivisão é possível ocorrer erros como o apresentado na figura 4.2, onde o cubo não é subdividido porque o teste de transversalidade nos vértices falha.

O exemplo mais popular de técnica de subdivisão é a octree onde o volume inicial e os subvolumes são representados por cubos e o grau da árvore de divisões recursivas é oito, ou seja, um cubo é dividido em oito cubos menores (Foley et al., 1990). A figura 4.3 exemplifica a poligonalização de um toro com uma octree com nível máximo de refinamento igual a quatro.

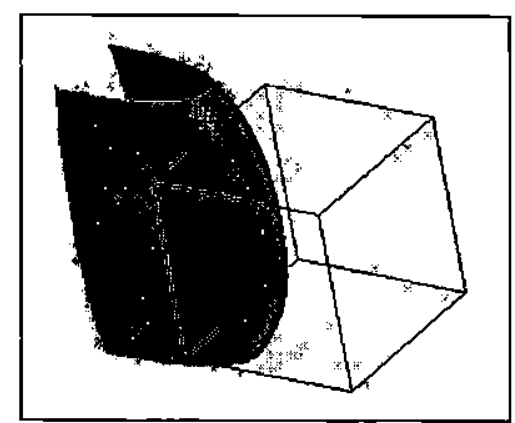

Figura 4.2 - erro no teste de transversalidade.

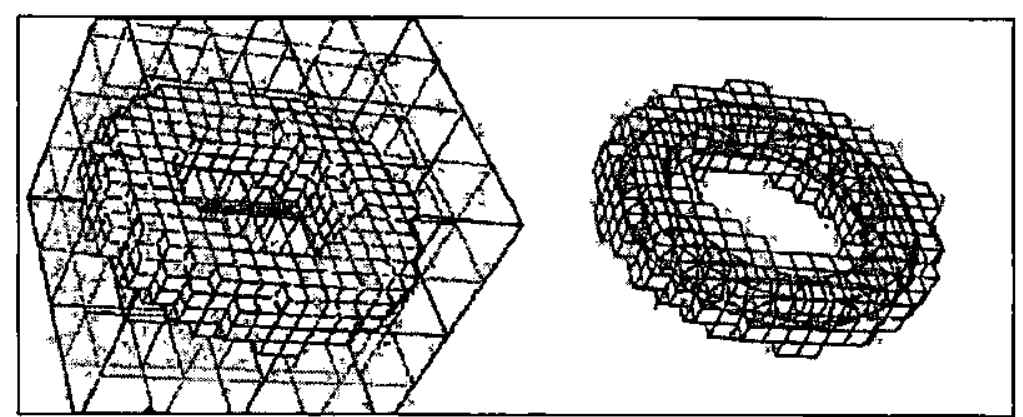

Figura 4.3 - poligonalização de toro com Octree. 


\section{Continuação Numérica}

Os métodos de continuação numérica obtêm a aproximação poligonal da superfície incrementalmente, ou seja, inicialmente é calculado um pedaço da aproximação e através de um percurso sobre a superfície novos pedaços são calculados até completar a aproximação.

Um exemplo de técnica de continuação numérica é a técnica de Previsão-Correção (Predictor-Corrector), PC, utilizado para aproximar curvas. Esse método consiste de dois passos: a previsão, a partir de um ponto inicial, um segundo ponto é calculado, na direção tangente conforme um certo intervalo; e a correção, o ponto calculado pela previsão é corrigido para se posicionar melhor sobre a curva (Möller \& Yagel, 1995). A figura 4.4 ilustra esse método.

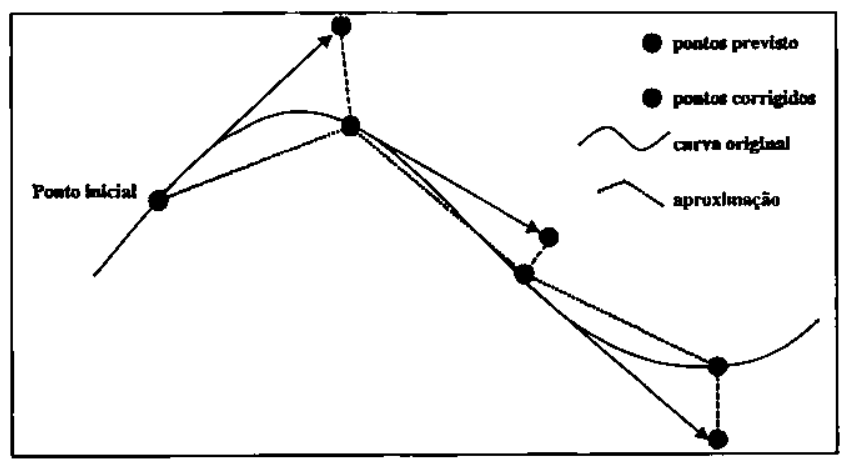

Figura 4.4 - método de Previsão e Correção.

Os métodos lineares por partes, utilizados na maioria do poligonalizadores, também se baseiam em continuação numérica. Nesse tipo a região onde está definida a superfície é representada por uma decomposição celular e a superficie poligonalizada é obtida por uma parametrização linear de paralelepípedos (Wyvill et al., 1986) ou tetraedros (Castelo, 1992).

Os métodos lineares por partes iniciam com a procura de uma célula semente que é uma célula qualquer transversal à superficie. Inicialmente a superficie poligonalizada consiste de um único polígono contido na célula semente. A superfície é propagada através das células vizinhas que são transversais à superfície. O processo termina quando toda a superfície for calculada. Para evitar que células já processadas sejam novamente processadas é necessário um mecanismo para armazená-las e recuperá-las. A principal característica dos métodos de continuação numérica é a redução do número de células processadas como mostra a figura 4.5, embora existam 21 células apenas 11 são utilizadas para o cálculo da aproximação linear por partes da curva.

Os métodos de continuação numérica produzem para uma célula semente uma única componente conexa da superfície. Como uma superfície implícita pode possuir mais de uma componente, para obter a representação correta da aproximação linear é necessário que o poligonalizador ou disponha de algum 
mecanismo para o cálculo de várias células sementes, ou o usuário informe uma célula semente para cada componente.

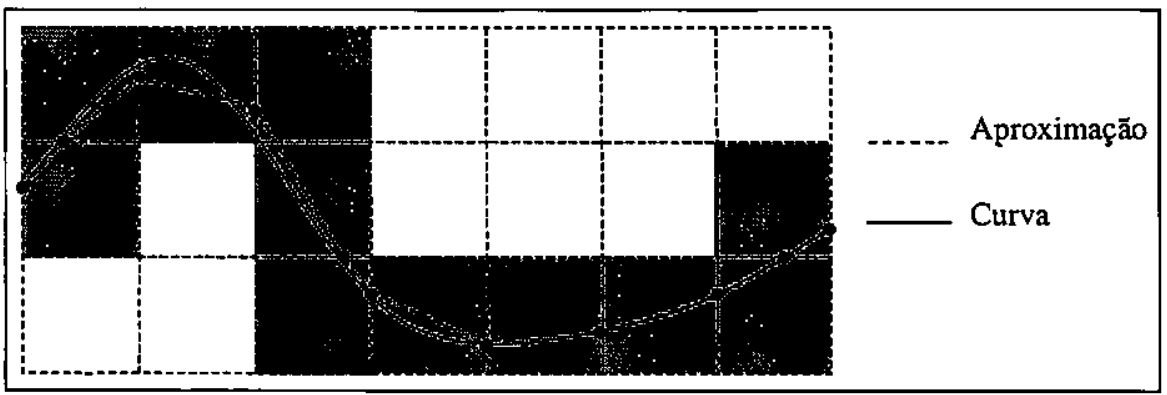

Figura 4.5 - aproximação linear por partes de uma curva.

O problema de cálculo de componentes não existe nos métodos de enumeração exaustiva uma vez que todas as células são processadas. Também não ocorre nos métodos de subdivisão, pois a análise topdown do volume pode detectar componente diferente e poligonalizá-las independentemente. Como apresentado na seção 4.4, o poligonalizador utilizado neste trabalho proposto mescla técnicas de subdivisão e de continuação numérica o que reduz a probabilidade de falha no cálculo de componentes conexas.

\subsubsection{Células cúbicas e as simpliciais}

Em uma decomposição celular onde as células são cubos elas podem ser indexadas facilmente o que permite uma implementação eficiente do armazenamento e dos procedimentos de percurso pela decomposição. $O$ gtande problema no uso de células cúbicas são as ambigüidades, como mostra a figura 4.6(a). Essa ambigüidade pode provocar buracos na poligonalização (figura 4.6(b)). Pela necessidade de tratar os casos de ambigüidades os algoritmos de decomposição em cubos podem tornar-se mais complexos que os de decomposição simplicial (Castelo et al., 1997).

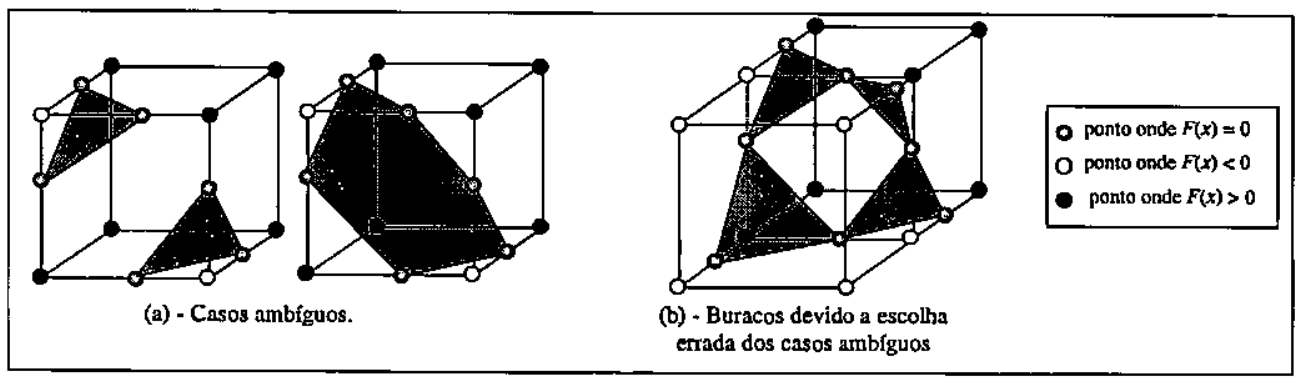

Figura 4.6 - ambigüidade na decomposição em cubos.

A decomposição simplicial (em tetraedros) não apresenta os problemas de ambigüidade, mas os processos de percurso e de armazenamento da decomposição são mais complexos. Os polígonos 
formados por esse tipo de decomposição possuem menos véttices que os formados por uma decomposição em cubos, mas são mais numetosos.

No método de poligonalização utilizado neste trabalho, utiliza a decomposição simplicial, mas durante os refinamentos são utilizadas decomposições em células cúbicas. Desse modo, é necessátio indexar e percorrer tanto as células cúbicas como as células simpliciais como descreve a seção 4.3.1.

\subsubsection{Poligonalização Uniforme e Poligonalização Adaptativa}

Os métodos de poligonalização podem utilizar uma decomposição celular uniforme ou adaptativa. Na decomposição uniforme todas as células possuem o mesmo tamanho, o que facilita o gerenciamento da decomposição. Entretanto, pode produzir um número excessivo de polígonos com uma resolução alta ou pode causar perdas de detalhes com uma resolução baixa (figura 4.7).

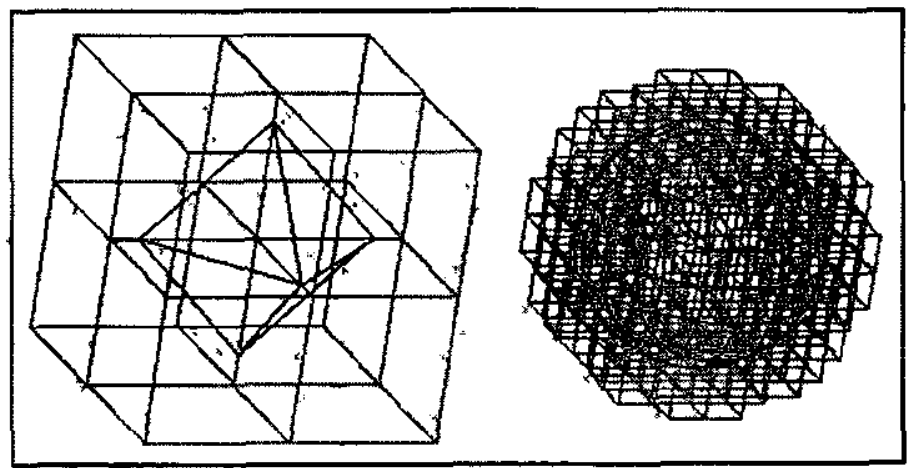

Figura 4.7 - perda de detalhes e número excessivo de células devido a decomposição uniforme.

$\mathrm{Na}$ decomposição adaptativa o gerenciamento é mais complexo, pois algumas regiões podem ser mais refinadas que outras. Nas regiões com mais detalhes as células são menores e nas regiões sem muitos detalhes são maiores. Logo, se dois métodos de poligonalização, um utilizando decomposição adaptativa e outro uniforme, forem utilizados para aproximar uma superfície com mesmo nível de detalhe, o método que utiliza decomposição adaptativa produzirá um número menor de polígonos.

O processo de decomposição adaptativa geralmente se inicia com uma decomposição uniforme "grossa", realizando refinamentos sucessivos conforme a necessidade de cada região da decomposição. Existem vários critérios para parar o refinamento como a variação de curvatura, variação da função ou do gxadiente dentro de uma célula. Outra condição de parada é o limite de refinamento para que a poligonialização possa ser executada em um tempo hábil e gerar um número limitado de polígonos.

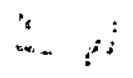




\subsubsection{Poligonalização Variedades não Diferenciáveis}

Os métodos de poligonalização convencionais têm como alvo as superfícies implícitas que definem variedades diferenciáveis sem bordo. Caso a variedade seja não diferenciável, podem ocorrer perdas significativas de detalhes como a apresenta a figura 4.8, que exemplifica a aproximação linear por partes de uma curva (variedade de dimensão 1) não diferenciável.

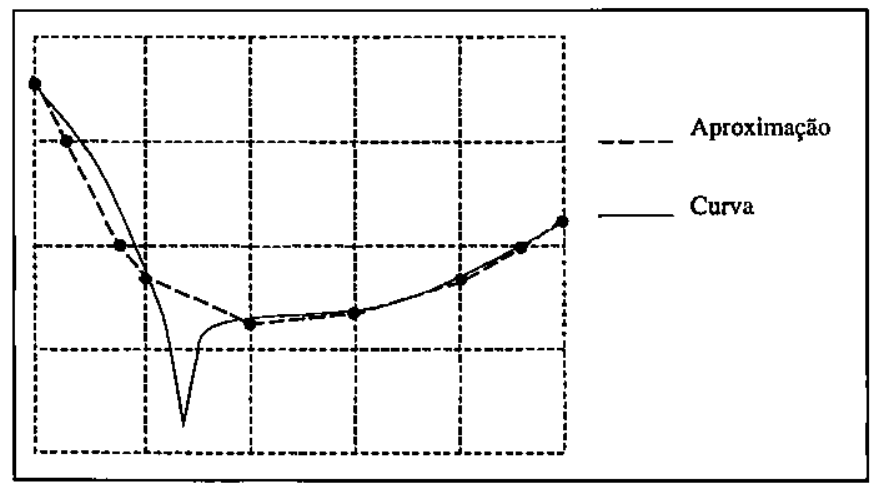

Figura 4.8 - aproximação Linear por partes de variedades não diferenciáveis.

(Wyvill \& Overveld, 1997) propõe um método de poligonalização para superfícies implícitas definidas com operadores definidos pelas funções $\min$ e $\max$ que introduzem a não diferenciabilidade na superficie. A base de funcionamento desse método é modificação no testes de transversalidade, tornando-o dependente da avaliação da árvore CSG. Quando uma célula é transversal a mais de uma primitiva é verificado se elas se interceptam no interior da célula. Caso isso ocorram, o método aproxima as interseções entre as primitivas melhorando a aproximação poligonal.

Os problemas de poligonalização, são maiores para as não variedades e para as variedades com bordo. Caso a superfície não seja uma variedade, a aproximação linear por partes obtida por métodos convencionais pode ser errada topologicamente, como mostra a figura 4.9. No caso das variedades com bordo, a superficie não enclausura uma região do espaço, de modo que, não é sempre possível caracterizar o interior da superfície dificultando o teste de transversalidade nas células.

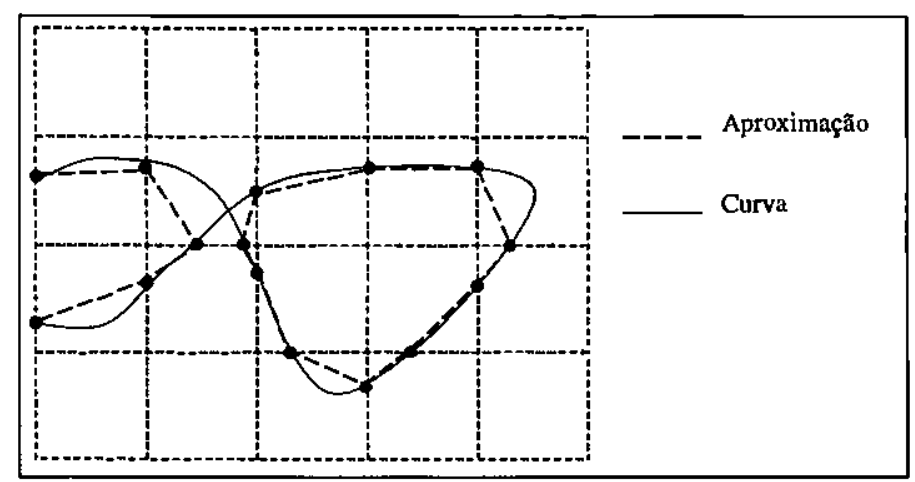

Figura 4.9 - uma possível aproximação linear por partes de uma não variedade. 
O método de poligonalização utilizado neste trabalho é um método adaptativo que privilegia as variedades diferenciáveis sem bordo. Esse método é baseado na parametrização linear de tetraedros que pertencem a uma triangulação denominada $J_{1}{ }^{*}$. A próxima seção apresenta essa triangulação $J_{1}{ }^{a}$ destacando como ela pode definir células de tamanhos diferentes e como os seus elementos podem ser identificados por números inteiros.

\subsection{A Triangulação $J_{1}^{a}$ em $\mathfrak{R}^{3}$}

Esta seção apresenta a triangulação $J_{1}^{a}$ conforme (Castelo et al., 1997). A triangulação $J_{1}^{a}$ em $\Re^{3}$ é uma decomposição celular de uma região compacta, paralelogramo. Essa triangulação é adaptativa. Os passos para se obter essa triangulação são os seguintes:

- Inicialmente a região $D$ do espaço é subdividida em blocos (paralelogramos) idênticos. Esses blocos são conhecidos como 0-blocos, pois o nível de refinamento é zero.

- A subdivisão inicial pode ser adaptada refinando cada bloco sucessivamente. A cada refinamento um bloco é dividido em $8\left(2^{3}\right)$ blocos menores. Um bloco no nível de refinamento $i$ é denominado $i$-bloco. Todo $i$-bloco só pode ser adjacente a blocos de níveis $(i-1), i$, ou $(i+1)$.

- Os blocos resultantes são particionados em tetraedros.

A figura 4.10 ilustra o processo similar a esse em $\Re^{2}$.

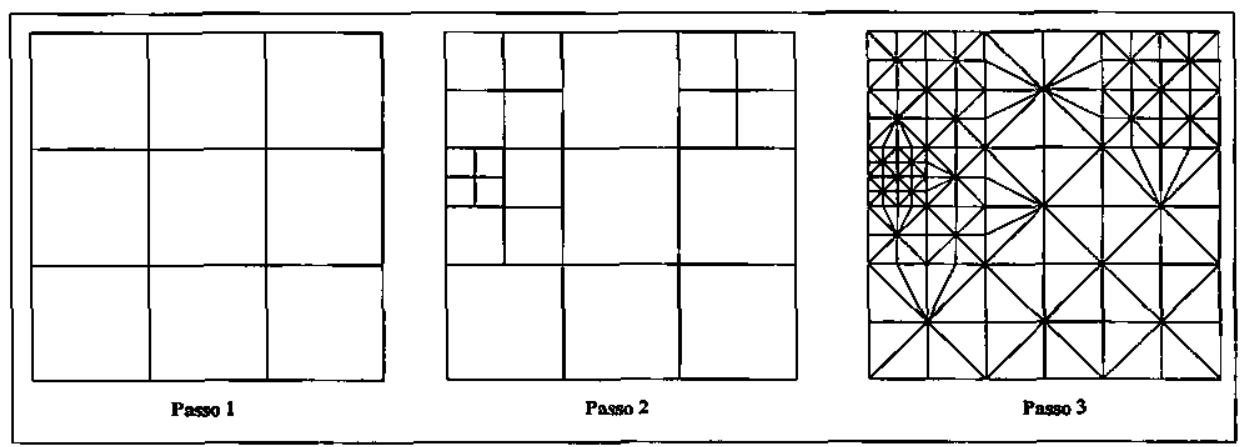

Figura 4.10 - passos da triangulaçāo $J_{1}^{a} \mathrm{em} \Re^{2}$.

Um bloco dessa triangulação cujos blocos vizinhos são do mesmo nível de refinamento ou menor é chamado bloco básico. Caso um $i$-bloco seja adjacente a um ou mais (i+1)-blocos, ou seja, blocos mais refinados, então ele é chamado bloco de transição. 
Para apresentar como os blocos (básicos ou de transição) são particionados em tetraedros, seja um cubo centrado na origem e com arestas de comprimento dois. Matematicamente esse cubo é expresso por $P^{3}=[-1,1]^{3}$. As faces $r$-dimensionais $(0 \leq \mathrm{r} \leq 2)$ podem ser expressas por subconjuntos $\phi$ de $\{-3,-2,-$ $1,1,2,3\}$ :

$\phi=\{-3\}$ especifica a face bidimensional onde $z=-1$;

$\phi=\{2\}$ especifica a face bidimensional onde $y=1$;

$\phi=\{-2,1\}$ especifica a face unidimensional (aresta) formada pela interseção das faces $\{-2\}$ e $\{1\}$;

$\phi=\{-1,-2,3\}$ especifica um vértice formado pela interseção de $\{-1\},\{-2\}$ e $\{3\}$.

O conjunto $\{-3,3\}$ não denota uma face. A figura 4.11 ilustra apresenta essas faces.
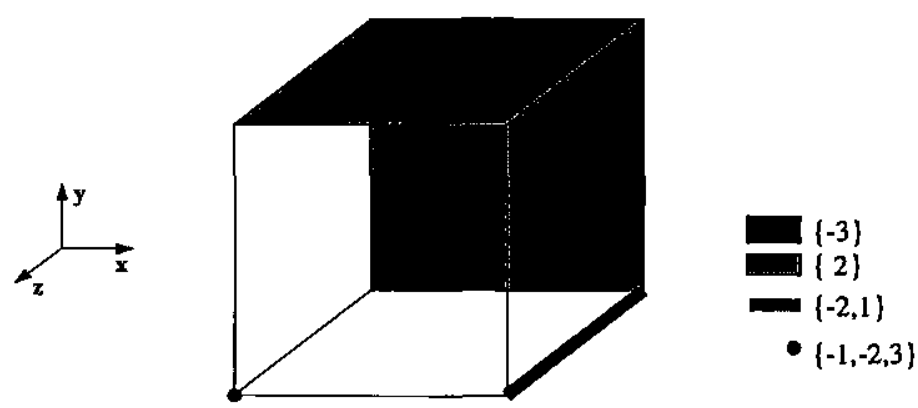

Figura 4.11 - exemplos das faces.

Em um bloco básico os vértices dos tetraedros são obtidos por uma permutação $\pi \mathrm{e}$ um vetor de sinais s. Em todo tetraedto o primeiro vértice é o centro do cubo e o i-ésimo yértice é obtido tomando o anterior e acrescentando a ele o vetor $s_{\pi_{(i)}} e_{\pi_{(i)}}$. Onde $s_{i}$ representa $i$-ésimo elemento do vetor de sinais e o $e_{\mathrm{i}}$ representa $i$-ésimo elemento da base canônica. $\pi(i)$ representa a permutação de $i$ e pode ser representado na forma de um vetor: $\pi=\left(\pi_{1}, \pi_{2}, \pi_{3}\right)$, assim $\pi(z)=\pi_{i}$. Se $I^{3}$ é um bloco básico, os vértices de um tetraedro representado por $\pi=\left(\pi_{1}, \pi_{2}, \pi_{3}\right)$ e $s=\left(s_{1}, s_{2}, s_{3}\right)$ são dados por:

$$
\begin{aligned}
& v_{0}=(0,0,0) \\
& v_{i}=v_{i-1}+s_{\pi(i)} e_{\pi(i)}
\end{aligned}
$$

Para exemplificar o tetraedro $\sigma=\left[v_{0}, v_{t}, v_{2}, v_{3}\right]$ denotado por $\pi=(3,2,1)$ e $s=(-1,1,1)$, é mostrado na figura 4.12 . 


$$
\begin{aligned}
& v_{0}=(0,0,0) \\
& v_{1}=v_{0}+s_{x(1)} e_{x(1)}=v_{0}+s_{3} e_{3}=v_{0}+e_{3}=(0,0,1) \\
& v_{2}=v_{1}+s_{x(2)} e_{x(2)}=v_{1}+s_{2} e_{2}=v_{1}+e_{2}=(0,1,1) \\
& v_{3}=v_{3}+s_{n(3)} e_{x(3)}=v_{2}+s_{1} e_{1}=v_{2}-e_{1}=(-1,1,1)
\end{aligned}
$$

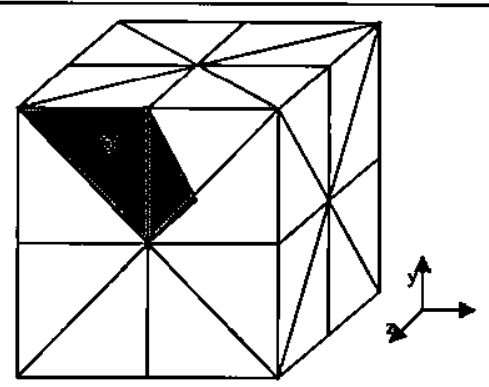

Figura 4.12 - triangulação em um bloco básico.

Em. um bloco de transição, é nẹcessário um segundo vetor de sinais, $t$, e conhecer quais são as faces refinadas, isto é, as faces do bloco de transição que são compartilhadas com blocos mais refinados. Essa segunda informação é dada por pelo conjunto de faces refinadas, $\Phi=\left\{\phi_{1}, \phi_{2}, \ldots\right\}$. A partir de $\pi, s$, e $\Phi$ é possível determinar em qual passo, $h$, uma face refinada é atingida. Assim, se $P$ é um bloco de transição com faces refinadas, dadas por $\Phi$, então um tetraedro, $\sigma=\left[v_{0}, v_{1}, v_{2}, v_{3}\right]$, definido por $\pi, s, t$ é dado por:

$$
\begin{aligned}
& v_{0}=(0,0,0) ; \\
& v_{i}=v_{i-1}+s_{\pi(i)} e_{\pi(i)}, \quad 1 \leq i<h ; \\
& v_{h}=v_{h-1}+s_{\pi(h)} e_{\pi(h)}+\frac{1}{2} \sum_{j=h+1}^{3} s_{\pi(j)} e_{\pi(j)} ; \\
& v_{i}=v_{i-1}+\frac{1}{2} t_{\pi(i)} e_{\pi(i)}, \mathrm{h}<i \leq 3 .
\end{aligned}
$$

Para exemplificar, considere o bloco da figura 4.13 como sendo $I^{3}$ com faces refinadas $\Phi=\{\{1,-3\}\}$ e o tetraedro $\sigma^{1}$ tal que $\pi=(1,3,2) ; s=(1,1,-1) ; t=(0,-1,0)$, logo seus vértices setão:

$$
\begin{aligned}
& v_{0}=(0,0,0) ; \\
& v_{1}=v_{0}+s_{\pi(1)} e_{\pi(1)}=v_{0}+e_{1}=(1,0,0)
\end{aligned}
$$

Tomando a próxima direção $s_{\pi(2)} e_{\pi(2)}=-e_{3}$ a face $\{1,-3\}$, que é refinada, será atingida. Logo $b=2$ então $v_{2}$ será dado por:

$$
v_{2}=v_{1}+s_{\pi(2)} e_{\pi(2)}+\frac{1}{2} \sum_{j=3}^{3} s_{\pi(j)} e_{\pi(j)}=v_{1}-e_{3}+\frac{1}{2} s_{2} e_{2}=v_{1}-e_{3}+\frac{1}{2} e_{2}=(1,0.5,-1)
$$

$\nu_{3}$ é dado por:

$$
v_{3}=v_{2}+\frac{1}{2} t_{\pi(3)} e_{\pi(3)}=v_{2}+\frac{1}{2} t_{2} e_{2}=v_{2}-\frac{1}{2} e_{2}=(1,0,-1)
$$

O segundo vetor sinais $t$ é definido como $\hbar_{(1)}=\hbar_{(\mathrm{h})}=0$ e $t_{\pi_{(h+1)}}= \pm 1, \ldots, \hbar_{\pi_{(3)}}= \pm 1$. 


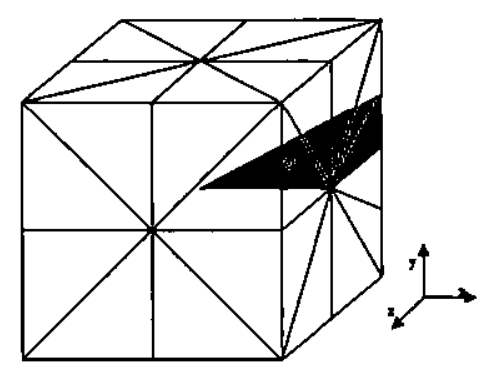

Figura 4.13 - triangulação em bloco de transição.

A triangulação $J_{1}^{2}$ é aplicada a um domínio de $\mathfrak{R}^{3}$ com forma de paralelogramo que pode ser identificado por dois pontos $v^{\mathrm{f}} \mathrm{e} v$ de modo que $v_{\mathrm{i}}^{\mathrm{f}}<v_{\mathrm{i}}^{\mathrm{i}}$ para $\mathrm{i}=1,2,3$. Inicialmente esse paralelogramo é dividido nos 0-blocos. $O$ número de 0 -blocos é dado pelo vetor de inteiros $K=\left\{K_{1}, K_{2}, K_{3}\right\}$ onde: $K_{1}$ representa o número de divisões no eixo $\mathrm{x}, K_{2}$ representa o número de divisões no eixo y e $K_{3}$ representa o número de divisões no eixo $\mathbf{z}$.

Os 0-blocos são refinados sucessivamente até que possam fornecer uma boa aproximação ou até atingir um limite de refinamento máximo (refmax). Um bloco em um nível de refinamento $r$ pode ser identificado por um vetor de inteiros, $g^{\prime}$, onde $g_{i}^{r} \in\left\{0,1, . .2^{r} \times K_{\mathrm{i}}-1\right\}$ para $\mathrm{i}=1,2,3$. Na figura 4.14 um paralelogramo apresenta blocos até o nível de refinamento 2 e refinamento inicial definido por $K=\{3$, $2,1\}$, na tabela 4.1 são apresentado os possíveis índices para um bloco conforme o refinamento.

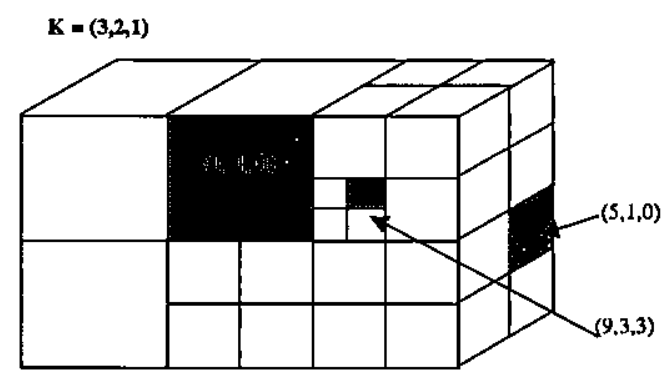

Figura $4.14-$ exemplo da identificação de blocos por vetor de inteiros.

Tabela 4.1 - possiveis índices dos blocos conforme o refinamento.

\begin{tabular}{|l|l|l|}
\hline \multicolumn{1}{|c|}{ 0-Blocos: } & \multicolumn{1}{c|}{ 1-Blocos: } & \multicolumn{1}{c|}{ 2-Blocos: } \\
\hline$g_{1}^{0} \in\{0,1,2\}$ & $g_{1}^{1} \in\{0,1,2,3,4,5\}$ & $g_{1}^{2} \in\{0,1,2,34,5,6,7,8,9,10,11\}$ \\
$g_{2}^{0} \in\{0,1\}$ & $g_{2}^{1} \in\{0,1,2,3\}$ & $g_{2}^{2} \in\{0,1,2,3,4,5,6,7\}$ \\
$g_{3}^{0} \in\{0\}$ & $g_{3}^{1} \in\{0,1\}$ & $g_{3}^{2} \in\{0,1,2,3\}$ \\
\hline
\end{tabular}

Os pontos que pertencem a um bloco podem ser obtidos definindo um paralelogramo a partir do vetor $q$. Para isso um vetor de intervalos, $\delta$, é definido por: 


$$
\delta_{i}=\frac{v_{i}^{l}-v_{i}^{f}}{2 K_{i}}, \text { para } \mathrm{i}=1,2,3
$$

O elemento $\delta_{i}$ é igual a metade da aresta de um 0 -bloco no eixo identificado por $i$. Assim, dado o nível de refinamento $r$ e o vetor que identifica um bloco os pontos contidos nesse bloco podem ser dado por:

$$
q\left(g^{r}, r\right)=\left[v_{1}^{f}+\frac{g_{1}^{r} \delta_{1}}{2^{r-1}}, v_{1}^{f}+\frac{\left(g_{1}^{r}+1\right) \delta_{1}}{2^{r-1}}\right] \times\left[v_{2}^{f}+\frac{g_{2}^{r} \delta_{2}}{2^{r-1}}, v_{3}^{f}+\frac{\left(g_{2}^{r}+1\right) \delta_{2}}{2^{r-1}}\right] \times\left[v_{3}^{f}+\frac{g_{3}^{r} \delta_{3}}{2^{r-1}}, v_{3}^{f}+\frac{\left(g_{3}^{r}+1\right) \delta_{3}}{2^{r-1}}\right]
$$

A triangulação em um bloco $q\left(g^{\prime}, r\right)$, é definida como a translação e escalonamento da triangulação de $P^{3}$. Se $q\left(g^{\prime}, r\right)$ é um bloco básico então os tetraedros resultantes de sua triangulação podem ser obtidos identificando o bloco, a permutação, $\pi$, e o vetor de sinais, $s$, assim o tetraedro $\sigma$ pode ser escrito como $\sigma\left(g^{r}, r, \pi, s\right)$. Se $q\left(g^{r}, r\right)$ é um bloco transição, então seus tetraedros necessitam também do vetor $t$ e a partir de quando se atingiu uma face faces refinada, o parâmetro $h$, assim: $\sigma(g, r, \pi, s, t, h)$.

A seguir são apresentadas três mecanismos que tornam mais eficiente a utilização da triangulação $J_{1}{ }^{a}$ na poligonalização de superfícies implícitas. Esses mecanismos são :rotulagem, pivoteamento e perturbação.

\subsubsection{Rotulagem}

Os elementos de uma triangulação $J_{1}{ }^{a}$ são identificados pelos seguintes itens:

- um bloco é identificado pelo seu nível de refinamento $r$ e por um vetor de inteiros $g^{r}$.

- um tetraedro de um bloco de básico é identificado por três itens: a identificação do bloco a que pertence e os vetores de sinal $s$ e de permutação $\pi$.

- um tetraedro de um bloco de transição é identificado por cinco itens: a identificação do bloco a que pertence, os vetores de sinais $1 s$ e $t$, o vetor de permutação $\pi$ e o inteiro $h$.

A maioria dos itens que identificam os tetraedros e dos blocos da triangulação $J_{1}{ }^{a}$ são vetores, para tornar o armazenamento e a recuperação dos elementos da triangulação mais eficientes esses vetores são substituídos por números inteiros por um processo conhecido como rotulagem.

A rotulagem consiste em mapear os vetores que identificam os tetraedros e os blocos em inteiros para obter uma representação mais compacta. Isto é possível porque todos esses vetores são formados 
apenas números inteiros que variam em uma faixa de valores fixa. Os mecanismos para rotular todos esses vetores podem ser encontrados em (Castelo et al., 1997).

Se $m$ é um vetor de inteiros o rótulo de $m$ é denotado por $l(m)$. Rotulando $g$, um bloco é identificado por dois números inteiros: $\left(l\left(g^{g}\right), r\right)$. Rotulando um tetraedro de um bloco básico, $q\left(g^{\prime}, r\right)$, esse tetraedro é identificado por 4 inteiros: $\left(l\left(g^{\prime}\right), r, l(\pi), l(s)\right)$. Caso $q\left(g^{\prime}, r\right)$ seja um bloco de transição um tetraedro pode ser representado por 6 inteiros: $\left(l\left(g^{\prime}\right), r, l(\pi), l(s), b, l(t)\right)$.

\subsubsection{Regras de pivoteamento}

As regras de pivoteamento consistem em regras para se determinar qual tetraedro $\sigma_{\mathrm{i}}$ é vizinho a $\sigma_{\mathrm{i}}$ pela face $k$ de $\sigma_{i} ; k \in\{0,1,2,3\}$ e representa a face bidimensional aposta ao vértice $v_{k}$ de $\sigma_{i}$. Então pode se dizer que $\sigma_{i}$ é atingido pivoteando $\sigma_{i}$ pelo vértice $v_{k}$.

$\mathrm{Na}$ triangulação $J_{1}{ }^{a}$ existem 24 regras de pivoteamento sendo 5 para os blocos básicos e 19 para os blocos de transição. Através dessas regras, as relações de vizinhança entre os tetraedros são eterminadas e é possível percorrer a triangulação. Com a rotulagem dos elementos da triangulação as zgras de pivoteamento podem ser implementadas através de aritmética de inteiros.

\subsubsection{Perturbação}

Seja $\mathrm{T}$ uma triangulação em $\Re^{\mathrm{m}}$, para todo vértice $v$ de $\mathrm{T}$ um raio pequeno, $\boldsymbol{\varepsilon}(v)$, e uma esfera $B(v, \mathcal{E}(v))$ centrada em $v$. Assume-se que $\varepsilon(v)$ seja suficientemente pequeno tal que se $v$ for substituído por qualquer ponto em $B(v, \mathcal{E}(v))$, o resultado ainda é uma triangulação de $\Re^{\mathrm{m}}$. Esse processo é definido como perturbação de T. A figura 4.15 ilustra uma perturbação de uma triangulação em $\Re^{2}$.

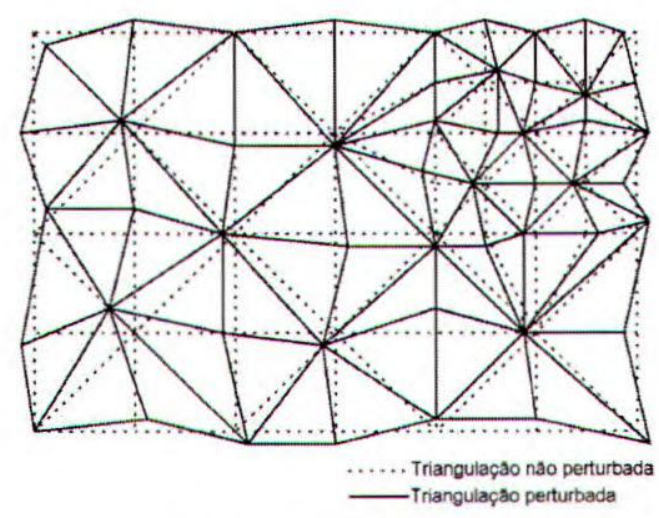

Figura 4.15 - perturbação de uma triangulação em $R^{2}$. 
A triangulação $J_{1}{ }^{a}$ é utilizada para obter uma aproximação linear por partes, $S_{\mathrm{T}}$, de $S$. É importante que cada parte $S_{\sigma}$ de $S_{\mathrm{T}}$ seja um polígono não degenerado que está contido em $\sigma$. Isso permite encontrar $S_{\sigma}$ pelos rótulos de $\sigma$, e através das regras de pivoteamento obter as relações de vizinhança entre as partes de $S_{\mathrm{T}}$. A perturbação de uma triangulação evita a criação de polígonos degenerados durante a poligonalização.

O esquema de perturbação utilizado na poligonalização $J_{1}^{a}$ consiste em inicialmente construit um cubo de perturbação, uma malha tegular onde a cada vértice é associado um desvio $\varepsilon=\left(\varepsilon_{1}, \varepsilon_{2}, \varepsilon_{3}\right)$. Cada vértice, $v$, da triangulação é associado a um único vértice do cubo de perturbação, de modo que para cada vértice é definido um desvio.

O calculo da aproximação LP da superficie implícita utiliza a totulagem para manipular de forma eficiente os elementos da triangulação, as regras de pivoteamento para percorter a estrutura da triangulação e o cubo de perturbação para definir a geometria da triangulação. A próxima seção apresenta o cálculo da aproximação LP de uma superfície implícita através da triangulação $J_{1}$.

\subsection{A Poligonalização de Superfícies Implícitas através da Triangulação $J_{1}^{a}$}

A poligonalização de uma superficie $S$ em $\Re^{3}$ é o cálculo de uma aproximação linear por partes, $S_{\mathrm{T}}$, a partir de uma triangulação $\mathrm{T}$ de uma região de $\Re^{3}$. $S_{\mathrm{T}}$ é definida por cada aproximação $S_{\sigma}$ em cada um dos simplexos $\sigma \in \mathrm{T}$.

O algoritmo poligonalização de superfícies implícitas através da triangulação $J_{1}^{a}$ é realizado em três passos: inicialização, poligonalização uniforme e poligonalização adaptativa. Um diferencial da poligonalização de superfícies implícitas com a triangulação $J_{1}^{a}$ é a estimativa de refinamentos que permite a realização de refinamentos múltiplos. Para realizar a poligonalização de uma superfície $S$, é necessário definit:

- a função de superficie implícita $f$ que define, $S=f^{-1}(0)$;

- uma região de $\mathfrak{R}^{3}$, paralelogramo $D$, caracterizado pelos pontos $\underline{v}$ e $\underline{v}$, onde será realizada a amostragem de $f$;

- número de subdivisões iniciais em cada um dos eixos coordenados, dado pelo vetor $\underline{K}$, para realizar a poligonalização uniforme (inicial); e 
- limite máximo de refinamento, refmax.

Inicialização: Nesse passo é construída a triangulação $J_{1}^{*}$ inicial que será utilizada para obter a aproximação uniforme da superfície. São gerados os blocos do nível de refinamento zero e o cubo de perturbação, definindo a triangulação $J_{1}^{a \varepsilon}$.

Poligonalização Uniforme: Nesse passo são obtidos os polígonos de $S_{\mathbf{T}}$ nos tetraedros de $J_{1}{ }^{a \mathcal{E}}$ e é estimado quantas vezes é necessário subdividir cada 0 -bloco, considerando um erro relativo máximo. Caso exista algum bloco que precisa ser refinado então é realizada a poligonalização adaptativa.

Poligonalização Adaptativa: Cada bloco que necessita de refinamento possui uma estimativa do nível de refinamento ideal. Nesse passo a triangulação é adaptada conforme as estimativas e as restrições de vizinhança. As faces $\tau$ de $S_{T}$ que estão em blocos que serão refinadas são descartadas. Nos blocos gerados pelo refinamento são calculadas novas faces para todos os tetraedros $\sigma$, onde $\left(\sigma \cap S_{\mathrm{T}}\right) \neq \varnothing$. Nesses blocos é feita uma nova estimativa de refinamento, e se necessário esse passo é repetido. Caso contrário o algoritmo termina e a poligonalização de $S$ é dada pelas faces $\tau$ de $S_{\mathrm{T}}$.

A seguir é apresentado como é realizada a estimativa de refinamentos e como é representada a aproximação da superfície ao final da poligonalização.

\subsubsection{Estimativa do número de refinamentos}

A partir da poligonalização uniforme, para cada bloco é estimado o tamanho ideal de suas célulass, considerando uma taxa de erro. Uma vez, estimado o tamanho da célula, é calculado o número de refinamentos do bloco para atingir esse tamanho. A estimativa do tamanho da célula em um bloco, é realizada considetando um valor de erro máximo e aproximando a superfície em cada uma das células desse bloco pot uma esfera. Com essa aproximação é calculado o erro, e em seguida é determinado o quanto a célula deve ser refinada para atingir o erro máximo permitido.

Pata compreender esse procedimento, seja $S$, uma esfera de raio $R$ centrada na origem, e $S_{\mathrm{T}}$ a aproximação linear por partes de $S$, definida pela triangulação $J_{1}{ }^{a}$ uniforme $\mathrm{T}$. Em uma face (triangulo) $\tau$ de $\mathrm{T}$ interceptada por $S_{\mathrm{T}}$. Existem dois pontos $\mathbf{u}$ e $\mathbf{v}$ pertencentes a $\tau$ que definem a aresta [u,v] de $S_{\mathrm{T}}$ (figura 4.16(a)). Dessa forma, o erro máximo , $\varepsilon$, da aproximação de $S_{\mathrm{T}}$ em $\tau$ é dado por: 
(4.1) $\varepsilon=R-\left\|\frac{1}{2}(\mathbf{u}+\mathbf{v})\right\|=R-\sqrt{\frac{4 R-\|\mathrm{u}-\mathrm{v}\|^{2}}{4}}$

Como || $\mathbf{u}-\mathbf{v} \mid$ | é no máximo igual ao diâmetro da triangulação $\mathrm{T}$, é definida a seguinte inequação:

(4.2) $\varepsilon \leq R-\sqrt{\frac{4 R-\rho^{2}(\mathrm{~T})}{4}}, \mathrm{e}$

$O$ valor $\varepsilon$ indica o erro máximo absoluto, e a partir da equação (4.2) pode ser definido o erro máximo relativo, $\varepsilon / \rho(\mathrm{T})$, equação (4.3). O erro relativo máximo e depende exclusivamente da relação $R / \rho(\mathrm{T})$, e quanto maior o valor dessa relação melhor será a aproximação da esfera.

(4.3) $\frac{\varepsilon}{\rho(\mathrm{T})} \leq \frac{R}{\rho(\mathrm{T})}-\sqrt{\left(\frac{R}{\rho(\mathrm{T})}\right)^{2}-\frac{1}{4}}$.

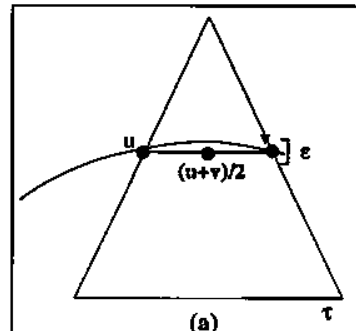

(a)

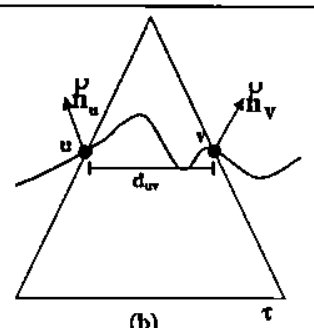

(b)

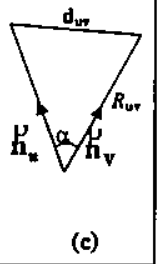

(c)

Figura 4.16 - aproximação da superfície implícita para estimativa do refinamento.

Generalizando, seja uma superfície definida implicitamente $S=f^{-1}(0)$; onde $f: \mathfrak{R}^{3} \rightarrow \mathfrak{K}$ é uma função diferenciável e 0 é um valor regular de $f$. Seja $T$ uma triangulação $J_{1}^{a}$, onde todas as células possuem o nível de refinamento 0 . Supondo $S_{\mathrm{T}}$, a aproximação linear por partes obtida na triangulação $\mathrm{T}$, de tal modo que, todos os vértices de $S_{\mathrm{T}}$ estejam em $S$. Considerando uma face $\tau$ de $\mathrm{T}$ cuja interseção $\tau \cap S_{\mathrm{T}}$ seja uma aresta $[\mathbf{u}, \mathbf{v}]$ de $S_{\mathrm{T}}$, e os vetores unitátios notmais a $S$ em $\mathbf{u}$ e $\mathbf{v}, \mathfrak{h}_{\mathbf{u}}$ e $\mathfrak{h}_{\mathbf{v}}$, como ilustra a figura $4.16(\mathrm{~b})$.

A figura 4.16(c) apresenta um triangulo isósceles onde o ângulo $\alpha$ é o mesmo ângulo entre os vetores $h_{\mathbf{u}}$ e $\mathfrak{h}_{\mathbf{v}} \cdot \mathrm{R}_{\mathbf{u v}}$ pode ser considerado o raio de uma esfera que passa pelos pontos $\mathbf{u}$ e $\mathbf{v}$ cuja interseção com $\tau$ é um arco de circunferência aproximado pelo segmento [u, v]. Após essas considerações, é possível estimar o erro máximo substituindo o valor de $R_{u v}$ na equação (4.2). $O$ valor de $R_{u v}$ pode ser calculado por:

$$
\text { (4.4) } R_{\mathrm{uv}}=\frac{d_{\mathrm{uv}}}{\sqrt{2(1-\cos (\alpha))}} \cdot
$$


Voltando ao problema original e considerando a seguinte reformulação: encontrar o tamanho dos simplexos $\omega$ na região de $\mathrm{T}$ definida por um simplexo $\sigma$, tal que o erro relativo máximo seja limitado por $\varepsilon / \rho(\mathrm{T})$. Esse problema pode ser resolvido do seguinte modo:

1. utilizando a inequação (4.3), calcula-se o valor de $R / \rho(T)$.

2. para cada face de $\sigma$ que contenha uma aresta $[u, v]$ de $S_{T}$, calcula-se o valor de $R_{u v}$

3. toma-se o menor valor dentre os $R_{u v}: R_{\text {urmin }}$;

4. calcula-se o valor de $\rho(\omega)$ por:

$$
\rho(\sigma) \leq R_{\mathrm{uvmin}} \cdot \frac{\rho(\omega)}{R}
$$

Sendo T uma triangulação $J_{1}{ }^{\circ}$ com nível de refinamento 0 (zero), a partir da estimativa do tamanho das células para cada simplexo $\sigma$ de um bloco $q\left(l\left(g^{g}\right), 0\right)$ é possível definir a estimativa do nível de refinamento desse bloco, $\kappa_{q\left(l\left(g^{0}\right), 0\right)}$. Uma vez que a relação entre o diâmetro de um simplexo no nível de refinamento 0 (zero) e o simplexo no nível $i$ pode ser expressa por:

$$
\rho\left(q\left(l\left(g^{0}\right), 0\right)\right)=2^{i} \cdot \rho\left(q\left(l\left(g^{i}\right), i\right)\right)
$$

tomando $R / \rho(\mathrm{T})=c$, a estimativa do nível de refinamento $\kappa_{q\left(l\left(l^{\circ}\right) .0\right)}$ é obtida por:

$$
(4.5) \kappa_{q\left(l\left(g^{0}\right), 0\right)}=\max \left\{\max _{\sigma}\left\{\kappa_{\mathrm{uv}}\right\}, 0\right\}
$$

onde, para cada simplexo $\sigma$, o valor de $\kappa_{\mathrm{uv}}$ é dado por:

$$
\text { (4.6) } \kappa_{\mathrm{uv}}=\left\{\begin{array}{ll}
\log _{2}\left(c \cdot \frac{\rho\left(q\left(l\left(g^{0}\right), 0\right)\right)}{R_{\mathrm{uvmin}}}\right)^{0,} & \text { se } \cos (\alpha)=1 \\
\text { caso contrário }
\end{array}\right. \text {. }
$$

A estimativa de refinamento indica qual deve ser o tamanho de uma célula em uma região da triangulação $\mathrm{T}$, para respeitar a condição do erro máximo relativo na aproximação $S_{\mathrm{T}}$. Ao invés de verificar se uma célula deve ou não ser dividida em cada passo de adaptação da malha e realizar refinamentos sucessivos, com a estimativa de refinamento é possível atingir o tamanho ideal em um único passo de adaptação da malha.

Por ser uma estimativa, após a realização de um passo adaptativo da malha $T$ o calculo na nova aproximação $S_{\mathrm{T}}$, é necessário realizar uma nova estimativa para os blocos que foram refinados. Essa nova estimativa irá validar a estimativa anterior, ou indicar a necessidade de novos refinamentos. Esse 
procedimento pode ser realizado de modo sucessivo até limitar o erro relativo da malha a $\varepsilon / \rho(\mathrm{T})$ ou até atingir o nível máximo de refinamento da triangulação $J_{1}{ }^{a}$.

\subsubsection{Esqueleto Combinatório}

A superfície LP resultante do processo de poligonalização é representada em uma estrutura de dados denominada esqueleto combinatório. Essa estrutura proposta em (Castelo, 1992) representa uma variedade de dimensão $m$ em $\mathfrak{R}^{\mathfrak{n}}$. Na poligonalização de superfícies implícitas em $\mathfrak{R}^{3}$ essa estrutura representa as faces de dimensão 2, 1 e 0 que definem a aproximação da superficie. Para isso, existem três conjuntos: um de faces, um de arestas e um de vértices. Entre os conjuntos existem "ligações" de modo a indicar os componentes, assim:

- Uma face de dimensão 2 referência 3 ou 4 faces de dimensão 1 (arestas) que a delimitam. A referência é limitada a 3 ou 4 arestas porque todas as facetas obtidas a partir da triangulação são quadriláteros ou triângulos. Uma face, $\mathrm{F}$, de $S_{\mathrm{T}}$ é identificada pelo rótulo do tetraedro da triangulação, $(l(\sigma))$, que a contém de modo que $F=\sigma \cap S_{\mathrm{T}}$.

- Uma face de dimensão 1 (aresta) referência 2 faces de dimensão 0 (vértices) que a delimitam. Uma aresta, A, de $S_{\mathrm{T}}$ é identificada pelo rótulo de uma face da triangulação, $\left(l\left(\nu_{\hat{\nu}}\right)\right.$, $\left.l\left(v_{\mathrm{j}}\right), l\left(v_{\mathrm{k}}\right)\right)$, que a contém de modo que $\mathrm{A}=\left[v_{\mathrm{i}}, v_{\mathrm{j}}, v_{\mathrm{k}}\right] \cap S_{\mathrm{T}}$.

- Uma face de dimensão 0 (vértice), $\mathrm{V}$, de $S_{\mathrm{T}}$ é identificado pelo rótulo de uma aresta da triangulação, $\left(l\left(\nu_{i}\right), l\left(\nu_{\mathrm{j}}\right)\right)$, que o contém de modo que $\mathrm{V}=\left[\nu_{i}, \nu_{\mathrm{j}}\right] \cap S_{\mathrm{T}}$.

Um exemplo de esqueleto combinatório é apresentado na figura 4.17. Em (a) é mostrado uma superfície LP composta pelas faces $F_{1}$ e $F_{2}$ sendo que os rótulos dos vértices são apresentados entre parênteses. Em (b) é apresentada o esqueleto combinatótio para essa superfície LP, em cada elemento do esqueleto a tupla representa o tótulo de um simplexo da triangulação que contém esse elemento.

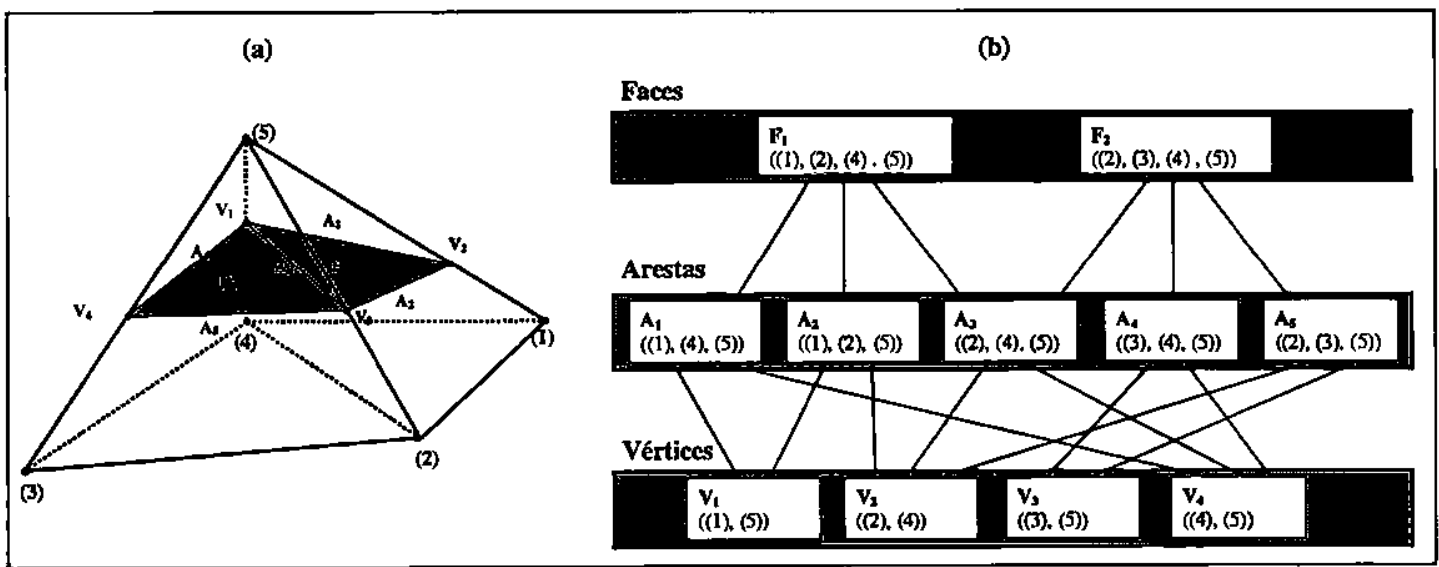

Figura 4.17 - exemplo de esqueleto combinatório. 


\subsection{Representação de Superfícies}

O processo de poligonalização descrito tem como saída o esqueleto combinatótio da aproximação linear por partes de uma superficie. O esqueleto combinatótio consiste na parametrização de cubos e tetraedros e apresenta dois pontos de inconveniência: é uma estrutura cara computacionalmente, pois as faces, arestas e vértices estão associados aos tetraedros; e cubos; e a orientação da superficie não es tá explícita, sendo necessário algum processamento para obtê-la. Além disso, o esqueleto combinatório não identifica, de modo eficiente, diferentes componentes conexas em uma aproximação da superficie.

Para facilitar os processos de iluminação da superficie e geração de malha é necessária uma estrutura mais concisa para representação da superfície. Existem várias estruturas de dados que podem ser utilizadas representar a geometria e a topologia de uma superficie, a maioria derivada da estrutura aresta-alada (Winged-Edge), proposta por (Baumgart, 1975). Elas têm complexidade variável dependendo da quantidade de informação sobre as relações de adjacência que armazenam. A maioria dessas estruturas de superfície segue o paradigma B-Rep (Boundary Representation) por considerar a superficie como bordo de um sólido. Nas subseções a seguir são apresentadas duas formas de representação de superfície a semi-aresta (balf-edge) e a brep-estendida.

\subsubsection{Semi-Aresta}

A estrutura semi-aresta foi proposta em (Mäntyla, 1988) e é derivada da estrutura aresta-alada. Essa estrutura interpreta cada aresta como composta de duas metades que correspondem aos sentidos positivos e negativos da aresta-alada, a essas metades dá-se o nome de semi-arestas. A figura 4.18(a) ilustra a decomposição da aresta em semi-arestas.Os elementos da estrutura semi-aresta são: sólidos, faces, ciclos, semi-arestas, arestas e vértices.

A figura 4.18(b) apresenta um diagrama da estrutura de dados, neste diagrama as setas entre elementos indicam a representação do elemento, por exemplo: em uma semi-aresta as setas:

- sa_vértice indica o vértice inicial da semi-aresta;

- sa_aresta indica a aresta onde a semi-aresta está contida;

- sa_ciclo indica o ciclo onde a semi-aresta está contida;

- sa_próxima e sa_anterior indicam as semi-arestas próximas e anteriores em um ciclo de face.

A notação rótulo_seta ${ }^{+}$entre dois elementos indica que um elemento (o da pé da seta) é composto por uma lista dos elementos indicados no final da seta. A seguir é apresentada a descrição dos elementos: 
Sólidos - os sólidos são representadas pelos seus bordos, ou seja, por uma superficie. A estrutura de dados permite a representação de vários sólidos através de uma lista. Um sólido indica as cascas que o constituem, explicitando sua casca externa.

Cascas - as cascas são definidas por um conjunto de faces que definem uma superficie. Uma casca mantém uma lista para as arestas e outra para os vértices que definem suas faces, e também possui indicadores para outras cascas do mesmo sólido.

Face - as faces são representadas por polígonos planares definidos como ciclos de semi-arestas. Uma face pode conter mais de um ciclo, neste caso o bordo da face é definido pelo ciclo mais externo e os ciclos interiores indicam buracos na face. Uma face possui indicadores para outras faces da mesma casca.

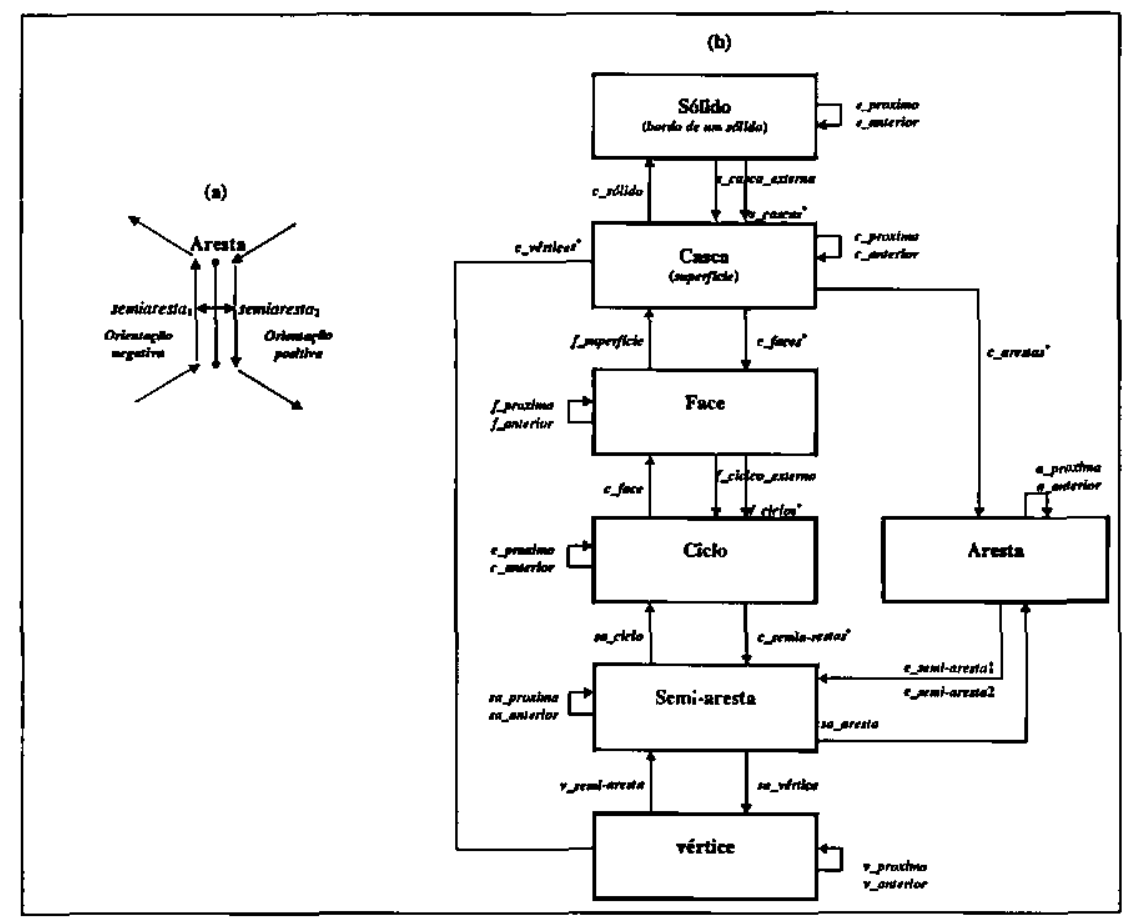

Figura 4.18 - representação semi-aresta.

Ciclo - um ciclo é um elemento auxiliar para descrição de faces. Esse elemento é definido por uma lista de semi-arestas e por indicadores de outros ciclos que definem a mesma face.

Semi-aresta - descreve um segmento dentro de um ciclo. Uma semi-aresta é representada por um vértice inicial, pelas semi-arestas antecessora e posterior em um ciclo e pela aresta a que pertence.

Aresta - as arestas são representadas por duas semi-arestas e indica outras arestas que definem a casca.

Vértice - representa um vértice de uma casca. Além das suas coordenadas um vértice indica uma semiaresta que emana dele e outros vértices da superficie. 
As estruturas de aresta-alada e semi-aresta seguem o paradigma B-Rep, ou seja, são representadas apenas superficies fechadas e imersas em $\Re^{3}$.

\subsubsection{Brep-Estendida}

$O$ interesse deste trabalho é por superfícies definidas sem bordo. Assim a representação da aproximação dessas superfícies pode ser realizada pelas estruturas semi-aresta ou aresta-alada. Entretanto, a poligonalização da superfície implícita pode definir uma superfície poligonalizada com bordo, caso a região (domínio) onde for realizada a poligonalização não contenha toda a superfície definida (figura 4.19). Para representação dos bordos de uma superficie foi desenvolvida uma estrutura denominada brep-estendida.

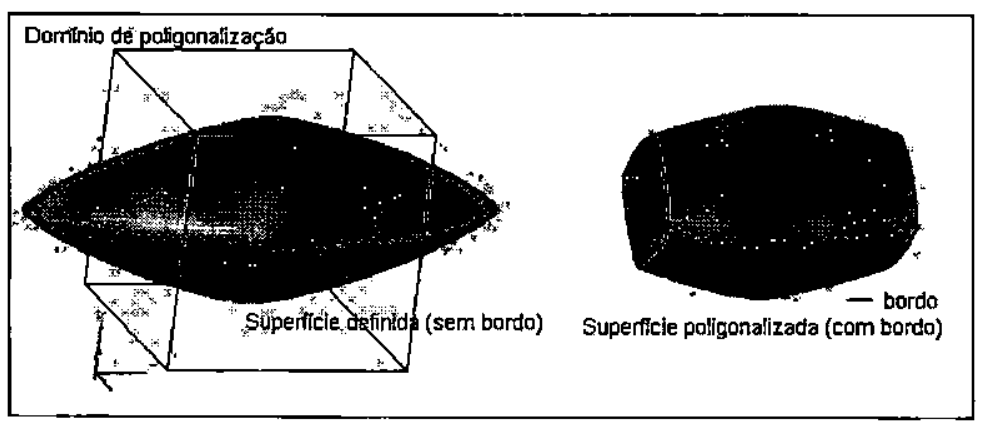

Figura 4.19 - superfície com bordo devido ao domínio da poligonalização.

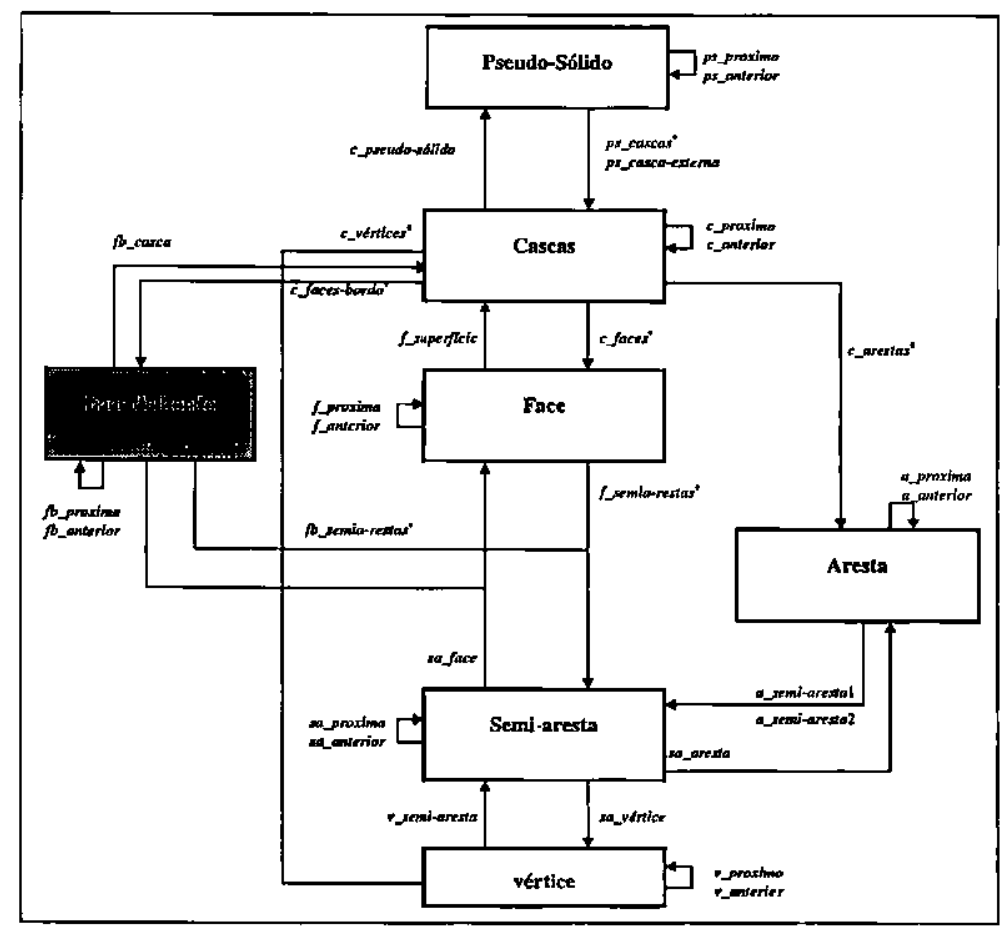

Figura 4.20 - estrutura brep-estendida. 
A brep-estendida mantém uma lista de faces de bordo, para cada casca. Uma face de bordo representa uma curva fechada que define o bordo da superficie (figura 4.20). A estrutura de dados que tepresenta a face de bordo é a mesma utilizada para representar as faces comuns. Como as cascas não tepresentam mais superfícies fechadas, os sólidos da estrutura de semi-arestas são renomeados para pseudo-sólidos. A figura 4.20 apresenta a estrutura semi-aresta estendida.

\subsection{Considerações Finais}

A poligonalização de superfície implícita é um meio de obter uma tepresentação explícita a partir da definição implícita. Essa representação explícita pode ser utilizada tanto para visualizar a superfície como para fazer simulações. Existem três tipos de métodos para se poligonalizar uma superfície implícita: enumetação exaustiva, subdivisão e continuação numérica. O método utilizado no modelador de superfícies implícitas é um método adaptativo baseado na triangulação $J_{1}^{a}$ e mescla os métodos de subdivisão, para adaptar a malha, e de continuação numética.

Ao fim da poligonalização, a superfície aptoximada é representada por uma estrutura de dados atrelada à estrutura da triangulação $J_{1}^{a}$, denominada esqueleto combinatótio. Essa estrutura possui algumas ineficiências e para representar melhor a aproximação da superfície foi apresentada a estrutura brepestendida.

O próximo capítulo descreve a arquitetura do Modelador de superfícies implícitas, desenvolvido neste projeto de mestrado, e em os outros dois capítulos detalham a implementação do Modeladot. 


\section{Capítulo 5 - Arquitetura e Ambiente de Desenvolvimento do Modelador}

\subsection{Considerações Iniciais}

Este capítulo apresenta a arquitetura do Modelador, o seu princípio de funcionamento e descreve os seus componentes. Também é apresentado o ambiente de desenvolvimento do Modelador enfatizando as bibliotecas de programação utilizadas na interface gráfica com o usuário e nos módulos responsáveis pela apresentação de modelos tridimensionais.

\subsection{Arquitetura do Modelador}

Esta seção apresenta a arquitetura do Modelador e o seu princípio de funcionamento, apresentando os subsistemas que o compõem e como eles cooperam entre si para realizar a tarefa de modelagem. Estes subsistemas são referenciados no texto como componentes do Modelador. São três os componentes: a Interface de Modelagem, o Poligonalizador e o Visualizador de Modelos Aproximados. Esses três módulos estão associados às três etapas do processo de construção de um modelo: a definição, a poligonalização e a apresentação do modelo poligonalizado.

O Modelador permite a definição de um modelo implícito attavés da construção de uma árvore CSG na Interface de Modelagem, essa árvore CSG é chamada nesse texto de árvore implícita. Após a definição da árvore implícita na Interface de Modelagem, o usuário submete o modelo implícito ao Poligonalizador, que gera sua aproximação linear por partes e essa é apresentada ao usuário pelo Visualizador.

Embora os três componentes sejam programas independentes, a Interface de Modelagem é considerada o componente principal, porque ativa os outros dois componentes. A comunicação entre os componentes é realizada pelo arquivo de definição do modelo implícito e pelo arquivo de modelo 
poligonal. Ao ser solicitada a poligonalização do modelo implícito, a Interface de Modelagem registra a definição do modelo em um arquivo e invoca o Poligonalizador. O Poligonalizador monta uma estrutura de avaliação do modelo e realiza a poligonalização. A aproximação por partes gerada na poligonalização é registrada em um arquivo, e o Poligonalizador encerra sua execução retornando o status da poligonalização. Quando o componente de interface recebe do Poligonalizador a informação que a poligonalização ocorreu com sucesso, ele invoca o Visualizador para exibir a aproximação. Este fluxo de controle é indicado na figura 5.1.

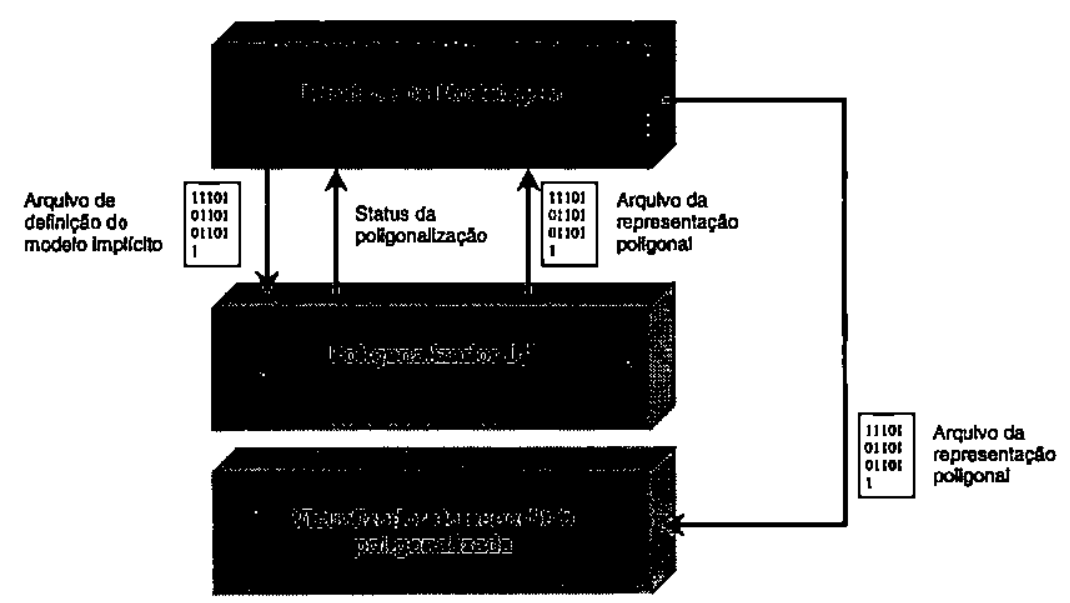

Figura 5.1 - componentes do Modelador e comunicaçāo entre eles.

As seções 5.3, 5.4 e 5.5 apresentam a funcionalidade de cada um dos componentes, descrevendo os principais módulos de cada componente.

\subsection{Interface de modelagem}

O componente de Interface de Modelagem é esquematizado na figura 5.2, os módulos que definem este componente são o Editor de Árvores Implícitas e o Visualizador de Primitivas. Além destes módulos, a Interface de Modelagem possui outros elementos para interface com o usuário como janelas para a definição dos parâmetros das primitivas e das operações de composição, janelas para controle da posição, orientação e escala das primitivas e menus para executar tarefas envolvidas no processo de modelagem.

O Editor de Átvores Implícitas, juntamente com o Visualizador de Primitivas compõe a interface principal com o usuário. A seguir são apresentados cada uns desses módulos. 


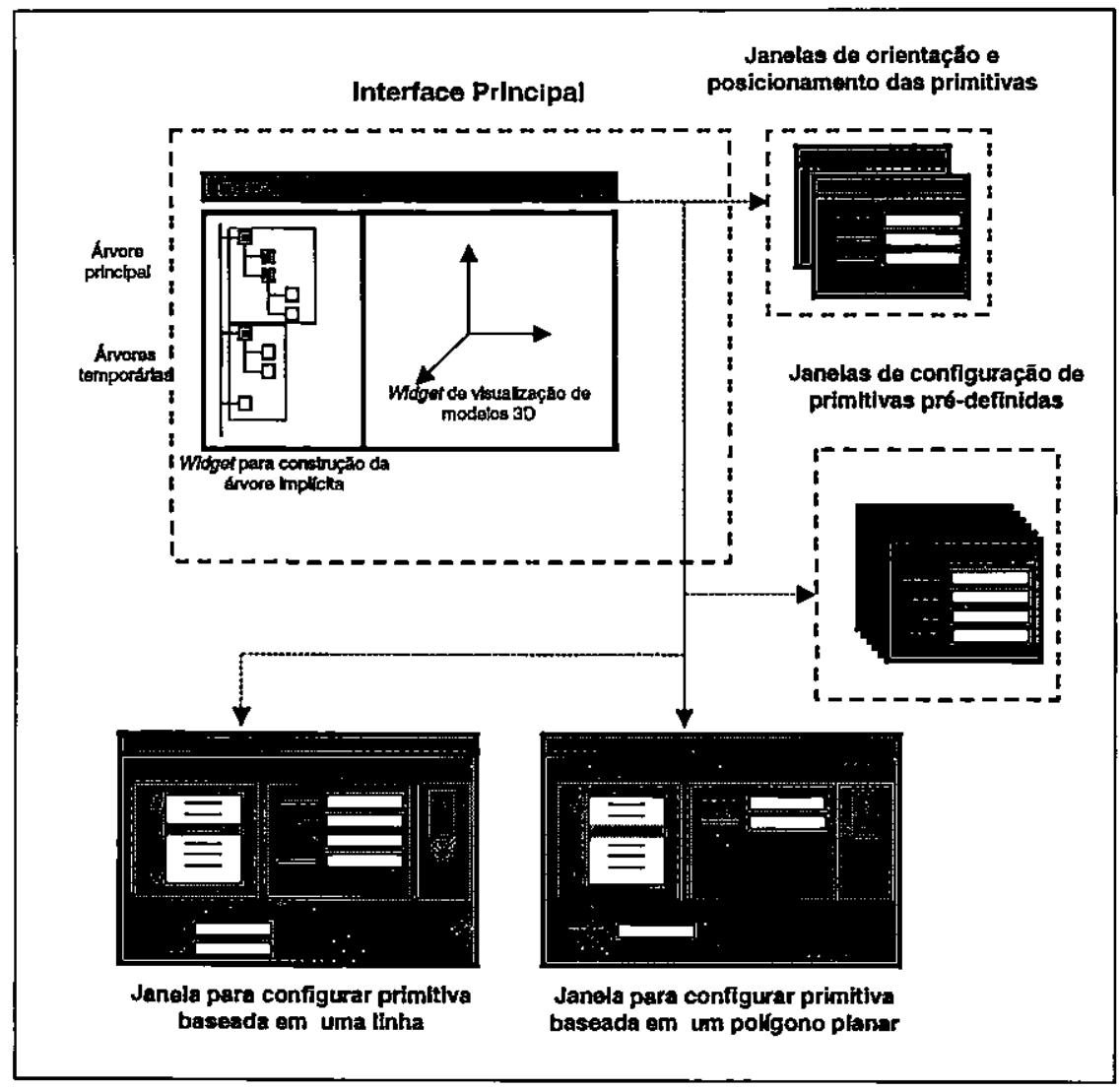

Figura $5.2 \rightarrow$ módulos da Interface de Modelagem.

\subsubsection{Editor de Árvores Implícitas}

Uma árvore implícita é uma árvore CSG onde os nós folhas são primitivas implícitas e os demais nós representam operações de composição. As primitivas implícitas são modelos implícitos simples que podem ser pré-definidas ou definidas por esqueletos. Na interface principal um modelo implícito É construído criando novas primitivas ou operações de composição e inserindo primitivas nas composições

As primitivas pré-definidas disponíveis no Modelador são esfera, toro, superelipsóide, cone, cilindro e paralelogtamo. As primitivas baseadas em esqueletos são definidas a partir de distância de pontó, segmentos de reta e polígonos planares.

As operações de composição disponíveis são as operações CSG: união, interseção e diferença. O Modelador permite ao usuário definir o tipo de blend a ser utilizado nessas operações. Os tipos de blend estudados são apresentados na seção 3.4 e os disponíveis no Modelador são o blend global e o blend pseudo-euclidiano. 
O Editor de Árvores Implícitas permite editar uma coleção de árvore implícitas, cada uma representando um modelo. Nessa coleção pode existir uma única árvore representando um modelo principal, sendo que as demais representam modelos temporários ou auxiliares. A utilização de modelos temporários permite ao usuário construir um modelo por partes, ou seja, é possível construir vários modelos temporários e, posteriormente, compor o modelo principal.

É importante definir alguns termos para compreensão do funcionamento de uma árvore implícita:

- nó: refere-se a um elemento da árvore implícita que pode ser ou uma operação de composição ou uma primitiva.

- nó filho e nó pai: nó filho refere-se ao nó que é operando em uma operação de composição. Desse modo, se um nó A é uma operação, então A possui uma lista de nós operandos cada qual denominado nó filho de A; e o nó A é denominado nó pai dos seus operandos.

- raiz da árvore: refere ao nó de uma árvore que não possui pai.

Durante a construção de um modelo um nó da árvore implícita é marcado pelo usuário como nó selecionado. Os parâmetros do nó selecionado podem ser alterados, por exemplo, se o nó for uma esfera o usuário pode alterar o seu raio, ou se for uma operação de união com blend global o usuário pode alterar o expoente da equação de blend. O modelo que possui o nó selecionado é chamado de modelo ativo. As primitivas que pertencem ao modelo ativo formam o conjunto das primitivas ativas.

A partir do nó selecionado são definidas as primitivas selecionadas. Quando o nó selecionado for uma operação as primitivas selecionadas são as primitivas descendentes deste nó. Quando o nó selecionado for uma primitiva, ela é a única primitiva selecionada. Dessa forma, o conjunto das primitivas selecionadas é um subconjunto das primitivas ativas. Esses termos, primitivas selecionadas e primitivas ativas, são importantes para descrever a funcionalidade do Visualizador de Primitivas.

Considerando a figura 5.3, são apresentadas quatro árvores implícitas: se o nó $\mathbf{n}$ (do terceiro modelo temporário) é marcado como selecionado as primitivas ativas são os nós $\mathbf{1}, \mathbf{m}$, o e p (primitivas do terceiro modelo temporário) e as primitivas selecionadas são as definidas pelos nós o e p. Outro exemplo, se o nó $\mathbf{g}$ for selecionado, as primitivas ativas são os nós $\mathbf{g}$ e $\mathbf{h}$ e a primitiva selecionada é o nó g.

O Editor de Árvores Implícitas permite ao usuário manipular um modelo implícito como uma árvore de diretórios. As funções disponíveis nesse módulo são: 
- Inserir uma nova primitiva implícita.

- Inserir uma nova operação de composição informando obrigatoriamente dois filhos.

- Adicionar uma nova primitiva ou um modelo temporário como operando em um nó que define uma operação.

- Criar um novo modelo temporário a partir de um nó qualquer.

- Remover um nó.

- Mover um nó A para o nó B inserido-o como filho do nó B. Nesse caso se o nó A for filho de algum outro nó $\mathrm{C}$ ele é removido da lista de filhos de C.

- Copiar um nó A para ser inserido como filho de um nó B.

- Definir um novo modelo principal a partir de um nó qualquer. Nesse, caso se existir um modelo principal ele será transformado em um modelo temporário.

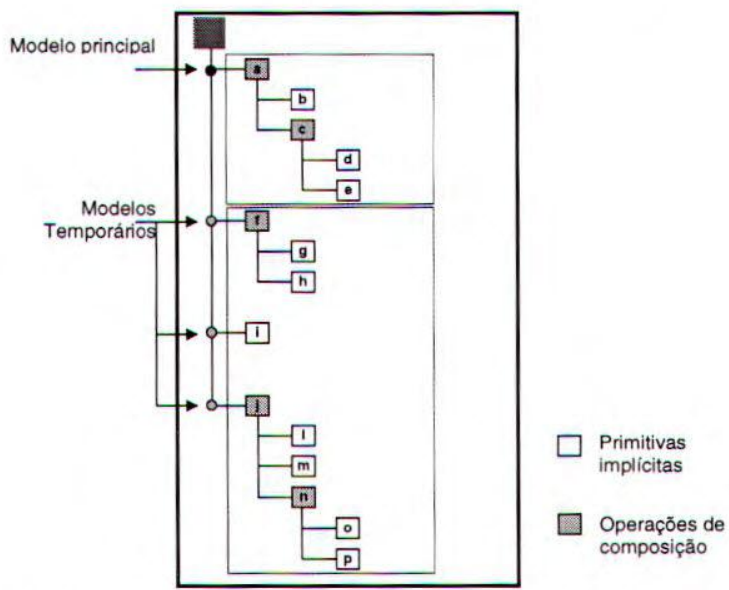

Figura 5.3 - exemplo de uma coleção de árvores implícitas manipuladas no editor.

Ao criar um novo nó, seja uma primitiva ou uma operação de composição, este novo nó é inserido na árvore implícita como um novo modelo temporário. $\mathrm{Na}$ definição de uma primitiva é possível alterar os valores de um conjunto de parâmetros a fim de obter variações da primitiva. A tabela 5.1 relaciona as primitivas pré-definidas disponíveis no Modelador e os seus parâmetros configuráveis. A manipulação das primitivas baseadas em esqueletos é apresentada na seção 5.3.2. Um parâmetro comum a todas as primitivas implícitas, e não apresentado na tabela 5.1, é o raio de blend que é utilizado apenas quando o modelo em construção suportar o blend pseudo-euclidiano.

Os nós que representam operações de composição são criados a partir da definição do tipo da operação, união, interseção ou diferença, e da indicação de dois operandos. Esses operandos, ou filhos, podem ser uma primitiva ou um modelo temporário, previamente construído. Outro parâmetro que 
pode ser definido durante a criação de uma operação de composição é o expoente de blend, caso o modelo em construção seja definido com algum tipo de blend.

Tabela 5.1 - parâmetros configuráveis das primitivas pré-definidas no Modelador.

\begin{tabular}{|c|c|c|}
\hline Primitiva & Descriçẫ. & Parâmetros configuráveis \\
\hline Esfera & $\begin{array}{l}\text { Primitiva definida por uma esfera centrada na origem definida } \\
\text { inicialmente com raio } 1(\mathrm{um}) \text {. }\end{array}$ & Raio \\
\hline Cilindro & $\begin{array}{l}\text { Primitiva definida por um segmento de cilindro definido } \\
\text { inicialmente com raio e altura iguais a } 1 \text { e } 2 \text { (um e dois) } \\
\text { respectivamente. O centro do cinlindro é a origem e sua } \\
\text { orientação é ao longo do eixo y. }\end{array}$ & $\begin{array}{l}\text { Raio } \\
\text { Altura }\end{array}$ \\
\hline Cone & $\begin{array}{l}\text { Primitiva definida por um cone orientado ao longo do eixo y } \\
\text { cujo vértice está localizado em }(0 \text {, Altura } 2,0) \text {. Inicialmente } \\
\text { definido com Altura igual a } 2 \text { (dois) e angulo de rotação igual a } \\
20^{\circ} \text {. }\end{array}$ & $\begin{array}{l}\text { Ângulo de rotação } \\
\text { Altura }\end{array}$ \\
\hline Toro & $\begin{array}{l}\text { Primitiva de finida por um toro centrado na origem com o } \\
\text { círculo de rotaçāo posicionado sobre o plano xz. Inicialmente o } \\
\text { Raio menor é igual a } 0.5 \text { e o Raio maior a } 1.0 \text {. }\end{array}$ & $\begin{array}{l}\text { Raio menor } \\
\text { Raio maior }\end{array}$ \\
\hline Superelipsóide & $\begin{array}{l}\text { Superfície definida por uma elipsóide modificada, ou } \\
\text { controlada, por dois expoentes. O primeiro expoente (expoente } \\
\text { xz) - controla o formato ao longo dos eixos } \mathbf{x} \text { e z, o segundo } \\
\text { (expoente y) controla o formato ao longo do eixo y. O centro } \\
\text { da superelipsóide e a origem e inicialmente os raios ao longo } \\
\text { dos eixos } \mathbf{x}, \text { y e z são iguais a } 1 \text { (um) e e os expoentes iguaia a } \\
0.5 \text {. }\end{array}$ & $\begin{array}{l}\text { Raios ao longo dos eixos } \bar{x} \\
\text { y e } z \\
\text { Expoentes } x z \text { e y }\end{array}$ \\
\hline Paralelogramo & $\begin{array}{l}\text { Paralelogramo centrado na origem com arestas paralelas aos } \\
\text { eixos coordenados. Inicialmente as arestas ao longo dos eixos } \\
\mathbf{x}, \mathbf{y} \in \mathbf{z}\end{array}$ & $\begin{array}{l}\text { Tamanho das arestas ao } \\
\text { longo dos eixos } \mathbf{x}, \text { y e } \mathbf{z}\end{array}$ \\
\hline
\end{tabular}

Além dos parâmetros para as primitivas, essas podem ser transformadas por operações de rotação, escala e translação. Essas transformações são aplicadas sobre as primitivas selecionadas, o que permite a alterar a posição, a orientação e a escala de uma ou de um conjunto de primitivas.

\subsubsection{Primitivas Baseadas em Esqueleto}

No capítulo 3 são apresentadas três formas de definir uma superfície a partir de um esqueleto: superficies eqüidistantes, superfícies eqüipotenciais e superfícies por convolução. A modelagem baseada em esqueleto implementada neste trabalho consiste em definir superfícies eqüidistantes a um elemento 
esqueletal. Um elemento esqueletal pode ser um ponto, uma linha definida por segmentos de reta adjacentes, ou um polígono planat. Cada elemento esqueletal define uma primitiva implícita, primitiva esqueletal, que é representada como um nó de uma átvore implícita e pode participar de operações de composição como as primitivas pré-definidas.

Uma primitiva esqueletal é definida a partir do range de um elemento esqueletal. O range de um elemento é um número real positivo que indica o seu raio de ação, ou seja, a distância entre a superfície e o elemento que a define. A seguir são apresentados os parâmetros configuráveis para cada elemento esqueletal.

\section{Primitivas definidas a partir de pontos}

Os parâmetros para a configuração de uma primitiva definida a partir de um ponto são as coordenadas e o range desse ponto. Essa primitiva é uma esfera centrada neste ponto e cujo raio é definido pelo range do ponto.

\section{Primitivas definidas a partir de linhas}

Uma linha é formada como uma seqüência de vértices no espaço tridimensional que define um conjunto de segmentos de reta adjacentes. Em uma linha cada vértice é associado a um range e a definição de um range no interior de um segmento é realizada por interpolação. A forma definiđa por uma linha é um cilindro generalizado, com os extremos arredondados e com o raio ao longo de um segmento vatiando conforme o range dos vértices extremos, a figura 5.4 ilustra uma forma definida por uma linha.
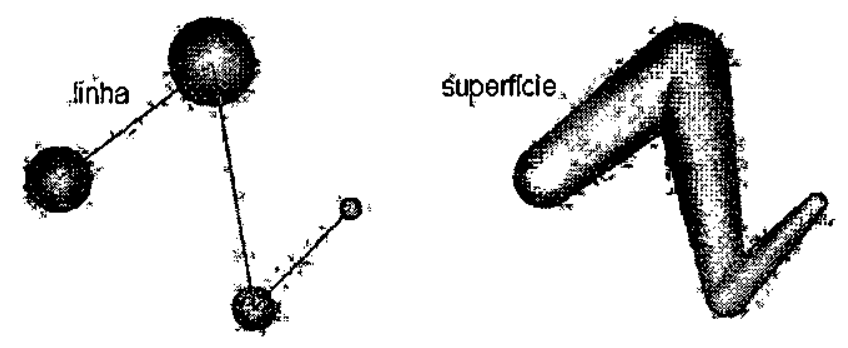

Figura 5.4 - forma definida por uma linha.

Os parâmetros de definição da linha e da primitiva que ela define são as coordenadas dos vértices da linha e os range de cada um. Estes parâmetros são modificados a partir de uma caixa de diálogo de definição da linha, que também permite adicionar e remover vértices. 


\section{Primitivas definidas a partir de polígonos planares}

Um polígono que define uma primitiva esqueletal é sempre definido no plano $\mathbf{x z}(\mathbf{y}=0)$. Associado a um poligono existe um range que define a primitiva. A forma desta primitiva é similar a uma superfície por offset, como mostra a figura 5.5.

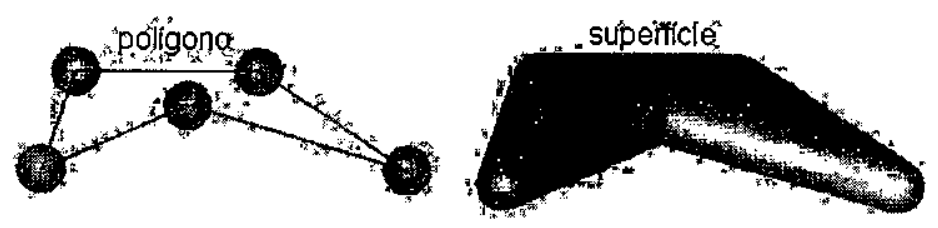

Figura 5.5 - forma definida por um poligono.

Os parâmetros de definição de um polígono são os vértices sobre o plano xz (apenas as coordenas $\mathrm{x} e$ $\mathbf{z}$ podem ser definidas) e o range do polígono.

Assim como as primitivas pré-definidas as primitivas esqueletais podem ser escalonadas, transladadas, e rotacionadas no espaço. Dessa forma a limitação de definir sempre um polígono sobre o plano xz é superada.

\subsubsection{Visualizador de Primitivas}

O Visualizador auxilia a atividade de modelagem permitindo visualizar as primitivas durante a construção do modelo. Desta forma as primitivas podem ser posicionadas, escalonadas e orientadas da melhor maneira para a construção do modelo implícito. $O$ Visualizador exibe as ptimitivas ativas e permite destacar as primitivas selecionadas. As primitivas são apresentas em três formas possíveis: em fio de arame (ivireframe) ou como uma superfície iluminada e com tonalização constante (flat shading) ou por interpolação de cores (gouraud shading).

O modo de apresentação das primitivas selecionadas pode diferit das demais primitivas ativas, ou seja, das primitivas ativas não selecionadas, o que toma possível destacar as primitivas selecionadas. $O$ Visualizador possui funções que permitem visualizar as primitivas de formas diferentes, estas funções são:

- a realização de operações de totação e zoom sobre a cena;

- a projeção da cena ortogonalmente ou em perspectiva;

- a remoção das primitivas ativas não selecionadas da cena; 
É importante destacar que o Visualizador de primitivas não apresenta o resultado da modelagem, ou seja, o resultado das operações de composição, mas apenas as primitivas que fazem parte do modelo ativo.

A função da Interface de Modelagem é a definição de um modelo implícito. Esse modelo é criado como uma composição de primitivas implícitas. Quando o modelo principal estiver concluído ele pode ser submetido à poligonalização. Essa tarefa é realizada pelo componente denominado Poligonalizador apresentado na próxima seção. Detalhes do funcionamento e da implementação da Interface de modelagem são apresentados no capítulo 6 .

\subsection{Poligonalizador}

O componente Poligonalizador é responsável pela conversão do modelo implícito em uma malha de polígonos que aptoxima a superfície. O Poligonalizador é composto por três módulos: o avaliador de função implícita, o método de poligonalização e o conversor para Brep, como mostra a figura 5.6.

$O$ avaliador de função implícita é responsável pela leitura do modelo implícito tegistrado em um arquivo, e pela a avaliação da função implícita em um ponto do espaço. Para realizat a avaliação o Poligonalizador monta uma estrutura de avaliação, apresentada no capítulo 7.

O método de poligonalização calcula a aproximação linear por partes do modelo implícito por meio da triangulação $f_{\mathrm{a}}^{1}$ e registra esta aproximação em uma estrutura chamada esqueleto combinatório. Este método de poligonalização é apresentado no capítulo 4. O conversor de brep converte o esqueleto combinatótio em uma brep-estendida, capítulo 4, e registra essa estrutura em um arquivo. A brepestendida pode apresentada com o Visualizador de Modelos Aproximados.

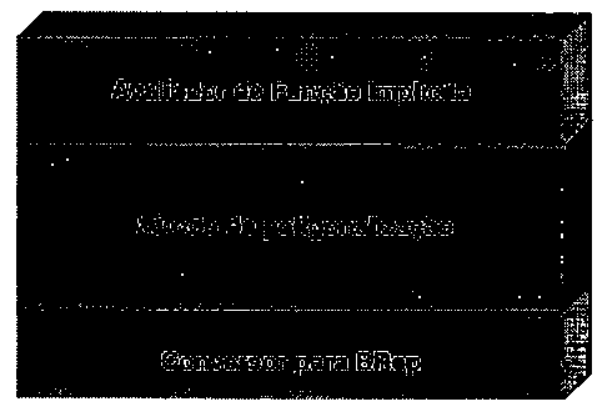

Figura 5.6 - módulos do Poligonalizador. 


\subsection{Visualizador de Modelos Aproximados}

O Visualizador de Modelos Aproximados é o componente mais simples do Modelador. Sua função é permitir a verificação do resultado da poligonalização de um modelo implícito. Basicamente esse componente recupera a brep-estendida registrada ao fim da poligonalização e apresenta os pseudosólidos nela registrados. Detalhes do funcionamento e da implementação desse componente são apresentados no capítulo 7. Seu o layout do visualizador é na figura 5.7. As suas principais funções são:

- a tealização de operações de rotação, zoom e translação sobre a cena;

- a apresentação dos pseudo-sólidos em projeção ortogonal e perspectiva;

- a facilidade de alterar a cor e o modo de apresentação de um pseudo-sólido. O modo de apresentação pode ser wireframe ou com superfície tonalizada com os métodos flat ou gouraud;

- a remoção de um pseudo-sólido da cena;

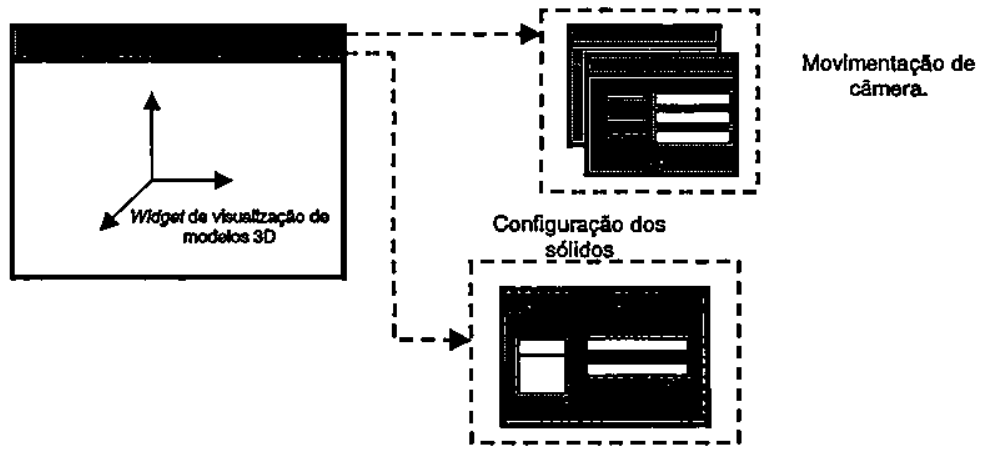

Figura 5.7 - Visualizador de Modelos Aproximados.

A próxima seção apresenta o ambiente de desenvolvimento utilizado no desenvolvimento do Modeladot, destacando as bibliotecas para construção da interface com o usuário e a de auxílio na apresentação de modelos tridimensionais.

\section{5:6 Ambiente de desenvolvimento}

A principal linguagem de desenvolvimento utilizada no Modelador é a linguagem $C$, bastante difundida tanto no meio acadêmico como no comercial de modo que esta seção não discutirá as características ou o uso dessa linguagem. Esta seção apresenta as bibliotecas que auxiliaram o desenvolvimento do Modelador, a biblioteca para apresentação de modelos tridimensionais, OpenGL, e a biblioteca para construção da interface gráfica com o usuário, Tcl/Tk. Esta seção auxilia a compreensão dos capítulos seguintes que aptesentam a implementação do Modeladot. 


\subsubsection{OpenGL}

OpenGL é um sistema gráfico que implementa uma interface entre uma aplicação e o hardware gráfico. Esse sistema está disponível na forma de uma biblioteca de programação, normalmente utilizada com a linguagem C, (Woo et al., 1997). Existe uma implementação livte (código fonte disponível) do OpenGL conhecida como Mesa3D (Mesa3D, 2000).

A interface implementada pelo OpenGL, entre a aplicação e o hardware gráfico, consiste de um conjunto de procedimentos e funções que permitem a um programador especificar os objetos e as operações que os envolvem, produzindo imagens de boa qualidade. OpenGL integra a manipulação de objetos 3D ao sistema de janelas e provê controle direto sobte operações gráficas fundamentais em duas e três dimensões. Dentre essas operações inclui-se a especificação de parâtmetros como matrizes de transformação e coeficientes de iluminação, métodos de antialiasing e operações sobre pixels. Entretanto, OpenGL não provê mecanismos para descrever ou modelar objetos geométricos complexos. Os modelos apresentados devem ser construídos como uma coleção de primitivas geométricas: pontos, segmentos de reta e polígonos convexos.

O uso de OpenGL no desenvolvimento do Modelador tem como função auxiliar a apresentação de modelos tridimensionais. Este auxílio é necessário no Visualizador de Primitivas e no Visualizador de Modelos Aproximados. Em ambos, o modelo a ser apresentado deve ser convertido em uma malha de polígonos e, em seguida, apresentado por funções do OpenGL. As características da biblioteca OpenGL mais interessantes ao desenvolvimento do Modelador são listadas a seguir.

Modo Imediato e Display list - os comandos da OpenGL podem ser executados imediatamente, ou armazenados em uma lista de comandos, display list, que é processada previamente e executada quando necessário. $O$ uso de display list permite uma execução mais eficiente, mas necessita que os comandos que fazem parte da lista não sejam alterados.

Buffer duplo - cada cena a ser apresentada pode armazenada em um buffer secundário antes da apresentação, o que permite uma transição suave entre duas imagens diferentes durante uma animação.

Materiais e luzes - os pontos de um polígono podem ser associados a propriedades materiais e podem ser definidas luzes na cena, o que permite um bom realismo nas cenas geradas.

Transformações geométricas tridimensionais - existem comandos do OpenGL que permitem a realização de operações de escala, rotação, translação e de projeção perspectiva ou ortogonal de objetos no espaço tridimensional. 
$Z$-buffer - z-buffer é um algoritmo implementado no OpenGL que determina a relação de proximidade dos objetos com a câmera que registra a cena. Esse algoritmo é importante para na remoção de superfícies escondidas.

Outros fatores influenciaram a escolha do OpenGL como sua eficiência, a boa documentação disponivel, tanto em forma de livros como pela Internet, e especialmente a facilidade de integrat a apresentação de cenas produzidas com OpenGL a interfaces gráficas construídas com Tcl/Tk como é apresentado na próxima seção.

\subsubsection{Tcl/Tk}

Esta seção apresenta a biblioteca de programação que auxilia a construção da interface gtáfica com o usuário, Tcl/Tk, são descritas suas principais características, os elementos para construção de interfaces e como integrar programas escritos em $\mathrm{C}$ com Tcl/Tk. Os conceitos aqui apresentados foram extraídos do livro "Practical Programming in Tcl and Tk" (Welch, 1997), exceto quando houver outras referências.

Tcl não é comumente referenciado como uma biblioteca de programação e sim com outtos dois significados, como uma linguagem de scripts $^{7}$ e como um interpretador para esta linguagem. $O$ uso de Tcl está, em geral, associado ao uso de seu toolkit para os sistemas de janelas, o Tk. Existem interpretadores $\mathrm{Tcl} / \mathrm{Tk}$ para as plataformas Unix, Windows e Macintosh. A linguagem Tcl pode ser vista como uma linguagem de programação procedimental, assim como outras linguagens para construção de scripts.

A referência do $\mathrm{Tcl} / \mathrm{Tk}$ como biblioteca de programação é devido à possibilidade de integração de procedimentos escritos em $\mathrm{C}$ com scripts $\mathrm{Tcl} / \mathrm{Tk}$ através de bibliotecas de progtamação que implementam o núcleo de funções do $\mathrm{Tcl} / \mathrm{Tk}$. Essas bibliotecas estão disponíveis em todas as plataformas que possuem interpretadores Tcl/Tk. Uma aplicação construída com essa integração funciona como um novo interpretador $\mathrm{Tcl} / \mathrm{Tk}$ que além das funções básicas do $\mathrm{Tcl} / \mathrm{Tk}$ pode utilizar novas rotinas implementadas em $\mathrm{C}$ que são exportadas como comandos do $\mathrm{Tcl} / \mathrm{Tk}$.

A figura 5.8 ilustra como é a organização do código de uma aplicação escrita com Tcl/Tk e C. O código da aplicação escrito em $\mathrm{C}$ pode ser dividido em duas partes distintas: uma responsável pelo núcleo da aplicação e outra responsável pela inicialização da aplicação. O núcleo da aplicação é a 
implementação das rotinas escritas em $\mathrm{C}$, getalmente responsáveis pelas computações mais catas. A inicialização utiliza funções da biblioteca de programação Tcl/Tk pata criar um interpretador Tcl/Tk e para exportar as rotinas implementadas em $\mathrm{C}$ como comandos Tcl/Tk. Também na inicialização é definido o script principal responsável pelo controle em alto nível da aplicação.

$\mathrm{O}$ código da aplicação escrito em Tcl/Tk, o script principal, funciona como o módulo principal da aplicação responsável pela interação com o usuário e pela coordenação das funções, ou módulos, que compõem a aplicação. O script principal pode utilizat todas as facilidades dos scripts $\mathrm{Tcl} / \mathrm{Tk}$ como acesso ao sistema de arquivos e execução de outros programas, além de utilizar os comandos implementados no núcleo da aplicação. Em particular, a facilidade de execução de outros programas a partir de uma aplicação escrita com Tcl/Tk foi muito atraente para a implementação dos componentes do Modelador como programas independentes.

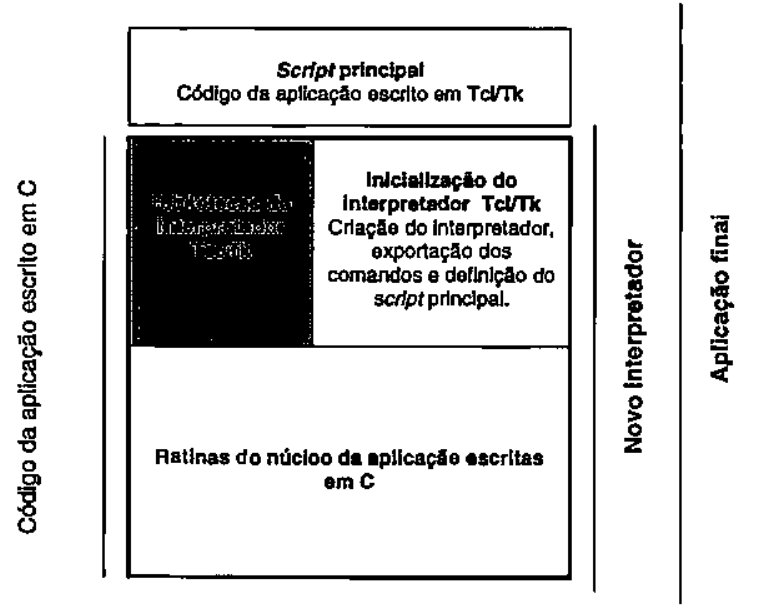

Figura 5.8 - arquitetura de uma aplicação escrita em C e Tcl.

A seguir são apresentadas algumas características do Tcl/Tk: como as estruturas de listas e de arrays, elementos de interface (widgets) do Tk e a extensão do $\mathrm{Tcl} / \mathrm{Tk}$ que permite a apresentação de cenas tridimensionais em interfaces implementadas com $\mathrm{Tcl} / \mathrm{Tk}$.

\section{Listas e Arrays em Tcl}

A estrutura básica da linguagem $\mathrm{Tcl}$ é a string. Adicionalmente, existem duas estruturas de alto nível definidas a partir das strings. as listas e arrays.

\footnotetext{
7 Script é uma seqüência de comandos de linguagem interpretada, são comuns na execução de tarefas rotineiras e na instalação de sistemas.
} 
A estrutura de dados lista em Tcl é definida como uma string com uma interpretação especial. A lista é representada por uma string onde seus elementos são separados por espaços em branco. Para representar elementos que possuem espaços em bancos são utilizados pares de chaves ou aspas duplas para delimitá-los. Através desses delimitadores podem ser definidas listas genéricas, ou listas de listas. Tcl possui uma variedade de comandos para a manipulação de listas permitindo a inserção e remoção de elementos assim como a classificação e a busca de elementos. Alguns exemplos de listas são apresentados a seguir. O comando set utilizado define uma variável, ou a redefine caso já exista, sua sintaxe é set variável valor.

(1) set lista "laranja limao acerola"

(2) set lista "goiaba banana \{laranja limao acerola\} carambola"

em (1) é criada uma lista de 3 elementos e em (2) a lista possui 4 elementos sendo que o terceiro elemento é uma lista com três elementos.

A outra estrutura de alto nível são os arrays. Um array é uma variável indexada por strings e cujos valores de cada elemento também são strings. Logo, um array pode ser entendido como um mapeamento de strings para strings. Internamente um array em Tcl é implementado como uma tabela bash (Langsam et al., 1996) o que permite um acesso uniforme aos seus elementos.

Para construit um array é necessário definir cada um dos seus elementos através do comando set e para remover qualquer um desses elementos basta utilizar o comando unset. Uma característica interessante do array em Tcl é o seu funcionamento como uma estrutura dinâmica, ou seja, novos elementos podem ser criados ou removidos a qualquer momento em um array. Veja o exemplo apresentado a seguir.
(1) set numeros (zero) 0
(2) set numeros (um) 1
(3) set numeros (dois) 2
(4) set numeros(tres) 3
(5) unset numeros (zero)

$\mathrm{Na}$ linha (1) é definido um array numeros com um elemento cujo índice é "zero" e seu valor é "0"; nas linhas (2), (3) e (4) são definidos, ou inseridos, outros três elementos no array numeros; por fim, na linha (5) é removido o elemento cujo índice é "zero".

\section{Widgets do Tk}

Widgets são janelas utilizadas na construção de interfaces gráficas com o usuário e que possuem uma determinada aparência e comportamento como, por exemplo, botões, labels, caixas de entrada de texto e barras de rolagem. O Tk é uma extensão do Tcl que implementa um conjunto de comandos para: 
- a criação e a configuração das widgets,

- o posicionamento das widgets na interface, $\mathrm{e}$

- a definição de scripts ativados quando o usuário executa uma ação na interface, através do mecanismo de binding.

Ao construir uma aplicação que utiliza o Tk, essa toolkit cria uma janela principal. A medida que são definidas outras widgets nessa aplicação é definida uma hierarquia de widgets. As widgets criadas são descendentes da janela principal e são chamadas de janelas internas pata refletir o fato de aparecem dentro da área da janela principal. Entretanto aplicações freqüentemente necessitam criar widgets que não estarão dentro da janela principal, por exemplo uma caixa de diálogo. Nesse caso, Tk fornece um terceiro tipo de janela chamada top-level. As Widgets desse tipo aparecem como internas na hierarquia de definição, mas sua janela não é criada dentro da janela principal.

Além das widgets comuns como botões e caixas de entrada de texto, Tk oferece a widget canvas que possui várias características interessantes ao desenvolvimento da Interface de Modelagem. Essa widget mostra uma janela de desenho, onde podem ser apresentados vários itens gráficos e textos e outras widgets encaixadas. Os itens do canvas podem ser criados e apagados a qualquer momento e seus atributos podem ser modificados dinamicamente. Os itens de uma canvas podem ser marcados por tags. Tags são strings associadas a um item e utilizadas para configuração do item e para definir bindings. A figura 5.9 apresenta um exemplo do uso de canvas com alguns elementos gráficos, textos e widgets encaixadas.

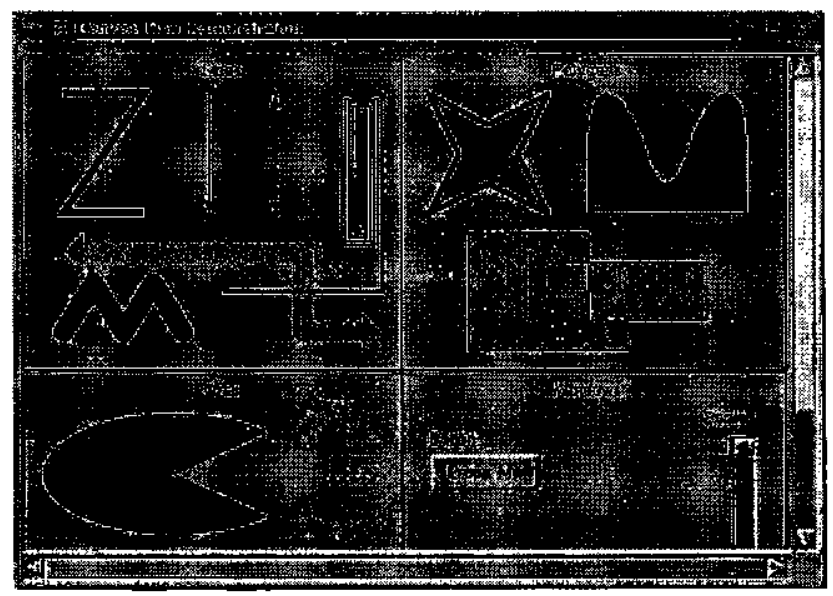

Figura 5.9 - exemplo da widget canvas do TK, (Tcl Consortium, 2000).

\section{Gerenciamento de eventos do Tk}

Uma aplicação construída com $\mathrm{Tcl} / \mathrm{Tk}$ tem seu fluxo de controle dirigido pelos eventos devido à ação do usuário na interface. Geralmente esses eventos estão associados ao mouse ou ao teclado comó, por 
exemplo: mouse em movimento, botão direito do mouse pressionado, tecla $\angle A>$ pressionada, tecla $<$ Shift> liberada, assim por diante.

Os eventos sempre são associados a uma widget da interface, a widget em foco, e podem ser associados também a uma ação definida por um script $\mathrm{T}$ cl. A associação entre um widget, um evento e um script $\mathrm{Tcl}$ recebe o nome de binding. Alguns bindings são pré-definidos como nos botões e nos menus associados a scripts $\mathrm{Tcl}$ que são executados quando houver um clique do botão direito do mouse sobre eles. Outros bindings podem ser criados ou redefinidos a partir do comando bind do $\mathrm{Tcl} / \mathrm{Tk}$. O Tk registra os binding em uma tabela utilizada na recuperação e no gerenciamento dos scripts.

Além de associar eventos e scripts a uma widget o mecanismo de binding permite realizar essa associação com tags. As tags podem ser utilizadas para referenciar um conjunto de widgets ou um conjunto de elementos de um texto (widget text) ou de um desenho (widget canvas) de forma que podem ser criados hipertextos e hipergráficos em interfaces implementadas com Tcl/Tk.

Quando um evento ocorre, ele é inserido em uma fila de eventos. Os eventos são processados um a um por um loop infinito denominado loop de eventos. A figura 5.10 ilustra esse processo que utiliza a tabela de bindings para recuperar o script associado com o evento e a widget em foco.

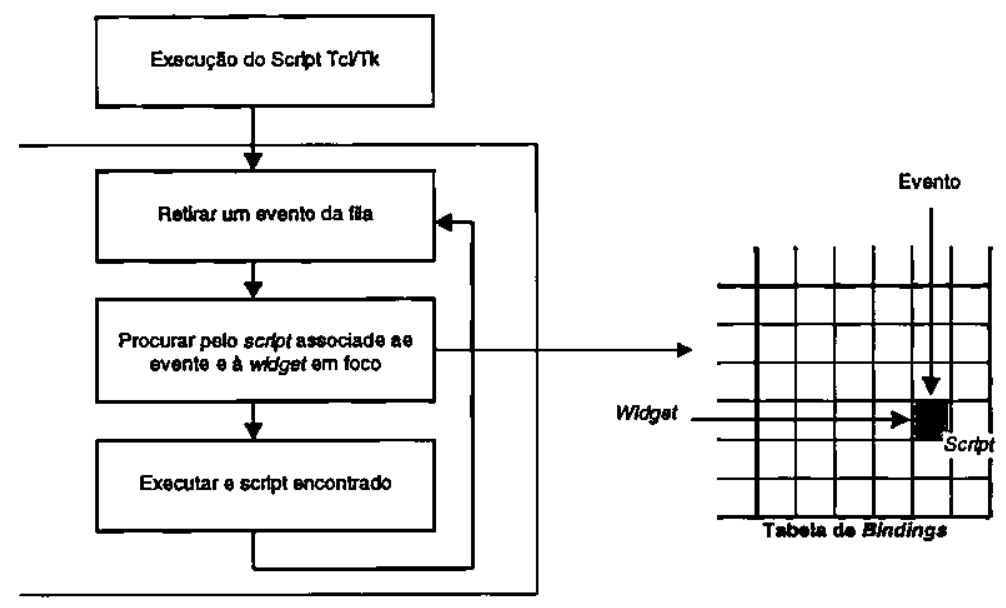

Figura $5.10 \rightarrow$ loop de eventos do Tk.

\section{Togl}

Dentre as diversas extensões de $\mathrm{Tcl} / \mathrm{Tk}$, existe uma para a apresentação de modelos gráficos bidimensionais e tridimensionais renderizados com OpenGL conhecida como Togl. Togl é uma widget desenvolvida por Brian Paul e Benjamim Bederson (Togl, 2000). Essa widget fornece uma janela onde podem ser apresentadas cenas renderizadas com OpenGL e pode ser posicionada e responder a eventos como outras widgets do Tk. 
No desenvolvimento de um aplicativo com a widget Togl é necessário integrar $\mathrm{Tcl} / \mathrm{Tk}$ e $\mathrm{C}$. O código Tcl/Tk é responsável pela interface com o usuário inclusivc para criação e posicionamento da vidget Togl. O código escrito em linguagem $C$ utiliza as funções da OpenGL para computar a renderização da cena a ser apresentada da widget Togl. Ao utilizar a Togl devem ser especificadas quatro funções invocadas na ocorrência de eventos especiais, essas funções são:

- Uma função de criação utilizada na inicialização da widget Togl, essa função é útil para iniciar a estrutura de dados que representa o modelo a ser tenderizado e para definir os valores iniciais dos parâmettos da cena, como luzes e materiais.

- Uma função de remoção ou destruição que é invocada quando a widget Togl for destruída. Essa função pode ser utilizada para remover da memória alguma estrutura de dados auxiliar ou para registrar os últimos valotes dos parâmetros da rendetização.

- Uma função de desenho (display) utilizada para tenderizar a cena. Essa função é invocada automaticamente quando a janela que contém a Togl for ativada. Além disso, quando o modelo que está sendo renderizado for alterado o código da alteração deve invocar a função de desenho para atualizar a cena.

- Uma função de definição da viewport (reshape) utilizada para definir, ou redefinir, a viewport onde a cena será apresentada e para definir os limites da cena (volume de projeção). Essa função é invocada sempre que o tamanho da widget $T$ ogl for alterado.

Além dessas funções o desenvolvedor pode implementar no núcleo da aplicação procedimentos para alterar os parâmetros da cena como luzes e posição da câmera e para transformar, ou alterar, o modelo que está sendo apresentado. Esses procedimentos podem ser exportados e utilizados nos scripts Tcl/Tk.

\subsubsection{Algumas considerações sobre o ambiente de desenvolvimento}

As bibliotecas que auxiliam o desenvolvimento são utilizadas de forma diferentes em cada um dos componentes do Modelador. Na Interface de Modelagem e no Visualizador de Modelos Aproximados são utilizados scripts $\mathrm{Tcl} / \mathrm{Tk}$ para a construção das janelas da interface e a linguagem $\mathrm{C}$ para implementar os procedimentos de render com OpenGL e para manter a estrutura de dados que contenha as informações do modelo tridimensional. A apresentação desses modelos na interface com o usuário é realizada com a widget Togl. Já na implementação do Poligonalizador é utilizado apenas a linguagem $C$.

A principal desvantagem de programas desenvolvidos com linguagens interpretadas é a baixa eficiência. Entretanto, uma interface desenvolvida $\mathrm{em} \mathrm{Tcl} / \mathrm{Tk}$ não é ineficiente a ponto de dificultar a interação do 
usuário com a aplicação. Outro ponto negativo também se deve ao fato de Tcl ser uma linguagem interpretada, o que obriga a execução de todo o código para assegurar que não existe erro de sintaxe. Mas, podem ser destacados três pontos favoráveis ao uso do Tcl/Tk no desenvolvimento da interface gráfica com o usuário:

- desenvolvimento da interface não requer a etapa de compilação, ou seja, o desenvolvedor pode codificar e testar diretamente a interface;

- a manipulação das widgets attavés do Tk é mais simples do que pelas toolkits mais difundidas, Motif e Xview;

- a aplicação pode ser dividida em software de interface e software que implementa a funcionalidade do sistema o que facilita a localização e a correção de eventuais erros na aplicação.

\subsection{Considerações finais}

Este capítulo apresentou a arquitetura do Modelador descrevendo os três componentes que o constitui: a Interface de Modelagem, o Poligonalizador e o Visualizador de Modelos Aproximados. Foi apresentado também como esses módulos cooperam entre si para realizar a modelagem.

Além da arquitetura do Modelador foi apresentado o ambiente de desenvolvimento do Modelador, descrevendo o uso de Tcl/Tk e OpenGL. Tcl/Tk é utilizada para a implementação da interface com o usuário e OpenGL é utilizada para auxiliar a apresentação dos modelos tridimensionais ao usuário do Modelador. A integração da linguagem C, da Tcl/Tk e da OpenGL foi apresentada.

Os próximos dois capítulos descrevem a implementação dos componentes do Modelador, destacando as estruturas de dados para representar os modelos tridimensionais e as funções disponíveis na interface com o usuário. 


\section{Capítulo 6 - Interface de Modelagem}

\subsection{Considerações Iniciais}

Este capítulo apresenta a Interface de Modelagem, principal componente do Modelador e responsável pela definição do modelo implícito. São apresentadas as funções que a interface oferece para a definição de um modelo implícito e descritas as estruturas de dados para representar a árvore implícita.

A aparência visual da Interface de Modelagem foi implementada em Tcl/Tk e sua versão atual é apresentada na figura 6.1, que mostra a definição de um modelo implícito de uma caneca. Nessa figura são observados o Editor de Árvores Implícitas e o Visualizador de Primitivas.

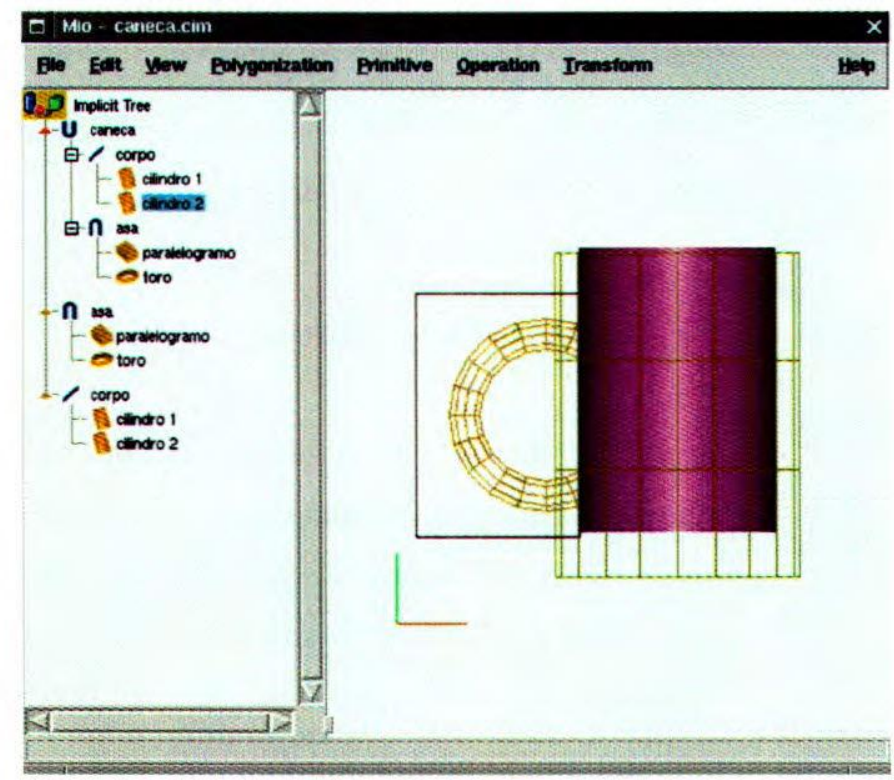

Figura 6.1 - interface com o usuário do componente Interface de Modelagem.

Este capítulo está organizado da seguinte forma a seção 6.2 descreve a estrutura da árvore implícita; a seção 6.3 apresenta as funções que estão disponíveis na interface com o usuário destacando o Editor de Árvores Implícitas e Visualizador de Primitivas. A seção 6.4 apresenta a edição das primitivas 
esqueletais. A seção 6.5 descreve como a Interface de Modelagem interage com os outtos componentes do Modelador, e por fim, a seção 6.6 apresenta as considerações finais deste capítulo.

\subsection{A Representação da Árvore Implícita}

O Modelador permite manipular uma coleção de árvores implícitas. Essa coleção é representada através de duas estruturas de dados: um array do Tcl e uma tabela bash auxiliar implementada em $\mathrm{C}$. $\mathrm{O}$ array do Tcl é referenciado neste texto como iTreeTcl e a tabela bash, como iTreeC. A iTreeTcl é responsável por manter a topologia de árvore das árvores implícitas da coleção e registrar os parâmetros das primitivas e das operações de composição. A iTreeC é utilizada para registrar as transformações das primitivas e auxiliar a apresentação das primitivas durante a modelagem. Nesta seção inicialmente é descrita a estrutura iTreeTcl, e em seguida é apresentada a iTreeC.

\subsubsection{A Árvore Implícita em TCL}

A iTreeTcl possui dois conjuntos de entradas distintos, um responsável por registrar os nós das árvores implícitas e outto por registtar informaçōes da configuração da coleção. Cada entrada da iTreeTcl possui um identificador único utilizado como índice. Para as enttadas que registram as informações de configuração, os identificadores são strings que indicam a informação registrada. A tabela 6.1 apresenta as informações de configuração da coleção de árvores implícitas.

Tábela 6.1 - informaçōes de coníiguração da coleçāo de árvores implícitas.

\begin{tabular}{|c|c|}
\hline Entradada TreeTcl ** & Descrico \\
\hline ItreeTcl (MainIndex) & $\begin{array}{l}\text { identificador do nó raiz da árvore implícita que representa o modelo } \\
\text { principal. Caso nāo exista um modelo principal seu valor é }-1 \text {. }\end{array}$ \\
\hline ItreeTcl(ListofTemp) & $\begin{array}{l}\text { lista com os identificadores dos nós que são raizes dos modelos temporários. } \\
\text { Essa entrada é definida como uma lista vazia caso não existam modelos } \\
\text { temporários. }\end{array}$ \\
\hline ItreeTcl (LastIndex) & $\begin{array}{l}\text { Identificador no último no criado, inicialmente seu valor é -1. Essa entrada é } \\
\text { utilizada para assegurar que cada nó criado possui um indetificador que é } \\
\text { único em toda coleção de árvores implícitas. }\end{array}$ \\
\hline ItreeTcl(win) & Identificador da janela onde o Editor de Árvores Implícitas é apresentada. \\
\hline ItreeTcl (Selection) & Identificador do no selecionado. \\
\hline ItreeTcl (Rootofselection) & $\begin{array}{l}\text { Identificador do nó raiz do modelo onde está o nó selecionado, ou seja, o nó } \\
\text { raiz da árvore que representa o modelo ativo. }\end{array}$ \\
\hline
\end{tabular}


As entradas da iTreeTcl que representam os nós de uma árvore implícita são indexadas por identificadores seqüenciais. Cada entrada da iTreeTcl que representa um nó é uma lista. Essa lista possui oito elementos que registram informações, como o tipo do nó, a lista de parâmetros do nó e a lista dos filhos do nó, a descrição desses elementos é apresentada na tabela 6.2 .

Tabela 6.2 - parâmetros dos nós de uma árvore implícita.

\begin{tabular}{|c|c|c|}
\hline rdem & Elemento & Descrição \\
\hline $1^{\circ}$ & dor-Id & Número inteiro que identifica o n6, utilizado para indexar o n6 na iTreeTcl. \\
\hline $2^{\circ}$ & Tipo & $\begin{array}{l}\text { String que indica o tipo do n6. Para as primitivas, os valores pOSSíveis São: SPHERE, } \\
\text { CONE, CXIINDER, TORUS, SUPERIILIPSOID, PARALLELOGRAM, SKELPOINT, } \\
\text { SKRLIINE, e SKELPOLYGON, indicando respectivamente se o nó é uma esfera, cone, } \\
\text { cilindro, toro, superelips6ide, paralelogramo, uma primitiva esqueletal baseada em } \\
\text { ponto, em linha ou em polígono. Para as operações seus valores podem ser: UNIABs, } \\
\text { INTABs, DIFABs, UNIBGL, INTBGL, DIFBGL, UNIBEL, INIBEL e DIFBEL. } \\
\text { Esses identificadores seguem um padrão: os três primeiros caracteres identificam a } \\
\text { operação (UNI - união, INT - interseção e DIF - diferença) e os três últimos identificam } \\
\text { o tipo de blend utilizada na operação (ABS - nenhum, BGL - global e BEL - psuedo- } \\
\text { euclidiano). }\end{array}$ \\
\hline $3^{\circ}$ & Rótulo - Label & String utilizada para rotular o nó. \\
\hline $4^{\circ}$ & Pai & $\begin{array}{l}\text { Número inteiro que indica o identificador do nó pai. Se o no representado for um nó raiz } \\
\text { de uma árvore implícita então seu valor } 6-1 \text {. }\end{array}$ \\
\hline $5^{\circ}$ & Filhos & $\begin{array}{l}\text { Lista de filhos. Esse elemento é representado como uma lista vazia para as primitivas e } \\
\text { como uma lista com no mínimo dois números para as operações de composição. Cadá } \\
\text { número dessa lista } e \text { um identificador para um nó operando. }\end{array}$ \\
\hline $6^{\circ}$ & $\begin{array}{l}\text { Parâmetros - } \\
\text { Params }\end{array}$ & $\begin{array}{l}\text { Lista de parâmetros. O conteúdo desse elemento depende do tipo do nó representado. A } \\
\text { relação entre os parâmetros e o tipo do elemento é apresentada na tabela } 6.3 \text {. }\end{array}$ \\
\hline $7^{\circ}$ & $\begin{array}{l}\text { Raio de blend - } \\
\text { RB }\end{array}$ & $\begin{array}{l}\text { Número real que indica o raio de blend de uma primitiva. Caso nó representado seja } \\
\text { uma operação de composição esse parâmetro é definido como uma lista vazia. }\end{array}$ \\
\hline $8^{\circ}$ & Cor & $\begin{array}{l}\text { String que representa a cor de uma primitiva e para as operações é representada com } \\
\text { uma lista vazia. A string é formada por sete caracteres seguindo o padrao do Tk para } \\
\text { representar cores, a saber: "\#RRGGBB", onde RR, GG e BB representam númerais } \\
\text { hexadecimais de dois digitos, logo valores entre } 0(00) \text { e } 255 \text { (FF), que representam a } \\
\text { cor no sistema RGB. }\end{array}$ \\
\hline
\end{tabular}

Pela tabela 6.2 observa-se que em uma entrada da iTree'Tcl que representa um nó dois elementos são definidos como listas, os parâmetros e os filhos do nó. A lista de filhos é o elemento que permite a representação de uma estrutura de átvore em um array. Para os nós que representam primitivas 
implícitas essa lista é vazia e para os nós que representam operações de composição ela.é formada pela lista de identificadores dos nós que representam seus operandos, nesse caso deve possuir no mínimo dois identificadores. Cada número na lista de filhos funciona como um apontador para um nó operando de forma que é possível realizar um percurso do nó raiz para os nós folhas através da lista de filhos. Para realizar o percurso na ordem inversa é utilizado o elemento Pai, que funciona como um apontador de um nó operando para o nó que representa a operação.

A lista de parâmetros é definida conforme o tipo do nó. A tabela 6.3 apresenta a lista de parâmetros conforme o tipo do nó representado.

Tabela 6.3 - identificadores dos tipos dos nós da árvore implícita e suas listas de parâmetros.

\begin{tabular}{|c|c|c|}
\hline Identificador do tipo & Descriçáo & Lista de paraimetros \\
\hline SPEERRE & Esfera & - Raio \\
\hline CYLINDER & Cilindro & $\begin{array}{ll}- & \text { Raio } \\
- & \text { Altura }\end{array}$ \\
\hline CONE & Cone & $\begin{array}{l}\text { - Ângulo de rotação } \\
\text { - Altura }\end{array}$ \\
\hline TORUS & Toro & - $\quad$ Raio menor e maior \\
\hline SUPERELISOID & Superelipsóide & $\begin{array}{l}-\quad \text { Raios nos eixos } x, \text { y e z } \\
-\quad \text { Expoentes xz e y }\end{array}$ \\
\hline PARALLILOGRAY & Paralelogramo & - Tamanhos das arestas em $\mathbf{x}, \mathbf{y}$ e $\mathbf{z}$ \\
\hline SKELPOINI & $\begin{array}{l}\text { Primitiva esqueletal } \\
\text { baseada em ponto }\end{array}$ & $\begin{array}{l}\text { - Coordenadas do ponto } \\
\text { - Range do ponto }\end{array}$ \\
\hline SKRLLINE & $\begin{array}{l}\text { Primitiva esqueletal } \\
\text { baseada em linha }\end{array}$ & $\begin{array}{l}\text { - Número de pontos que define a linha (mínimo 2) } \\
\text { - Lista com as coordenadas dos pontos que definem a linha } \\
\text { - Lista com os ranges de cada ponto que define a linha } \\
\text { - Flag que indica se a linha é fechada ou não. }\end{array}$ \\
\hline SKELPOLYGON & $\begin{array}{l}\text { Primitiva esqueletal } \\
\text { baseada em polígono }\end{array}$ & $\begin{array}{l}\text { - Número de pontos do polígono (mínimo 3) } \\
\text { - Lista com as coordenadas } \mathrm{x} \text { e } \mathrm{z} \text { dos pontos do polígono } \\
\text { - } \quad \text { Range do polígono }\end{array}$ \\
\hline $\begin{array}{l}\text { UNIBGL, INIBGL, } \\
\text { DIPBGL, ONIBEL, } \\
\text { INIBEL D DIFBEL }\end{array}$ & $\begin{array}{l}\text { Operações com } \\
\text { blend }\end{array}$ & - Expoente da equação de blend. \\
\hline $\begin{array}{l}\text { UNIABS, INTABS } \\
\text { DIFABS }\end{array}$ & $\begin{array}{l}\text { Operações Sem } \\
\text { blend }\end{array}$ & - \\
\hline
\end{tabular}


Para exemplificar a estrutura do array iTreeTcl, a figura 6.2 apresenta uma coleção de árvores implícitas. Essa coleção possui três modelos, um principal e dois temporários, definindo uma caneca. O modelo principal é definido como a união de uma cópia do modelo temporário as a com uma cópia do modelo temporário corpo.

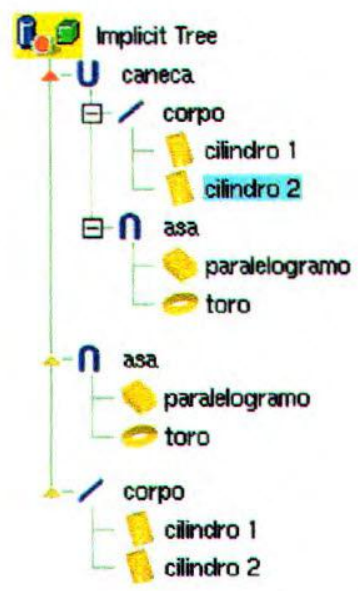

Tabela 6.4 - informações de configuração de uma árvore implícita exemplificada.

\begin{tabular}{|ll|}
\hline Entradas & Valor \\
\hline iTreeTcl (LastIndex) & 22 \\
\hline iTreeTcl (MainIndex) & 16 \\
\hline iTreeTcl (TempModelsList) & 49 \\
\hline iTreeTcl (Win) & .pw.pane1.iTree \\
\hline iTreeTcl (Selection) & 19 \\
\hline iTreeTcl (RootofSelection) & 16 \\
\hline
\end{tabular}

Figura 6.2 - exemplo de coleção de árvores implícitas.

Tabela 6.5 - representação da uma árvore implicita exemplificada em um array do Tcl.

\begin{tabular}{|c|c|c|c|c|c|c|c|c|}
\hline Entradas & Id & Tipo & Label & Pai & Filhos & Params & RB & Cor \\
\hline iTreeTcl (3) & 3 & PARALLELOGRAM & paralelogramo & 4 & \{\} & $\left\{\begin{array}{lll}2 & 3 & 2\end{array}\right\}$ & 0.2 & $\# 400 \mathrm{c} 00$ \\
\hline iTreeTcl (4) & 4 & INTABS & asa & -1 & $\{36\}$ & 2 & 0.0 & \{\} \\
\hline iTreeTcl (6) & 6 & TORUS & toro & 4 & \{\} & $\{0.21\}$ & 0.04 & $\# \mathrm{~b} 07 \mathrm{a} 00$ \\
\hline iTreeTcl (7) & 7 & CYLINDER & $\{c i l i n d r o 1\}$ & 9 & \{\} & $\{1.54\}$ & 0.2 & $\# 788800$ \\
\hline iTreeTcl (8) & 8 & CYLINDER & $\{c i l i n d r o 2\}$ & 9 & \{\} & $\{1.23 .5\}$ & 0.2 & $\# \mathrm{f} 700 \mathrm{fe}$ \\
\hline iTreeTcl (9) & 9 & DIFABS & corpo & -1 & $\left\{\begin{array}{ll}7 & 8\end{array}\right\}$ & 2 & 0.0 & \{\} \\
\hline iTreeTcl (16) & 16 & UNIBGL & caneca & -1 & $\{1720\}$ & 10 & 0.0 & \{\} \\
\hline iTreeTcl (17) & 17 & DIFBGL & corpo & 16 & $\left\{\begin{array}{ll}18 & 19\end{array}\right\}$ & 20 & 0.0 & \{\} \\
\hline iTreeTcl (18) & 18 & CYLINDER & $\{c i l i n d r o 1\}$ & 17 & \{\} & $\{1.54\}$ & 0.2 & \#788800 \\
\hline iTreeTcl (19) & 19 & CYLINDER & $\{c i l i n d r o 2\}$ & 17 & \{\} & $\{1.23 .5\}$ & 0.2 & $\# f 700 \mathrm{fe}$ \\
\hline iTreeTcl (20) & 20 & INTBGL & asa & 16 & $\left\{\begin{array}{ll}21 & 22\end{array}\right\}$ & 10 & 0.0 & \{\} \\
\hline iTreeTcl (21) & 21 & PARALLELOGRAM & Paralelogramo & 20 & \{\} & $\left\{\begin{array}{lll}2 & 3 & 2\end{array}\right\}$ & 0.2 & $\# 400 \mathrm{c} 00$ \\
\hline iTreeTcl (22) & 22 & TORUS & Toro & 20 & \{\} & $\{0.21\}$ & 0.04 & $\# 0000$ ff \\
\hline
\end{tabular}

A representação dessa coleção (figura 6.2) na iTreeTcl são indicadas nas tabelas 6.4 e 6.5 que representam respectivamente as informações de configuração e as representações dos nós. Pelas informações de configuração sabe-se que o nó raiz do modelo principal é o nó 16 e existem dois 
modelos temporários um cuja raiz é o nó 4 e outro o nó 9 . Através da representação dos nós sabe-se que:

- o nó 16 possui o tótulo caneca e representa uma operação de união com blend global (JNIBGI), cujo expoente é10, entre os nós 17 e 20;

- o nó 20 possui o tótulo asa e representa uma interseção com blend global (INTBGL), cujo expoente é 20 , entre os nós 21 e 22;

- o nó 22 possui o tótulo toro e representa um toro (TORUs), cujo taio maior é 1 e o raio menot 0.2, o taio de blend dessa primitiva é 0.04 e sua cot é um azul intenso (\#0000ff).

\subsubsection{A Estrutura Auxiliar da Árvore Implícita}

A Interface de Modelagem é responsável por duas tarefas que se tornam ineficientes se realizadas por rotinas implementadas em Tcl: as transformações geométricas e a renderização das primitivas implícitas durante a modelagem. Para torna-las mais eficiente essas rotinas foram implementadas em linguagem $\mathrm{C}$.

As rotinas implementadas em $C$ poderiam acessar os dados armazenados na iTreeTcl através de funções da biblioteca de progtamação do Tcl. Mas como a representação dos dados em Tcl é sempre por strings esse acesso é ineficiente pois envolve procura de dados dentro de strings e conversão de strings para valores numéricos. Dessa forma, foi construída uma estrutura de dados escrita em $C$ para o controle das transformações geométricas e da renderização de primitivas que é uma tabela hash como apresentado a seguir.

A Interface de Modelagem permite a realização de translações, rotações e de escalonamentos sobre as primitivas. Essas transformações geométricas são úteis especialmente para as primitivas pré-definidas que são criadas com uma posição e orientação fixa. É necessátio que cada primitiva possua um registro das transformações que ela sofreu durante a definição do modelo implícito. A forma mais usual de representar as transformações geométricas são as matrizes de transformações (Heam \& Baker, 1997).

As transformações geométricas envolvem multiplicações de matrizes e são realizadas freqüentemente durante a modelagem. Tcl não é uma boa linguagem para tratar tipos ou funções matemáticas que envolvam ponto flutuante. Assim, as rotinas responsáveis pelas transformações geométricas foram implementadas em C e uma das funções da estrutura auxiliar é armazenar a matriz de transformação de cada primitiva construída durante a modelagem.

Outra tarefa difícil de ser implementada em Tcl é a renderização de primitivas, especialmente por essa linguagem não fornecer nenhum suporte à apresentação ou representação de modelos tridimensionais. 
Como descrito no capítulo 5, as rotinas para apresentação de modelos tridimensionais são implementados em C com o auxilio da biblioteca OpenGL. Para renderizar as primitivas durante a modelagem, é necessário, além das transformações geométricas, conhecer os parâmetros de definição de cada primitiva. Esses parâmetros são armazenados na iTreeTcl, mas por questão de eficiência optouse por replicá-los na estrutura auxiliar de forma que as rotinas de renderização utilizem somente essa estrutura.

A estrutura auxiliar é uma tabela bash implementada em $C$ que armazena as primitivas das árvores implícitas. Cada primitiva é representada pelos parâmetros de sua definição, pela sua matriz de transformação, pela sua cor e pelo seu bounding-box $x^{8}$. Essa tabela bash e referenciada neste texto como iTreeC. Os dados da iTreeC são utilizados para transformar geometricamente as primitivas e para renderizá-las. A figura 6.3 apresenta o diagrama que ilustra a iTreeC e a tabela 6.6 apresenta as definições dos tipos relacionados com a iTreeC.

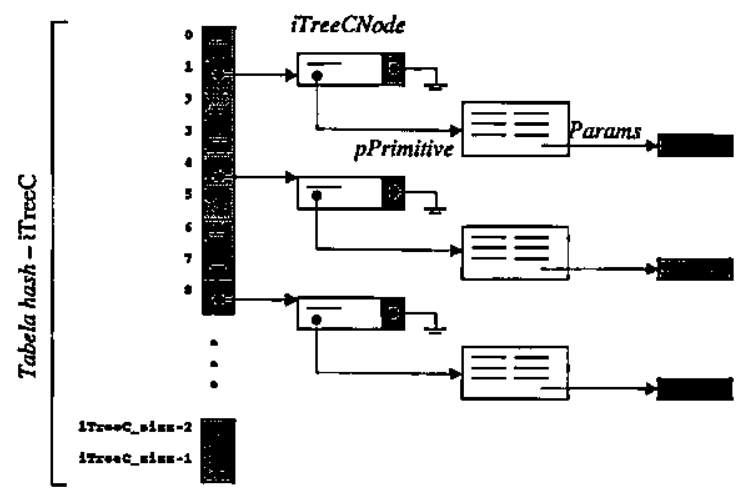

Figura 6.3-estrutura da iTreeC.

Tabela 6.6 - definição dos tipos da iTreeC.

\begin{tabular}{|l|ll|}
\hline struct iTreecNode \{ & struct primitive \{ \\
Word & word & type; \\
Primitive* pPrimitive; & void* & params; \\
ITreeNode* nxt; & real & color [3]; \\
\}; & real & bbox [8] [3]; \\
& real & blendRadius; \\
& matrix4x4 & transform; \\
& \}; & \\
\hline
\end{tabular}

$\mathrm{Na}$ estrutura que representa uma primitiva (struct primitivo) o campo params é um apontador para uma primitiva qualquer. Conforme o tipo da primitiva, campo type, o conteúdo apontado por

${ }^{8}$ Bonding-Box de um objeto, no caso de uma superficie definida por uma primitiva implícita, é o menor paralelogramo que contém essa primitiva. 
params é uma estrutura que define uma primitiva pré-definida ou uma estrutura que define uma primitiva esqueletal. A tabela 6.7 apresenta as estruturas para as primitivas pré-definidas e a seção 6.2 .3 apresenta as estruturas para representação das primitivas esqueletais.

Tabela 6.7 - definição dos tipos das primitivas pré-definidas na iTreeC.

\begin{tabular}{|c|c|c|}
\hline $\begin{array}{l}\text { struct sphere } \\
\text { Real radius; } \\
\text {; }\end{array}$ & $\begin{array}{l}\text { struct cylinder } l \\
\text { real radius; } \\
\text { real height; } \\
\}_{i}\end{array}$ & $\begin{array}{l}\text { struct cone }\{ \\
\text { real angle; } \\
\text { real height; } \\
\text {; }\end{array}$ \\
\hline $\begin{array}{l}\text { struct torus }\{ \\
\text { real radiusminor; } \\
\text { real radiusLarger; } \\
\text {; }\end{array}$ & $\begin{array}{l}\text { struct } \text { कuperelipsoid } f \\
\text { real radius[3]; } \\
\text { real sxz; } \\
\text { real sy; } \\
\text { \} }\end{array}$ & $\begin{array}{l}\text { struct parallelogram }\{ \\
\text { real lenghts }[3] ; \\
j_{i}\end{array}$ \\
\hline
\end{tabular}

A iTreeC possui um número limitado de entradas, iTreeC_size, mas pode armazenar um número indefinido de primitivas, pois cada uma de suas entradas é uma lista de primitivas. As entradas da iTreeC são indexadas por valores inteiros entre 0 e iTree_size-1.

A função bash para determinar o índice da entrada de iTreeC, entry_index, que representa a lista onde está uma primitiva cujo identificador é primitive_id é: entry_index= primitive_id $q$ iTreeC_size, ou seja, o resto da divisão inteira de primitive_id por iTreec_size. A procura pela primitiva na lista é realizada de modo seqüencial com o identificador da primitiva.

$\mathrm{Na}$ atual implementação da iTreeC o valor de iTree_size é 512. Como os valores dos identificadores de primitivas são gerados seqüencialmente, para que a lista definida por uma entrada da iTreeC, possua mais de uma primitiva é necessário que durante a modelagem tenham sido criados mais de 512 nós. Um valor tão alto torna o controle da definição do modelo difícil. Assim, quase sempre as entradas da iTreeC serão listas vazias ou com apenas uma primitiva, e o tempo para a recuperação de uma primitiva na íTreeC será constante.

Junto com a implementação da iTreeC foi implementado um conjunto de procedimentos para a manipulação das primitivas:

- Procedimentos para alteração dos parâmetros das primitivas que foram exportados como comandos do $\mathrm{Tcl} / \mathrm{Tk}$.

- Procedimentos para definir e consultar a matriz de transformação de uma primitiva implícita. Esses também foram exportados como comandos Tcl/Tk. 
- Procedimentos para a realização das transformações de escala, translação e 'rotação das primitivas.

Como as transformações geométricas são representadas por uma matriz de transformação, os procedimentos de transformações apenas calculam a matriz correspondente à ttansformação e em seguida multiplicam a matriz de transformação da primitiva pela matriz calculada.

A iTreeC replica os parâmetros das primitivas que estão presentes na iTreeTcl. Essa replicação dos dados traz dois inconvenientes: requer o espaço de memória extra e impõe a necessidade de gerenciar as réplicas. $O$ espaço não apresenta um grande problema, pois um modelo implícito geralmente não possui mais que centenas ${ }^{9}$ de nós. Logo, o espaço de memória alocado para o modelo é comumente pequeno. $O$ controle de réplicas foi implementado nos procedimentos mantêm os dados referentes às primitivas implícitas. Sempre que houver a atualização desses dados são invocados procedimentos Tcl que cuidam das atualizações. Esses procedimentos mantêm as primitivas na iTreeTcl e executam comandos que realizam a mesma manutenção na îTreeC.

Outra forma de atualização dos dados das primitivas é a realização das transformações geométricas. Nesse caso, uma transformação sempre ativa um procedimento $\mathrm{Tcl}$ que executa um comando para atualizar as matrizes de transformação das primitivas selecionadas na iTreeC. A figura 6.4 ilustra cọmo é realizada a atualização dos dados da árvore implícita.

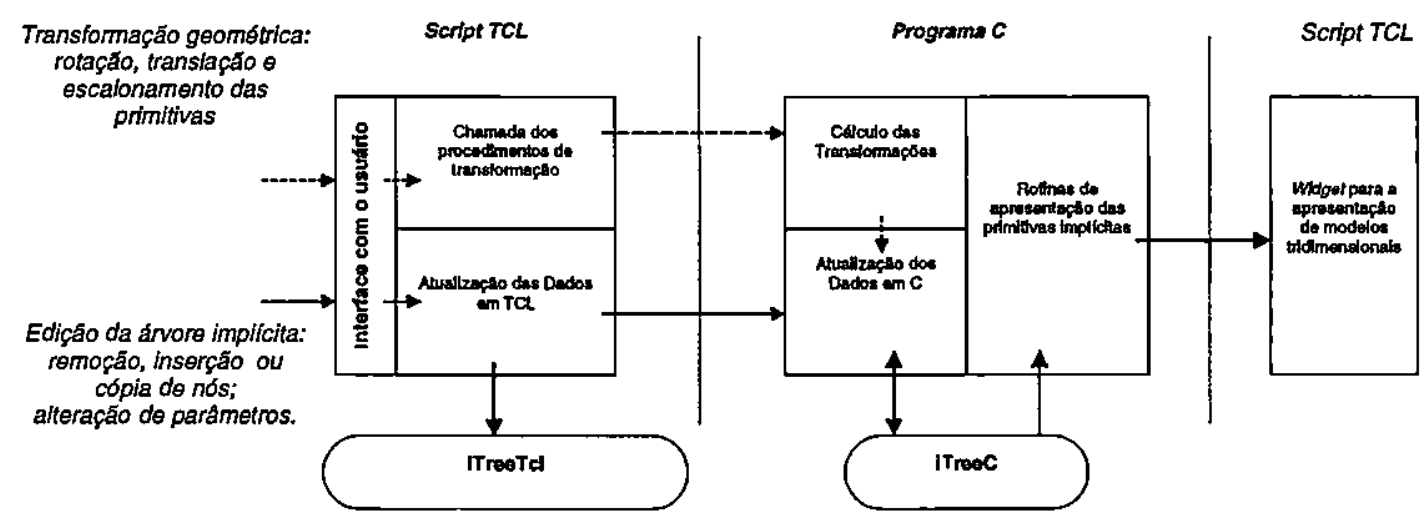

Figura 6.4 - manutenção dos dados que representam a árvore implícita.

A descrição dos dados da iTreeC não apresentou como é a representação das primitivas esqueletais, essa representação é um pouco mais complexa se comparada com as representações das primitivas prédefinidas, por isso é descria a parte na seção 6.2.3.

${ }^{9}$ Esta limitação não é do Modelador, e sim da capacidade do usuátio de gerenciar um modelo implícito com muitas operaçōes e primitivas. 


\subsubsection{Representação das Primitivas Esqueletais}

Como apresentado na seção 5.3.2 o Modelador representa os elementos de um esqueleto individualmente, ou seja, cada elemento define uma primitiva implícita. A representação de primitivas baseadas em pontos é bem simples, são registrados apenas as coordenadas do ponto e o range dessa primitiva esqueletal, como apresentado a seguir.

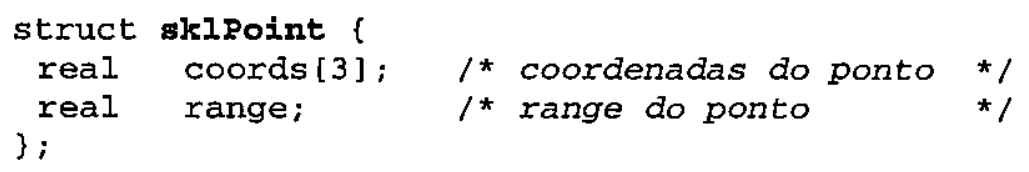

As representações das outras primitivas esqueletais não são tão simples. As estruturas que representam as linhas e os polígonos necessitam de uma representação dinâmica para os pontos que os definem $\mathrm{e}$ para os ranges, no caso das linhas. Isso porque a uma linha, ou a um polígono podem ser adicionados ou removidos pontos durante a modelagem. Uma escolha natural seria a representação desses campos por listas lineares, mas essa representação torna obrigatória uma pesquisa seqüencial a cada operação de alteração, adição e remoção de pontos. Para representar esses campos foi escolhida uma estrutura bem simples que assegurasse a facilidade de acessar os dados de um vértice pela sua ordem em uma linha ou em um polígono.

A estrutura escolhida é uma tabela (array) de números teais, essa estrutura possui inicialmente um tamanho pré-definido, que pode ser aumentado conforme um passo, também pré-definido, a medida que a adição de pontos extrapola a capacidade da tabela. A seguir são apresentadas as estrutura para a representação de linhas e polígonos.

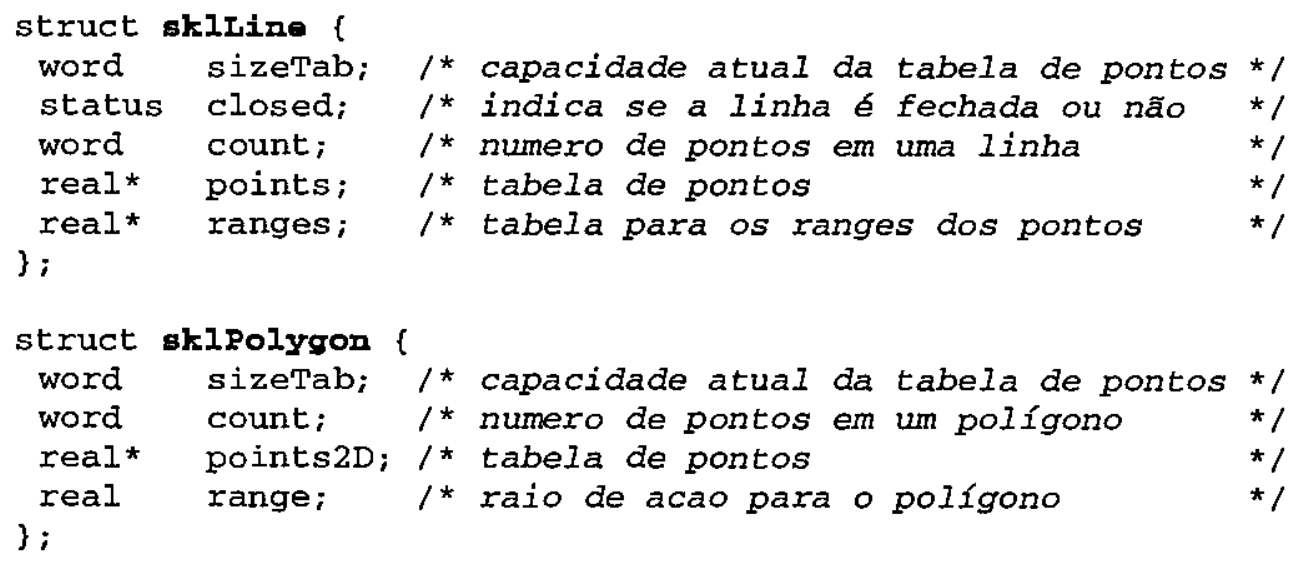

O registro dos pontos de uma linha na tabela definida pelo campo points é feito de forma linear, ou seja, para um ponto são armazenados em ttês posições contíguas da tabela as suas coordenadas $\mathbf{x}, \mathbf{y}$ e $\mathbf{z}$. Assim as primeiras três entradas da tabela são referentes ao primeiro ponto, as três seguintes são referentes ao segundo ponto e assim por diante. De forma análoga é realizado o registro dos pontos na 
estrutura de polígonos, destacando que nesse caso são registradas apenas as cootdenadas $\mathbf{x}$ e $\mathbf{z}$, uma vez que um polígono é sempre criado no plano $\mathrm{y}=0$.

\subsubsection{Primitivas Ativas e Primitivas Selecionadas}

A coleção de árvotes implícitas possui um conjunto de primitivas ativas e um de primitivas selecionadas, seção 5.3.1. Internamente esses conjuntos são representados a partir da estrutura auxiliar, iTreeC, por uma estrutura que registra as primitivas os constituem. Essa estrutura é apresentada a seguir.

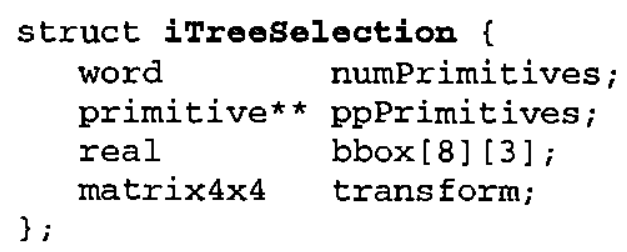

O Modelador mantêm duas instâncias da estrutura imreeselection uma para registrat as primitivas ativas e outra para as primitivas selecionadas. As informações registradas em cada um dos campos da iTreeselection são:

numPrimitives: indica número de primitivas que definem o conjunto.

ppPrimitives : é um array de apontadores para as primitivas que constituem o conjunto. Essas primitivas devem estar na iTreeC;

bbox : representa oitos pontos que definem um hexaedro onde estão todas as primitivas do conjunto, ou seja, o bounding-box do conjunto de primitivas. Para as primitivas ativas o bounding-box é utilizado para ajustat a apresentação das primitivas no Visualizador de Primitivas, de -modo que todas as primitivas ativas possam ser apresentadas. Para as primitivas selecionadas é utilizado para calcular o ponto base para as transformações de rotação e escala.

transform: é uma matriz que descreve as transformações que o conjunto de primitivas sofreu. Esse campo é utilizado apenas pata as primitivas selecionadas, pois as operações de transformação geométricas são realizadas apenas sobre esse conjunto.

A atualização das estruturas que mantêm as primitivas selecionadas e as primitivas ativas é realizada sempre que mudar o nó selecionado no Editor de Árvores Implícitas. Internamente a Interface de Modelagem determina os identificadores das primitivas ativas e das primitivas selecionadas e a partir desses identificadores as estruturas são atualizadas. 


\subsubsection{Transformações Geométricas sobre as Primitivas}

As transformações geométricas disponíveis no Modelador são escalonamento, rotação e translação. Essas transformações são realizadas sobre das primitivas selecionadas, sendo possível transformá-las como se fossem um único objeto. Os procedimentos para a realização das transformações sobre as primitivas selecionadas foram implementados em $\mathrm{C}$ e exportados como comandos $\mathrm{Tcl} / \mathrm{Tk}$ permitindo a realização das transformações a partir dos scripts que implementam a Interface de Modelagem.

$\mathrm{Na}$ translação das primitivas selecionadas são definidos os incrementos de translação nos eixos coordenados. O algoritmo 6.1 apresenta como é realizada uma translação sobre as primitivas selecionadas.

Algoritmo 6.1 - translação das primitivas selecionadas.

MT $\leftarrow$ (calculax matriz de translaçăo a partir dos incrementos de translação)

multiplicar a matriz da estrutura (primitivas selecionadas) por MT

pàra cada primitiva selecionada $P$

multiplicar a matriz de p por MT

As transformações de escalonamento e de rotação necessitam de um ponto de referência para a sua realização, usualmente esse ponto é a origem do sistema de coordenada, ou o centro do objeto que está sendo transformado. Para que as primitivas selecionadas se comportem como um único objeto, o ponto tomado como referencial é sempre o centro do bounding-box das primitivas selecionadas. Os escalonamentos são definidos por três fatores positivos que indicam a escala nos eixos coordenados e as rotações são definidas pelo eixo de rotação (sempre um dos eixos coordenados) e pelo ângulo da rotação.O algoritmo 6.2 apresenta a como são aplicados a rotação e o escalonamento sobre as primitivas selecionadas.

A Interface de Modelagem permite que o usuátio possa re-iniciar a matriz de transformação de uma primitiva, permitindo anular as translações sobre as primitivas selecionadas ou anular as rotações e escalas. Um mecanismo que permite a anulação de apenas uma transformação pode ser implementado, mas necessita de uma representação mais detalhada da seqüência de transformações e não apenas uma única matriz que representa todas as transformações realizadas. 
Algoritmo 6.2 - rotação e escalonamento das primitivas selecionadas.

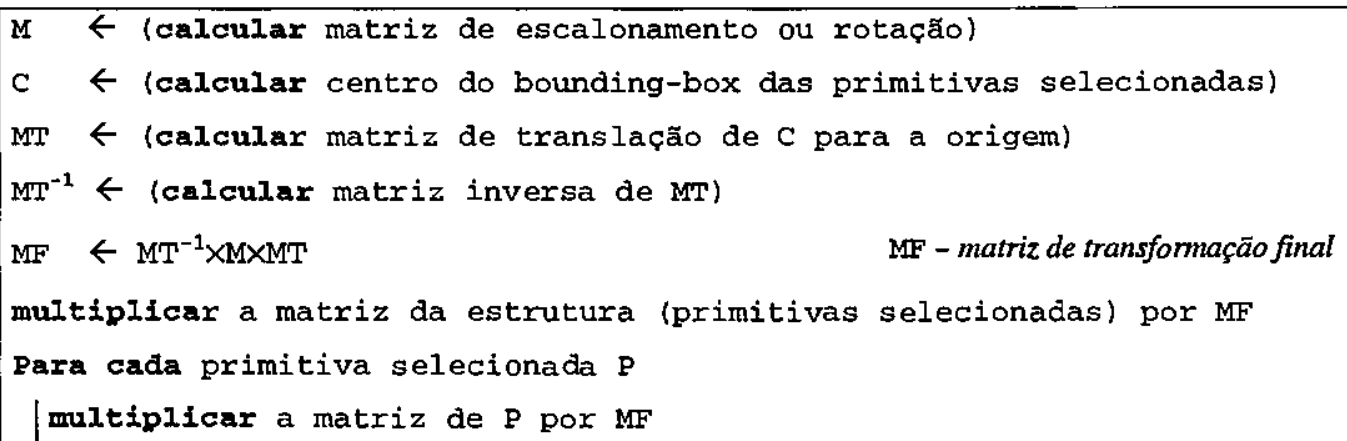

\subsubsection{Registro e Recuperação da Árvore Implícita em Disco}

As definições dos modelos implícitos representados em uma árvore implícita podem ser registradas em disco. Foi definida uma sintaxe para o arquivo que registra a árvore implícita e procedimentos para leitura e escrita da árvore em disco. A sintaxe é apresentada na figura 6.5

Os procedimentos de escrita e de leitura foram implementados em $\mathrm{Tcl}$, aproveitando as facilidades que essa linguagem oferece para manipular listas. Esses procedimentos utilizam comandos implementados em $C$ para consultar as transformações das primitivas, no caso da escrita, e para atualizar a iTreeC, no caso da leitura.

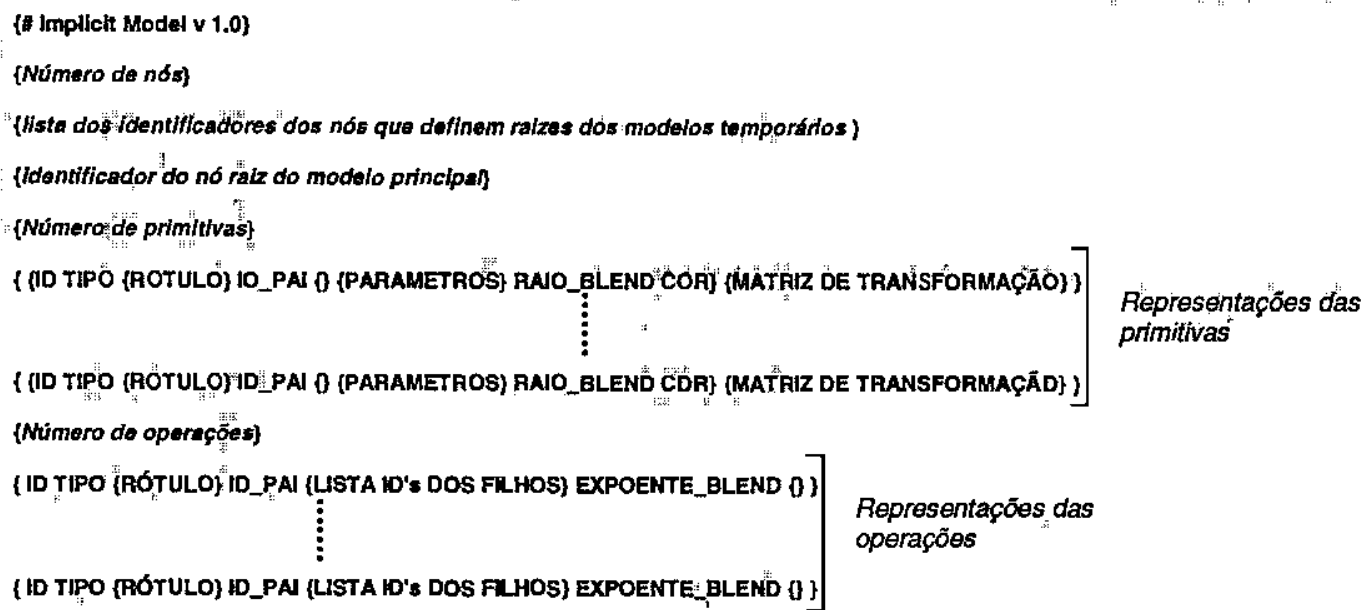

Figura 6.5 - sintaxe do arquivo que uma árvore implícita.

Uma vez definido como é a estrutura da árvore implícita, o restante deste capítulo destaca a funcionalidade da Interface de Modelagem, apresentando como é a interface com o usuário para a construção de um modelo implícito. 


\subsection{Interface com o Usuário}

Nesta seção é apresentada a interface com o usuário para a definição de modelos implícitos. São apresentados os elementos que a constituem destacando a função de cada um. A aparência da interface principal é apresentada na figura 6.1, onde podem ser observados o Editor de Árvores Implícitas, o Visualizador de Primitivas e o menu principal.

Inicialmente são apresentadas as características do Editor de Árvores Implícitas e do Visualizador de Primitivas. Em seguida são apresentadas as funções disponíveis nos menus da interface principal; a interface para a edição dos nós e para edição das primitivas esqueletais. Também é apresentado como podem ser definidos modelos temporário e o modelo principal. Por fim, são apresentadas as funções para que podem ser realizadas de modo mais rápido através do teclado e do mouse. Nesta seção o termo diálogo é utilizado no mesmo sentido de caixa de diálogo, ou seja, uma janela, que compõem a interface com o usuário, utilizada para entrada de valores ou para apresentar alguma mensagem.

\subsubsection{Editor da Árvore Implícita}

O Editor de Árvores Implícitas é o elemento de interface como o usuário que aparece à esquerda na interface principal, é similar a uma árvore de diretório presente na maioria dos gerenciadores de arquivos. Como uma árvore de diretótio esse editor permite mover ou copiar elementos com o auxilio do mouse e expandir ou contrair a apresentação dos modelos implícitos. A figura 6.6 apresenta o Editor de Árvores Implícitas.

A implementação desse editor se baseia nas facilidades oferecidas pela widget canvas do Tcl/Tk. Essa widget permite o desenho de ícones, linhas e textos, necessários para a apresentação da árvore implícita no editor. Os itens que compõem o desenho da árvore implícita são:

- ícone e texto para ilustrar o Editor de Árvores Implícitas;

- ícones que indicam o tipo de nó da árvore e um texto para identificar;

- linhas para o desenho da estrutura de árvore;

- ícones para indicar se os nós que representam operações estão expandidos ou contraídos; e

- ícones para indicar se os modelos, principal e temporário, estão expandidos ou contraídos.

Esses itens podem ser observados na figura 6.6. As árvores implícitas, ou os modelos implícitos, presentes no editor são apresentados em uma linha vertical a partir do ícone que ilustra o editor. Os 
modelos são identificados por losangos, caso os seus filhos não sejam apresentados, ou por triângulos, caso contrário. O modelo principal é diferenciado dos demais pela cor desse ícone.

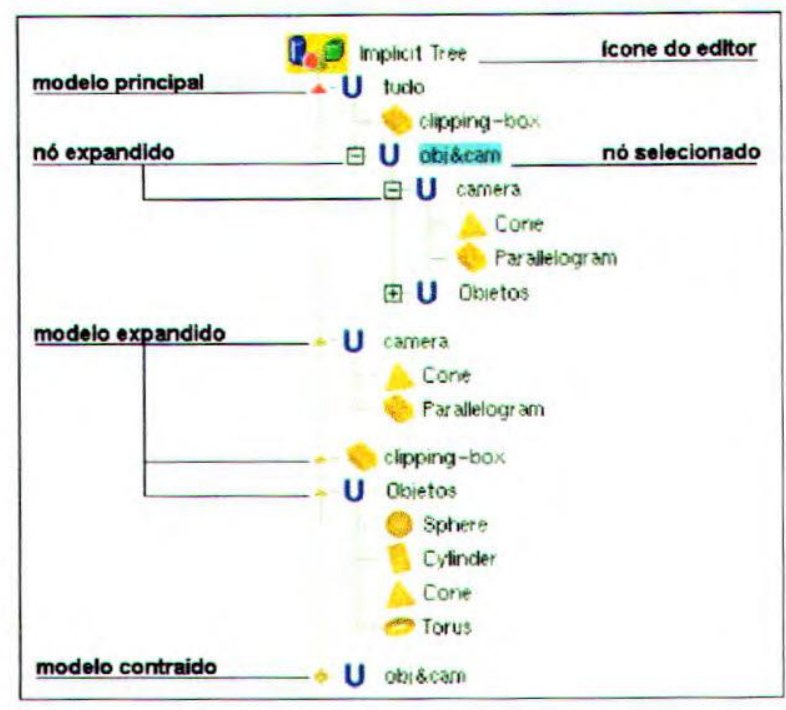

Figura 6.6 - editor de Árvores Implícitas

Ao desenhar um item no Editor de Árvores Implícitas é gerado um identificador para esse item. Além do identificador do item, é possível associar tags a um item e através de bindings os itens do editor podem responder a eventos do mouse e do teclado. Utilizando esse mecanismo o Editor de Árvores Implícitas é criado como um hipergráfico, ou seja, uma representação gráfica onde a ação do usuário sobre os elementos dessa representação é utilizada para realizar algumas funções.

Para apresentar a árvore implícita em um canvas são utilizadas duas estruturas de dados: a iTreeTcl que fornece a topologia da árvore e os rótulos dos nós e uma tabela que relaciona os itens do canvas (linhas, ícones e textos) com os nós da iTreeTcl, referenciada neste texto como canvasTable. A canvasTable é dividida em três conjuntos distintos:

- O primeiro conjunto relaciona os identificadores dos itens do canvas (ícones e textos) com os identificadores dos nós da iTreeTcl. Esse conjunto é utilizado para determinar qual é o nó da árvore implícita corresponde a um determinado item do canvas.

- O segundo conjunto relaciona os identificadores dos nós da árvore com os identificadores dos itens que representam o texto na canvas. Esse conjunto é utilizado para destacar o nó selecionado: quanto o usuário clica com o mouse sobre um item que representa um nó (ícone ou texto), a partir do primeiro conjunto é determinado o nó que foi selecionado e com o segundo conjunto é determinado o item de texto que será desenhado com destaque. 
- O terceiro conjunto relaciona os identificadores dos nós com seu estado de apresentação (expandido ou contraído). Esse conjunto é utilizado no desenho da árvore implícita para determinar se é necessário, ou não, desenhar os filhos de um nó.

A partit da íree'Tcl e da canvas'Table foi implementado um algoritmo para o desenho da árvore em uma widget canvas.

\subsubsection{Visualizador de Primitivas}

O Visualizador de Primitivas é o elemento de interface com o usuátio que aparece à direita do Editor de Árvores Implícitas. A função desse elemento não é apresentar o resultado das composições definidas no modelo, mas somente apresentar as primitivas implícitas que compõem o modelo ativo. $O$ Visualizador é útil pata verificat o tamanho, orientação e posicionamento das primitivas durante a modelagem. Para facilitar a distinção entre as primitivas, elas podem ser apresentadas com cores diferentes, mas essas cores não têm nenhum significado no resultado final do modelo. A cena definida pelas primitivas ativas é renderizada através de rotinas da OpenGL e apresentada ao usuátio através de uma widget Togl (ver seção 5.6.2).

O Visualizador permite que a apresentação das primitivas selecionadas seja diferente das primitivas ativas não selecionadas, como definido na seção 5.3.3. Como exemplo, na figura 6.1 as primitivas visualizadas compõem o modelo principal rotulado por caneca, essas primitivas são: cilindro 1, cilindro 2, paralelogramo e toro. Existe uma única primitiva selecionada, cilindro 2, que é apresentada com tonalização gouraud e as demais primitivas são apresentadas em wireframe.

Pata apresentar as primitivas no Visualizador são utilizadas suas representações paramétricas. Todas as primitivas pré-definidas disponiveis no Modelador possuem uma representação paramétrica, algumas dessas representações são apresentadas no capítulo 3. A representação paramétrica de uma primitiva é utilizada para gerat um conjunto de poligonos que representa uma aptoximação para a primitiva. $O$ Visualizador de Primitivas toma esses poligonos e os apresenta.

As primitivas esqueletais são representadas de forma simples na implementação atual. Uma superficie definida por um ponto é representada por ưma esfera cujo raio é definido pelo range do ponto. As superfícies definidas por linhas são representadas por uma linha com esferas nos vértice $\mathrm{da}$ linha, os raios dessas esferas indicam o range de cada vértice. As superficies definidas por polígonos planates também são representas por uma linha que representa o bordo do polígono e por esferas nos vértices para indicar o range do poligono. 
O Visualizador de Primitivas determina quais primitivas devem ser apresentadas acessando as estruturas que registram as primitivas ativas e as selecionadas (scção 6.2.5). Para cada primitiva sua representação paramétrica gera um conjunto de polígonos. Esses polígonos são posicionados e orientados conforme a matriz de transformação da primitiva. Em seguida, são renderizados através de rotinas da OpenGL considerando a cor dessa primitiva e se ela é ou não uma primitiva selecionada.

A apresentação de uma cena com OpenGL é análoga ao registro de uma cena do mundo real através de uma câmera, como ilustra a figura 6.7. Para apresentar uma cena com OpenGL devem ser definidos o volume de visualização e também a posição e orientação da câmera que registrará a cena. Seguindo a analogia da figura 6.7 , as operações de rotação da cena são definidas como rotações sobre a câmera e as operações de zoom são definidas como a aproximação ou afastamento dessa câmera do volume de visão.

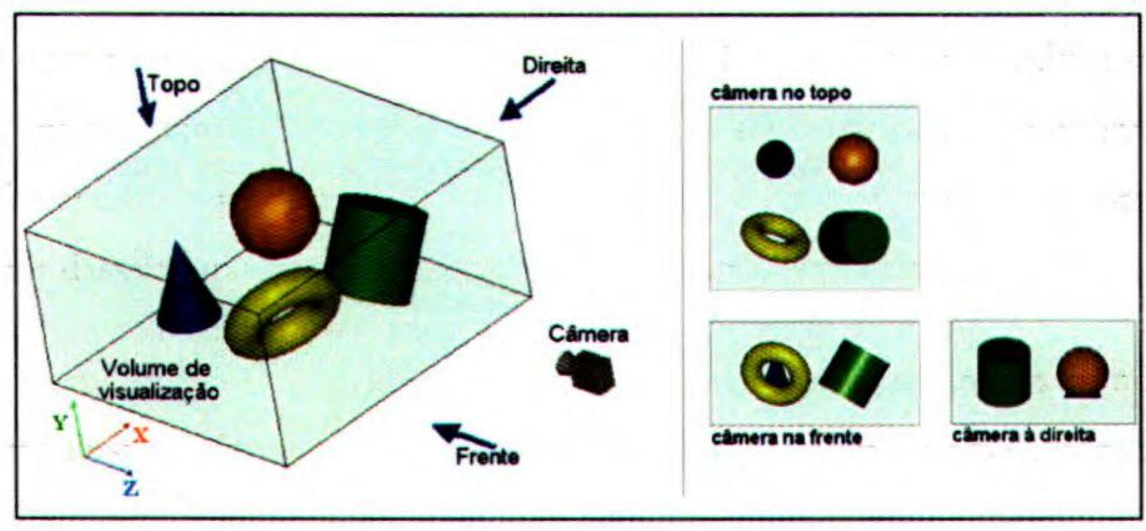

Figura 6.7 - apresentação das primitivas com OpenGL.

A câmera que registra a cena das primitivas ativas pode ser rotacionada no eixo $\mathbf{x}$, movimento chamado de elevation, e eixo y, movimento chamado de az̧imuth. Na implementação do Visualizador foram prédefinidos três pontos para o posicionamento da câmera, de modo que a cena pode ser observada pela frente, pelo topo ou pela direita, como mostra a figura 6.7. Esses pontos pré-definidos podem ser escolhidos na Interface de Modelagem.

Existe um problema na visualização das primitivas, ao movimentar ou alterar o tamanho de uma primitiva, parte dessa primitiva pode sair do volume de visualização, gerando uma imagem errada da cena. Para contornar esse problema o usuário pode solicitar que o volume de visualização seja redefinido para englobar todas as primitivas do modelo ativo. 


\subsubsection{Menus da Interface Principal}

Todas as funçôes disponíveis na Interface de Modelagem podem ser acessadas a partir do menu principal. As opções desse menu são apresentadas na tabela 6.8 .

Tabela 6.8 - opçöes do menu principal

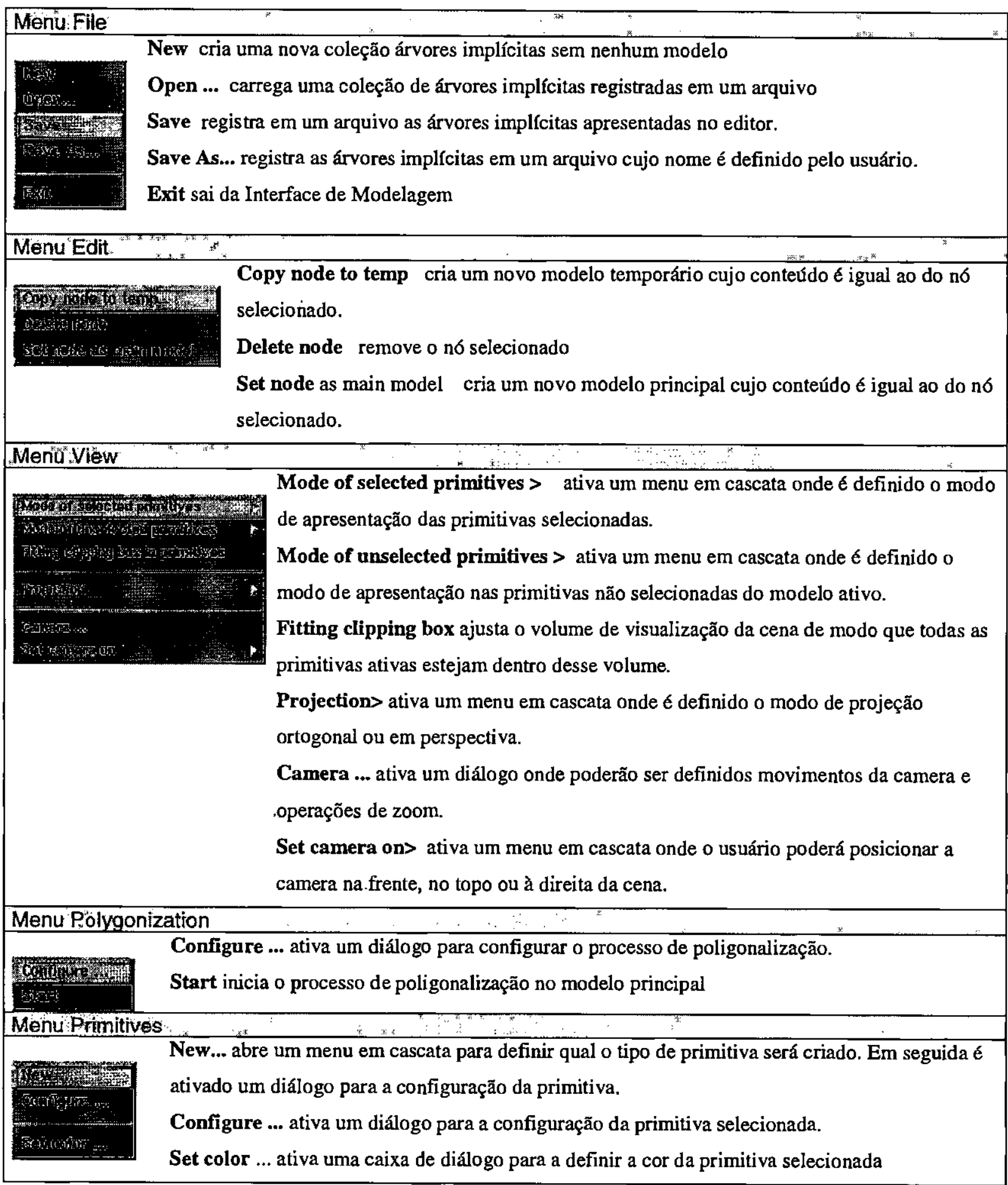




\begin{tabular}{|c|c|}
\hline Aenu Operation & $x^{\frac{5}{3}}$ \\
\hline 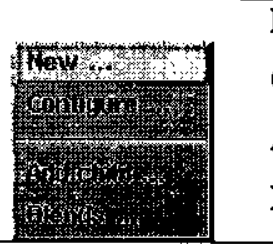 & $\begin{array}{l}\text { New ... ativa um diálogo para a criação de uma operação. } \\
\text { Configure ... ativa um diálogo para configurar a operação definida pelo nó selecionado. } \\
\text { Add child ... ativa um diálogo para a adição de novos operandos ao nó selecionado. } \\
\text { Blend ... ativa uma caixa de diálogo para configurar o tipo de blend. }\end{array}$ \\
\hline Menư Transform & 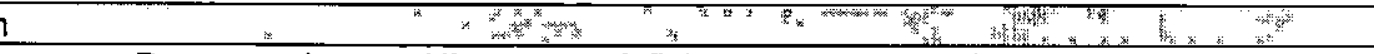 \\
\hline 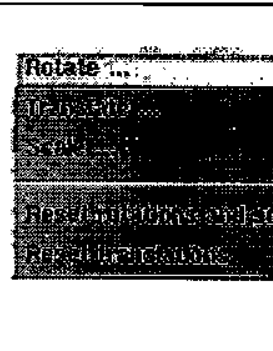 & $\begin{array}{l}\text { Rotate ... ativa um diálogo para a definição das rotações aplicadas sobre as primitivas } \\
\text { selecionadas. } \\
\text { Translate ... ativa um diálogo para a definição das translaçōes. } \\
\text { Scale ... ativa um diálogo para a definição dos escalonamentos. } \\
\text { Reset rotations and scale desfaz as rotaçōes e as escalas das primitivas selecionadas. } \\
\text { Reset translations desfaz as translaçōes aplicadas sobre as primitivas selecionadas. }\end{array}$ \\
\hline
\end{tabular}

Além do menu principal existem dois menus pop-ups : um com genéricas do editor e outro com operações com para os nós. Esses menus são apresentados na tabela 6.9.

Tabela 6.9 - opções dos menus pop-ups.

\begin{tabular}{|c|c|}
\hline Menu pop-up'genérico do ed & 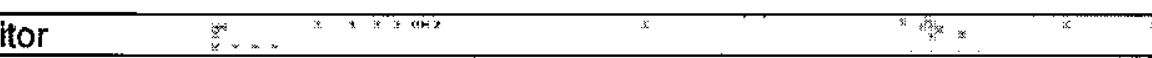 \\
\hline 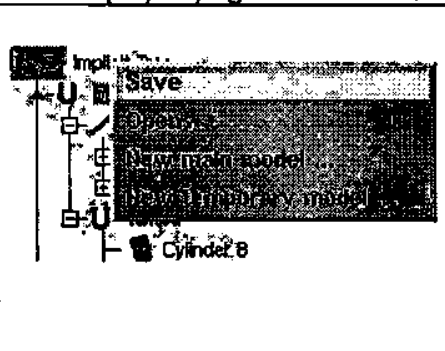 & $\begin{array}{l}\text { Save registra em um arquivo as árvores implícitas apresentadas no editor. } \\
\text { Open ... carrega uma coleção de árvores implícitas registrada em um arquivo. } \\
\text { New main ... ativa um diálogo para a criação de um novo nó que será inserido no } \\
\text { editor como modelo principal. } \\
\text { New temporary model ... ativa um diálogo para a criação de um novo nó que } \\
\text { será inserido no editor como modelo temporário. }\end{array}$ \\
\hline Menu pop-up dos nós da án & 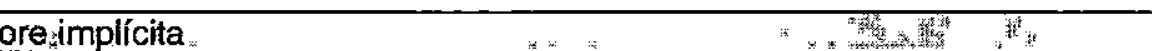 \\
\hline 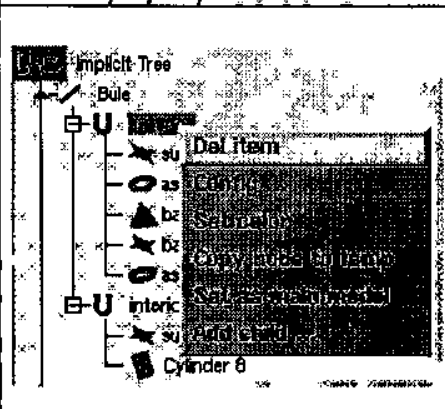 & $\begin{array}{l}\text { Del item ... remove o nó selecionado } \\
\text { Config ... ativa o diálogo para configuração do nó. } \\
\text { Set color ... ativa o diálogo para definição da cor das primitivas selecionadas. } \\
\text { Copy node to temp cria uma cópia do modelo definido pelo nó selecionado e } \\
\text { insere essa cópia na lista de modelos temporários. } \\
\text { Set as main model cria uma cópia do modelo definido pelo nó selecionado e } \\
\text { define essa cópia como o modelo principal. }\end{array}$ \\
\hline
\end{tabular}

\subsubsection{Edição de Nós}

Os nós da árvore implícita são criados e alterados através de caixas de diálogos. Os nós que representam as primitivas pré-definidas são criados, ou configurados, por diálogos simples. Esses 
diálogos são formados por widgets para entrada de texto (entries) e botões para aplicar a alteração e para terminar o diálogo. Os parâmetros configurados nesses diálogos são os parâmetros de definição (tabela 6.3) das ptimitivas, além do rótulo (label) e raio de blend da primitiva. O rótulo da primitiva é utilizado no desenho do nó no editor de árvore. A figura 6.8 apresenta os diálogos para a configuração das primitivas pré-definidas.

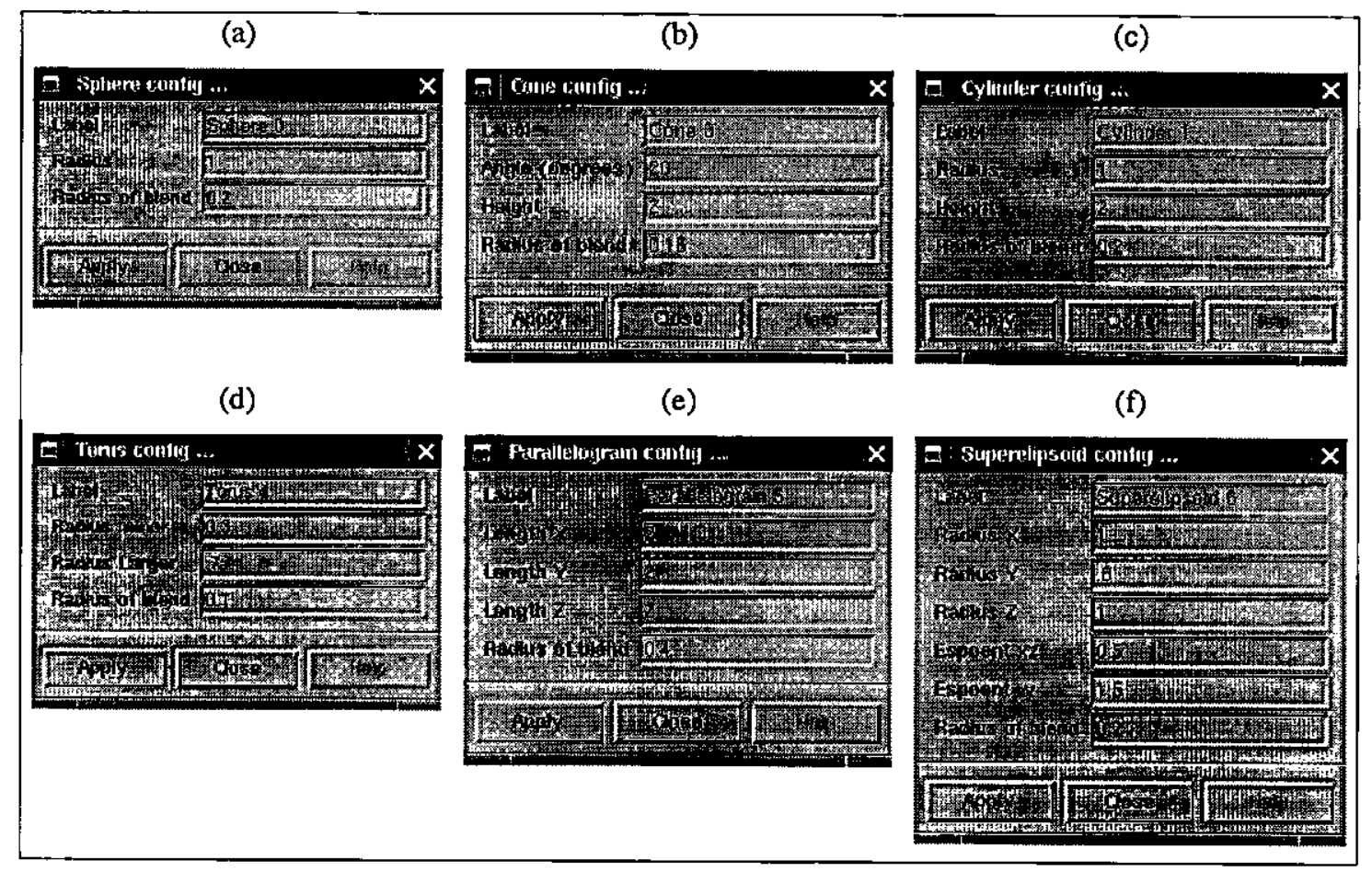

Figura 6.8 - diálogos para a configuração das primitivas pré-definidas: (a) esfera, (b) cone, (c) cilindro, (d) toro, (e) paralelogramo, (f) superelipsóide.

Os nós que representam operações podem ser alterados de diversas formas. Antes mesmo de criar uma operação pode ser definido o tipo de blend a ser utilizado em uma operação. A figura 6.9(a) apresenta o diálogo de configuração do blend em que é definido o tipo de blend (nenhum, blend global ou blend pseudo-euclidiano) e em quais modelos o blend escolhido será aplicado (em todos os modelos, apenas no modelo principal, ou em todos os modelo temporários).

Pata a criação de uma operação é utilizado o diálogo apresentado na figura 6.9(b). Ao criar uma operação é definido o tipo da operação de composição, o rótulo do nó que representa essa operação e o expoente de blend, necessário somente se o modelo suportar algum tipo de blend. Além desses parâmetros são definidos dois filhos, ou operandos, para a nova operação. Esses filhos podem ser modelos temporários criados previamente, ou primitivas novas.

Uma operação pode ser configurada através do diálogo apresentado na figura 6.9(c). Na configuração pode ser definido um novo tótulo, um novo expoente de blend, ou mesmo, um novo tipo para a 
operação. A alteração do tipo é restrita, pois para uma operação de união ou interseção seja convertida em uma diferença é necessário que essas operações tenham apenas dois operandos.

Outra forma de alterar uma operação é adicionando novos filhos a essa operação. Essa adição é possível apenas para operações de união e de interseção, e é realizada pelo diálogo apresentado na figura 6.9(d). Podem ser inseridos modelos temporátios ou novas primitivas.

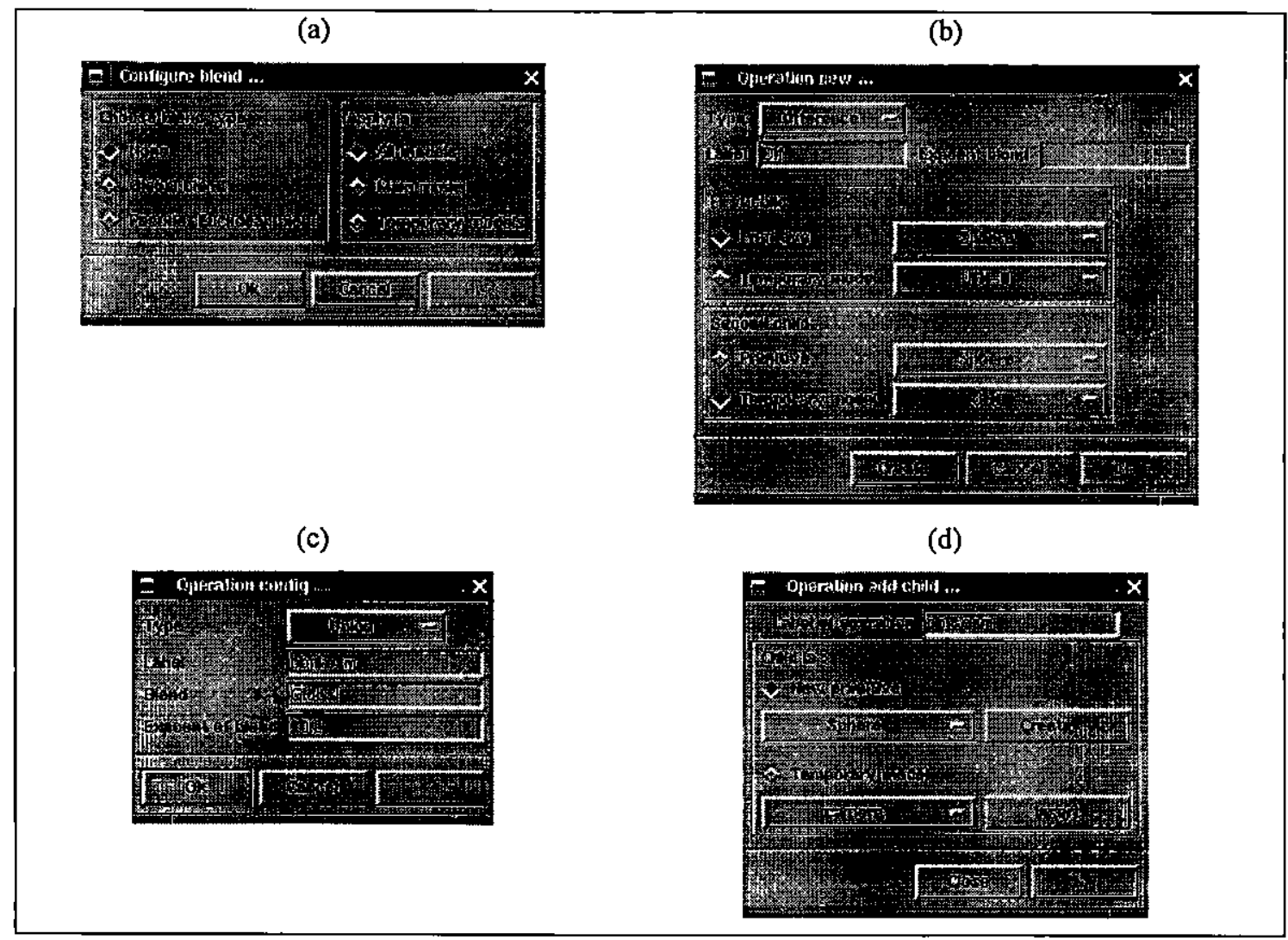

Figura 6.9 - diálogos para os nós que representam operações: (a) configuração do blend, (b) criação da operaçāo, (c) configuração da operação, (d) adição de novo filho.

Além dos diálogos para a configuração dos nós existem outros para a definição da poligonalização, para alterar a câmera do Visualizador de Primitivas e para transformar as primitivas selecionadas.

\subsubsection{Edição das Primitivas Esqueletais}

A interface para edição de primitivas esqueletais permite a especificação dos vértices que definem um elemento do esqueleto. $\mathrm{Na}$ implementação atual são utilizados diálogos para configuração das primitivas baseadas em pontos, em linhas e em polígonos. Esses diálogos permitem definir os vértices que constituem os elementos esqueletais, o range do elemento e também o raio de blend e o rótulo do nó para apresentação no Editor de Árvores implícitas. 
A interface para definição de superficies definidas a partir de pontos, figura 6.10 , é similar aos diálogos para primitivas pré-definidas. Nesse diálogo são especificadas as coordenadas do ponto, o range para a definição da superficie.

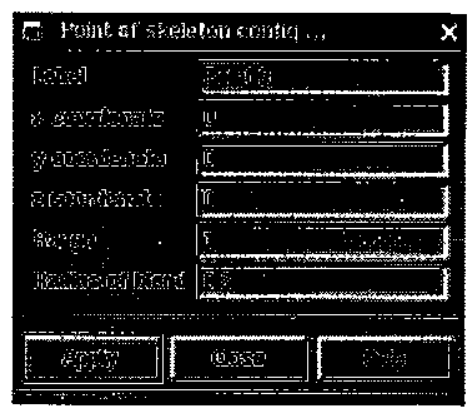

Figura 6.10 - diálogo para configuraçăo de uma primitiva baseada em um ponto.

As interfaces para edição de superficies baseadas em linhas e em polígonos são mais elaboradas por permitir a adição e a remoção de vértices a esses elementos. A edição de um vértice é realizada escolhendo-o dentro de uma lista e alterando suas propriedades através das caixas de texto. Para as linhas é possível definir as coordenadas do vértice e o seu range. Além disso no diálogo para edição de linha o pode definir uma linha como fechada e definir um range uniforme para a linha. No diálogo para edição de um polígono os dados de um vértice são apenas as coordenadas $\mathbf{x}$ e $\mathbf{z}$, isso porque o Modelador sempre definir um polígono no plano $\mathrm{y}=0$ e o range do polígono é uniforme em todos os seus vértices.

$\mathrm{Na}$ edição de linha e de polígonos sempre que um vértice é selecionado ele é destacado no Visualizador de Primitivas. As figuras 6.11 e 6.12 apresentam os diálogos para configuração de linha e polígono.

\subsubsection{Definição do modelo principal e de modelos temporários}

O modelo principal pode ser definido a partir de qualquer nó. A opção <set as main model>, disponivel no menu principal e no menu pop-up dos nós, cria uma cópia do modelo definido pelo nó selecionado e estabelece essa cópia como o novo modelo principal. Caso já exista um modelo principal, então o modelo princípal antigo é inserido na lista de modelos temporários. Outra forma de criar um novo modelo principal é a partir da opção <New main . . > disponível no menu pop-up do editor.

Os modelos temporários podem ser criados de duas formas. Sempre que um novo nó for criado a partir dos menus <primitive> e <operation> ele é inserido como um novo modelo temporário. A outra forma é semelhante à definição do modelo principal, a opção <Copy node to temp>, 
disponível no menu principal e no menu pop-up dos nós, cria uma cópia do modelo implícito definido pelo nó selecionado e insere essa cópia como um novo modelo temporário no editor.

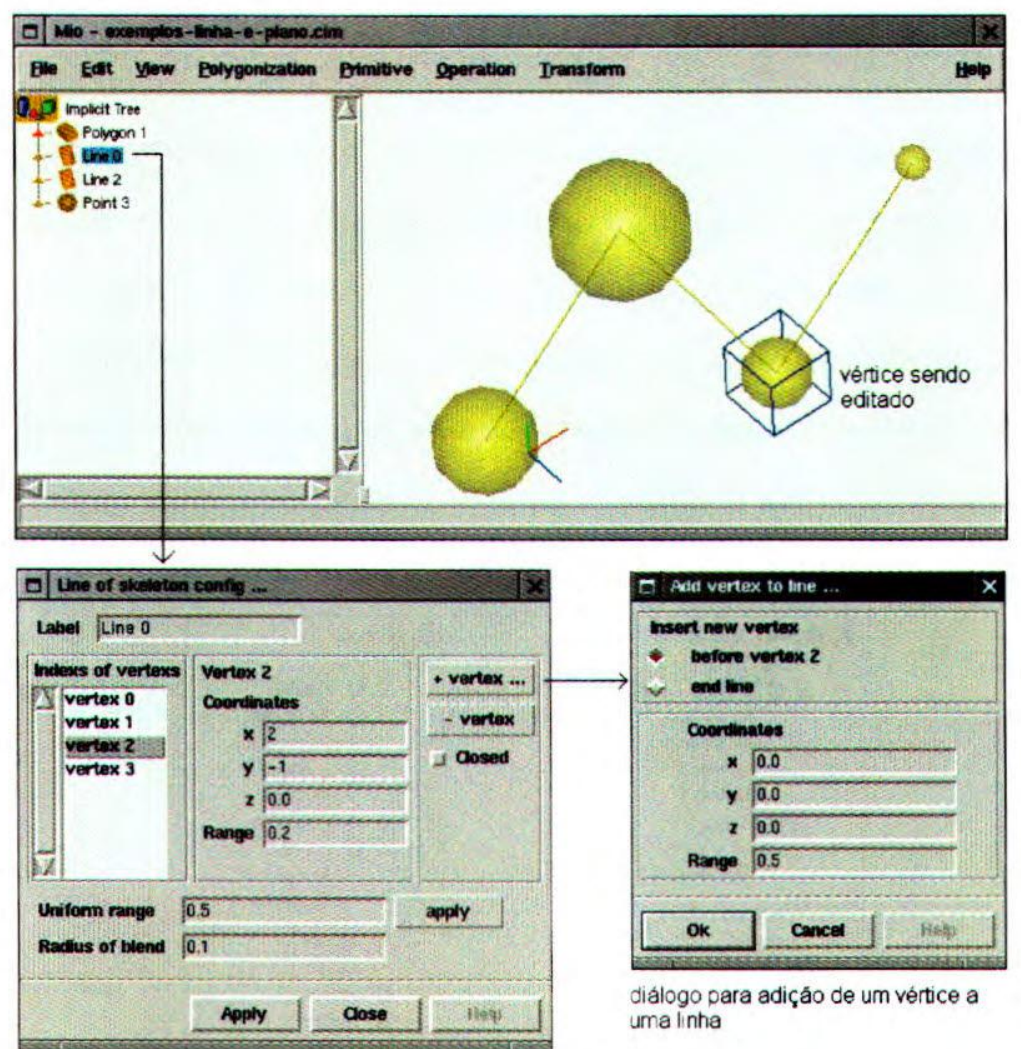

diálogo para configuraçáo de uma prim:tive definida por linha

Figura 6.11 - configuração de uma primitiva baseada em uma linha.

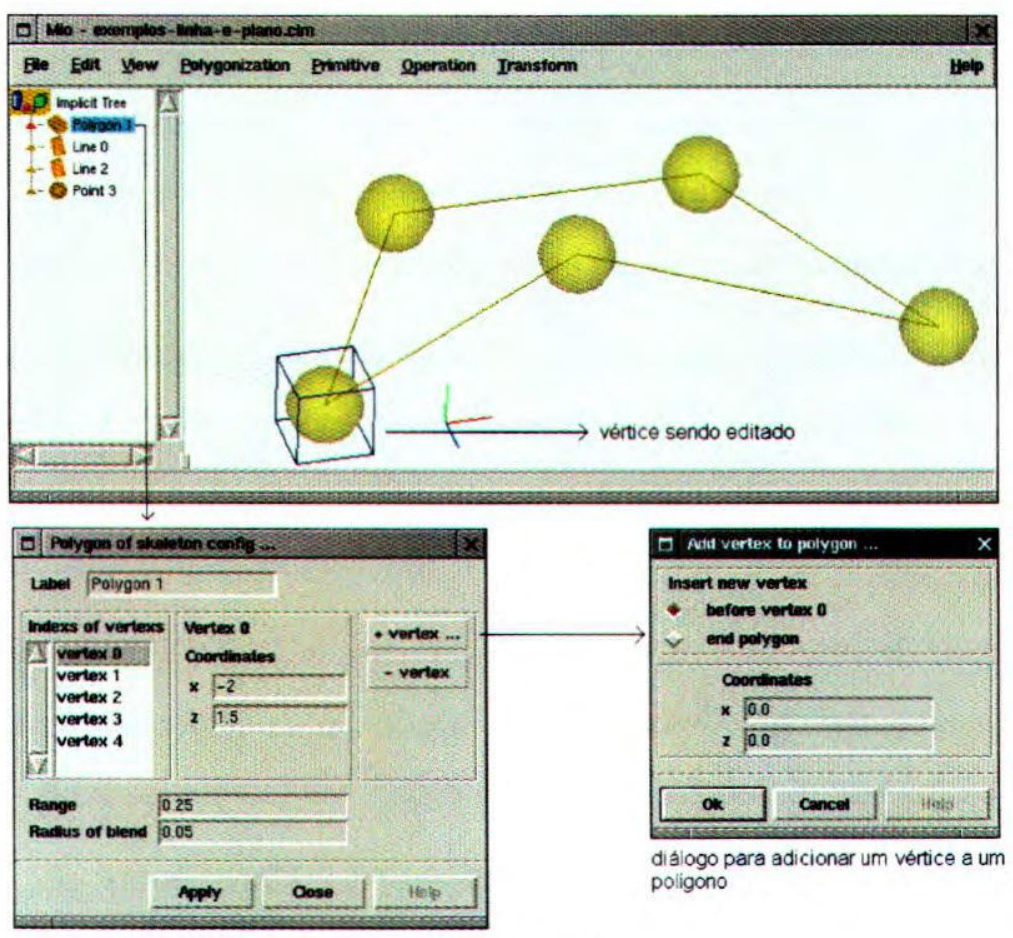

diálogo para configurar uma primitiva definida por um poligono

Figura 5.12 - configuração de uma primitiva baseada em um polígono. 


\subsubsection{Operações com o Mouse e Teclado}

Para facilitar a definição do modelo implícito, várias, tarefas podem ser executadas de modo mais eficiente com o auxílio do mouse e teclado, esta seção apresenta quais são estas tarefas.

Cópia e movimentação de nós - Qualquer nó no Editor de Árvores Implícitas pode ser copiado ou movido para dentro de um outro nó (como filho desse), desde que não invalide a árvore. Essa operação pode ser realizada com o mouse, para isso basta clicar sobre um nó e arrastá-lo até o seu destino. Se o nó destino for uma operação de união ou de interseção e não for descendente do nó arrastado, então ao liberar o botão do mouse, o nó arrastado é inserido como filho do nó destino. A operação de cópia é similar à de movimentação, apenas requer que a tecla <Ctrl> esteja pressionada ao liberar o mouse. A figura 6.13 ilustra a movimentação de um nó.

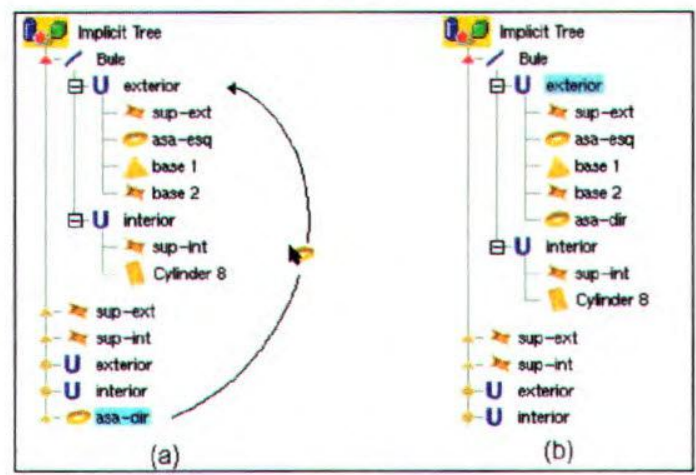

Figura 6.13 - exemplo de movimentação de nós no editor com o mouse - (a) movimento; (b) final

Remoção de nós - Para remover o nó selecionado basta pressionar a tecla <Del>

Ajuste da apresentação primitivas ativas no visualizador - As transformações geométricas, ou a edição das primitivas podem colocá-las , total ou parcialmente, fora do volume de visualização. Para redefinir o volume de visualização basta pressionar a combinação de teclas $\langle\operatorname{Ctrl+a}\rangle$.

Movimento de câmera - A cena apresentada no Visualizador de Primitivas pode ser rotacionada com o mouse. Basta pressionar o botão esquerdo do mouse sobre o Visualizador e arrastar, conforme o deslocamento do mouse são realizadas operações de elevation e ąimuth com a câmera.

Zoom - No Visualizador de Primitivas o zoom pode ser alterado através do mouse e do teclado. Para aumentar o zoom bastar clicar sobre o Visualizador com o botão direito do mouse, e para diminuir usa-se o mesmo procedimento com a tecla $\langle$ Shift $>$ pressionada.

Posições pré-definidas para a câmera - A câmera do Visualizador de Primitivas pode ser posicionada nos três pontos pré-definidos (frente, topo e direita - apresentados na figura 6.7) através de teclas de atalho: 
- pressionando $<\mathrm{Ctrl}+\mathrm{f}>$ as primitivas são vista pela frente;

- pressionando $\langle\mathrm{Ctrl}+\mathrm{t}\rangle$ as primitivas são vista pelo topo $\mathrm{e}$

- pressionando $\langle\operatorname{Ctrl}+d>$ as primitivas são vista pela direita.

\subsection{Poligonalização e Visualização do Modelo Implícito}

Além de ser responsável pela definição do modelo implícito a Interface de Modelagem é responsável por ativar os outros dois componentes do Modelador: o Poligonalizador e o Visualizador de Modelos Aproximados. Como a Interface de Modelagem possui seu módulo principal implementado em Tcl/Tk, o Poligonalizador e o Visualizador podem ser invocados a partir desse componente. A comunicação entre os módulos é realizada da seguinte forma:

4. Após a definição do modelo principal o usuário define a triangulação onde será realizada a poligonalização e o arquivo onde será registrada a brep-estendida que aproxima o modelo implícito. Essas definições, juntamente com a definição do modelo principal, são registradas no arquivo de definição do modelo implícito, apresentado na seção 7.2.1.

5. O usuário pode ativar a poligonalização através da opção <strart> do menu <Polygonization>. Essa opção gera o arquivo de definição do modelo implícito e invoca o Poligonalizador passando como parâmetro o arquivo de definição.

6. Caso a poligonalização termine com sucesso, a aproximação da superfície estatá armazenada como uma brep-estendida em um arquivo, então o Visualizador de Modelos Aproximados é invocado para apresentar essa aproximação.

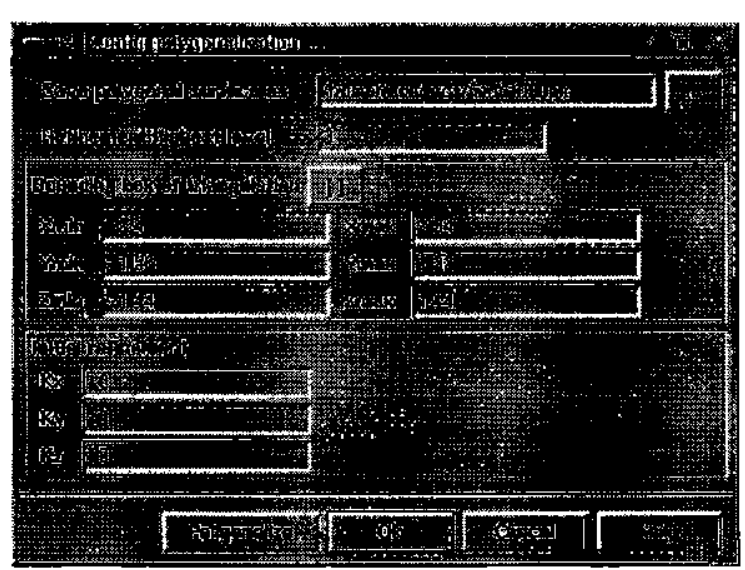

Figura 6.14 - diálogo para configuração da poligonalizaçāo. 
A definição dos parâmetros necessátios à poligonalização é realizada no do diálogo aptesentado na figura 6.14. Nesse diálogo são definidos:

- o arquivo onde será armazenado o modelo implícito poligonalizado;

- o maior nível de refinamento suportado pela triangulação;

- o domínio de $\Re^{3}$ onde é definida a triangulação; e

- os refinamentos iniciais da triangulação.

\subsection{Considerações finais}

Neste capítulo foram apresentadas as estruturas de dados para representar a átvore implícita. A árvore implícita é representada por um array do Tcl sendo que os dados de definição das primitivas são teplicados, etm utma tabela bash implementada em C. Os procedimentos de definição dos nós atuam sobre a representação do array $\mathrm{Tcl}$ e os procedimentos para transformações geométricas atuam sobre a tabela bash. Para manter a consistência entre as duas representações foi implementado um mecanistmo de controle de réplicas.

Esse capítulo aptesentou, também, as funções de modelagem disponíveis na interface com o usuátio. Foi descrito como é o funcionamento do Editor de Árvores Implícitas e do Visualizador de Primitivas. Além disso, foi apresentado como a Interface de Modelagem interage com os outros dois componentes do Modelador: o Poligonalizador e o Visualizador de Modelos Aproximados. Esses componentes são apresentados no próximo capítulo. 


\section{Capítulo 7 - Poligonalização e Apresentação dos Modelos Implícitos}

\subsection{Considerações Iniciais}

Este capítulo apresenta o desenvolvimento de dois componentes do Modelador: o Poligonalizador e o Visualizador. O Poligonalizador é responsável pela conversão da definição implícita de um modelo em uma malha poligonal, que aproxime o modelo definido implicitamente, e o Visualizador é résponsável por aptesentar essa malha poligonal para uma verificação.

O Poligonalizador é definido por três módulos apresentados nas três próximas seções. A seção 7.2 apresenta como é a avaliação de um modelo implícito no Poligonalizador, descrevendo a estrutura de dados responsável por essa avaliação. A seção 7.3 apresenta como é definida a aptoximação do modelo implícito pelo método de poligonalização utilizado. A seção 7.4, finaliza a descrição do Poligonalizador apresentando o módulo responsável por gerar a brep-estendida que tepresente a aproximação do modelo implícito.

O Visualizador é apresentado na seção 7.5, onde é destacada sua interface e as funções que podem ser realizadas com esse componente. Por fim, são feitas as considerações finais deste capítulo na seção 7.6.

\subsection{Avaliação do Modelo Implícito}

O componente Poligonalizador implementa o método de poligonalização descrito no capítulo 4, esse método calcula as interseções da aproximação da superfície com uma triangulação adaptativa, $J_{1}{ }^{a}$, e gera uma malha de polígonos que aproxima a superfície implícita. Para o cálculo das interseções é necessátio que a função implícita, que define a superfície, seja avaliada nos vértices da triangulação. 
O modelo implícito é definido na Interface de Modelagem. Essa definição é repassada ao Poligonalizador através de um arquivo de definição do modelo implícito. Antes de iniciar a poligonalização propriamente dita o Poligonalizador deve construir uma estrutura de avaliação a partir desse arquivo. Nas próximas seções são apresentadas a descrição do arquivo de definição do modelo implícito, a estrutura de avaliação e como é realizada a avaliação da função implícita.

\subsubsection{Arquivo de Definição do Modelo Implícito}

O Poligonalizador recebe a definição do modelo implícito através do arquivo escrito pela Interface de Modelagem, a sintaxe desse arquivo é apresentada na figura 7.1. Esse arquivo define a triangulação onde será realizada a poligonalização e o modelo implícito definido na Interface de Modelagem.

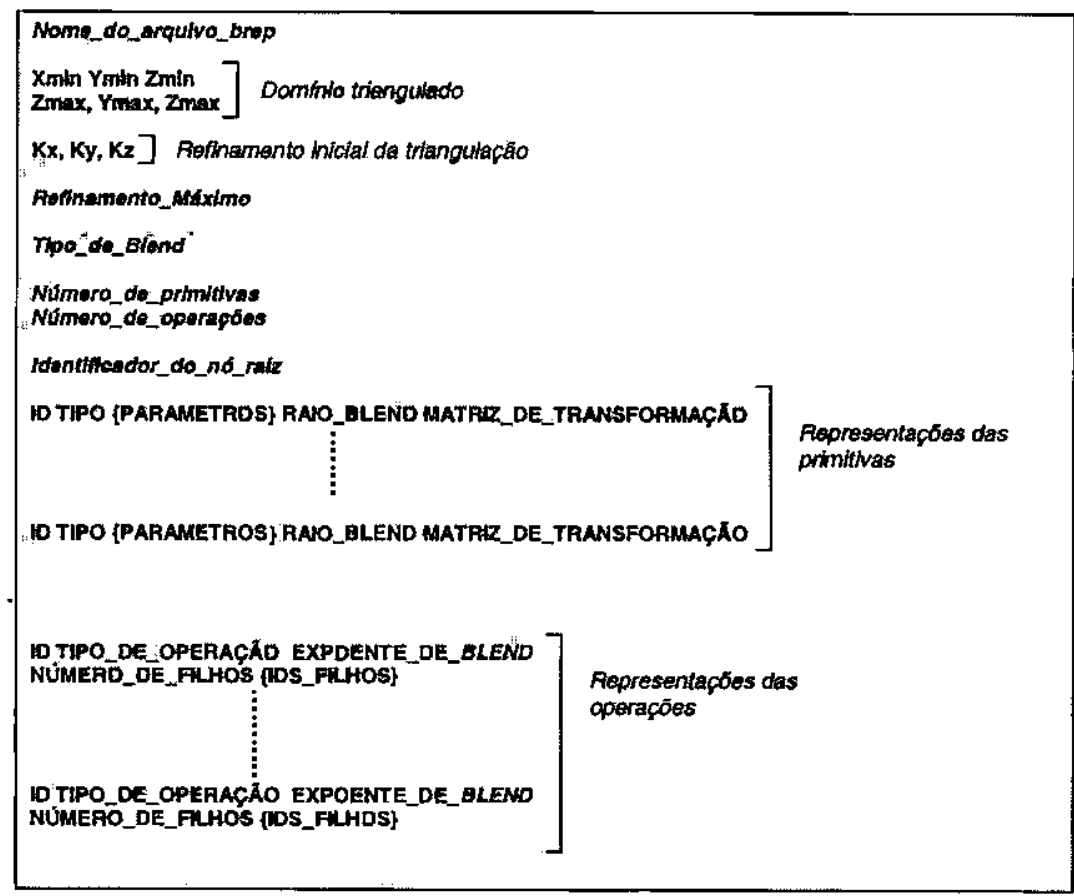

Figura 7.1 - sintaxe do arquivo de definição do modelo implícito.

Os itens definidos no arquivo de definição do modelo implícito são:

Nome arquivo B-Rep - é uma string que indica o nome e o caminho do arquivo onde deve ser registrado o resultado final da poligonalização.

Domínio da triangulação - é uma seqüência de seis números reais que definem um paralelogramo em $\Re^{3}$ onde será realizada a poligonalização. Esse paralelogramo é definido pelos pontos (Xmin, $\left.Y_{\min }, Z_{\min }\right)$ e $\left(\mathrm{Xmax}_{\max } \mathrm{Y}_{\max } \mathrm{Z} \max \right)$. 
Refinamento inicial - é uma seqüência de três números inteiros $(\mathrm{Kx}, \mathrm{Ky}, \mathrm{Kz})$ que definem o número de subdivisões iniciais nos eixos coordenados para a construção da triangulação.

Refinamento máximo - é um númeto inteiro que indica o refinamento máximo da triangulação $J_{1}{ }^{\circ}$ onde é realizada a poligonalização.

Tipo de blend - é um número inteiro que indica o tipo de blend utilizado nas operações do modelo implícito, a tabela 7.3 relaciona o número com o tipo de blend. O tipo de blend utilizado em um modelo é único.

Número de primitivas - indica o número de primitivas presentes no modelo implícito.

Número de operações - indica o número de operações presentes no modelo implícito.

Identificador do nó raiz - indica o identificador do nó raiz do modelo implícito.

Representação das primitivas - consiste de uma lista de itens, conforme o número de primitivas, que descreve as primitivas implícitas presentes no modelo. Cada primitiva é descrita por:

- um identificador numérico que identifica a primitiva dentro do modelo;

- um identificador numérico para tipo da primitiva (tabela 7.1);

- uma lista de parâmettos que definem a primitiva, essa lista depende do tipo da primitiva e seus itens são apresentados na tabela 6.3.

- o taio de blend da primitiva; e

- uma matriz de transformação representada por 16 números reais, essa matriz indica as transformações geométricas realizadas sobre as primitivas durante a modelagem.

Representação das operações - consiste de uma lista que descreve as operações de composição do modelo implícito. Cada operação é descrita por:

- um identificador numérico que identifica a operação dentro do modelo;

- um identificador numérico para tipo da operação (tabela 7.2);

- o expoente da equação de blend;

- o número de filhos, ou operandos, da operação; e

- uma lista com os identificadores dos nós que são filhos da operação.

O conjunto definido por operações e primitivas define uma árvore implícita, uma vez que esse conjunto foi construído na Interface de Modelagem. A primeira tarefa realizada pelo Poligonalizador é recuperat o atquivo de definição modelo implícito e montat uma estrutura para a avaliação do modelo implícito. 
Tabela 7.1 - identificadores para os tipos das primitivas

\begin{tabular}{|l|c|}
\hline \multicolumn{1}{|c|}{} & 0 \\
\hline Esfera & 1 \\
\hline Cilindro & 2 \\
\hline Cone & 3 \\
\hline Toro & 4 \\
\hline Superelipsóide & 5 \\
\hline Paralelogramo & 7 \\
\hline Primitiva baseada em ponto & 8 \\
\hline Primitiva baseada em linha & 9 \\
\hline Primitiva baseada em polígono & \\
\hline
\end{tabular}

Tabela 7.2 - identificadores para os tipos das operaçöes

\begin{tabular}{|l|c|}
\hline \multicolumn{2}{|c|}{$\mid$} \\
\hline União & 0 \\
\hline Interseção & 1 \\
\hline Diferença & 2 \\
\hline
\end{tabular}

Tabela 7.3 - identificadores para os tipos de blend.

\begin{tabular}{|l|c|}
\hline \multicolumn{2}{|c|}{} \\
\hline Nenhum & 0 \\
\hline Global & 1 \\
\hline Pseudo-Euclidiano & 2 \\
\hline
\end{tabular}

\subsubsection{Estrutura de Avaliação do Modelo Implícito}

A função da estrutura de avaliação é representar a função implícita que define o modelo construído na Interface de Modelagem. Essa função implícita é representada por uma árvore implícita, na qual os nós folhas são funç̧ões implícitas definidas pelas primitivas, e os demais nós são as operações de composição que definem uma função implícita a partir de seus operandos. A função implícita do modelo é definida pela função do nó raiz da árvore implícita.

A tabela 7.4 apresenta as estruturas de dados para representação dos nós da árvore implícita. Cada nó da árvore possui um apontador para a descrição do elemento que representa: uma primitiva ou uma operação. As operações possuem uma lista de apontadores para os nós filhos (operandos) e as primitivas possuem um apontador para a descrição dos seus parâmetros, conforme o seu tipo. Para exemplificar a estrutura de avaliação, considerando o modelo implícito a apresentado na figura 6.1 (modelo da.caneca) sua estrutura de avaliação é representada na figura 7.2.

Observando a figura 7.2 cada nó da árvore possui um apontador para uma função que o avalia. Essa função depende do tipo do nó, além disso, conforme o tipo de blend utilizado no modelo a avaliação das primitivas é tealizada pot funções diferentes, como descreve a próxima seção.

\subsubsection{Avaliação dos Nós do Modelo Implícito}

A avaliação do modelo implícito é realizada através da função apontada pelo nó raiz da estrutura de avaliação. Caso o nó taiz seja uma primitiva somente uma função é avaliada. Caso contrátio, o nó raiz seja uma operação, a função de avaliação invoca as funções apontadas pelos nós descendentes. 
Tabela 7.4 - estruturas que implementam a árvore implícita.

\begin{tabular}{|c|c|}
\hline Hothon & 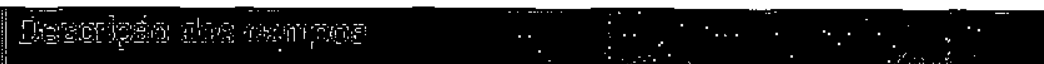 \\
\hline $\begin{array}{l}\text { struct } \text { nodeITree }\{ \\
\text { word } \\
\text { word type; } \\
\text { real radiusofBlend; } \\
\text { void* pElement; } \\
\text { real (*evaluate) ( } \\
\\
\text { nodeITree *ptr, } \\
\text { real } \mathrm{x}, \\
\text { real } \mathrm{Y} ; \\
\text { real } \mathrm{z} \text { ); }\end{array}$ & $\begin{array}{l}\text { index - identificador numérico para um nó da árvote implícita. } \\
\text { type - númeto de } 2 \text { bytes, sendo que o byte mais significativo indica se o } \\
\text { nó é uma primitiva ou uma operação, e o segundo indica o tipo da } \\
\text { operação ou da primitiva. Para as operações o tipo é definido por } \\
\text { uma combinação entre o tipo de blend utilizado no modelo, tabela } \\
7.3 \text {, e o tipo da operação, tabela } 7.2 \text {. Para as primitivas, os valores } \\
\text { são conforme a tabela 7.1. } \\
\text { radiusOfBlend - indica o raio de blend da função implícita definida } \\
\text { pelo nó. Esse campo só é utilizado se o modelo for definido com } \\
\text { blend pseudo-euclidiano, seu valor é fixo para as primitivas e para } \\
\text { as operações é definido a cada avaliação da função. } \\
\text { pElement - é um apontador para a descrição de uma operação ou de } \\
\text { uma primitiva. } \\
\text { (resultado da função implícita) e possui como argumentos a } \\
\text { descrição do nó e as cootdenas do ponto onde a função deve ser } \\
\text { avaliada. }\end{array}$ \\
\hline $\begin{array}{l}\text { struct operation }\{ \\
\text { word } \\
\text { numchildren; } \\
\quad \text { nodeITree* } \\
\text { ptrschildren; } \\
\quad \text { real expoent; } \\
\text {; }\end{array}$ & $\begin{array}{l}\text { numChildren - indica o número de operandos. } \\
\text { ptrsChildren - vetor de apontares que indicam os operandos da } \\
\text { operação representada pelo nó. } \\
\text { expoent - expoente de equação de blend. Esse campo é utilizado se } \\
\text { operação definida pelo nó for definida com blend. }\end{array}$ \\
\hline $\begin{array}{l}\text { struct primitive } \\
\quad \text { void* params; } \\
\quad \text { matrix } 4 \times 4 \\
\text { transformInv; } \\
\text {; }\end{array}$ & $\begin{array}{l}\text { params - é um apontador para urna estrutura que descreve os } \\
\text { parâmetros da primitiva tepresenta. Essa estrutura depende do } \\
\text { tipo da primitiva. As estrutura apontadas pór esse campo são } \\
\text { similares às apresentadas na seção } 6.2 \text {; não'são iguais devido a } \\
\text { presença de alguns campos que auxiliam a avaliação das funções } \\
\text { implícitas das primitivas (seção 7.2.3). } \\
\text { transformInv - matriz de transformação da primitiva invertida.. }\end{array}$ \\
\hline
\end{tabular}




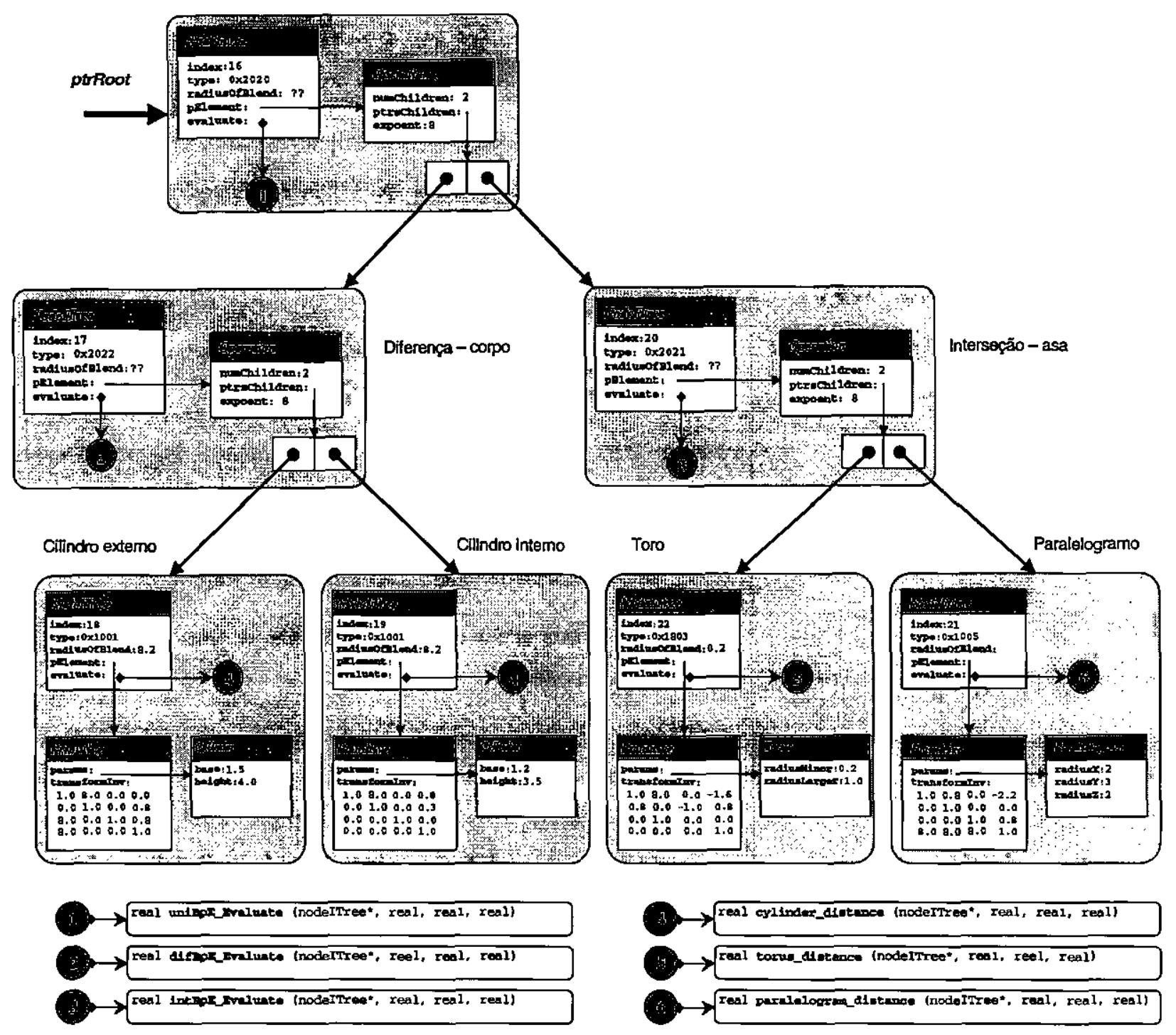

Figura 7.2 - exemplo da estrutura de avaliação.

Conforme a seção 3.4.1, as operações definidas com blend global necessitam que as funções implícitas dos seus operandos, possuam imagem em $\mathfrak{R}^{+}$e definam a superficie pelo valor 1 , ou seja, a superficie é definida por $\left\{\mathrm{p} \in \mathfrak{R}^{3} \mid f(\mathrm{p})=1\right\}$. Já as funções para as operações definidas por blend pseudoeuclidiano, assumem que a definição das superficies a partir do valor 0 , e a função implícita deve indica uma medida de distância para que o raio de blend dos nós faça sentido. Devido a esse problema, as funções para a avaliação das primitivas dependem do tipo de blend utilizado no modelo.

Ó resultado da função de avaliação sempre representa uma medida de distância entre o ponto em que a função é aplicada e a superficie definida implicitamente pela primitiva. Para cada primitiva existem duas m1 edidas de distância: 
distância euclidiana - indica a distância com sinal entre um ponto e a superfície definida pela primitiva. Na superficie o valor dessa função é 0 , no exterior da superfície o valor é positivo e no interior é negativo.

distância relativa - indica uma distância normalizada. Cada primitiva possui loco central, que pode ser um ponto, uma curva ou um polígono. No loco central da primitiva o valor da função implícita é 0 (zero). Na superfície o valor dessa função é 1, no exterior da superfície o valor é maior que 1 e no interior é menor que 1.

As funções que definem a distância euclidiana são utilizadas quando o modelo é definido com blend pseudo-euclidiano, e as de distância relativa são utilizadas com blend global. Caso o modelo seja definido sem blend, é possivel utilizar qualquer uma das medidas. A implementação atual utiliza a distância relativa.

\subsubsection{Avaliação das primitivas}

$\mathrm{Na}$ Interface de Modelagem uma primitiva implícita é criada com uma orientação e posição prédefinidas, mas durante a construção do modelo as primitivas podem sofrer transformações geométricas pata dar a elas uma nova orientação ou posição. Os procedimentos que realizam a avaliação das primitivas implícita assumem que essas primitivas estejam na posição e com a orientação pré-definidas. Para que esta estratégia seja utilizada sem descaracterizar um modelo definido foi utilizada a seguinte propriedade das superficies implícitas:

Seja uma transformação geométrica $T$ tal que, $\mathrm{p}^{\prime}=\mathrm{T}(\mathrm{p})$. Se $\mathrm{T}$ é aplicada a uma superfície implícita, é obtido o mesmo resultado aplicando a transformação inversa nos pontos do espaço onde está a superfície implícita, em outras palavras, $f_{\mathrm{T}}(\mathrm{p})=f\left(\mathrm{~T}^{-1}(\mathrm{p})\right)$, onde $f$ é a função implícita que define a superficie original e $f_{\mathrm{T}}$ define a superficie transformada (Bloomenthal, 1997).

$\mathrm{Na}$ estrutura de avaliação uma primitiva é representada pelos parâmetros de sua definição e por uma matriz que representa o inverso das transformações que a primitiva sofreu durànte sua definição. Como os procedimentos para a avaliação das primitivas supõem uma posição e orientação específica, $\dot{a}$ matriz inversa "ajusta" os pontos do espaço para que a avaliação da função implícita resulte na superfície definida anteriormente. Dessa forma, a avaliação de uma primitiva implícita em um ponto p é dividida em duas etapas: a transformação do ponto p e a resolução da função implícita por um procedimento.

A transformação do ponto é apenas a multiplicação entre uma matriz 4 por 4 e um ponto em coordenadas homogêneas. Para cada primitiva existem dois procedimentos responsáveis pela avaliação 
da função implícita: um representando a distância relativa e outro a distância euclidiana. As funções que esses procedimentos apresentam são apresentados a seguir. É importante destacar que para tornar a avaliação de uma primitiva mais eficiente alguns valores calculados a partir das suas proptiedades são pré-computados como o seno, co-seno e tangente do seu ângulo de rotação de um cone.

\section{Esfera}

O procedimento para a avaliação de uma esfera considera uma esfera de raio $R$ centrada na origem.

$\begin{array}{ll}\text { Distância relativa } & f(\mathbf{p})=\sqrt{\mathbf{p}_{x}^{2}+\mathbf{p}_{y}^{2}+\mathbf{p}_{z}^{2}} / R \\ \text { Distância euclidiana } & f(\mathbf{p})=\sqrt{\mathbf{p}_{x}^{2}+\mathbf{p}_{y}^{2}+\mathbf{p}_{z}^{2}}-R\end{array}$

\section{Toro}

O procedimento para avaliação do toro é definido pela varredura de uma esfera de raio $R_{\text {menor }}$ ao longo de um círculo (círculo gerador) definido no plano xz de taio $R_{\text {maior }}$ A razão entre o $R_{\text {maior }}$ e $R_{\text {menor }}$ é précomputada.

Distância relativa

$$
f(\mathbf{p})=\sqrt{\left(\sqrt{\left(\frac{\mathbf{p}_{x}}{R_{\text {menor }}}\right)^{2}+\left(\frac{\mathbf{p}_{z}}{R_{\text {menor }}}\right)^{2}}-\frac{R_{\text {maior }}}{R_{\text {menor }}}\right)^{2}+\left(\frac{\mathbf{p}_{y}}{R_{\text {menor }}}\right)^{2}}
$$

Distância euclidiana

$$
f(\mathbf{p})=\sqrt{\left(\sqrt{\mathbf{p}_{x}^{2}+\mathbf{p}_{z}^{2}}-R_{\text {maior }}\right)^{2}+\mathbf{p}_{y}^{2}}-R_{\text {menor }}
$$

\section{Superelipsóide}

A função para avaliação da superelipsóide considera uma superelipsóide centrada na origem, definida pelos raios $R_{x}, R_{y}, R_{x}$ e pelos expoentes $s_{x z}$ (controla a forma ao longo dos eixos $\mathbf{x}$ e $z$ ) e $s_{y}$ (controle ao longo de $y$ ).

O calculo da distância euclidiana para o superelipsóide é realizado através do seguinte procedimento:

1. seja $\mathbf{p}$ o ponto em que a função é avaliada;

2. seja $t$ uma semi-reta, definida a partir da origem e passando pelo ponto $\mathbf{p}$, tal que os pontos dessa semi-reta podem ser expressos por $\mathbf{x}=\lambda \mathrm{p}, \operatorname{com} \lambda \geq 0$; 
3. a semi-reta $t$, possui um ponto de interseção com a superficie da superelipsóide, esse ponto é calculado através do parâmetro $\lambda$, através da cquação $g\left(\lambda_{\mathrm{p}}\right)=1.0$, onde $g$ é a função de distância relativa para a superelipsóide;

4. com o valor de $\lambda$, é calculado a distância euclidiana entre p e a superelipsóide.

Distancia relativa

$$
f(\mathbf{p})=\sqrt{\left[\left(\frac{\mathbf{p}_{x}}{R_{s}}\right)^{2 / s_{x}}+\left(\frac{\mathbf{p}_{z}}{R_{z}}\right)^{2 / s_{x}}\right]^{s_{x} / s_{y}}+\left(\frac{\mathbf{p}_{y}}{R_{y}}\right)^{2 / x}}
$$

Distancia euclidiana

$$
\begin{aligned}
\lambda & =\left(\left[\left(\frac{\mathbf{p}_{x}}{R_{x}}\right)^{2 / s_{z}}+\left(\frac{\mathbf{p}_{z}}{R_{z}}\right)^{2 / s_{x}}\right]^{s_{z} / s_{,}}+\left(\frac{\mathbf{p}_{y}}{R_{y}}\right)^{2 / s_{y}}\right)^{-\frac{s_{y}}{2}} \\
f(\mathbf{p}) & =(1-\lambda) \sqrt{\mathbf{p}_{x}^{2}+\mathbf{p}_{y}^{2}+\mathbf{p}_{z}^{2}}
\end{aligned}
$$

Para um superelipsóide todas as divisões que indicam os expoentes das equações implícitas são précomputadas.

\section{Paralelogramo}

A função implícita para um paralelogramo é definida a partit de um paralelogramo centrado na origem e com os lados paralelos aos eixos coordenados e comprimentos definidos pelos parâmetros $L_{\mathrm{x}}, L_{\mathrm{y}} \mathrm{e}$ $L_{z}$. O valor da função implícito é calculado considerando distâncias ao longo de cada eixo e tomando o menor valor.

Distância relativa

$$
\begin{aligned}
& \mathrm{d}_{\mathrm{x}}=\left(L_{\mathrm{x}} / 2.0\right)-\left|\mathrm{p}_{\mathrm{x}}\right| \\
& \mathrm{d}_{\mathrm{y}}=\left(L_{\mathrm{y}} / 2.0\right)-\left|\mathrm{p}_{\mathrm{y}}\right| \\
& \mathrm{d}_{\mathrm{z}}=\left(L_{\mathrm{z}} / 2.0\right)-\left|\mathrm{p}_{\mathrm{z}}\right| \\
& \operatorname{se}\left(\mathrm{d}_{\mathrm{x}}<\mathrm{d}_{\mathrm{y}}\right) \text { e }\left(\mathrm{d}_{\mathrm{x}}<\mathrm{d}_{\mathrm{z}}\right) \text { então } f(\mathrm{p})=2\left|\mathrm{p}_{\mathrm{x}}\right| / L_{\mathrm{x}} \\
& \text { se }\left(\mathrm{d}_{\mathrm{y}}<\mathrm{d}_{\mathrm{y}}\right) \text { e }\left(\mathrm{d}_{\mathrm{y}}<\mathrm{d}_{\mathrm{z}}\right) \text { então } f(\mathrm{p})=2\left|\mathrm{p}_{\mathrm{y}}\right| / L_{\mathrm{y}} \\
& \text { se }\left(\mathrm{d}_{\mathrm{z}}<\mathrm{d}_{\mathrm{y}}\right) \text { e }\left(\mathrm{d}_{\mathrm{z}}<\mathrm{d}_{\mathrm{x}}\right) \text { então } \mathrm{f}(\mathrm{p})=2\left|\mathrm{p}_{\mathrm{z}}\right| / L_{\mathrm{z}}
\end{aligned}
$$

Distância euclidiana

$$
\begin{aligned}
& \mathrm{d}_{\mathrm{x}}=\left(L_{\mathrm{x}} / 2.0\right)-\left|\mathrm{p}_{\mathrm{x}}\right| \\
& \mathrm{d}_{\mathrm{y}}=\left(L_{\mathrm{y}} / 2.0\right)-\left|\mathrm{p}_{\mathrm{y}}\right| \\
& \mathrm{d}_{\mathrm{z}}=\left(L_{\mathrm{z}} / 2.0\right)-\left|\mathrm{p}_{\mathrm{z}}\right| \\
& \operatorname{se}\left(\mathrm{d}_{\mathrm{x}}<\mathrm{d}_{\mathrm{y}}\right) \text { e }\left(\mathrm{d}_{\mathrm{x}}<\mathrm{d}_{\mathrm{z}}\right) \text { então } f(\mathrm{p})=\mathrm{d}_{\mathrm{x}} \\
& \operatorname{se}\left(\mathrm{d}_{\mathrm{y}}<\mathrm{d}_{\mathrm{y}}\right) \text { e }\left(\mathrm{d}_{\mathrm{y}}<\mathrm{d}_{\mathrm{z}}\right) \text { entäo } f(\mathrm{p})=\mathrm{d}_{\mathrm{y}} \\
& \operatorname{se}\left(\mathrm{d}_{\mathrm{z}}<\mathrm{d}_{\mathrm{y}}\right) \text { e }\left(\mathrm{d}_{\mathrm{z}}<\mathrm{d}_{\mathrm{x}}\right) \text { entāo } f(\mathrm{p})=\mathrm{d}_{\mathrm{z}}
\end{aligned}
$$

Em paralelogramo são pré-computadas as metades de cada comprimento, $L_{x}, L_{y}$ e $L_{z}$. 


\section{Cilindro}

A função implícita tradicional de um cilindro descreve uma superfície ilimitada. Por exemplo, a equação $f(\mathbf{p})=\mathbf{p}_{x}^{2}+\mathbf{p}_{z}^{2}-R^{2}=0$, descreve um cilindro de raio $R$ ao longo do eixo y. Para utilização de cilindtos no Modelador, foi necessátio definit uma função implícita para um cilindro limitado, ou segmento de cilindro, de modo que as iso-superfícies descritas pela equação $f(p)=c$ sejam superfícies concêntricas.

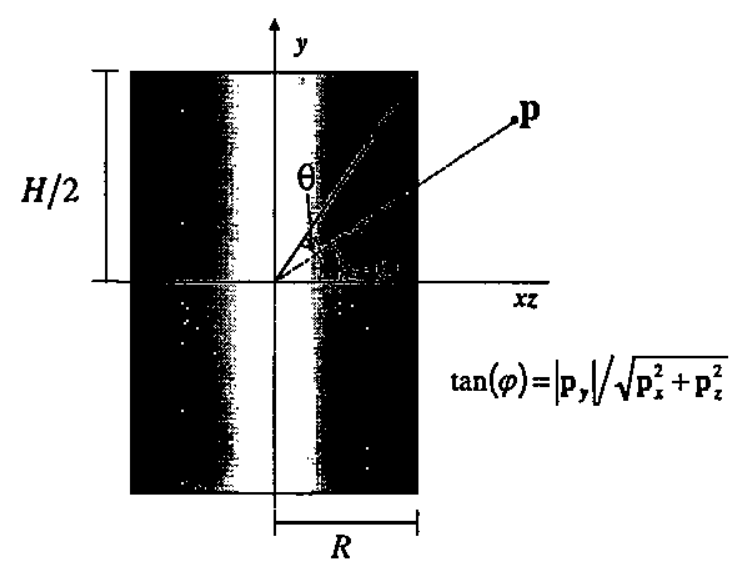

Figura 7.3 - configuração de um cilindro implícito.

Considerando a figura 7.3 , a função implícita implementada no Modelador define um cilindro de raio $R$ e de altura $H$, centrado na origem e orientado ao longo do eixo y. Essa função define uma forma simétrica $\mathrm{em}$ todos os octantes, de modo que toda avaliação pode ser reduzida ao primeiro octante. A avaliação da função implícita do cilindro aplicada em um ponto $\mathrm{p}$ é resolvida do seguinte modo:

1. Seja um triângulo retângulo definido pelos catetos de comprimentos $R$ e $H / 2$, entre a hipotenusa desse triângulo e o cateto $R$ é definido o ângulo $\theta$. $O$ segmento de reta, definido pela origem e o ponto $\mathrm{p}$, define um ângulo $\varphi$ com o plano $\mathbf{x z}$.

2. Se $\varphi$ for maior ou igual a $\theta$, o valor da função implícita do cilindro indicará a distância de $\mathbf{p}$ em relação à base do cilindto.

3. Caso contrário, o valor da função implícita indicará a distância entre p e a lateral do cilindro. 4.

Distância relativa

$$
\begin{aligned}
& \text { se }(\tan (\theta) \geq \tan (\varphi)) \\
& \text { então } f(\mathbf{p})=\sqrt{\mathbf{p}_{x}^{2}+\mathbf{p}_{z}^{2}} / R \\
& \text { senão } f(\mathbf{p})=2|\mathbf{p},| / H
\end{aligned}
$$

Distância euclidiana

$$
\begin{aligned}
& \text { se }(\tan (\theta) \geq \tan (\varphi)) \\
& \text { então } f(\mathbf{p})=\sqrt{\mathbf{p}_{x}^{2}+\mathbf{p}_{z}^{2}}-R \\
& \text { senão } f(\mathbf{p})=\left|\mathbf{p}_{y}\right|-H / 2
\end{aligned}
$$


Para um cilindro é pré-computada a tangente de $\theta$ e a metade da altura.

\section{Cone}

Seja a equação que define um cone com vértice na origem e com o ângulo de rotação $\alpha$ ao longo do eixo $\mathbf{y}, f(\mathbf{p})=\mathbf{p}_{x}^{2}+\mathbf{p}_{z}^{2}-\tan (\alpha) \cdot \mathbf{p}_{y}^{2}=0$. A função implícita definida por essa equação apresenta problemas por descrever uma forma ilimitada, como a função do cilindro, e além de descreve uma não variedade. Para contornar esses problemas foram definidos alguns pontos:

- O cone da equação descreve uma não variedade, potque a tegião dessa forma vizinha ao vértice (origem) não é homeomorfa a um disco. Para contornar esse problema, no Modelador o cone é definido apenas pela porção abaixo do vértice.

- Além do vértice, o cone possui um limite inferior, conforme a altura do cone.

- As formas definidas por $f(\mathbf{p})=c$ devem ser superfícies concêntricas.

Para atender esses pontos foi definido um procedimento semelhante ao do cilindro. A função implícita define um cone com ângulo de rotação $\alpha$ e altura $H$. Esse cone é definido ao longo do eixo y e seu centro (ponto médio do segmento que liga o vértice à base) é a origem.

Seja $\mathbf{p}$ o ponto onde a função implícita do cone é avaliada. Seja um eixo $\mathbf{w}$, tal que a cootdenada de $\mathbf{p}$ nesse eixo é dada por $\mathbf{p}_{w}=\sqrt{\mathbf{p}_{x}^{2}+\mathbf{p}_{z}^{2}}$. Como a forma do cone possui o eixo y como eixo de simetria, a resolução de sua equação pode ser reduzida ao plano wy, mais especificamente ao semi-plano definido por $\mathbf{y} \in \Re \mathrm{ew} \in \mathfrak{R}^{+}$. A figura 7.4 auxilia a compreensão do procedimento que implementa essa função implícita:

1. O ângulo $\theta$ é definido em função do ângulo $\alpha$.

2. A partir dos valores de $\alpha$ e de $H$ é calculado o valor do taio da base $R=H \cdot \tan (\alpha)$.

3. O ponto $\mathbf{p}$, define o ângulo $\varphi$, cuja tangente é dada por: $\tan (\alpha)=\left|\mathbf{p}_{y}\right| / \sqrt{\mathbf{p}_{x}^{2}+\mathbf{p}_{z}^{2}}$

4. Se o valor de $p_{y}$ é menor que 0 e o ângulo $\varphi$ for maior que $\theta$, definido pelo cone, então o valor $\mathrm{da}$ função implícito é definido pela distancia entre o ponto e a base do cone. O ponto $\mathbf{p}^{1}$ ilustra essa condição.

5. Caso contrário, o valor da função implícita é definido pela distância entre o ponto $\mathbf{p}$ e a reta t. Essa teta é definida no plano wy conforme o vértice do cone e o ângulo de rotação $\alpha$. $O$ ponto $\mathbf{p}^{2}$ ilustra essa condição. 


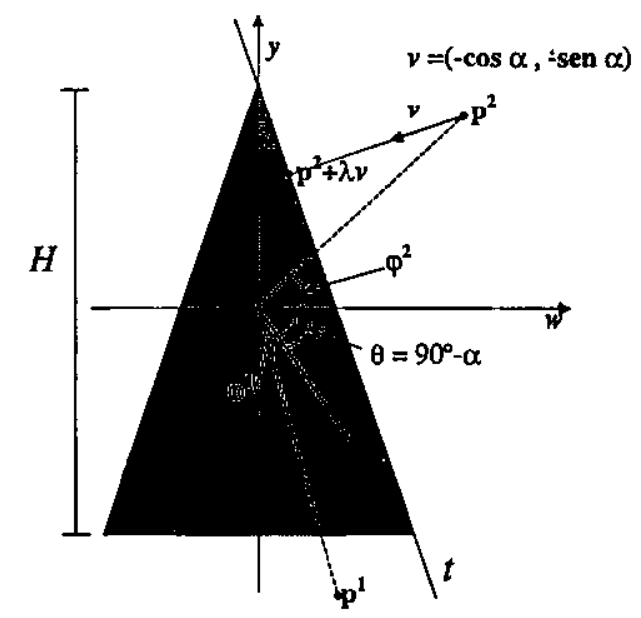

Figura 7.4 - configuração de um cone implícito.

Distância relativa

se $\left(\left(\mathbf{p}_{y} \leq 0\right)\right.$ e $\left.(\tan (\theta) \leq \tan (\varphi))\right)$

entāo $f(\mathbf{p})=\frac{2\left|\mathbf{p}_{y}\right|}{H}$

senão $f(\mathbf{p})=\frac{2 \sqrt{\mathbf{p}_{x}^{2}+\mathbf{p}_{z}^{2}}}{R}+\frac{2 \mathbf{p}_{y}}{H}$

Distância euclidiana

$$
\begin{aligned}
& \text { se }\left(\left(\mathbf{p}_{y} \leq 0\right) \text { e }(\tan (\theta) \leq \tan (\varphi))\right) \\
& \text { então } f(\mathbf{p})=\left|\mathbf{p}_{y}\right|-\frac{H}{2} \\
& \text { ' senão } f(\dot{\mathbf{p}})=\left(\sqrt{\mathbf{p}_{x}^{2}+\mathbf{p}_{z}^{2}}\right) \cdot \cos (\alpha)+\left(\mathbf{p}_{y}-\frac{H}{2}\right) \cdot \operatorname{sen}(\alpha)
\end{aligned}
$$

Para um cone são pré-computados os valores da tangente de $\theta$, seno e co-seno de $\alpha$ e os valotes de $\mathrm{R} / 2 \mathrm{e} \mathrm{H} / 2$.

As funções implícitas do cilindro e do cone implementadas no Modelador não apresentam os inconvenientes das funções originais, mas introduzem pontos não diferenciáveis nas superfícies. Para os cilindros, esses pontos estão definidos nas circunferências que limitam as bases, e para os cones as estão na circunferência da base e no vértice. O problema provocado por esses pontos na poligonalização é a realização de aproximações grosseiras, o que às vezes pode ser contornado por uma poligonalização em uma malha mais refinada.

\section{Primitiva esqueletal definida por ponto}

A superfície definida por um ponto q é uma esfera cujo raio é igual ao range do ponto, Rangeq. As equações para esse tipo de primitivas são similares às equações implementadas pelas esferas. 
Distância relativa

$$
f(\mathbf{p})=\sqrt{\left(\mathbf{p}_{x}-\mathbf{q}_{x}\right)^{2}+\left(\mathbf{p}_{y}-\mathbf{q}_{y}\right)^{2}+\left(\mathbf{p}_{z}-\mathbf{q}_{z}\right)^{2}} / \text { Range }_{\mathbf{q}}
$$

Distância euclidiana

$$
f(\mathbf{p})=\sqrt{\left(\mathbf{p}_{x}-\mathbf{q}_{x}\right)^{2}+\left(\mathbf{p}_{y}-\mathbf{q}_{y}\right)^{2}+\left(\mathbf{p}_{z}-\mathbf{q}_{z}\right)^{2}}-\text { Range }_{\mathbf{q}}
$$

\section{Primitiva esqueletal definida por linha}

A forma definida por uma linha é um cilindro generalizado, como apresentado na seção 5.3. Essa forma é definida pela união das formas definidas pelos segmentos e a função implícita de uma linha é definida por:

$$
f(\mathbf{p})=\min _{i}^{n}\left(g\left(\mathbf{p}, \text { segmento }_{i}\right)\right)
$$

onde $g\left(\mathbf{p}\right.$, segmento $\left._{\hat{j}}\right)$ representa a distância euclidiana ou distância relativa entre o ponto $\mathbf{p}$ e a superficie definida pelo segmento

Para calcular a distância do ponto $\mathbf{p}$ a um segmento $\mathbf{a b}$, deve-se determinar o ponto de $a b$ mais próximo de p, ponto q. A partit de q é determinado o valor do range para o calculo da função g. As fórmulas dessa função são apresentadas a seguir:

Distância relativa

$$
\begin{aligned}
& g\left(\mathbf{p}, \text { segmento }_{i}\right)=\sqrt{\left(\mathbf{p}_{x}-\mathbf{q}_{x}\right)^{2}+\left(\mathbf{p}_{y}-\mathbf{q}_{y}\right)^{2}+\left(\mathbf{p}_{z}-\mathbf{q}_{z}\right)^{2}} / \text { Range }_{\mathbf{p}} \\
& g\left(\mathbf{p}, \text { segmento }_{l}\right)=\sqrt{\left(\mathbf{p}_{x}-\mathbf{q}_{x}\right)^{2}+\left(\mathbf{p}_{y}-\mathbf{q}_{y}\right)^{2}+\left(\mathbf{p}_{z}-\mathbf{q}_{z}\right)^{2}}-\text { Range }_{\mathbf{p}}
\end{aligned}
$$

Distância euclidiana

No procedimento que implementa a função implícita para uma linha o cálculo do ponto q é realizado projetando o ponto $\mathbf{p}$ sobre a reta suporte do segmento ab. A figura 7.5 ilustra essa projeção.

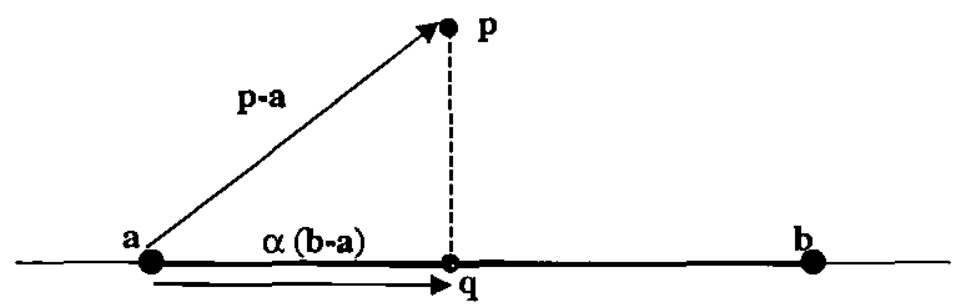

Figura 7.5 - projeção de um ponto em uma reta.

os valores de $\alpha$ e q são dados por:

$$
\begin{aligned}
& \alpha=(\mathbf{p}-\mathbf{a}) \cdot(\mathbf{b}-\mathbf{a}) /\|\mathbf{b}-\mathbf{a}\|^{2}, \mathrm{e} \\
& \mathbf{q}=\mathbf{a}+\alpha(\mathbf{b}-\mathbf{a}) .
\end{aligned}
$$


Para que o ponto $q$ pertença ao segmento ab o.valor de $\alpha$ deve ser truncado de modo que sempre esteja no intervalo [0,1]. Assim, se a projeção de p, estiver à esquerda de a, a equação acima fornece $\alpha$ $<0$, então $\alpha$ deve ser tomado como 0 , e o ponto $q$ deve ser tomado como a. Analogamente, se a projeção estiver à direita de $b$, a equação fornece $\alpha>1$, então $\alpha$ deve ser tomado como 1 e o ponto $q$ como b.

Para tornar os cálculos de $\alpha$ e q mais eficientes, para um segmento ab são pré-computados os vetores d e e:

$$
\begin{aligned}
& d=\mathbf{b}-\mathbf{a}, e \\
& e=d /\|d\|^{2},
\end{aligned}
$$

assim $\alpha$ e q são definidos como:

$$
\begin{aligned}
& \alpha=\max (0, \min ((\mathbf{p}-\mathbf{a}) \cdot \mathbf{e}, 1)), \mathrm{e} \\
& \mathbf{q}=\mathbf{a}+\alpha \mathbf{d} .
\end{aligned}
$$

Além do ponto $\mathbf{q}$ outro dado para computar a função $g$ é o Range $\mathrm{p}$ que indica o valor do range do segmento ab a proximidade de $q$ aos pontos a e b. Essa proximidade é indicada pelo o valor de $\alpha$, e assim o valor do range para o ponto $\mathbf{p}$ é dado por:

$$
\text { Range }_{\mathrm{p}}=(1-\alpha) \text { Rang }_{\mathrm{a}}+(\alpha) \text { Range }_{\mathrm{b}} \text {. }
$$

\section{Primitiva esqueletal definida por polígono}

A forma de uma primitiva definida por um polígono é apresentada na seção 5.3. Os pontos que pertencem à superfície definida por um polígono são aqueles cuja distância mínima em relação ao polígono, $d_{m i n}$, é igual ao range do polígono. Considerando a função $d \min (\mathbf{p})$ que calcula a menor distância entre o ponto $\mathbf{p}$ e o polígono, as funções implícitas para a forma definida por um polígono são:

Distância relativa

$$
f(\mathbf{p})=d \min (\mathbf{p}) / \text { Range }_{\text {poligono }}
$$

Distância euclidiana

$$
f(\mathbf{p})=d \min (\mathbf{p})-\text { Rang }_{\text {poligono }}
$$

A complexidade das funções implícitas descritas acima está no cálculo de dmin. Antes de descrever esse procedimento de cálculo, é importante relembrar que no Modelador um polígono é sempre definido no 
plano xz. O calculo de dmin inicia definindo a projeção p' do ponto p sobre o plano xz (figura 7.6). Conforme a posição de P' em relação ao polígono o calculo de dmin é realizado.

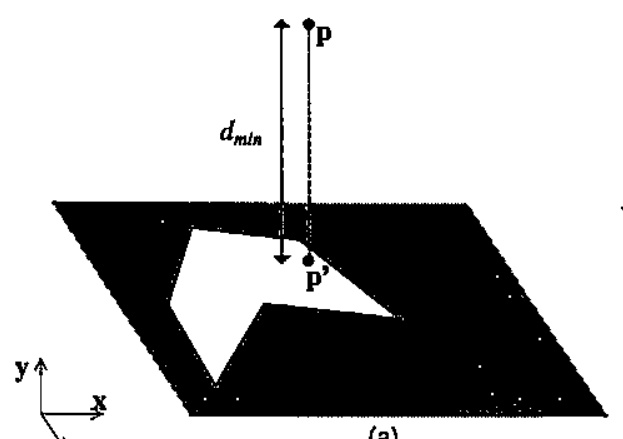

(a)

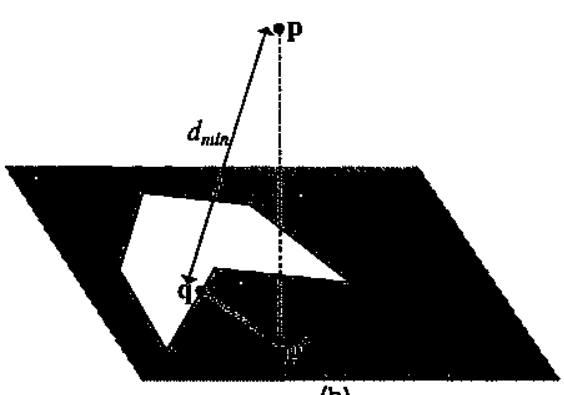

(b)

Figura 7.6 - projeção de um ponto no plano que contém o polígono.

Caso p' esteja dentro do polígono, então o valor de dmin é definido pela coordenada y de p, mais precisamente dmin $=\left|\mathrm{P}_{y}\right|$, esse caso é ilustrado na figura 7.6(a).

Quando p' está fora do polígono o calculo de $d_{\min }$ necessita do ponto do polígono mais próximo de p', o ponto $q$ ilustrado na figura 7.6(b). Para calcular o ponto $q$, em cada aresta do pólígono é determinado o ponto mais próximo de p', e dentre esses pontos, q é tomado como o mais próximo. $\mathrm{O}$ algoritmo utilizado para calcular o ponto mais próximo em uma aresta é similar ao utilizado para o calculo do ponto q em um segmento de reta, mas com a simplificação de arestas e p' estarem sobre o plano xz. Essa simplificação permite a resolução do problema em duas dimensões o que simplifica os cálculos.

Para agilizar o calculo do ponto $q$ em uma aresta $\mathbf{a b}$ do polígono $\left(\mathbf{a}=\left(\mathrm{a}_{\mathbf{x}}, \mathrm{a}_{2}\right)\right.$ e $\mathbf{b}=\left(\mathrm{b}_{\mathbf{x}}, \mathrm{b}_{2}\right)$ ), em cada aresta são pré-computados os vetores e e d, como nos segmentos de reta. Uma vez conhecido o ponto qo valor de dmin é dado por || $\mathbf{p}-\mathbf{q}||$.

Uma etapa importante da avaliação da função implícita definida por um polígono é o teste para verificar se a projeção p' está dentro ou fora do polígono. (Haines, 1994) apresenta um estudo sobre os métodos que realizam esse teste, o método mais eficiente é o Método de Malha (Grid Method). Esse é um método que requer uma etapa de pré-processamento e uma estrutura auxiliar para representar a malha, seu princípio é definir uma malha regular sobre o bounding-box do polígono e classificar as células da malha como internas, externas e intermediárias.

O Método de Malha pode ser dividido em duas etapas pré-processamento e teste. O préprocessamento é a construção da estrutura que representa a malha e a classificação das células. Essa 
etapa é descrita na tabela 7.5, e para cada primitiva definida por polígono na estrutura de avaliação é realizada uma única vez ao construir o polígono.

Tabela 7.5 - etapa de pré-processamento (construçāo da malha) do método de malha Conforme o bounding-box do polígono e uma resolução vertical e horizontal é construída uma malha retangular. Os limites da malha são um pouco maiores que os definidos pelo polígono, de forma que todos os vértices do bordo estejam fora do polígono.

Podem ocorrer problemas de precisão numérica quando um vértice da malha estiver muito próximo a aresta, impedindo a classificação correta do vértice como interno ou externo ao polígono. Para evitar esse problema todos os vértices da malha devem obedecer a uma distância mínima do polígono. Quando a distância mínima não é respeitada a malha é

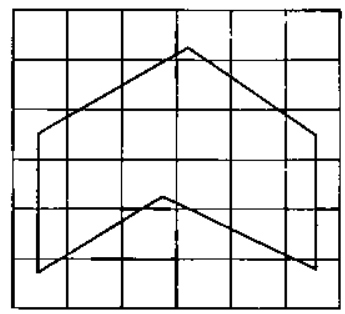
descartada e é construída uma nova tomando os limites da malha um pouco diferentes.

É realizado um percurso sobre as células cortadas pelas arestas do polígono (células intermediárias). Em cada uma đessas células sāo registrados quais dos seus vértices estão dentro do polígono, quais lados da célula sāo cortados e os segmentos de reta definidos pelas arestas do polígono dentro da célula.

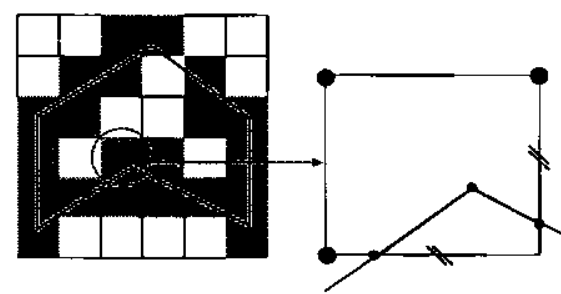

- Vértice da malha intemo ao poligono Segmento definido por uma aresta na célula Lado da célula cortada por uma aresta

Após percorrer as células intermediárias é realizado um percurso na malha marcando ern todas células quais dos seus vértices são internos ao polígono, e se a célula possuir ao menos um lado não cordado então é marcado um desses lados. Uma célula é classificada como interna se todos seus vértices são internos e se não possui vértices internos então é classificada com externa.

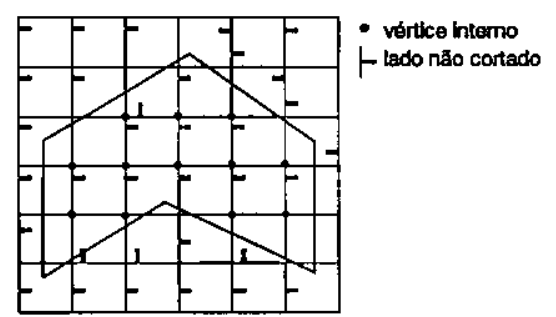

A etapa de teste sempre é realizada ao avaliar a função implícita de um polígono em um ponto p. $O$ teste é realizado com a projeção p'. Essa etapa define o estado do ponto, p', em relação ao polígono (dentro ou fora). O primeiro passo é determinar a célula da malha onde está p'. Se a célula for interna então p' está dentro do polígono, se for externa então p' está fora do polígono. Quando a célula é intermediária o teste é mais complexo. A figura 7.7 mostras os casos de testes.

Para as células intermediárias é realizado um teste de crossing (Haines, 1994) definindo uma linha entre o ponto e o bordo da célula, como uma célula é cortada por poucas arestas então esse teste é eficiente. A tabela 7.6 apresenta o teste de crossing para uma célula intermediária. Usualmente a tesolução da malha é boa o suficiente para que a grande maioria das células seja classificada externa ou interna, assim o teste se restringe a verificar se o ponto está sobe uma célula interna ou externa. 


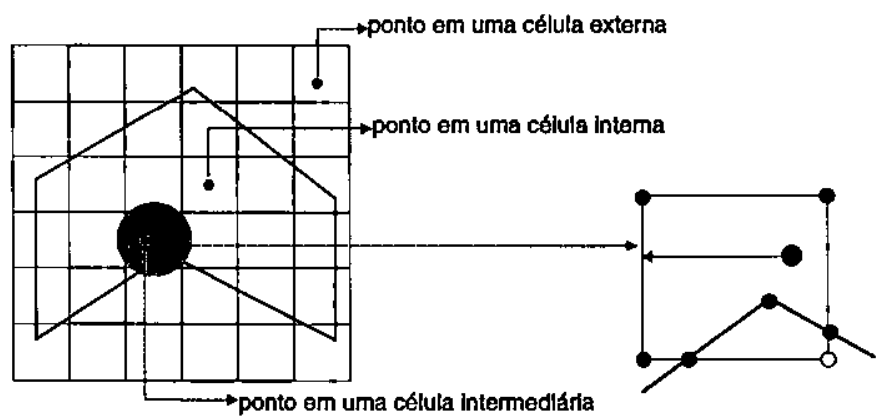

Figura 7.7 - teste de ponto polígono.

Tabela 7.6 - teste de crossing em uma célula intermediária.

\begin{tabular}{|c|c|}
\hline $\begin{array}{l}\text { Caso a célula possua ao menos um lado não cortado, é definida uma linha do } \\
\text { ponto até esse lado e contado o número de vezes que a linha corta os } \\
\text { segmentos definidos na célula. Se esse número for par então o estado do } \\
\text { ponto é igual ao do lado não cortado senão é o contrário. }\end{array}$ & \\
\hline $\begin{array}{l}\text { Caso a célula possua todos os lados cortados, um vértice dessa célula é } \\
\text { escolhido, e uma linha é definida entre esse vértice e o ponto. A definição do } \\
\text { estado do ponto é igual ao caso anterior: se o número de vezes que a linha } \\
\text { corta os segmentos for par então o estado do ponto é igual ao estado do } \\
\text { vértice, senão o contrário. }\end{array}$ & \\
\hline
\end{tabular}

\subsubsection{Avaliação das operações de composição}

Para avaliar uma operação de composição em um ponto $\mathbf{p}$ é necessário avaliar as funções implícitas de cada um dos seus operandos. Isso é realizado com o auxilio da estrutura de avaliação: dada uma operação, cada nó operando é recuperado e sua função implícita no ponto p é avaliada e o resultado é registrado.

As implementações das operações de composição que não utilizam blend, ou que utilizam blend global são simplesmente uma transcrição para linguagem de programação das funções apresentadas nas seções 3.3. e 3.4.1. Para a implementação das composições que utilizam blend pseudo-euclidiano foi necessário expandir as equações de união e interseção para mais de dois operandos e definir um mecanismo de calculo do raio de blend das superfícies definidas em uma composição, ou seja, definir o raio de blend de um nó que represente uma operação. 
$\mathrm{Na}$ aplicação de uma composição com blend pseudo-euclidiano em um ponto p, para cada modelo implícito que participa da composição (nó operando na estrutura de avaliação) é verificado se p está dentro do seu raio de blend, ou seja, se o valor da composição em p é influenciado por esse modelo. Caso p não esteja sob a influência de nenhum modelo implícito o resultado da composição é o menor (maior) valor dentre as funções implícitas dos operandos, caso a composição represente uma união (interseção). Quando a avaliação em p seja influenciada por dois ou mais modelos, para cada um desses modelos é definido um coeficiente $Q$ (equação 3.11 para união e equação 3.13 para interseção), e o resultado é definido a partir desses coeficientes.

De modo semelhante é calculado o raio de blend do nó que representa a operação. No ponto p o raio de blend é definido como uma média ponderada dos raios de blend das primitivas que influenciam o valor da composição em p. O raio de blend calculado é registrado no nó. Como o processo de avaliação da árvore é realizado a partir dos nós folhas para o nó raiz (button-up) o raio de blend calculado pode ser utilizada na avaliação da função de um nó superior.

O algoritmo 7.1 apresenta a avaliação da composição de uma união com blend pseudo-euclidiano em

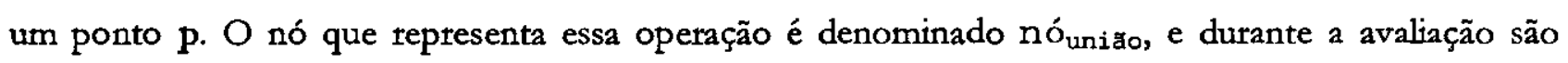
recuperados a lista de filhos e o expoente de blend desse nó. Além de avaliar a função, esse algoritmo calcula e registra o raio de blend do nóunião no ponto p. Para interseção, o algoritmo é muito semelhante, sendo que o critério para definir se uma primitiva influencia ou não um ponto é invertido. Para a diferença é realizada a interseção entre o primeiro operando e o complemento do segundo.

Algoritmo 7.1 - avaliaçäo da função implícita definida pela uniäo com blend pseudo-euclidiano.

\begin{tabular}{|c|c|c|}
\hline \multirow{2}{*}{\multicolumn{3}{|c|}{ 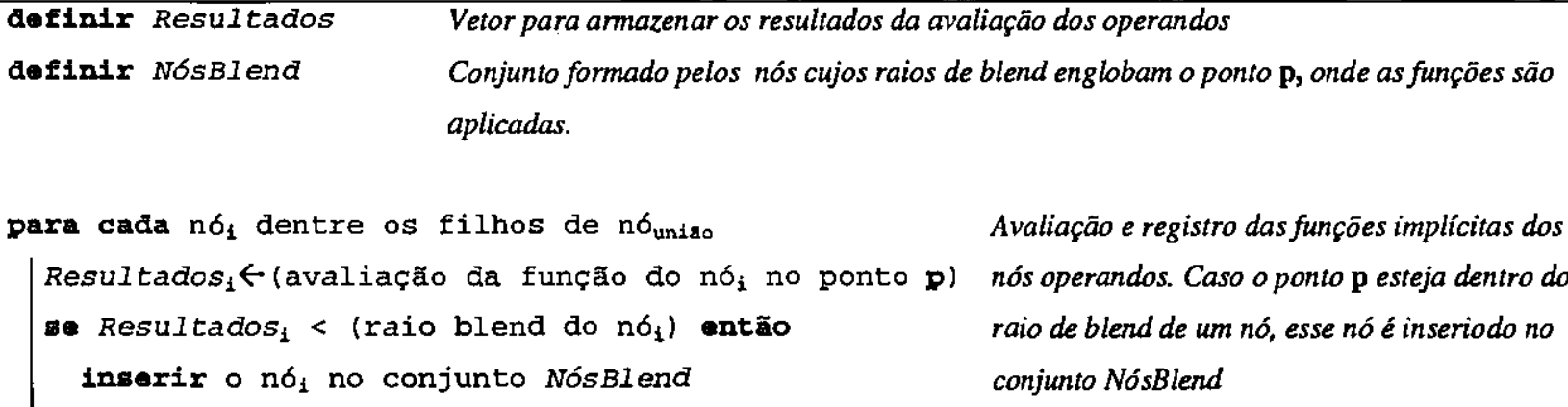 }} \\
\hline & & \\
\hline $\begin{array}{l}\text { (NósBlend está vazio) ontão } \\
\text { encontrar nój associado ao menor resultado } \\
\text { dentre os Resultados } \\
\text { (raio blend do nó }{ }_{\text {uniao }} \leftarrow \text { (raio blend do nó }{ }_{j} \text { ) } \\
\text { ResultadoFinal } \leftarrow \text { Resultados } j\end{array}$ & $\begin{array}{l}\text { Caso o } \\
\text { nos ope } \\
\text { valor de }\end{array}$ & $\begin{array}{l}\text { Donto p esteja fora do raio de blend de todos os } \\
\text { randos, o resultado da composição é o menor } \\
\text { ntre os Resultados e o raio de blend da } \\
\text { ção é igaul ao raio de blend do nó associado a } \\
\text { ultado }\end{array}$ \\
\hline
\end{tabular}




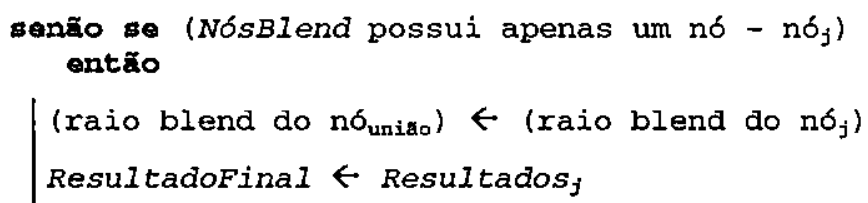

Caso o ponto $\mathrm{p}$ esteja dentro do raio de blend de apenas um nó operando, o resultado da composição e o raio de blend da composiçāo são definidos por esse nó.

Caso o ponto p esteja dentro do raio de blend de dois ou mais nós operandos, para cada um desses nós é definido um coeficiente $Q$ a partir do qual é calculado um raio de blend com média ponderada e o resultado da composição

hetornar Resultado inal

Nesta seção foi descrito como é a avaliação e a representação de uma função implícita definida a partir do modelo criado na Interface de Modelagem. A avaliação do modelo é necessária para construir a sua aproximação, descrita na próxima seção.

\subsection{Poligonalização do Modelo Implícito}

A estrutura de avaliação foi implementada neste o projeto, mas o processo de poligonalização foi implementado por Siqueira, e descrita em (Castelo et al., 1997). O código fonte do método foi estudado para a compreensão das estruturas que representam a superficie poligonalizada e para incorporar a estrutura de avaliação ao método implementado. Esta seção apresenta o comportamento da representação da superfície aproximada durante o processo de poligonalização.

A estrutura de dados para representar uma triangulação $J_{1}{ }^{a}$ e a aproximação da superfície é denominada esqueleto combinatótio, seção 4.4.2. A implementação do esqueleto combinatório é uma estrutura hierárquica que representa os blocos, os simplexos, as faces, as arestas e os vértices da triangulação. Apenas os elementos da triangulação que possuem interseção não vazia com aproximação são representados. Os elementos da triangulação são representados em quatro níveis hierárquicos, sendo 
que as arestas e os vértices, são representados no mesmo nível. .Na figura 7.8 apresenta a hierarquia das estruturas na implementação do esqueleto combinatótio e a seguir são descritas essas estruturas.

Bloco - descreve o conteúdo de um bloco da triangulação. A estrutura de um bloco permite gerenciar o cálculo das interseções entre a superfície aproximada e seus simplexos através de uma fila de simplexos ativos e de uma pilha de simplexos passivos. Um simplexo é classificado como ativo se possui intercessão e essa ainda não foi registrada; em um simplexo passivo a interseção já está registrada. Um bloco pode ser refinado e gerar oito novos blocos que são associados ao bloco gerador através oito apontadores. Apenas os blocos refinados com interseção são representados. A estrutura para representar um bloco também tegistra o nível de refinamento e o tipo do bloco (básico ou de transição).

Simplexo - representa um simplexo (tetraedro) da triangulação que possui uma interseção não vazia com a superficie aproximada. Para indicar a qual bloco pertence, um simplexo possui um apontador para o bloco. Durante o processamento, um simplexo pode registrar entre zero e quatro de suas faces interceptadas pela aproximação da superfície, e ao fim sempre três ou quatro faces. Para controlar essas interseções é utilizado um contador e um array que registrará as faces ativas, ou seja, as faces que possuem interseção (a estrutura de face ativa é apresentada a seguir). Um simplexo sempre está em uma fila de simplexos ativos ou em uma pilha de simplexo passivos e para implementar essas estruturas existe um apontador para um próximo simplexo.

Face ativa - uma face ativa é uma estrutura intermediária entre um simplexo e a descrição de uma face da triangulação. Uma face da triangulação interceptada é compartilhada por dois simplexos, exceto as faces do bordo da triangulação, mas cada simplexo registra uma face ativa diferente. A interseção entre a aproximação e uma face é um segmento de reta, definido pela interseção entre a aproximação e duas arestas da face. Uma face ativa registra além do seu rótulo, os rótulos de suas arestas interceptadas, a orientação da interseção e um apontador para a dẹscrição da face da triangulação.

Face - representa uma face da triangulação. Essa estrutura registra: dois apontadores para as suas duas arestas interceptadas pela aproximação; dois apontadores para os simplexos que compartilham a face representada; e um flag para indica se a face pertence ou não ao bordo da triangulação. Todas as faces são armazenadas em uma lista, de modo que são utilizados dois apontadores para indicar a face anterior e próxima dentro dessa lista.

Aresta - representa uma aresta da triangulação que possui uma interseção com a superfície aproximada. Essa interseção é um ponto. Uma aresta é definida por dois vértices da triangulação. A estrutura 
da aresta também registra as coordenadas do ponto de interseção e o valor do gradiente da função implícita nesse ponto. Todas as arestas são representadas em uma lista e por isso são utilizados apontadores para indicar a aresta anterior e a próxima dentro dessa lista.

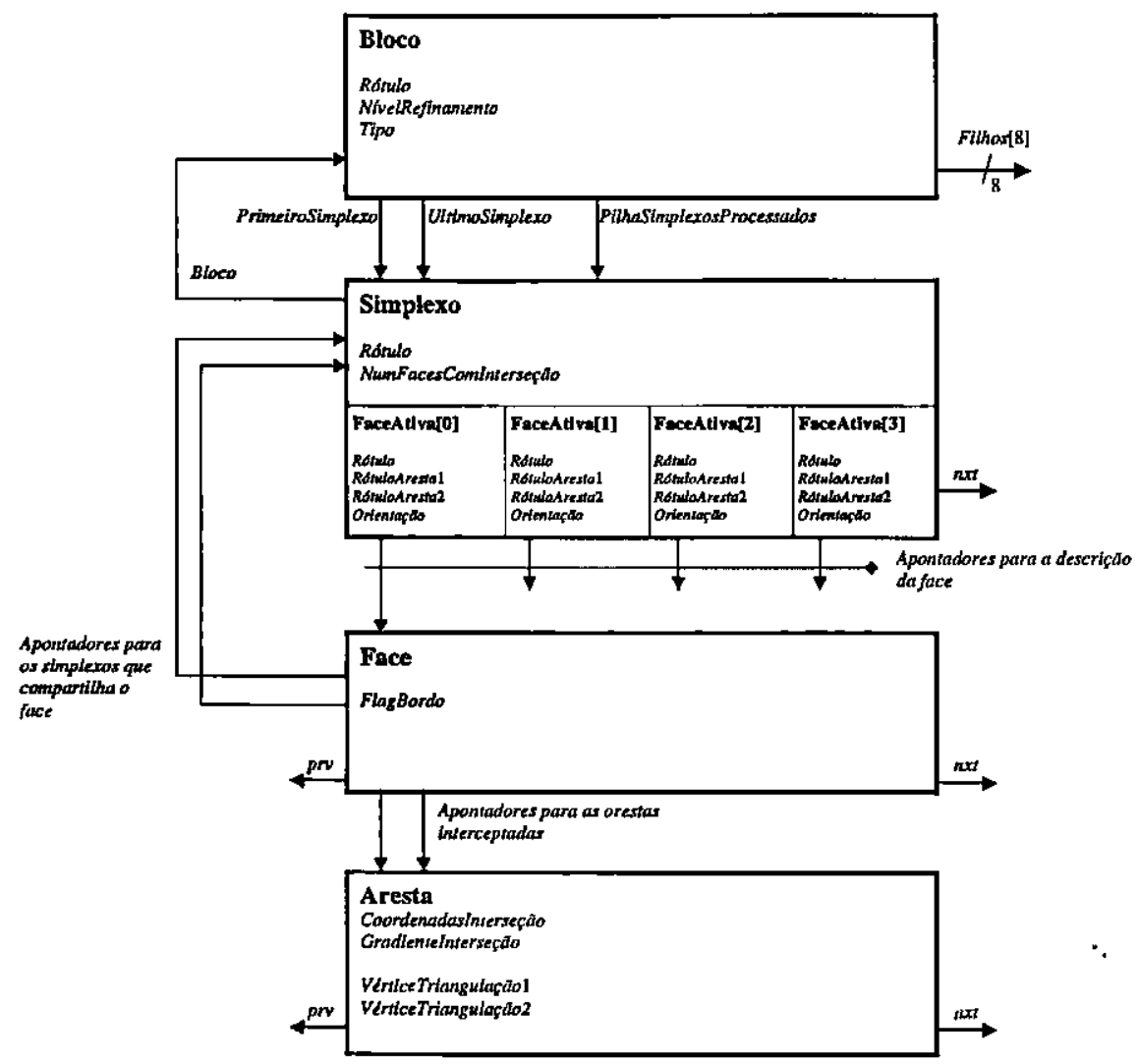

Figura 7.8 - estrutura do esqueleto combinatório.

O esqueleto combinatório é uma estrutura dinâmica, criada e alterada durante o processo de poligonalização. O comportamento dessa estrutura em cada etapa da poligonalização, inicialização, poligonalização uniforme e adaptativa, é apresentada a seguir.

\section{Inicialização}

Conforme o domínio da triangulação $\left(X \min , X_{\max }\right) \times(Y \min , Y \max ) \times\left(Z \min , Z_{\max }\right)$, o refinamento inicial $(\mathrm{Kx}, \mathrm{Ky}, \mathrm{Kz})$ e o refinamento máximo são construídos um array com os blocos do nível de refinamento zero e o cubo de perturbação da triangulação.

\section{Poligonalização Uniforme}

Durante o processo de poligonalização é utilizada uma fila de blocos ativos. A fila de blocos ativos indica os blocos que possuem interseção com a superficie, mas essa interseção aindà não está tegistrada, 
ou seja, ainda não estão determinados os polígonos gerados pela interseção entre dos simplexos do bloco e a superfície aproximada.

Em cada bloco do nível de refinamento zero gerado na inicialização, é verificado se existe um simplexo que possui interseção com a aproximação da superficie. Caso exista o bloco é inserido na pilha de blocos ativos e o simplexo é inserido na fila de simplexos ativos do bloco.

A aproximação da superfície é calculada desempilhando os blocos ativos, a fila de simplexos ativos desses blocos são processadas: para cada simplexo é gerado um polígono que representando a interseção com a superfície aproximada e esses simplexos são colocados na pilha de simplexos passivos do bloco. Os polígonos são definidos no esqueleto combinatório pelas faces e arestas da triangulação e representa a aproximação da superfície no simplexo. Além das interseções, para cada bloco é estimado um valor para o seu nível de refinamento.

Ao final da poligonalização uniforme, existe uma aproximação inicial da superficie e a estimativa de refinamento de cada bloco. Caso nenhum bloco necessite de refinamento a poligonalização é encerrada, caso contrário passa-se à poligonalizaçāo adaptativa.

\section{Poligonalização Adaptativa}

A poligonalização adaptativa deve ser realizada até que todos os blocos sejam refinados respeitando o erro relativo máximo e o nível de refinamento máximo. A implementação atual permite a realização de apenas um passo adaptativo, ou seja, após a poligonalização uniforme, os blocos do nível zero são refinados apenas uma vez conforme a estimativa e o processo não é realimentado.

A poligonalização adaptativa inicia refinando os blocos conforme a estimativa, gerando novos blocos na triangulação. Nesse processo cada nível de refinamento possui sua própria pilha de blocos ativos. As novas interseções são calculadas nos blocos refinados, utilizando a pilha de blocos ativos e as filas de simplexos ativos. Com essas novas interseções são gerados novos polígonos que substituem aqueles que foram definidos nos blocos refinados.

Ao fim de um passo adaptativo é definida uma nova aproximação:

- a estrutura de blocos é definida a partir do array de blocos do nível zero, que, indicam os blocos refinados da triangulação;

- nos blocos, as filas de simplexos ativos de cada bloco estão vazias, todos simplexos foram processados; 
- os simplexos que possuem interseção com a superficie aproximada estão nas pilhas de simplexos passivos dos blocos;

- os simplexos passivos registram as faces da triangulação que possuem interseção com a aproximação, faces ativas;

- as faces ativas indicam as arestas que possuem interseção; e

- os pontos de interseção entre aproximação e a triangulação são registrados nas arestas.

Os processo de poligonalização foi estudado pata incorporar a estrutura para avaliação de um modelo implícito definido no Modelador, mas o método em si não foi alterado. Além da estrutura de avaliação, foi adicionado no Poligonalizador um método pata converter o esqueleto combinatório na estrutura de brep-estendida apresentada na seção 4.5.2.

\subsection{Conversão do Esqueleto Combinatório para B-Rep Estendida}

O esqueleto combinatório representa a superficie aproximada pela parametrização dos elementos da triangulação, e apresenta alguns problemas descritos na seção 4.5. Pata contotnar esses problemas foi implementado um método para converter o esqueleto combinatório em uma brep-estendida.

Esse método é dividido em duas partes: extração das cascas e classificação das̀ cascas em pseudosólidos. Na extração das cascas todo esqueleto combinatório é percotrido para agrupar os polígonos da aproximação corretamente orientados em cascas, ou seja, superficies com uma única componente conexa. Após a extração das cascas, essas são agtupadas conforme a geometria em pseudo-sólidos.

\subsubsection{Extração das Cascas}

Ao final do processo de poligonalização os simplexos do esqueleto combinatótio definem os polígonos que compõem a aproximação do modelo implícito. Na extração das cascas cada um desses polígonos gera uma face da brep-estendida, com seus vértices, semi-arestas e arestas, e essas faces são agrupadas em cascas.

O algoritmo 7.2 descreve o processo de extração das cascas a partir do esqueleto combinatótio. Esse algoritmo utiliza:

- uma lista de faces para armazenar as faces da brep-estendida geradas pelos simplexos; 
- uma lista para armazenar as cascas getadas;

- uma fila para as faces incompletas, ou seja, aquelas cujo conjunto das semi-arestas não está completo;

- uma fila para armazenar as arestas do bordo;

O algoritmo inicia com a construção de uma lista de faces vazias, é criada uma face para cada simplexo e estabelecida uma associação entre o simplexo e a face da brep-estendida. Em seguida, é escolhida uma face vazia qualquer. Com as informações do simplexo a face é completada.

O processo de completar uma face da brep consiste em criar as semi-arestas e as arestas dessa face, que ainda não existem e ordená-las em um ciclo. Com a criação das arestas são criadas as semi-arestas nas faces vizinhas que passam a ser faces incompletas, ou seja, não possuem todas as semi-arestas. As faces incompletas são colocadas em uma fila de faces incompletas, e a face completada é inserida em uma casca. Para ilustrar:

Seja $F$ uma face da brep que está sendo completada, $F$ é definida em um simplexo $\sigma$ da triangulação, e uma semi-aresta $s$ de $F$ definida em uma face $\tau$ da triangulação, sendo que $\tau \in \sigma$ (figura 7.9). Ao criar $s$, utilizando as informações do esqueleto combinatório, é determinado o simplexo $\rho$ que compartilha a face $\tau$ :

1. Caso exista o simplexo $\rho$, então $\rho$ define uma face $F^{\prime}$ da brep-estendida que é vizinha a $F$, é criada uma semi-aresta $s^{\prime}$, oposta a $s$, na face $F^{\prime}$ e definida uma aresta a partir de $s$ e $s^{\prime}$. Se $F^{\prime}$ não estiver na fila de faces incompletas é colocada nessa fila.

2. Caso o simplexo $\rho$ não exista, o simplexo $\sigma$ está no bordo da triangulação e a semi-aresta $s$ está no bordo da aproximação. Nesse caso é criada uma aresta de bordo a partir de $s$ e essa aresta é colocada na fila de arestas de bordo. Inicialmente uma aresta de bordo possui apenas uma semi-aresta, a outra é definida na construção das faces de bordo.

Assim que uma face é completada ela é inserida na casca em construção. A fila de faces incompletas é a estrutura responsável por agtupar as faces de uma casca. Sempre é criada uma semi-aresta em uma face vazia, essa face é inșerida na fila, e quando fila está totalmente vazia significa que a não existem mais faces a serem adicionadas na casca. Essa afirmação é assegurada pelas relações de vizinhanças definidas no esqueleto combinatório. Como ilustra a figura 7.10 a face inicial de uma casca funciona como uma semente e recursivamente as faces vizinhas a uma face completada são inseridas na casca. 
Algoritmo 7.2 - extração de cascas do esqueleto combinatório.

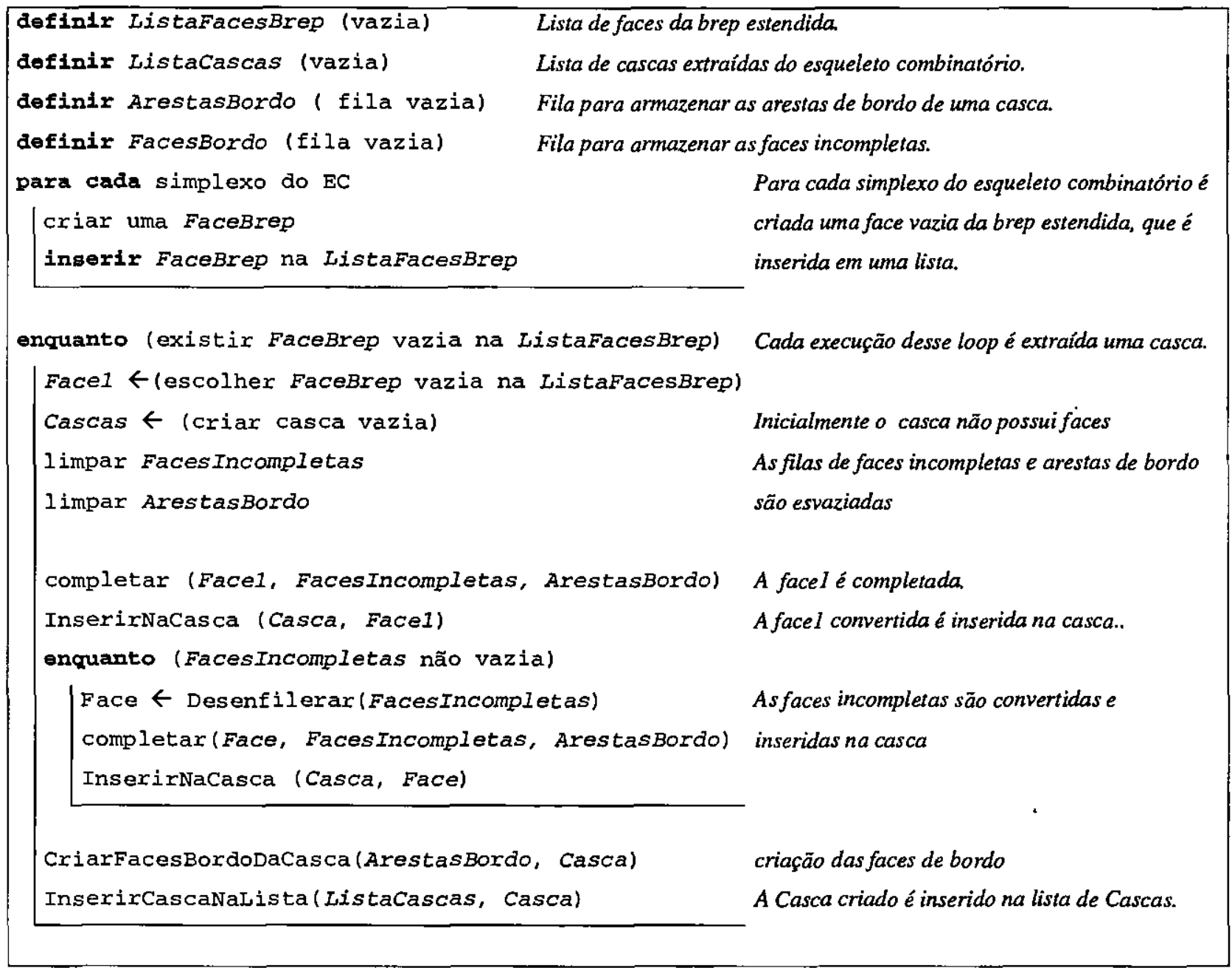

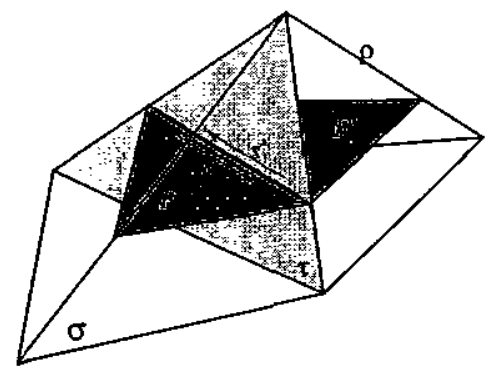

Figura 7.9 - criação das semi-arestas e arestas em uma face da brep.

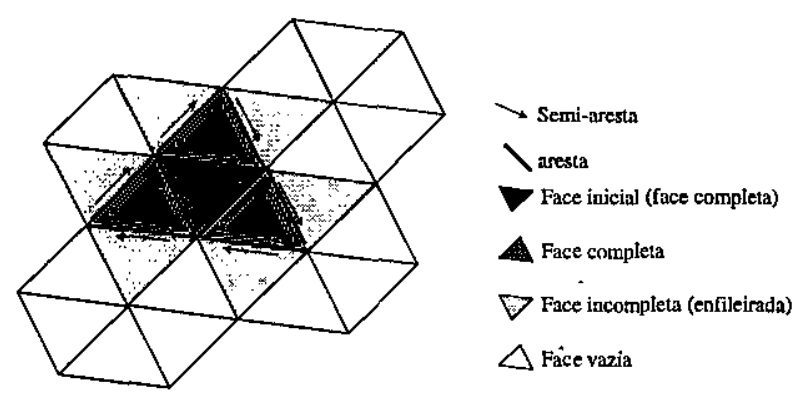

Figura 7.10 - faces completas e incompletas na extração de uma casca.

A fila de arestas de bordo é utilizada para criar as faces de bordo da casca. Uma casca pode possuir nenhuma, uma ou mais faces de bordo. A criação de uma face de bordo consiste em definir as semiarestas opostas para as arestas de bordo e agrupa-las em ciclos. Para agrupá-las é realizado um percurso pelo bordo através das relações de adjacência do esqueleto combinatório. 


\subsubsection{Classificação das Cascas em Pseudo-Sólidos.}

O resultado final da extração de cascas é uma lista que contém todas as cascas da aproximação. Essas cascas são superficies sem relações explícitas entre si. No Modelador podem ser definidos modelos que possuam buracos no seu interior. Esses modelos, são definidos por mais de uma casca: uma casca define o exterior e outras definem os buracos. A classificação das cascas procura agrupá-las em pseudo-sólidos finalizando a construção da brep-estendida que represente a aproximação do modelo.

Durante a extração de cada casca é calculado o seu bounding-box e um ponto $\mathbf{q}$ da casca que pertença ao seu bounding-box. A partir desses itens uma casca é classificada como positiva ou negativa: se o gradiente da função implícita no ponto $q$ "apontar" para o exterior do bounding-box então a casca é considerada positiva, caso contrátio a casca é considerada negativa, figura 7.11. Para que uma casca $A$ defina um buraco no interior de uma outra casca $\mathrm{B}$ é necessátio que o bounding-box da casca $\mathrm{B}$ contenha - bounding-box da casca A, e a casca B seja positiva e a casca A seja negativa. Nessa configuração é dito que a casca $\mathrm{A}$ é interior a casca $\mathrm{B}$.
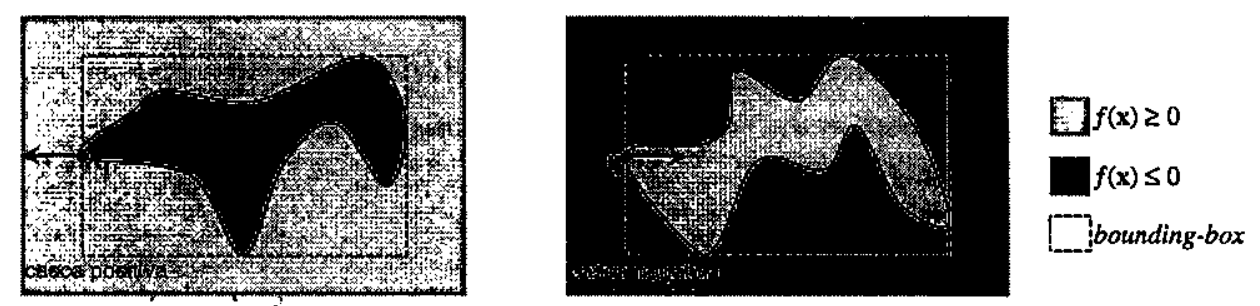

Figura 7.11 - classificação das cascas em positivas e negativas.

O algoritmo 7.3 apresenta o método para classificação das cascas em pseudo-sólidos. Esse método inicia com a ordenação das cascas conforme o volume dos respectivos bounding-box, o que agiliza o processamento, pois para uma casca $A$ ser interior a uma casca $B$ é necessátio que o bounding-box de $B$ seja maior que o de A. O primeiro pseudo-sólido é criado com a casca de maior bounding-box. Em seguida, todas as cascas são processadas. Se uma casca A for interior a outra casca B, então A é inserida no pseudo-sólido definido por $B$. Se a casca A não for interior a nenhuma outra casca, então a partir dessa casca é criado um pseudo-sólido.

Algoritmo 7.3 - classificação das cascas em pseudo-sólidos

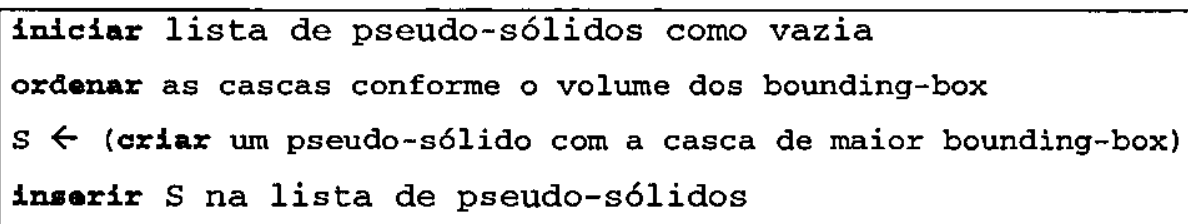




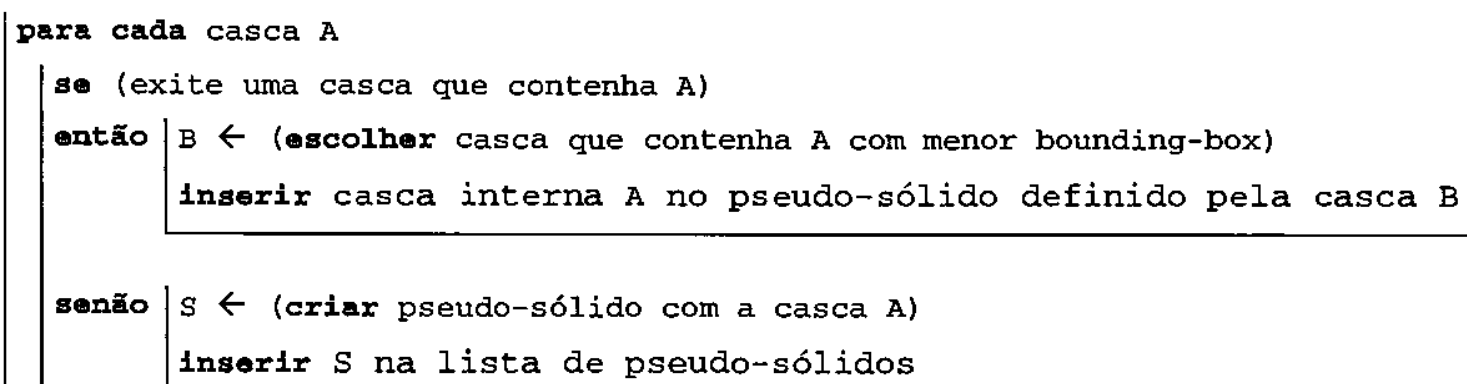

Depois da construção da lista de pseudo-sólidos, está definida a brep-estendida que representa a aproximação do modelo implícito. Essa estrutura é registrada em disco, e pode ser visualizada com o terceiro componente do Modelador, o Visualizador de Modelos Aproximados.

\subsection{Visualização de Modelos Aproximados}

O terceiro componente do Modelador é o Visualizador de Modelos Aproximados. A função desse componente é apresentar os pseudo-sólidos definidos em uma brep-estendida, permitindo a verificação dos resultados da poligonalização. $O$ Visualizador possui sua interface implementada em $\mathrm{Tcl} / \mathrm{Tk}$, e as rotinas para renderizar os pseudo-sólidos foram implementadas em C com o auxílio de OpenGL. A figuta 7.12 apresenta o Visualizador com um modelo poligonalizado, esse modelo é a caneca definida na figura 6.1.

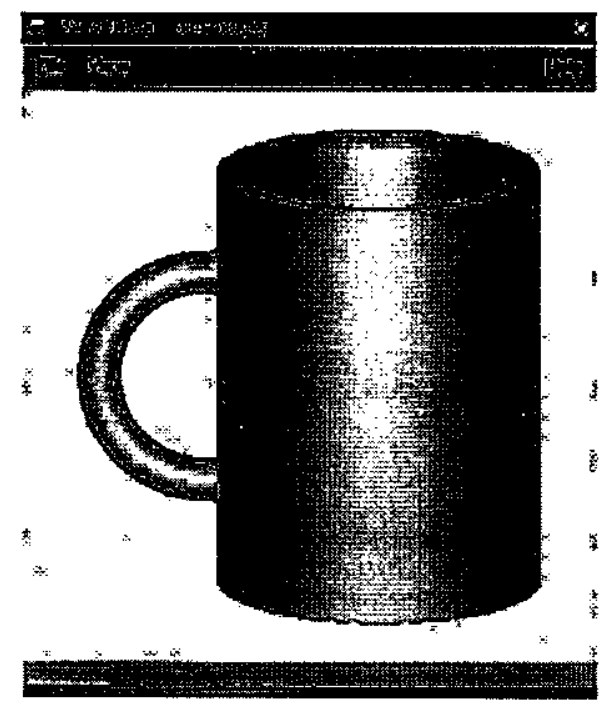

Figura 7.12 - visualização da brep-estendida que representa a caneca definida implicitamente. 
A interface do Visualizador é muito simples, composta apenas de um espaço para apresentação da cena, um menu principal e diálogos para configurar os pseudo-sólidos e a câmera que registra a cena. As funções disponíveis no menu principal do Visualizador são apresentadas na tabela 7.7.

Tabela 7.7 - funções disponíveis da interface do Visualizador.

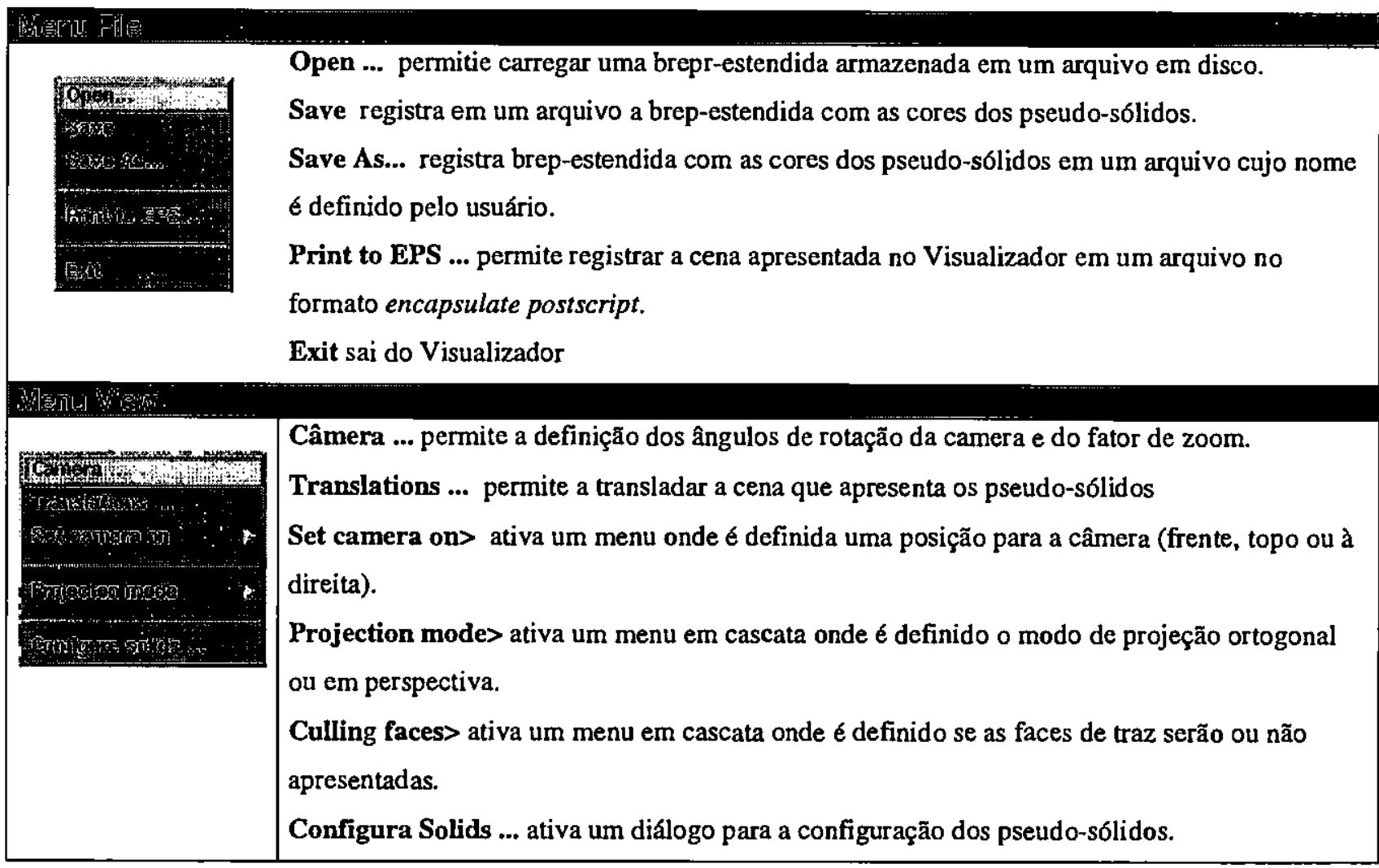

Uma brep-estendida registrada ao fim da poligonalização contém uma lista de pseudo-sólidos. O Visualizador apresenta esses pseudo-sólido atribuindo a cada um uma cor diferente. Ao salvar uma brep-estendida no Visualizador, o arquivo gerado conterá, além das informações geométricas, uma tabela que indica a cor dos pseudo-sólidos.

A implementação da renderização de uma cena nesse Visualizador é semelhante à renderização das primitivas, seção 6.3.2, sendo que ao invés de apresentar os polígonos obtidos parametricamente são apresentados os triângulos resultantes da poligonalização. As facilidades para movimentação da cena nesse componente são similares às do Visualizador de primitivas.

A única operação de edição realizada pelo Visualizador é a configuração da apresentação dos pseudosólidos. Essa operação é realizada a partir de um diálogo, onde pode ser definida a cor com a opacidade de um pseudo-sólido e o seu modo de apresentação. A figura 7.13 apresenta a visualização de uma cena com 2 pseudo-sólidos e a configuração da apresentação de um desses pseudo-sólidos. 
No Visualizador de Modelos Aproximados não é realizada a ordenação das faces do modelo conforme a posição da câmera. Essa ordenação é necessária para que as faces sejam apresentadas de traz para frente e a opacidade das superfícies seja utilizada de modo correto. Essa ordenação não é realizada porque a cada mudança de câmera é necessária uma ordenação e esse procedimento inviabilizaria a apresentação interativa do modelo. A não ordenação provoca erros na apresentação do modelo aproximado, como o observado na figura 7.13 onde apenas uma parte da superfície interior do bule é apresentada.

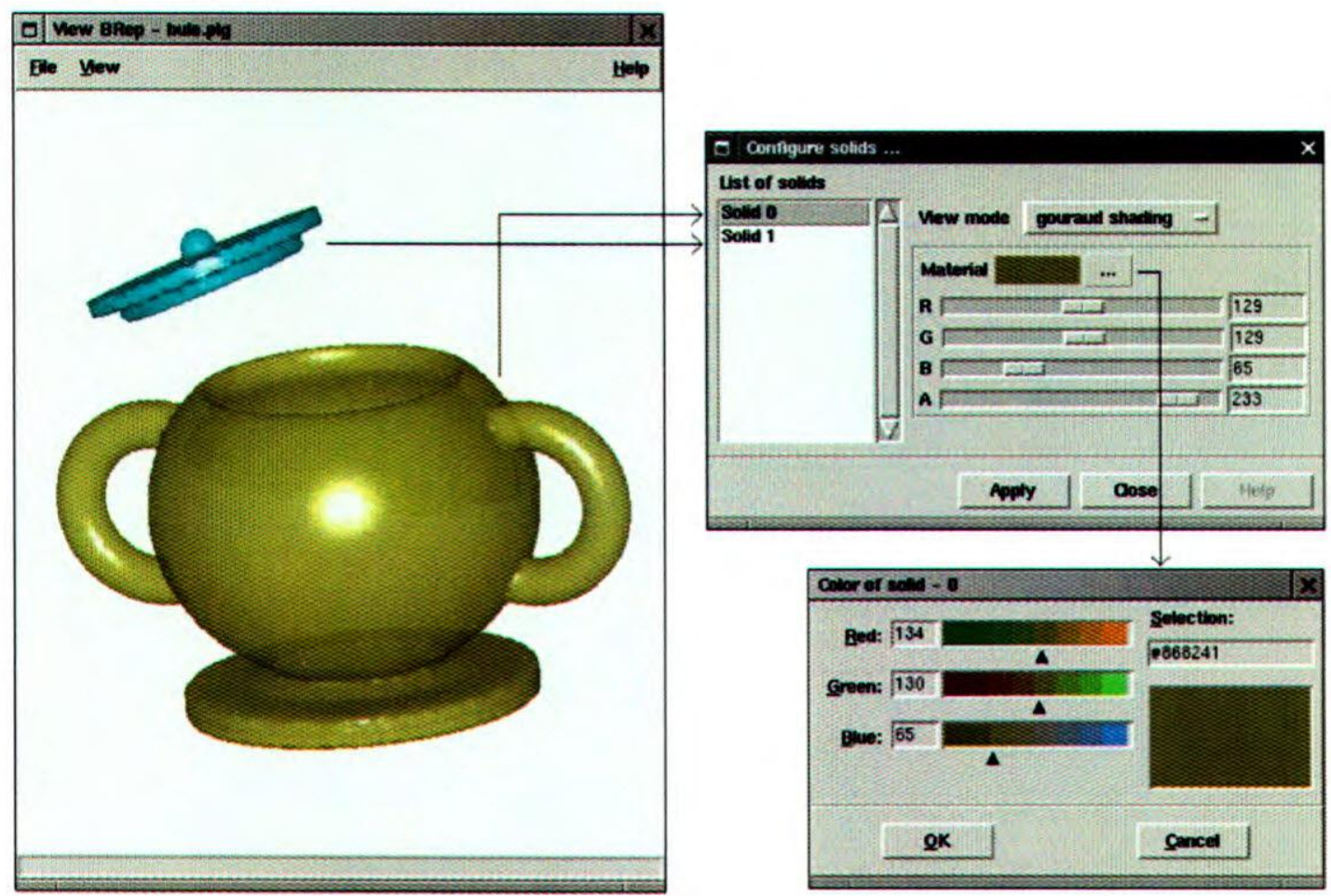

Figura 7.13 - configuração de um pseudo-sólido.

\subsection{Considerações Finais}

Este capítulo apresentou o desenvolvimento do Poligonalizador e do Visualizador de Modelos Aproximados. O Poligonalizador é utilizado para converter a definição implícita de um modelo em uma malha de polígonos representada por uma brep-estendida, e o Visualizador é responsável por apresentar essa malha poligonal. Foi apresentado como é a avaliação de um modelo implícito definido na Interface de Modelagem e como é construída a b-rep estendida a partir dos polígonos gerados na poligonalização.

Este capítulo encerra a apresentação do desenvolvimento do Modelador. No capítulo seguinte são apresentados as conclusões do trabalho realizado e alguns modelos construídos com o Modelador. 



\section{Capítulo 8 - Resultados e Conclusões}

\subsection{Considerações}

A motivação para o desenvolvimento do Modelador de superfícies implícitas foi a necessidade da definição de domínios complexos para simulação de escoamentos de fluídos. Essa necessidade partiu do grupo de mecânica de fluídos computacionais do ICMC/USP, e a partir dela foram estudas as técnicas de modelagem implícita e desenvolvido o Modelador apresentado nesta dissertação.

O Modelador desenvolvido é formado por três componentes, ou progtamas, independentes que cooperam pata realizar a tarefa de modelagem. A técnica implementada permite a criação de modelos complexos através de uma árvore CSG, onde as primitivas são modelos implícitos simples, e as composições usuais (união, diferença e interseção) podem ser definidas com blend pata que as formas modeladas sejam suaves.

Como apresentado no capítulo 2, o conjunto de formas possíveis de se modelar com um sistema baseado em CSG é delimitado pelo conjunto de primitivas que o sistema possui. Entretanto, o conjunto de formas possível de se modelar com o sistema atual é muito amplo, especialmente porque as primitivas baseadas em esqueletos aumentam consideravelmente a número de formas que podem ser modeladas.

A implementação do sistema em componentes independentes e a definição tígida da forma como eles cooperam entre si permite que cada componente possa evoluir independente um do outro. Por exemplo, o Poligonalizador atual deve ser substituído por outro melhor em breve, sem a necessidade de alterar a Interface de Modelagem ou o Visualizador.

Além dessas considerações, este capítulo apresenta algumas formas modeladas com o sistema implementado, as contribuições deste trabalho e sugestões para trabalhos futuros. 



\subsection{Alguns Modelos}

Esta seção apresenta alguns modelos criados com o Modelador desenvolvido. O primeiro exemplo ilustra o uso das diferentes formas de blends implementadas, o segundo ilustra a classificação de cascas em pseudo-sólidos e os demais são alguns exemplos construídos durantes os testes do Modelador.

\section{Formas de blend disponíveis no Modelador}

As formas de blends disponíveis no Modelador são o blend por norma p e o pseudo-euclidiano. Na figura 8.1 é definido um modelo denominado de cano/caixa, que consiste da diferença entre a união de um paralelogramo e um cilindro e uma união de cilindros. O modelo cano/caixa é utilizado para apresentar como a forma de blend influi no modelo final. As figuras de 8.2 a 8.7 apresentam o modelo poligonalizado com diferentes formas de blends. Essas figuras foram obtidas com a superfície um pouco transparente, mas como o Visualizador não ordena as faces do modelo aproximado as partes inferiores de algumas figuras não são apresentadas de modo correto.

As dimensões das primitivas que definem o modelo cano/caixa são as seguintes:

- o cilindro externo possui raio igual a 0.9 e altura igual a 6 ;

- o paralelogramo possui os lados iguais a 2.5 ; e

- os cilindros internos são definidos com raios iguais a 0.5 e a altura é igual a 6.25 para o cilindro maior e 2.75 para os cilindros menores.

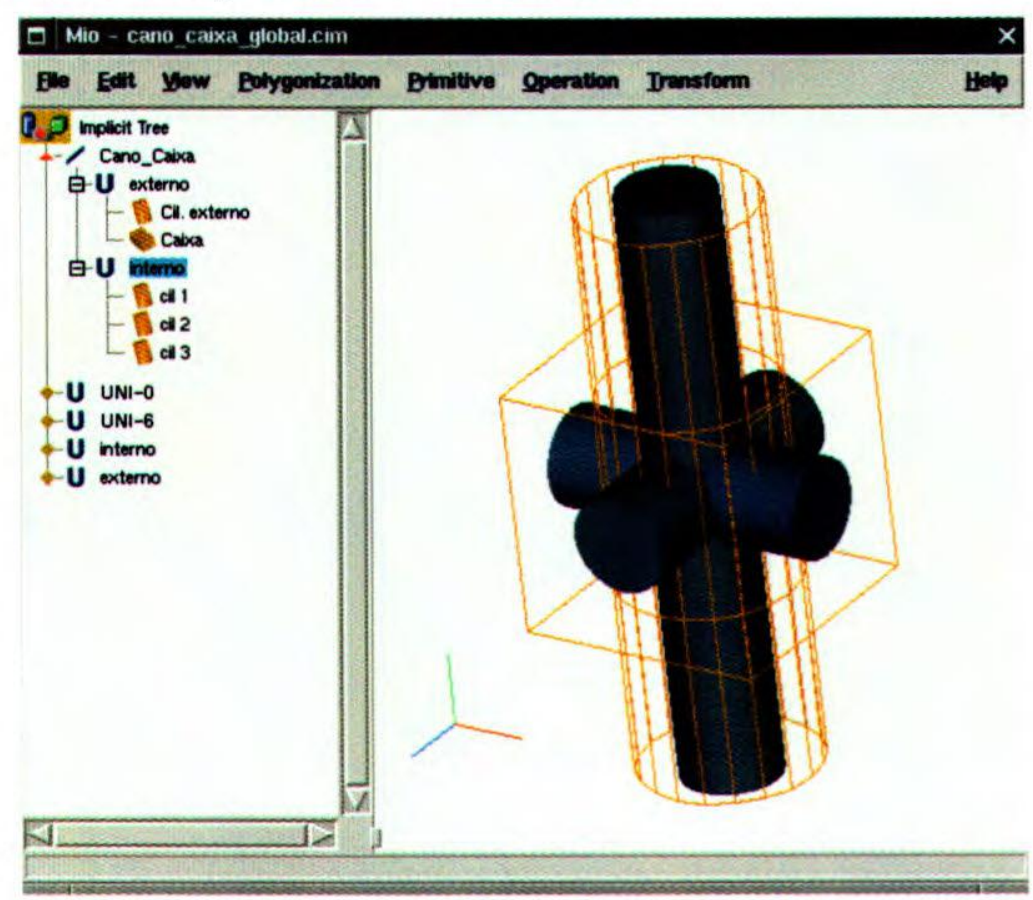

Figura 8.1 - definição do modelo cano/caixa. 


\section{Modelo sem blend}

A figura 8.2 apresenta o modelo cano/caixa sem blend. Em todas as regiões onde as primitivas se tocam deveriam apresentar quinas devido aos operadores min e max das operações de composição, assim como no paralelogramo, mas a poligonalização aproxima algumas dessas quinas incorretamente.

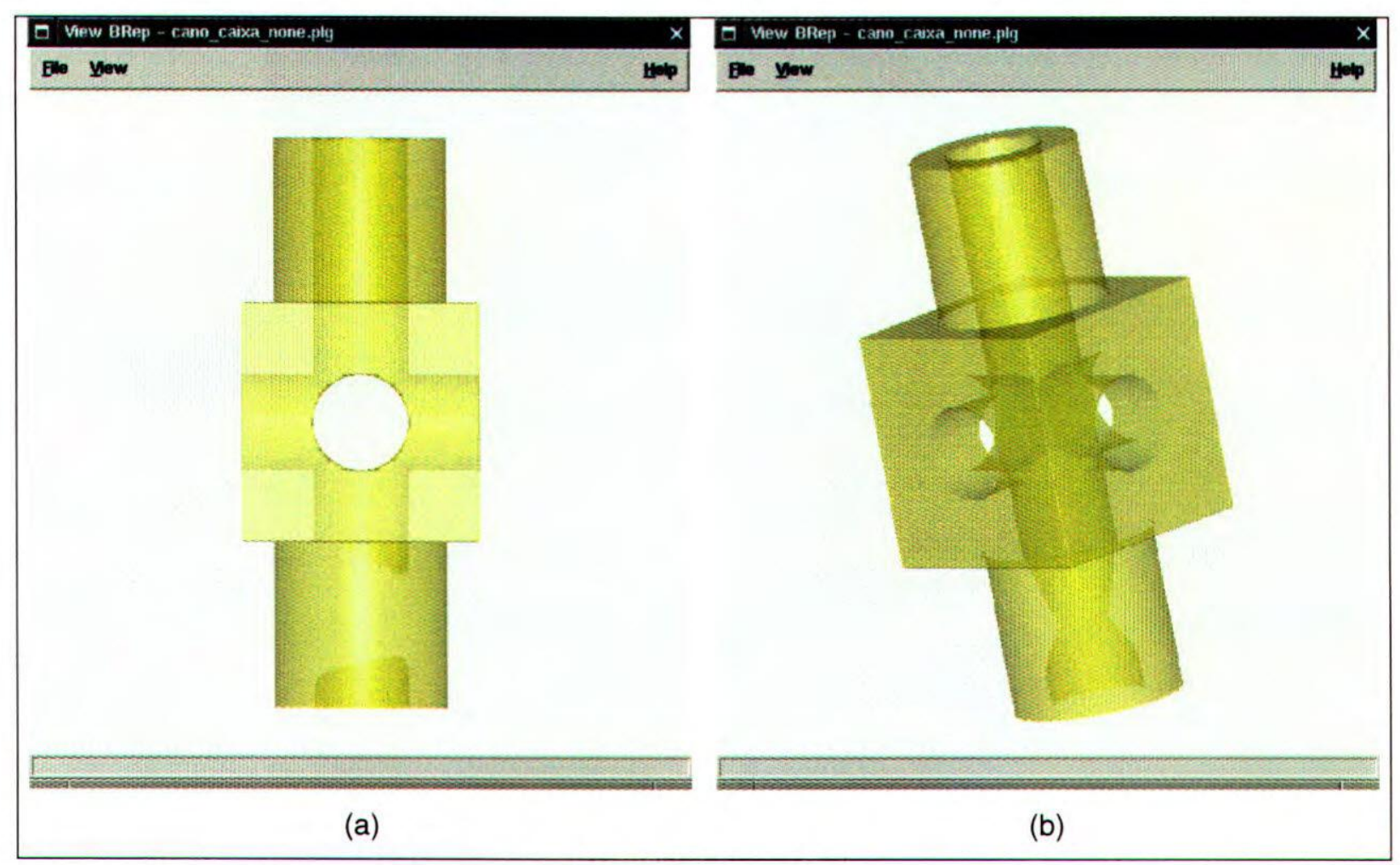

Figura 8.2 - modelo cano/caixa sem blend. 


\section{Modelo com blend por norma $\mathrm{p}$}

As figuras 8.3, 8.4 e 8.5 apresentam o modelo cano/caixa definido com blend por norma p com diferentes expoentes de blend. É observável que quanto menor o expoente mais suave é a forma resultante. Também, é observável que esse blend suaviza toda a superfície e especialmente na figuras 8.3 e 8.4 o resultado é bastante distorcido.

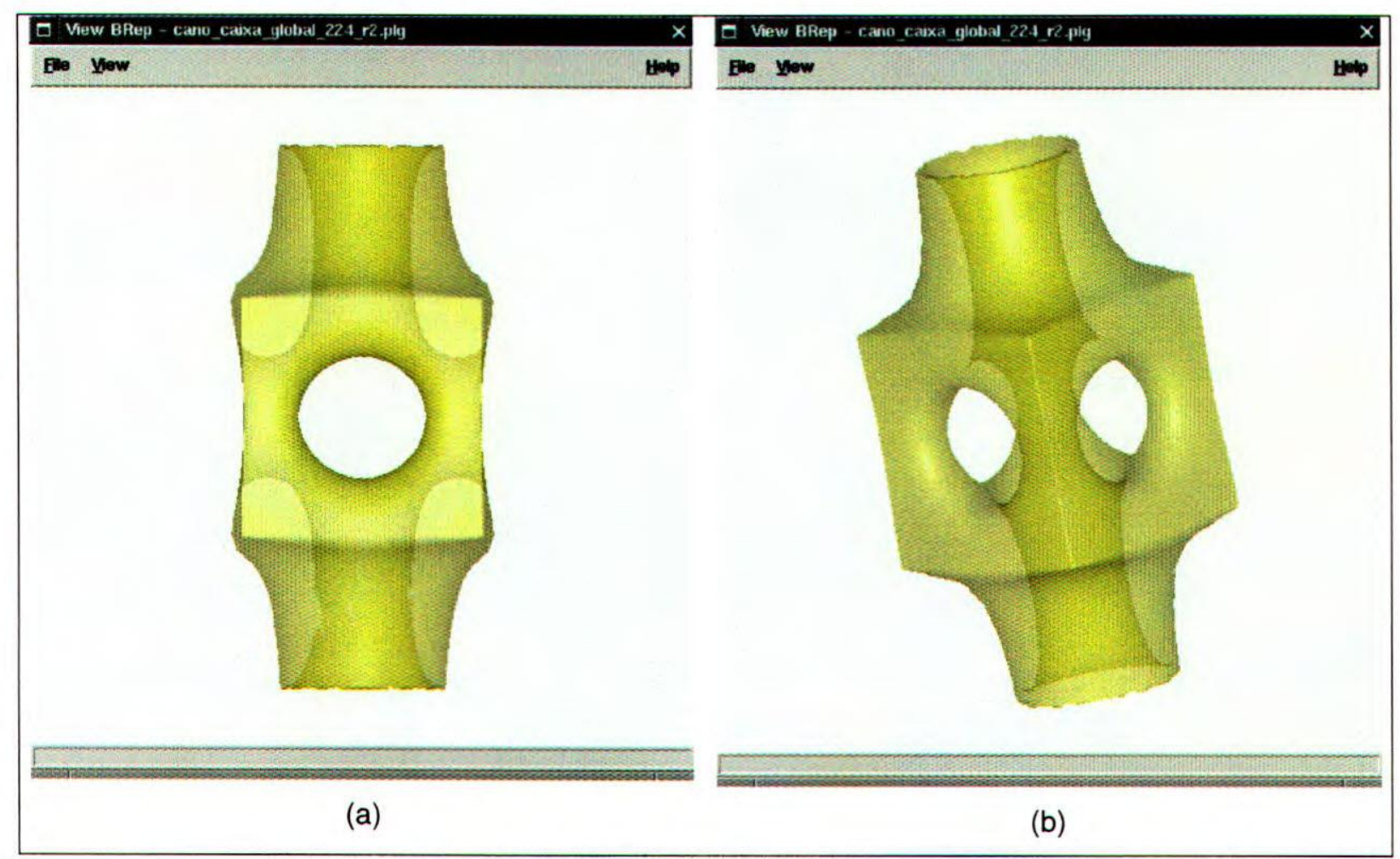

Figura 8.3 - modelo cano/caixa com blend norma p: as uniões são definidas com expoente 2 e a diferença é definida com expoente 4. 


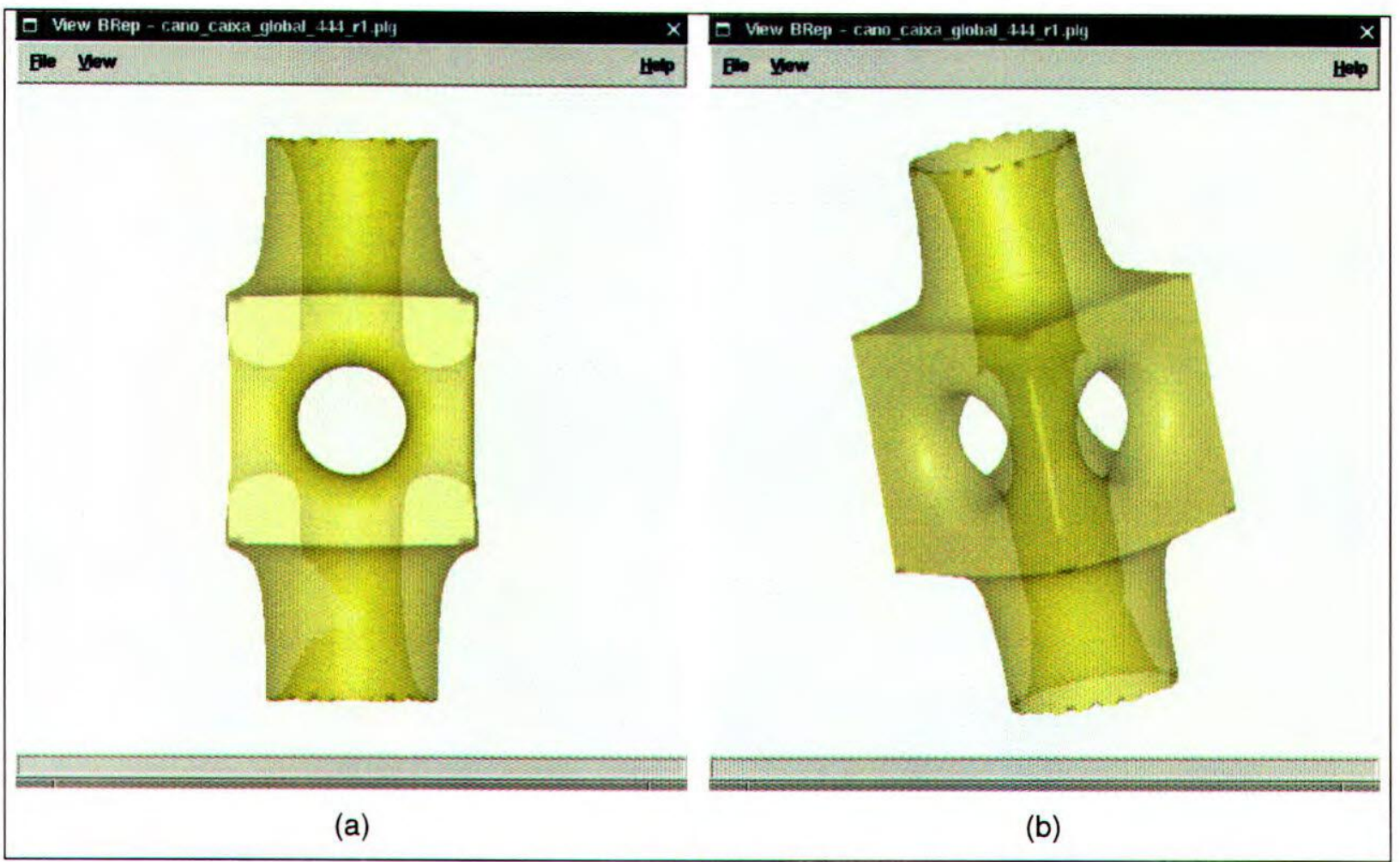

Figura 8.4 - modelo cano/caixa com blend norma p: as operações são definidas com expoente 4.

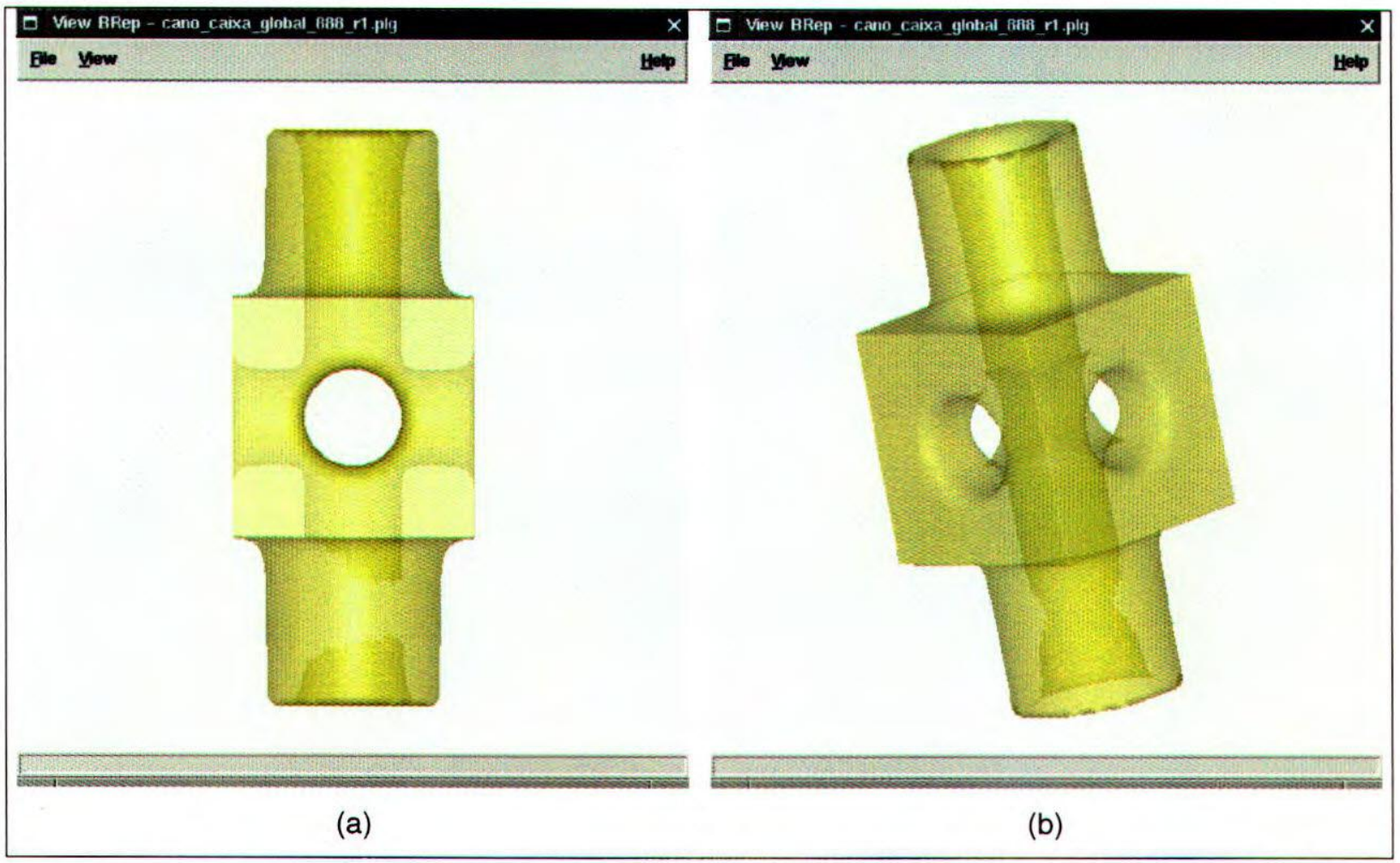

Figura 8.5 - modelo cano/caixa com blend norma p: as operações são definidas com expoente 8. 


\section{Modelo com blend pseudo-euclidiano}

As figuras 8.6 e 8.7 apresentam o modelo cano/caixa definido com blend pseudo-euclidiano. São definidos diferentes expoentes e raios de blend.

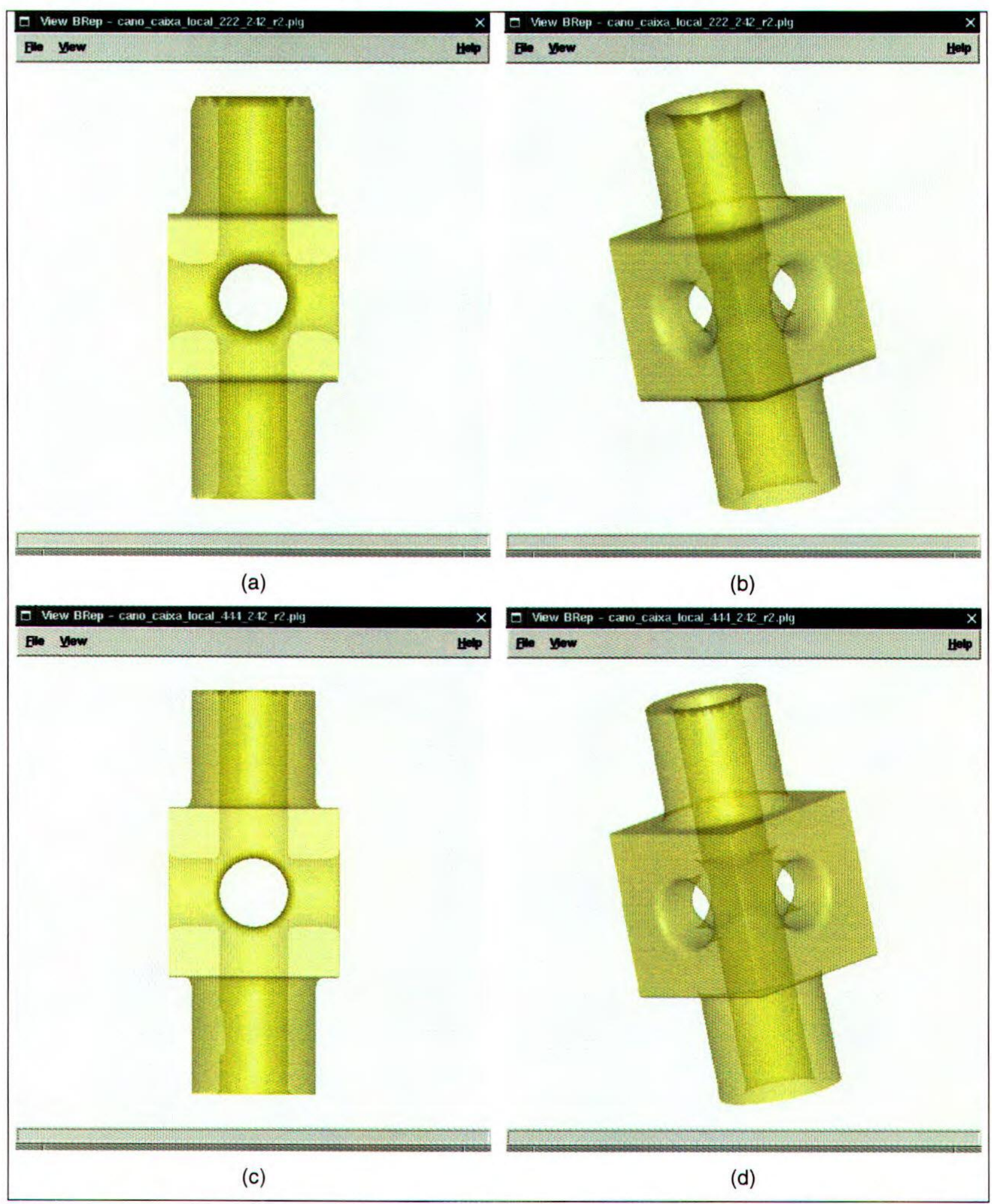

Figura 8.6 - modelo cano/caixa com blend pseudo-euclidiano: os raios de blend são iguais a 0.2 para os cilindros e 0.4 para o paralelogramo, em (a) e (b) as operações são definidas com expoente 2 e em (c) e (d) com expoente 4 


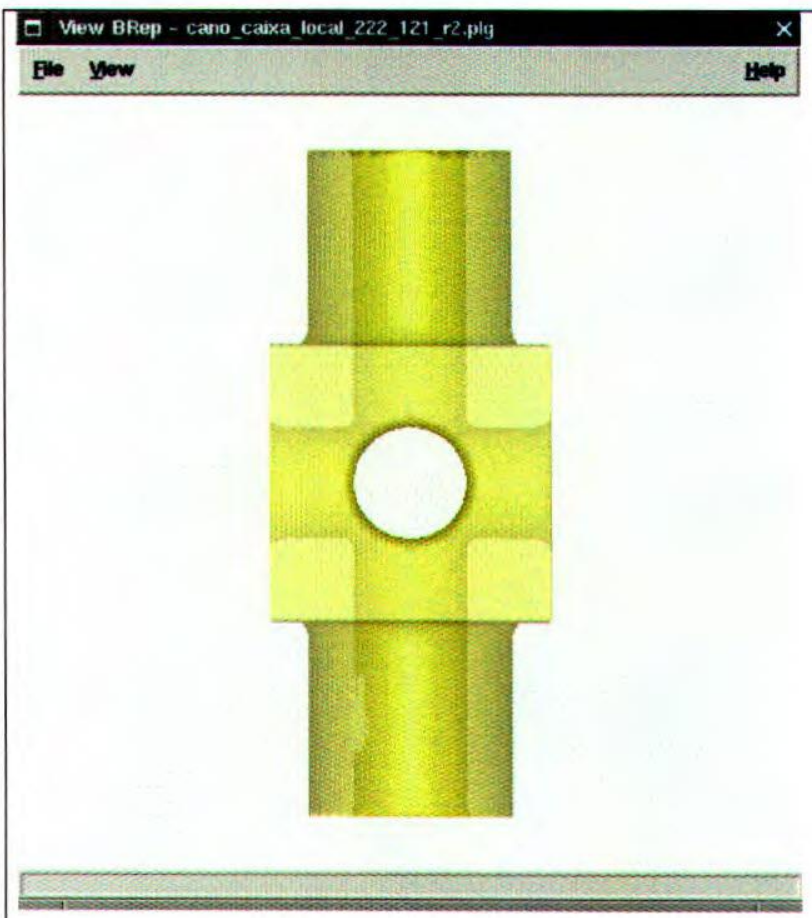

(a)

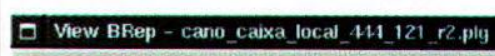

Ble Yew

\begin{tabular}{llr}
\hline D Vew BRep - cano_caixa_local_222_242_r2.plg & $\times$ \\
\hline Elo Wow & Help
\end{tabular}

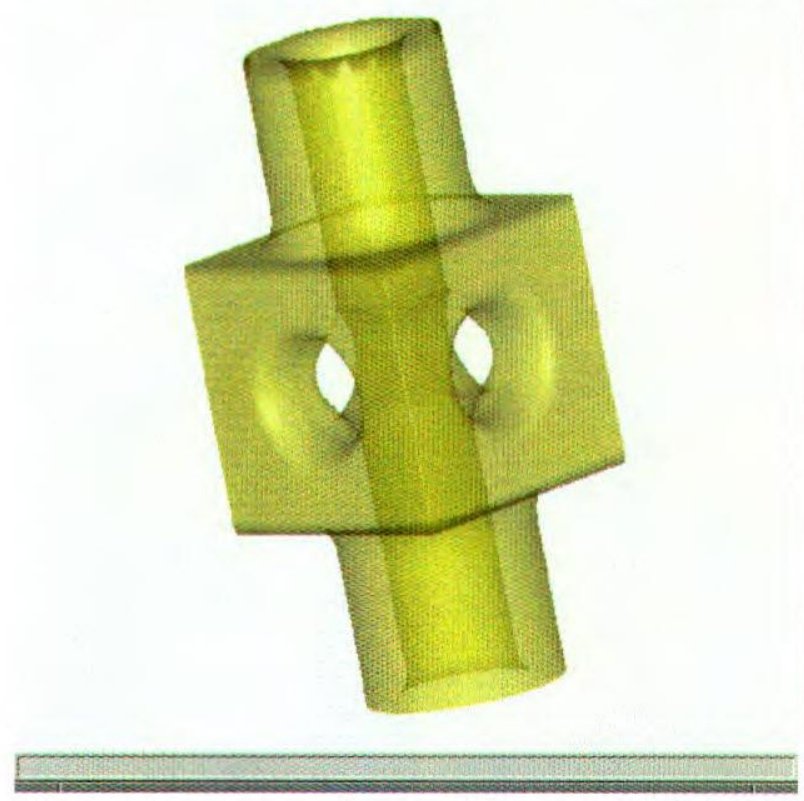

(b)

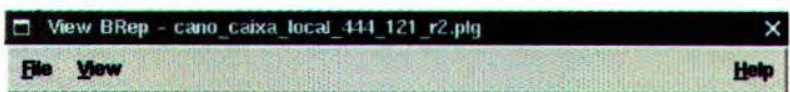

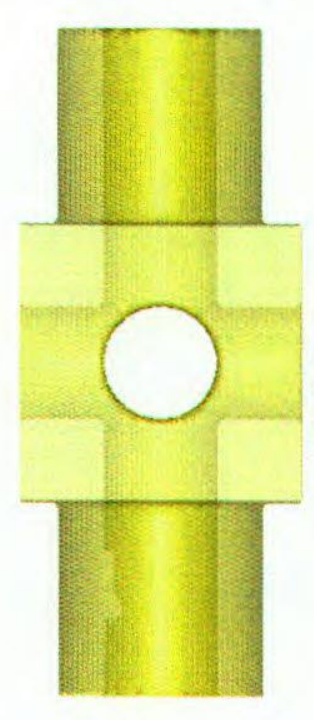

(c)

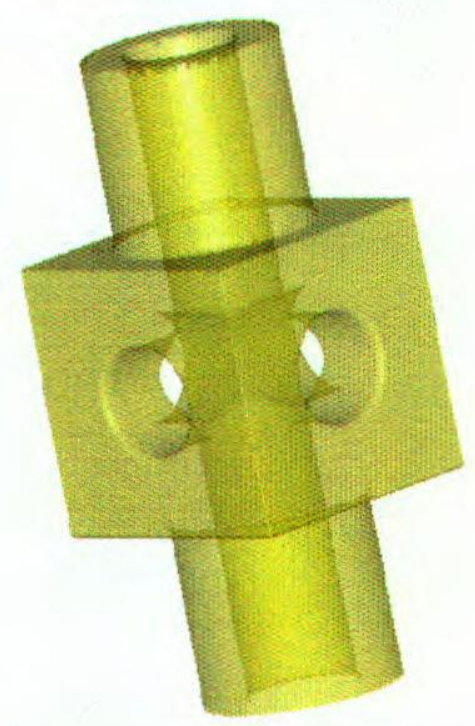

(d)

Figura 8.7 - modelo cano/caixa com blend pseudo-euclidiano: os raios de blend são iguais a 0.1 para os cilindros e 0.2 para o paralelogramo, em (a) e (b) as operações são definidas com expoente 2 e em (c) e (d) com expoente 4 


\section{Classificação das Cascas}

O exemplo aqui apresentado ilustra o processo de classificação de cascas em pseudo-sólidos. É definido um modelo composto pela união de: uma diferença de esferas, uma diferenças entre toros, uma diferença entre cilindros e uma interseção entre cones. Esse modelo define oito cascas:

- três esferas: 1 interna e 2 externas;

- dois cilindros: 1 interno e 1 externa;

- dois toros: 1 interno e 1 externo;

- e a interseção entre cones.

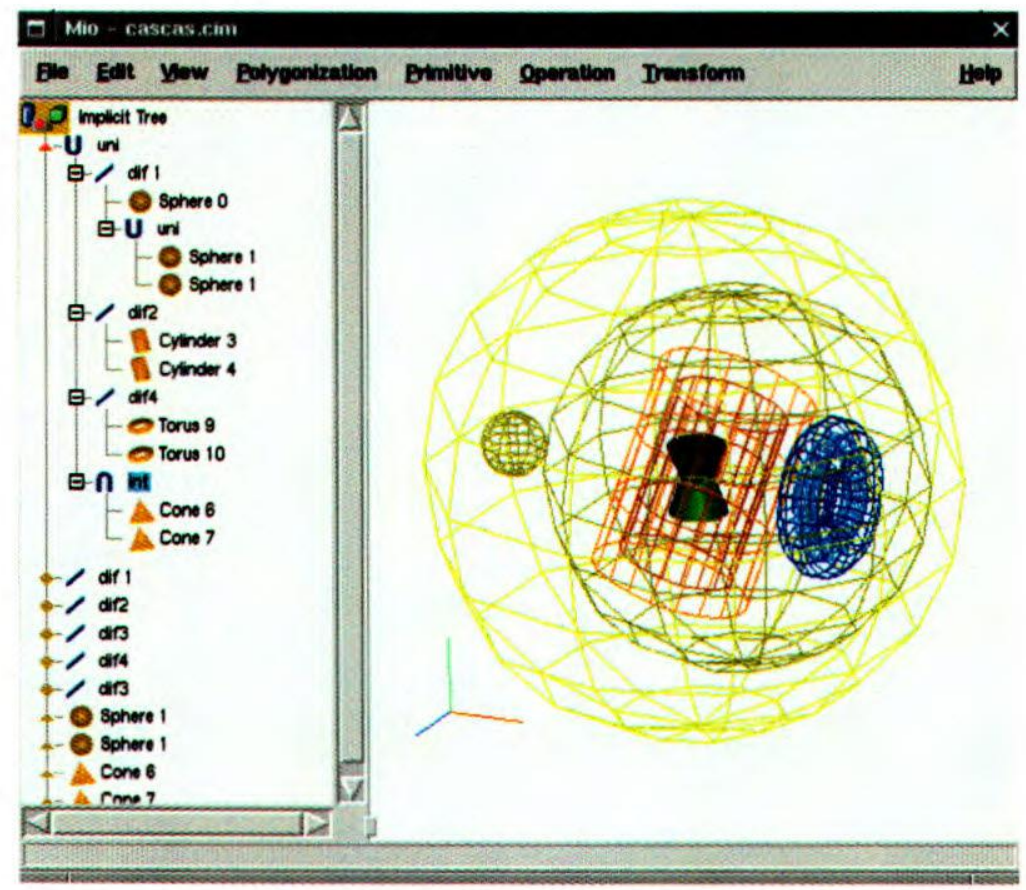

Figura 8.8 - modelo exemplo com múltiplas cascas: definição.

A partir das cascas geradas na poligonalização são construídos os pseudo-sólidos conforme o algoritmo 7.3 da seguinte forma:

- a diferença entre a esfera maior e a união de duas esferas gera um pseudo-sólido com duas cascas internas, ou buracos.

- a diferença entre os cilindros gera um pseudo-sólido oco, assim como na diferença entre os toros.

- a interseção entre os cones forma um pseudo-sólido definido por uma única casca. 
A figura 8.9 apresenta o resultado da poligonalização do modelo definido na figura 8.8. São apresentados quatro pseudo-sólidos, diferenciados pela cor, sendo que existem pseudo-sólidos definidos no interior de outro pseudo-sólido.

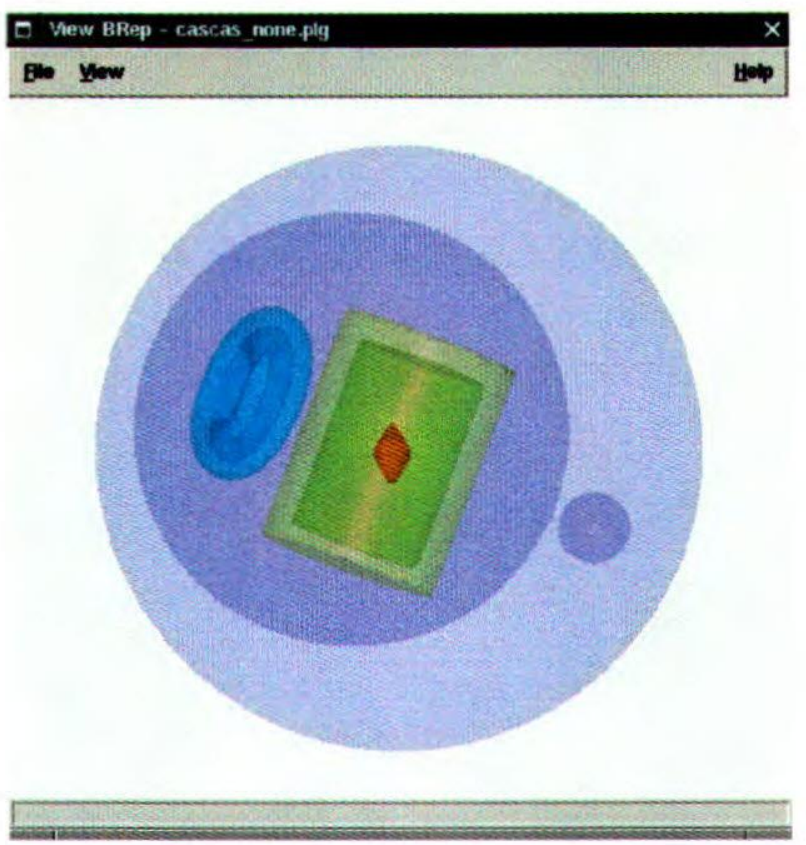

Figura 8.9 - modelo exemplo com múltiplas cascas: resultado. 


\section{Outros exemplos}

\section{T construído com cilindros}

Esse modelo é definido como a diferença entre duas uniões de cilindros definindo um $\mathrm{T}$ de uma tubulação.

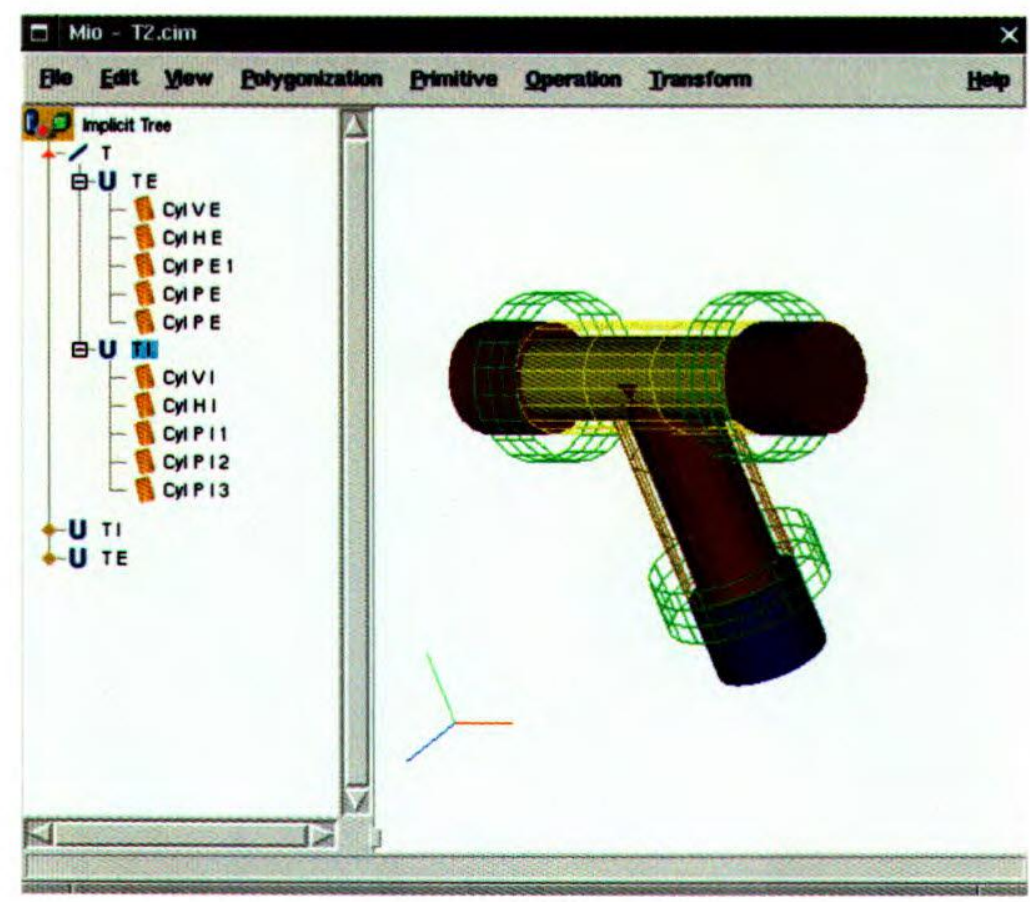

Figura 8.10 - definição do T.
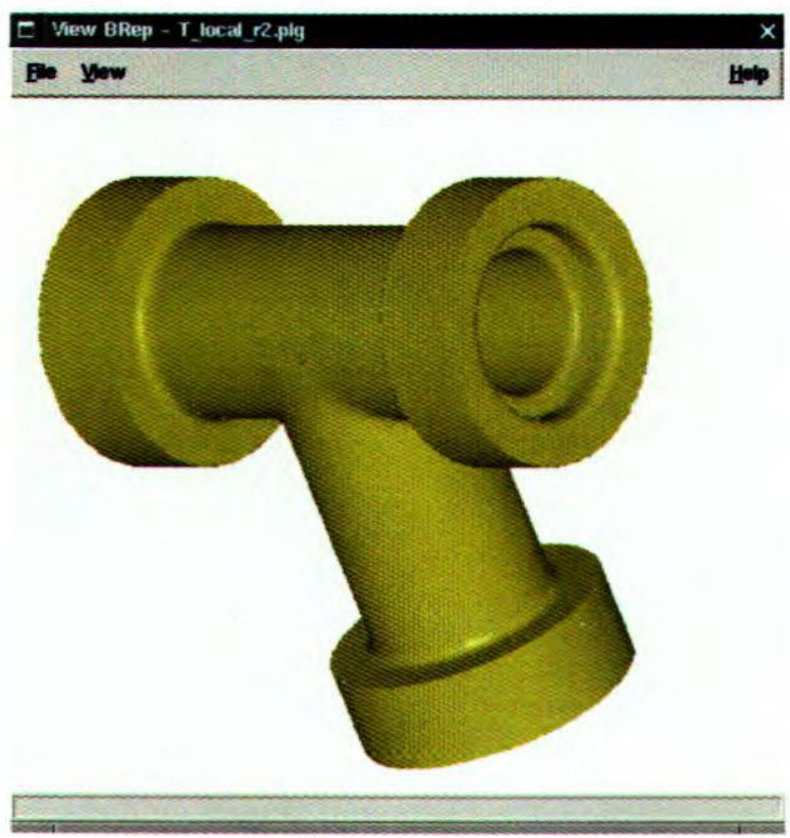

Figura 8.11 - T poligonalizado. 


\section{Dobradiça modelada com superelipsóides}

É um modelo simples que procura ilustrar a flexibilidade das formas possiveis de serem modeladas com superelipsóides. Esse modelo é definido apenas com superelipsóides e operações de união e diferença.

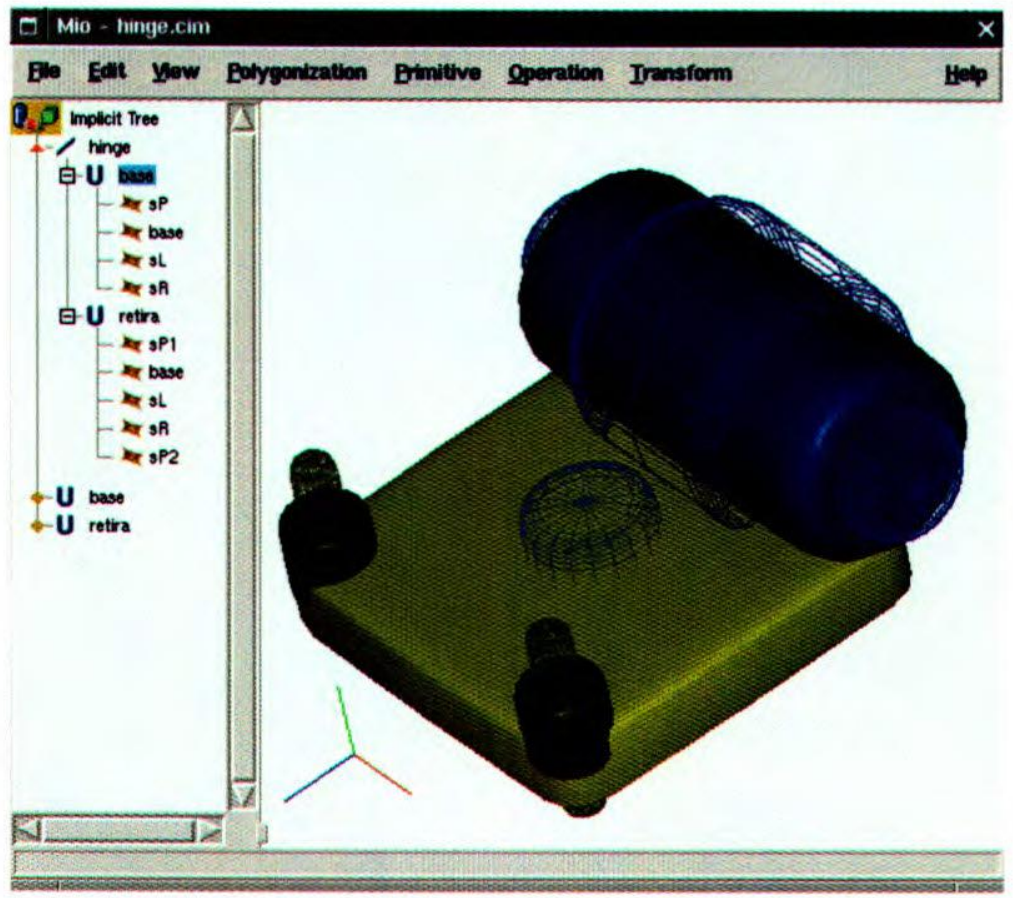

Figura 8.12 - definição da peça com superelipsóides.

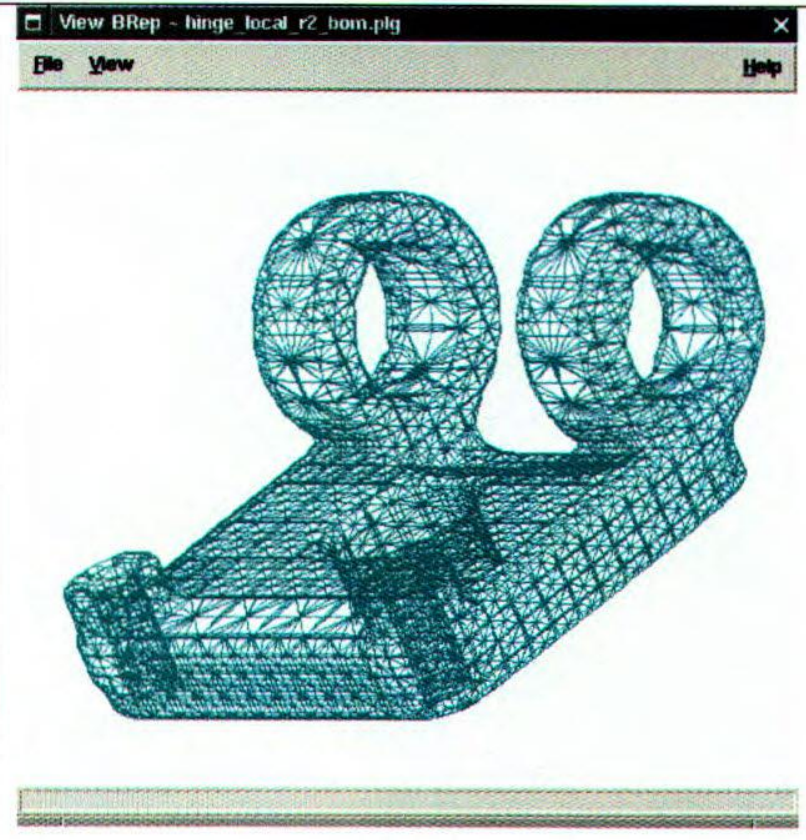

(a)

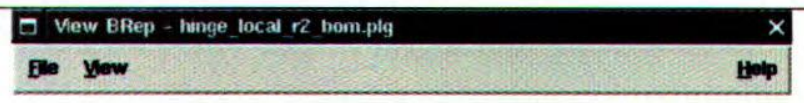

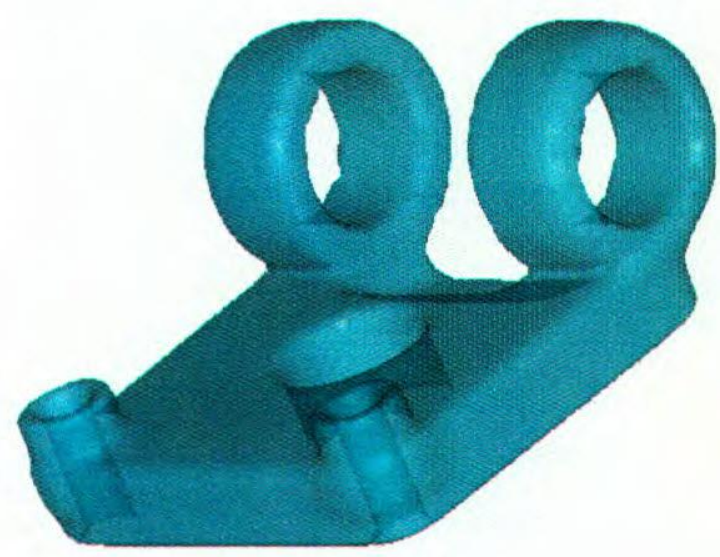

(b)

Figura 8.13 - peça com superelipsóides: (a) wireframe (b) tonalização gouraud. 


\section{Avião simplificado}

O modelo definido na figura 8.14 ilustra um avião simplificado modelado com primitivas baseadas em esqueletos juntamente com primitivas pré-definidas (esferas e superelipsóide). A figura 8.15 apresenta o modelo poligonalizado.

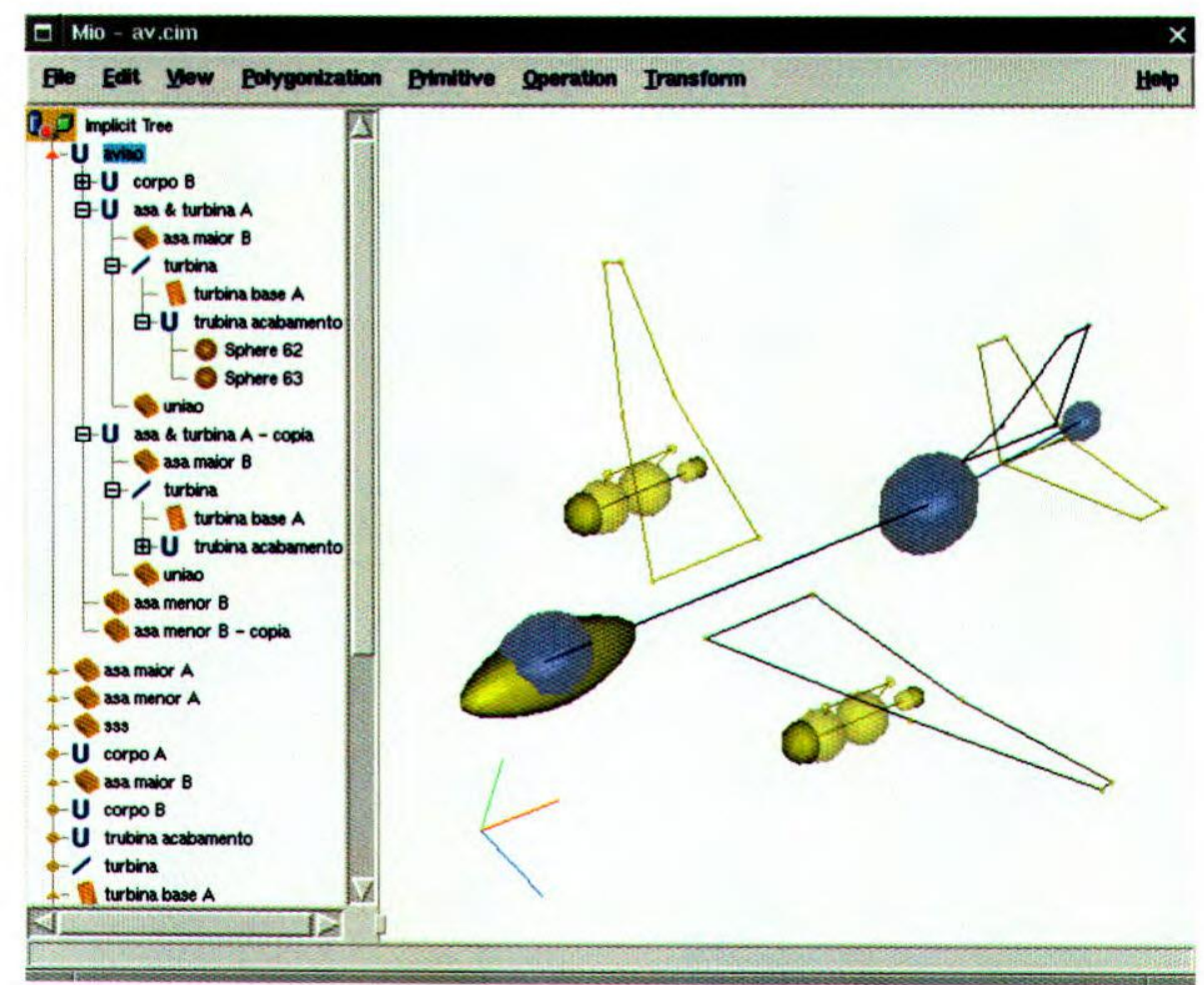

Figura 8.14 - definição do avião simplificado.

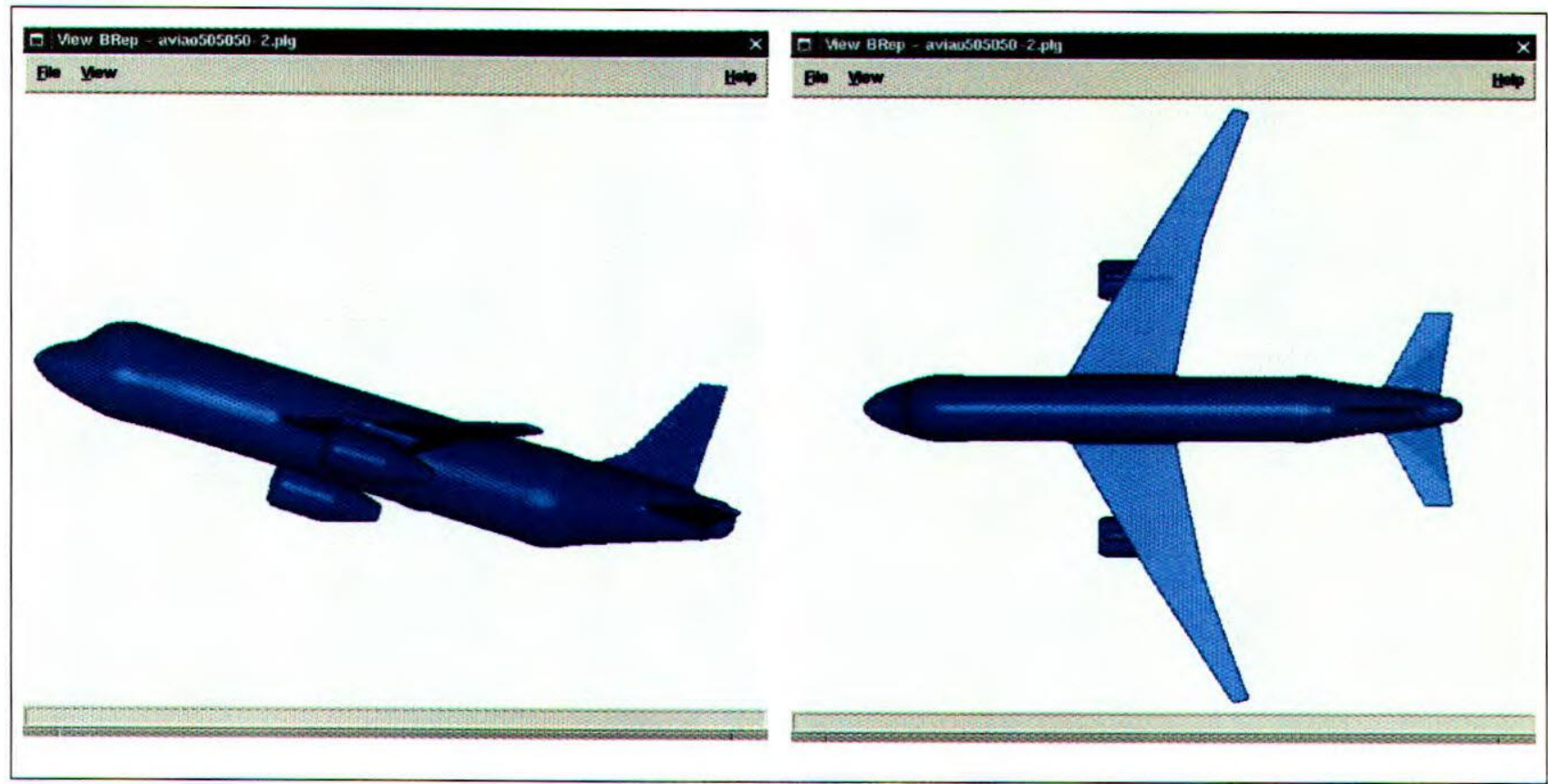

Figura 8.15 - avião poligonalizado. 


\section{Símbolo ICMC}

A figura 8.16 apresenta a definição do símbolo do ICMC estilizado (construído com segmentos de retas). Esse modelo é definido por uma única linha definida com trinta e três vértices. Afigura 8.17 apresenta a forma obtida.

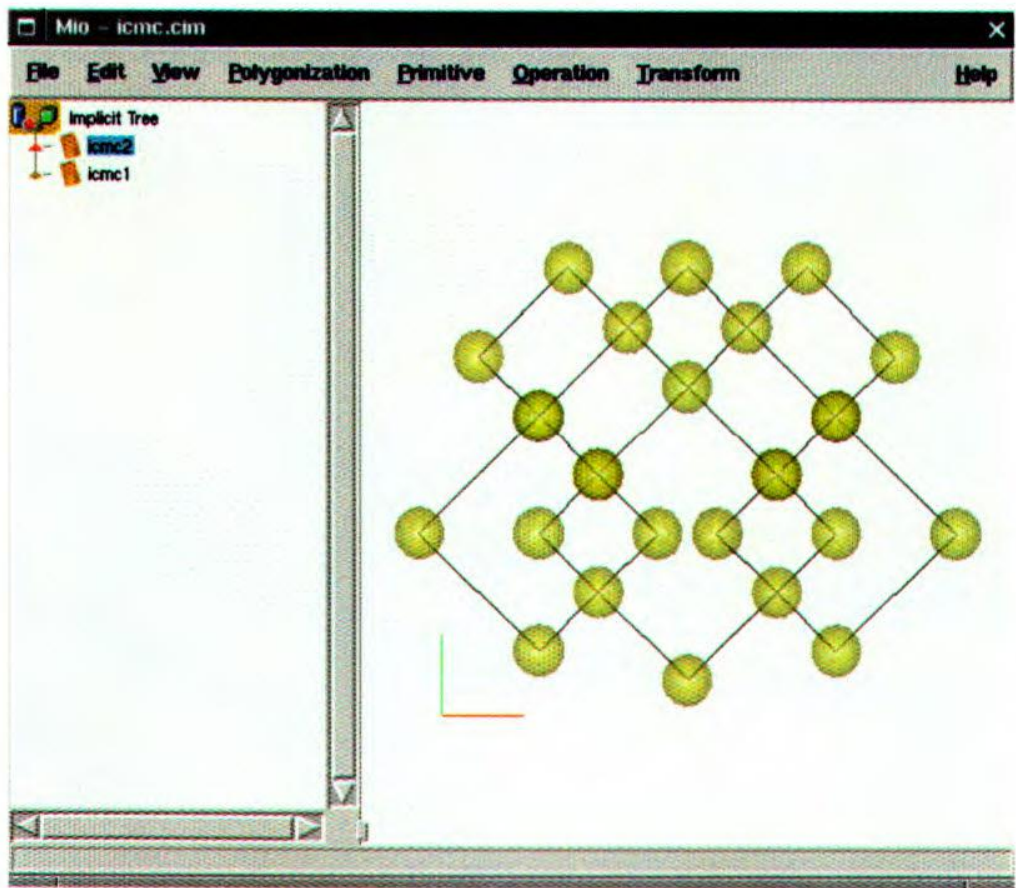

Figura 8.16 - definição do símbolo do ICMC

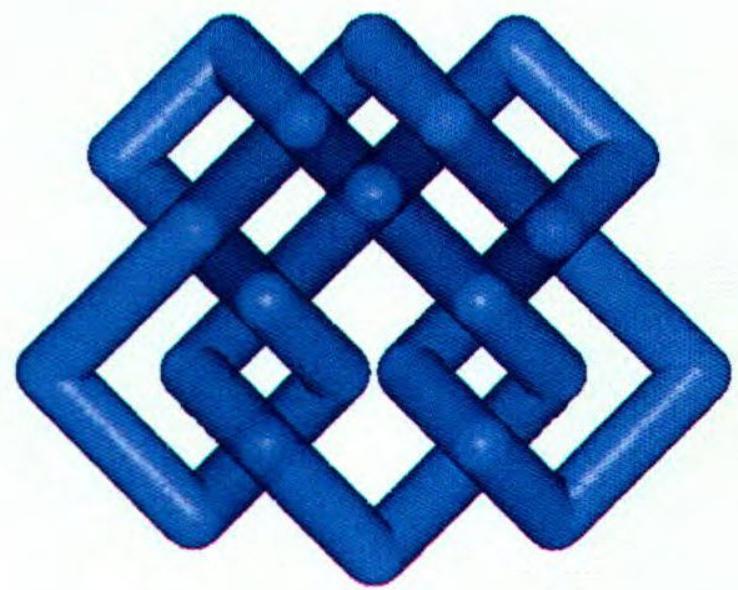

Figura 8.17 - símbolo do ICMC poligonalizado 


\subsection{Contribuições}

A principal contribuição deste trabalho de mestrado foi a construção do Modelador para o grupo de Mecânica de Fluídos do ICMC/USP, permitindo a definição de domínios complexos para simulações. Como contribuições adicionais associadas ao desenvolvimento do trabalho pode-se citar:

- O uso experimental de uma interface comum em sistemas de arquivos para a definição de um modelo baseado em CSG.

- O desenvolvimento da estrutura B-Rep estendida para representação dos modelos gexados pela poligonalização de modelos implícitos.

- A aquisição de experiência no desenvolvimento de sistemas de interface que mesclam a linguagem $\mathrm{C}$ com a $\mathrm{Tcl} / \mathrm{Tk}$, e em sistemas para apresentação de modelos tridimensionais auxiliados pela biblioteca OpenGL.

- O estudo das técnicas de modelagem implícita: definição de modelos complexos por CSG e por esqueletos.

\subsection{Sugestões para Trabalhos Futuros}

Possíveis extensões a serem introduzidas no Modelador dizem respeito ao aprimoramento da interface $3 \mathrm{D}$, aumento do poder descritivo e ao uso da brep-estendida.

\section{Interface com o usuário}

A grosso modo, o trabalho desenvolvido pode ser visto apenas como uma interface para modelagem, e, como dito anteriormente, o sucesso de um sistema computacional está diretamente relacionado com a aceitabilidade da sua interface com o usuário. Antes de qualquer acréscimo ao Modelador a interface deveria passar por uma análise de especialistas da área de interface com o usuário para que seja assegurado um produto de qualidade.

Uma das principais preocupações na construção de interfaces gráficas para aplicativos 3D está na obtenção de uma interação eficiente entre o usuátio e o ambiente 3D. A implementação atual todas as operações para a alteração de controle e posicionamento das primitivas no espaço 3D são realizadas através de caixas de diálogo. Essa forma de interface satisfaz um requisito que é o de controle fino das 
posições e orientação das primitivas. Mas, uma melhoria considerável na Interface de Modelagem é a implementação de técnicas de manipulação direta no espaço 3D para posicionar e orientar as primitivas. Essas técnicas de manipulação direta devem mapear os dispositivos de entrada bidimensionais e o espaço $3 \mathrm{D}$ e privilegiarão especialmente a definição dos elementos esqueletais.

\section{Aumento do poder descritivo}

Os elementos esqueletais disponíveis na implementação são linhas formadas por segmentos retos e polígonos. Podem ser definidos novos elementos esqueletais como curvas splines a partir das linhas e polígonos. Outra forma de aumentar o poder descritivo do Modelador é a definição de um mecanismo para variar o range ao longo do polígono, pois na implementação atual o range que define a superficie a partir de um polígono é fixo. Ainda relacionados às primitivas baseadas em esqueletos, poderiam ser implementados a geração de superfície por campos equipotenciais e por convolução de esqueletos.

O trabalho desenvolvido em (Wyvill \& Overveld, 1998) apresenta o uso de deformações na construção de modelos implícitos. Um trabalho futuro interessante é a definição de uma interface com o usuário para realizar essas deformações e sua implementação no Modelador. É importante destacar o uso da matriz de transformação na estrutura de avaliação apresentada no capítulo 7 favorece muito o uso dessas deformações no Modelador.

\section{A Brep-estendida}

O algoritmo de conversão do esqueleto combinatório com para uma brep-estendida é baseado nas relações de vizinhança explícitas no esqueleto combinatório e na sua geometria montando a brepestendida de forma direta. Não são utilizados operadores topológicos, como os de Euler ou Morse, para assegurar a validade da brep-estendida construída. Um trabalho interessante é a implementação de um conjunto de operadores topológicos para a brep-estendida e o uso desses operadores no procedimento de conversão. 


\section{Referências Bibliográficas}

(Badler \& Glassner, 1998a)

(Badler \& Glassner, 1998b)

(Baumgart, 1975)

(Blinn, 1982)

(Blinn, 1997)

(Bloomenthal \& Ferguson, 1995)

(Bloomenthal \& Ferguson, 1997)

(Bloomenthal \& Shoemake, 1991)

(Bloomenthal \& Wyvill, 1989)

(Bloomenthal, 1995)
Badler, N. I.; Glassner, A. S. - 3D Object Modeling, SIGGRAPH'98 Course Notes, 1998.

Badler, N. I.; Glassner, A. S. - A Glossary for Modeling and Animation, SIGGRAPH'98 Course Notes, 1998

Baumgart, B. G. - Winged-Edge Polyhedron Representation for Computer Vision, National Computer Conference, 1975, pp. 589-596

Blinn, J. - A Generalization of Algebraic Surface Drawing, ACM Transactions on Graphics, Jul. 1982.

Blinn, J. - The Algebric Properties of Second Order Surfaces, in Bloomenthal, J. (ed.) Introduction to Implicit Surfaces, Morgan Kaufmann Publishers, 1997, Cap. 4, pp. 52-97.

Bloomenthal, J.; Ferguson, K. - Polygonization of Non-Manifold Surfaces, Proceedings of SIGGRAPH 95, in Computer Graphics Proceedings, pp. 309$316,1995$.

Bloomenthal, J;; Ferguson, K. - Bulges Elimination in Convolution Surfaces, Computer Graphics Form, vol. 16, no. 1, pp-1-11, 1997.

Bloomenthal, J.; Shoemake K, - Convolution Surfaces, Proceedings of SIGGRAPH'91, in Computer Graphics vol. 25, no. 4, pp.251-256, Jul. 1991.

Bloomenthal, J.; Wyvill, B. - Interactive Techniques for Implicit Modeling, technical report P89-00106, Palo Alto, CA, Xerox Palo Alto Research Center, 1989 (também encontrado em Modeling and Animating with Implicit Surfaces notes, SIGGRAPH 1990)

Bloomenthal, J. - Skeletal Design of Natural Forms, Ph.D. dissertation Calgary, Alberta, University of Calgary, Dept. of Computer Science, 1995. 
(Bloomenthal, 1997a)

(Bloomenthal, 1997b)

(Castelo et al., 1997)

(Castelo et al., 1998)

(Castelo, 1992)

(Castelo, 1998)

(Dekkers et al., 1996)

(Foley et al., 1990)

(Gomes \& Velho, 1998)

(Haines, 1994)

(Hearn \& Baker, 1997)
Bloomenthal, J. - The Geometry of Implicit Surface, in Bloomenthal, J. (ed.) Introduction to Implicit Surfaces, Morgan Kaufmann Publishers, 1997, Cap. 1, pp. 2-50.

Bloomenthal, J. - Surface Tiling, in Bloomenthal, J. (ed.) Introduction to Implicit Surfaces, Morgan Kaufmann Publishers, 1997, Cap. 4, pp. 126-164.

Castelo Fo., A; Tavares, G.; Siqueira, M. F. - Adaptive Pobygonization of Implicit Surfaces in $\mathfrak{R}^{3}$. Relatório Técnico do Departamento de Matemática da PUC-Rio MAT. 14/97.

Castelo Fo., A; Tomé, M. F.; McKee, S.; César, C.; Cuminato, J. A. - Freeflow An Integrated Simulation System for Three-Dimensional Free Surface Flowy. Relatório Técnico do Departamento de Matemática do Instituto Superior Técnico de Lisboa 8/98. Aceito para publicação na revista Visualization and Simulation in Science.

Castelo Fo., A. - Aproximagöes Adaptativas de Variedades Implicitas e com Aplicaföes à Modelagem Implicita e Equajôes Algébrico-Diferenciais, Tese de Doutorado, Departamento de Matemática, Pontificia Universidade Católica do Rio de Janeiro, Brasil, 1992.

Castelo Fo., A; - Modelagem Geométrica: Representagãa de Objetos Geometricos Utilizando o Computador, Mini-Curso apresentado no III' Colóquio de PósGraduação e Pesquisa em Matemática Aplicada e Computacional e Io Encontro Regional de Matemática Aplicada e Computacional (I ERMAC), São José do Rio Preto, Brasil Junho de 1998, 27p.

Dekkers, D.; van Overveld; K. Golsteijn. - Combining CSG modeling with soft blending using Lipschitz-based Implicit Surfaces, Out. 1996. Pode ser encontrado em: http://www.win.tue.nl/cs/tt/kees/graphics.references.

Foley, J.; van Dam, A.; Feiner, S.; Hughes, J. - Computer Graphics, Principles and Practice Addison-Wesley, New York, 1990.

Gomes, J.; Velho, L. - Computaçāo Gráfica, Volume 1, Série de Computação e Matemática, IMPA, 1998.

Haines, E. -- Point in Pobygon Strategies, in Paul S. Heckbert (ed.) Graphics Gems IV, Morgan Kaufmann Publishers, 1994, pp. 24-46.

Hearn, D. ; Baker, M. P. - Computer Graphics C version, Prentice Hall, $2^{\text {nd }}$ ed., 1997. 
(Langsam et al., 1996)

(Mäntyla, 1988)

(McCormark \& Sherstyuk, 1998)

(Mesa3D, 2000)

(Minghim \& Oliveira, 1997)

(Möller \& Yagel, 1995)

(Pasko et al., 1995)

(Persiano, 1996)

(Ricci, 1973)

(Rockwood, 1989)

(Schroeder et al., 1998)

(Silva, 1996)

(Siqueira, 1994)
Langsam, Y; Augenstein, M. J.; Tenenbaum , A. M. - Data Structures Using C and C++, Second Edition, Prentice Hall, 1996.

Mäntyla, M. - An Introduction to Solid Modeling, Computer Science Press, Maryland, 1988.

McCormack, J; Sherstyuk, A. - Creating and Rendering Convolution Surfaces, Computer Graphics forum, vol 17 no 2, pp. 113-120, 1998.

Site da comunidade de usuários do Mesa3D na internet: www.Mesa3D.org, visitado em Março de 2000.

Minghim, R. e de Oliveira, M. C. F. - Uma Introdufão à Visualizagão Computacional, Jornadas de Atualização em Informática (JAI-97), XVII Congresso da SBC, Brasilia, 2 a 8 de agosto de 1997, pp. 85-131.

Möller, T.; Yagel, R. - Efficient Rasterization of Implicit Functions, Department of Computer and Information Science, Ohio State University. (OSU-CISRC11/95-TR50), Novembro de 1995.

Pasko, A.; Adzhiev, V; Sourin, A. e Savchenko, V. - Functional Representation in Geometric Modeling: Concepts, Implementation, and Applications. The Visual Computer, vol. 11, no. 8, 1995, pp.429-446.

Persiano, R. M. - Bases da Modelagem Geométrica, X Escola de Computaçāo, Campinas-SP, Brasil, Julho de 1996.

Ricci, A., - A Constructive Geometry for Computer Grapbics, The Computer Journal, vol. 16, no. 2,1973 , pp. 157-160.

Rockwood, A., - The Displacement for Implicit Blending Surfaces in Solid Models, ACM Transactions on Graphics, vol. 8, no. 4, 1989, pp. 279-297.

Schroeder, W. J.; Martin, K.; Lorenser, W. - The Visualization Toolkit - An Object-Oriented Approach to 3D Graphics, $2^{\text {nd }}$ ed., Prentice-Hall, 1998.

Silva, E. J. - Sistemas Interativos, Apostila utilizada como texto para o curso de Interface Homem-Computador, oferecido pelo Departamento de Computação da Universidade Federal de Ouro Preto, Brasil, Fevereiro de 1996.

Siqueira, M. F. - Modelagem por Semi-Espaços Definidos Implicitamente, Dissertação de Mestrado, Departamento de Ciência de Computação e Estatística Instituto de Ciências Matemáticas e de Computaçāo, Universidade de São Paulo, Brasil, Agosto, 1994. 
(Tavares et al., 1992)

(Tavares et al., 1997)

(Tcl Consortium, 2000)

(Togl, 2000)

(Welch, 1997)

(Woo et al., 1997)

(Wyvill \& Overveld, 1997)

(Wyvill \& Overveld, 1998)

(Wyvill et al., 1986)

(Wyvill et al., 1998)

(Wyvill, 2000)
Tavares, G.; Castelo Filho, A. e Lopes, H. - Topological Methods in Geometric Modeling. Mini-Curso do XV Congresso Nacional de Matemática Aplicada e Computacional (CNMAC), São Carlos, Brasil 1992, 141p.

Tavares, G.; Pesco, S.; Lopes, H. - Modelagem Topologica de Superficies e Volumes, Notas do curso lecionado no Sibgrapi'97, Campos do Jordão -SP, Brasil, Outubro de 1997.

Site da comunidade de desenvolvedores que utilizam Tcl/Tk: http://www.tcltk.com/tclconsortium/, visitado em Junho de 2000.

Togl - a Tk OpenGL widget, Manual da widget Togl, encontrado em: http://togl.sourceforge.net/, visitado em Junho de 2000.

Welch, B. - Practical Programming in Tcl and Tk, 2 ${ }^{\text {nd }}$ Edition, Prentice Hall, 1997.

Woo, M; Neider, J.; Davis, T. - OpenGL Programming Guide. 2nd Edition, Addison Wesley, 1997.

Wyvill, B. van Overveld, K. - Pobygonization of Implicit Surfaces with Constructive Solid Geometry, Journal of Shape Modeling, vol. 2, no. 4, World Scientific Publishing, 1997, pp. 257-273.

Wyvill, B. van Overveld, K. - Warping as a Modeling Tool for CSG/Implicit Models, Implicit Surfaces'98 Conference, Seattle, USA, Jun. de 1998.

Wyvill, G.; McPheeters, C.; Wyvill, B. - Data Structure for Soft Objects, The Visual Computer, vol. 2, no 4, Aug. 1986, pp. 227-234.

Wyvill, B; Guy, A.; Galin, E. - Extending the CSG Tree Warping, Blending and Boolean Operations in an Implicit Surface Modeling System, Implicit Surfaces'98 Conference, Seattle, USA, Jun. de 1998.

Wyvill, B. - Computer Graphics Course Notes, Universidade de Calgary, Canadá, <http://www.cpsc.ucalgary.ca/ jungle/555/index.html>, Site visitado em Fevereiro de 2000. 